Q

Is

(1)

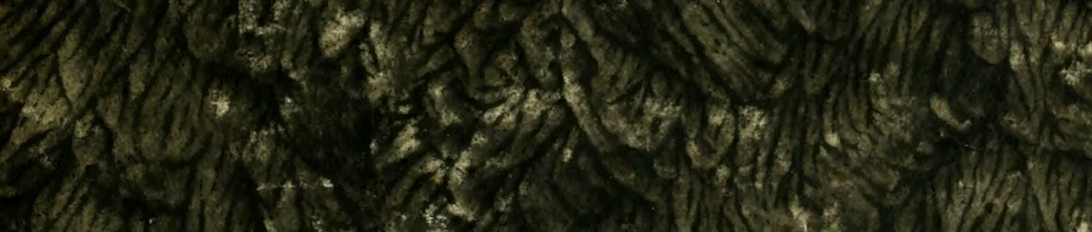

30

18.

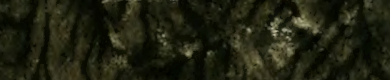

(3)

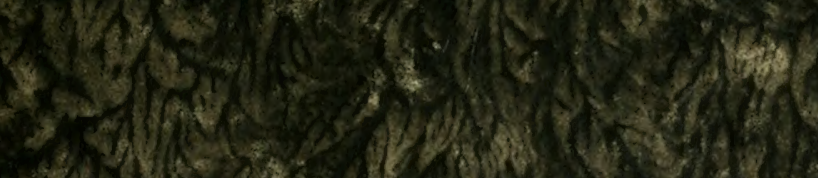

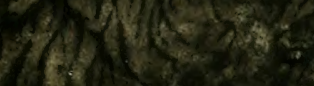

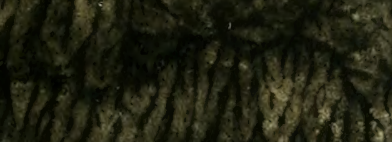

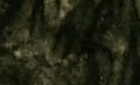

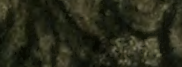

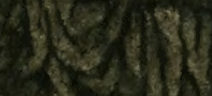

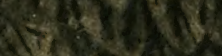
(4)

25.

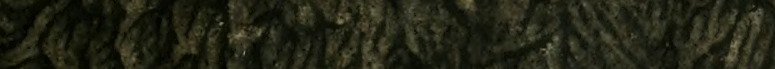


XowD. MARK.

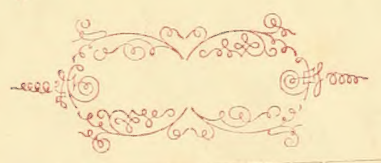

$\therefore$

$\therefore ?$ 
MARP 



\section{I E}

\section{LEH R E von den HAA REN}

IN DER

GESAMMTEN ORGANISCHEN NATUR.

Vollständig bearbeitet

von

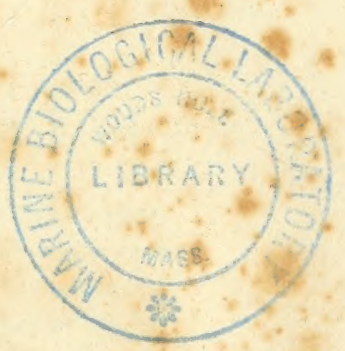

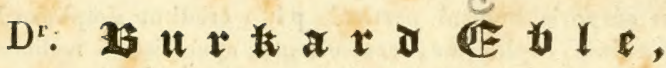

k. k. Ober-Feldarzte und Prosector der medicinisch - chirurgischen Josephs Akademie, und Mitglied der kaiserlich - Leopoldinisch-Carolinischen Akademie der Naturforscher.

E r s t e r B a n d.

Haare der Pflanzen und Thiere.

Mit 122 Abbildungen.

\section{ชชำ $\mathrm{i}, 1831$.}

Ver lag von J. G. H e u b n e $r$. 
Quáenam igitur corporis humani particula $\mathrm{p}\left\{\mathrm{l}_{0}\right.$ creditur simplicior? Attamen hic ipse, si sedulo exploratur, eam ostentat operosissimi moliminis pulchritudinem, ut ad absolutum ejus intellectum animo conciliandum non aetas hominis, non sufficiat omnis diligentia!

Hermanni B o erha a ve sermo academicus: de comparando certo in physicis p. 30. 


\section{S e ine $\mathrm{r}$ Ex e 11 e $\mathrm{n}$ z}

d e $\mathbf{~ n}$

Hoc h- und Wohlgebornen

H e r r n H e r r n

\section{A n d r e a s Y o s e p h}

\section{Freyherrnvon Stifft,}

der Philosophie und Medicin Doctor, Commandeur des königl. ungarischen St. Stephans-Ordens, Inhaber des silbernen Civil-Ehrenkreuzes, Grossband des königl. französischen St. Michael-Ordens, Commandeur des kaiserl, brasilianischen Ordens vom südlichen Kreuze, ferner des königl. portugiesischen Christus-, des königl. sicilianischen St. Ferdinandsund Verdienst-, so wie des königl, sächsichen Civil-Verdienst-Ordens; Ritter des königl. preussischen rothen Adler-Ordens zweyter Classe, und des Civil - Verdienst - Ordens der königl. baierischen Krone; k. k. wirklichem geheimen Rath, dann Staats - und Conferenz - Rath, erstem Leib und Protomedicus, Director der medicinisch-chirurgischen Studien und Präses der medicinischen Facultät, Indigena des Königreichs Ungarn, Landstand von Tyrol und Steyermark, Ehren - Mitglied der medicinisch chirurgischen Josephs-Akademie, ausserordentlichem Ehrenmitgliede der mährisch-schlesischen Gesellschaft zur Beförderung des Ackerbaues, Ehrenmitgliede der k. k. Akademie der bildenden Künste in Wien, der königl. böhmischen Gesellschaft der Wissenschaften und des vaterländischen Museums in Böbmen, dann Mitgliede der k, k. Landwirthschafts-Gesellschaft zu Wien, und der gelehrten Gesellschaften zu Venedig, Padua, London,

Petersburg, Bonn u. s. w.

in $t$ i e f s t e $r$ e $r$ e h r u $g$

gewidmet 



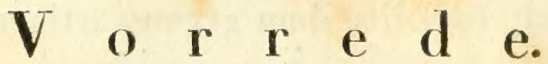

Indem ich hiemit der literarischen Welt dieses Werk übergebe, muss ich vor Allem das Bekenntniss ablegen, dass es eigentlich mein verehrter ehemaliger Lehrer, unser leider der Wissenschaft und Menschheit zu früh entrissener Professor $\mathrm{H}$ a r t m a n $\mathrm{n}$ war, der in mir die erste Idee davon weckte, indem er vom Lehrstuhl herab die Nothwendigkeit einer gründlichen und umfassenden Bearbeitnng dieses Gegenstandes als wahres Bedürfniss unserer gegenwärtigen Zeit seinen Schülern ans Herz legte. War mir ohnehin jedes seiner Worte theuer, so machte diese Aufforderung schnell den tiefsten Eindruck auf mich, und ich beschloss, so fremd dieses Gebiet, in dem ich arbeiten sollte, mir auch war, alsbald Hand ans Werk zu legen. Anfangs wollte ich diese Arbeit zum Gegenstand meiner Inaugural-Dissertation machen; aber je mehr ich mit der Sache vertraut wurde, desto schwieriger zeigte sich das Unternehmen, und desto weniger schien es zu einem solchen $Z_{\text {wecke }}$ geeignet. Denn 
es sollte ja etwas Besseres, etwas Vollkommeneres werden, als die bisher meist als Dissertationen erschienenen Schriften über die Haare; und was das Wichtigste ist, es sollte dem gegenwärtigen Standpunct unserer Wissenschaft in jeder Hinsicht entsprechen. Diess wohl erwägend, verkannte ich nicht, wie viel ich dabey wagte; aber je grösser und schwieriger die Sache vor mir stand, desto stärker wirkte ihr Reiz auf mich. So sind nun beynahe acht Jahre verstrichen, seit ich Materialien zu meinem Gebäude zu sammeln anfing, und ich übergebe es heute fertig dem Publikum, wahrlich nicht ohne Bekümmerniss: es möchte theils die Grundfeste zu locker gelegt, theils zu viel Material verschwendet, theils hie und da im Einzelnen gefehlt, theils endlich in der Neuerung zu kühn vorgegangen seyn. - Was mich jedoch in allen diesen Beziehungen tröstet, ist der Gedanke, mit meinem möglichsten Fleisse ein Werk über die Haare verfasst zu haben, welches alle bisher erschienenen entbehrlich macht, und überdiess noch den ganz besondern Vorzug hat, dass es den Gegenstand in seiner Totalität, in seinem ganzen Umfange zu begreifen strebt. Denn nur auf solche Art schien es mir möglich, der wahren Bedeutung der Haare auf die Spur zu kommen; (sie ganz zu ergründen, muss ich grössern Män- 


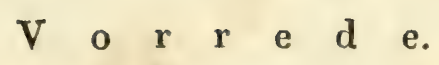

nern überlassen) nur so konnte ich diese, seither gleichsam verachteten, organischen Gebilde zu höherm Werthe emporheben, und ihnen eine bessere Stellung sichern.

In der Ausführung des Einzelnen bin ich auf manche Rüge gefasst; namentlich werde ich Vielen zu grossen Werth auf die Meinungen der ältern und ältesten Aerzte gelegt, und dadurch zu einer wortreichen Breite Veranlassung gegeben haben. Diese mögen bedenken, dass ich eine Monographie und keine Dissertation schrieb, und dass ich der Meinung bin, es solle sich kein Autor ohne gründliche Benützung der Alten an etwas Neues machen. Wic manche für neu gehaltene Erfindung würde dann in ihr Nichts zurückfallen! - Insbesondere aber sehe ich nicht ohne Besorgniss dem Urtheil über die Classification und überhaupt über die weite Ausdehnung, welche ich den Thierhaaren gegeben habe, entgegen, und werde mit Freude jede ernste kritische Belehrung hierüber empfangen.

Un dem Ganzen die mir möglichste Vollkommenheil zu geben, habe ich, wie gesagt, in jedem Thema alle die Ansichten und Meinungen zusammengestellt, welche vom Anbeginn unserer Wissenschaft bis auf diese Stunde von den berühmtesten Acrzten 
und Naturforschern gehegt, und in ihren Schriften nicdergelegt wurden. Diess mag nebstbey auch noch das Gute haben, dass dadurch das Eigenthum eines Jeden vor fremdem Eingriffe gesichert wird. Natürlich stiess ich aber dabey hüufig anf grosse Irrthümer, namentlich in anatomischer Hinsicht, wo theils nur auf leere Hypothesen gebaut, theils vom Microscop verführt, der Einbildungskraft ein zu weites Feld gelassen, theils endlich ohne dic nöthige Beschriinknng Beobachtungen aus dem Thierreich entlehnt, und auf den Menschen geradezu angewendet wurden.

Es war mein Plan, sowohl die Pflanzen- als auch die Thier- und Menschenhaare nach einer dreyfachen, nïmlich in naturhistorisch-anatomischer, physiologischer und pathologischer Rücksicht abzuhandeln. Allein bey cier niedrigen Organisationsstufe, auf welcher die Haare der Pflanzen, und mitunter auch die der Thiere slehen, treten einerseits die vitalen Erscheinungen nicht so klar vor die Sinne, andererseits lassen sich ihre krankhaften Processe kaum ahnen. So kam es, dass eigentlich nur bey den Haaren des Menschen, als den vollkommensten, auch die pathologischen Verhälınisse zweckmässig durchgeführt werden konnten. 
Dic beygefügten zahlreichen Abbildungen sind, mit Ausnahme von sechs, alle der Natur möglichst treu abgenommen worden, und ich schmeichle mir, hierin alle meine Vorgänger übertroffen zu haben.

Ich habe zwar in der medicinisch-chirurgischen Zeitung (Februar 1828) einen Aufruf an die Naturforscher und Aerzte ergehen lassen, und sic darin um Mittheilung interessanter, auf die Haare sich beziehender Beobachtungen ersucht; allein, so sehr ich von dem freundschaftlichen Wohlwollen wenigstens einer grossen Anzahl derselben für mich überzeugt bin, so ist mein Aufruf doch so zu sagen vergebens geschehen. - Doch kann ich nicht umhin, die besonders gütige Belehrung zu rühmen, mit welcher Herr Hofrath und Professor Dr. Oken mich beehrte; so wie ich andererseits die höchste Bereitwilligkeit mit gebührendem Danke erkenne, die ich jederzeit bey Hern Regierungsrath und Director Ritter von $\mathrm{S}$ ch reibers, Herrn Freyherrn von J a c qu in, dann bey dem Herrn Custos Nat te r e r und Inspector Kollar am hiesigen Naturalien-Cabinette fand; nicht zu gedenken des edlen Eifers, mit welchem mir die Herren Professoren unserer Akademie selbst an die Hand gingen. Insbesondere aber danke ich meinem sachkundigen Freunde Dr. Unger eine grosse Anzahl 
von Originalzeichnungen der Pflanzenhaare, so wie auch der Aufsatz: "Ueber das krankhafte Verhalten der Pflanzenhaare« sein Werk ist.

Somit hoffe ich wenigstens kein nutzloses Werk unternommen, sondern unsere Wissenschaft mit einem würdigen Beytrag vermehrt zu haben.

Geschrieben zu Wien in May 1831.

Der Verfasser. 


\section{Verzeich $\mathrm{n}$ is s \\ de r Herren Subseribenten.}

Anzahl der

Exemplare

Abramovich Jobann, k. k. feldärztlicher Gehülfe in Husaren-Regimente Fürst Lichtenstein . . . . 1

A rnold'sche Buchbandlung in Dresden .. . . - 1

Ba $\log$ h Dro, k. k. Regiments - Feldarzt im Chevaux-legers

Regimente Fürst Rosenberg

B isch off J. R., k. k. Rath, Stabs - Feldarzt und Professor,

Commandeur erster Classe des kurfürstl.-hessischen Haus-

ordens vom goldenen Lören

Böh Dr. Ferdinand, k, k。 Regiments-Feldarzt im Dra.

goner-Regirnente Knesevich

Buchinger, k. k. Oberfeldarzt im Infanterie-Regimente

Baron Strauch

C nobloch'sche Buchbandlung in Leipzig

Cöls, Landrath und Polizey - Director in Achen.

Cot $t$ a'sche literar. artist. Anstalt in Miinche

Finke G., Buchhändler in Berlin

Garthe'sche Buchhandlung in Marburg

Gläsers'sche Buchhandlung in Gotha

Göbel Dr., k. k. Regiments - Feldarzt im Infanterie - Regi-

mente Watlet

Götz Wilbelm Dr, in Lichienau am Rhein

Gräff Dr., k, k. Regiments - Feldarzt im Palatinal-Husaren-

Regimente

Il a u e r Dr., k. k. Rath und dirigirender Stabs-Feldarzt beym

General - Commando zu Prag

He yse'sche Buchhandlung in Bremen

Ilieronjmus Dr. von, grossherzoglich-Meblenburgisch-

Strelizischer Ober-Medicinal-Rath

H irschberg Dr. von, k, k. Regiments-Feldarzt im Infan-

terie-Regimente Graf Gyulay

II irschwald'sche Buchhandlung in Berlin

Hö g g Dro, k。 k. Regiments-Feldarzt im Infanteric-Fingimente

Fürst Lichtenstein

Horvath'sche Buchuandlung in Potsdam

illum. schw. 
Hu be r et Compagnie, Buchhändler in St. Gallen .

Karger Anton Dr, k. k. Regiments-Feldarzt und Opera-

teur im Infanterie-Regimente Mariassy

Kan fman Edler von, Dr. der Medicin

Ketterer Dr., k. k. Rath, dirigirender Stabs-Feldarzt beym

inner österreichischen General-Commando und Ritter

des $\mathbf{k}$. sicilianischen St. Georgs-Ordens

K le in, k. k. Ober-Feldarzt im Infanterie-Regimente Freyherr

Bakonyi

J. Fr. Korn'sche Buchhandlung, für die königliche Universitäts - Bibliothek in Breslau

Dieselbe Buchhandlung noch

Kottmayer Dr., k. k. Stabs-Feldarzt zu Linz

L, anger Wenzel Dr., k. k. Regiments-Feldarzt im Che.

vaux-legers Regimente O'Reilly .

I. a u p'sche Buchhandlung in Tiibingen

Marasse Christopl, k. k. feldürztlicher Gehiilfe im In-

fanterie-Regimente Baron Hohenegg .

Maschka Dr., k. k. Regiments-Feldarzt im Infanterie-Regimente Baron Kutschera

Maxilian Dro,k. k. Physicus der Pancsowaer-Communität M ïller. et Comp., Buchhändler in Amsterdam

Nest 1 er'sche Buchhandlung in Hamburg

Nicolai'sche Buchhandlung in Berlin

- - - dieselbe fïr den Verein zur Beförderung des

Gartenbaues in den $k$, preussischen Staaten

Nolden Dr, k. k. liegiments.Feldarzt im Gradiskaner Grïn-

Regimente.

Oswald Aug. Buchhändler in Heidelberg

Petelenz, k. k. feldärztlicher Gehiilfe im Husaren. Regi-

mente Geramb

Plahn'sche Buchhandlung in Berlin

Pustet'sche Buchhandlung in Regensbur

Anzahl der

Exemplare

illum. schw.

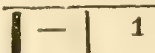

1

Rackhorsi'sche Buchhandlung in Osnabrück

Reitzel'sche Buchhandlung in Copenhagen

Riegg Dr., k. k. Regiments.Feldarzt im Husaren-Regimente

Geramb

Riess Ludwig Dr., k. k. Regiments-Feldarzt im Infantcrie-

Regimente Prinz Leopold beyder Sicilien.

R inglhann Dr., k, k. Stabs. Feldarzt in Mantua

li udolphi Dr., k. preussischer geheimer Ober-Medicinal. Rath und Professor

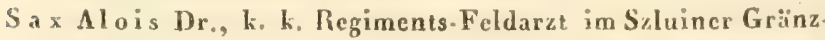
Regimente . 


\section{Verzeichniss der Herren Subscribenten. XIII}

Schindel ma yer Dr., k. k. Stabs-Feldarzt zu Yenedig

Schmid - und Grucker'sche Buchhandlung zu Strassburg S chubert Anton, Dr., k. k. Regiments.Feldarzt im Infanterie-Regimente Fürst Bentheim

Anzahl der Exemplare

illum. schw.

Söllner L othar, Dr., k. k. Regiments-Feldarzt im In fanterie-Regimente Herzog zu Würtemberg

Sommer Anton, k. k. Ober-Feldarzt im Infanterie-Reg:mente Erzberzog Albrecht

$S t a h e l$ 'sche Buchhandlung in Wiirzburg

Si orch Wenzel

*

Ts c höp pern, Dr., k。 k. Bath und dirigender Stabs-Feld arzt zu Lemberg

Fr. Yolke'sche Buchhandlung in W"

L. Voss Buchhändler in Leipzig . . . . 10

We ber Dr., $k$. Path und dirigirender Stabs-Feldarzt beym

Bannater General-Commando

Weber'sche Buchkandlung in Bonn

Werneck Dr., k. k. Regiments - Feldarzt im Infanteric - Regimente Grossherzog von Baden

Westinger Dr., k. k, Regiments-Arzt und Operatuer im Infanterie-Regimente Bakonyi . . . . .

IV u rm Dr., k, k. Regiments-Feldarzt im Infanterie-Regimente Graf Albert Gyulay

Zenger Wenzel, k. k, Ober. Feldarzt im ersten JägerBataillon

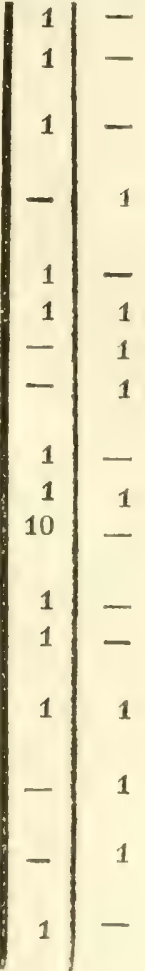

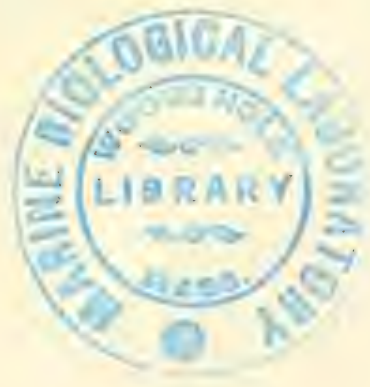





\title{
Inhalt des ersten Bandes.
}

\author{
Erste Abtheilung. Von den Haarender \\ Pflanzen überhaupt.
}

Erster Abschnit. Anatomische Bemerkungen.

$V_{\text {or }}$ on den Pflanzenharen iaberhaupt

Seite

Ursprung und Bildung der Pflanzenhare -

Verchiedenartige Beschaffenheit derselben -

Ob diese Haare immer $Z$ wiebeln besitzen?

Ueber die Gefässe derselben

Von den drïsenartigen Körpern, die sich häufig am Ursprung der Ptlanzen finden -

Von der Form dieser Hare.

Von den einfachen IIaaren, Arien derselben - _ . 8

Von den zusammengesetzten IIaaren, Arten derselben - $\quad 12$

Terminologie der Pflanzenhare. Unterschied zwischen Stachel

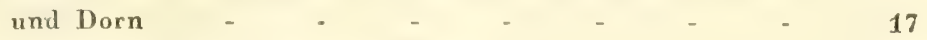

Vorkommen und Vertheilung der Haare - _ _ - $\quad 20$

Verschiedenheit dieser Haare nach dem Alter - - $\quad 25$

Verschiedenheit dieser Haare nach dem Klima, Standort und o

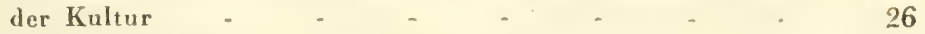

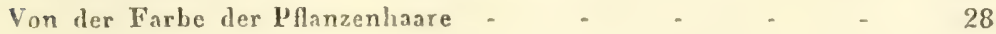

Zweyter Abschnit. Physiologische Bemerkungen.

Einleitung

Verschiedenheit der physiologischen Verrichtungen nach den allgemeinen anatomischen Charakteren - $\quad-\quad 30$

Wachsthurn der Pflanzenhaare _ _ _ _ _ _ _ $\quad 32$

Allgemeine Eintheilung ihrer Functionen - _ _ _ $\quad 33$

Von der Einsaugung der in der Luft, lem Wasser, und der Erde enthaltenen Fliissigkeiten 
Von der Aussonderung eigener, in der Pflanze bereiteter Stoffe

Von den Nebenverrichtungen in Bezug auf Schutz und Bederkung, auf das Befruchtungsgeschäft, genaue und anhaltende Beriihrung zweyer Pflanzen, und endlich auf Zierde

\section{Dritter Abschnitt. Ueberkrankhafte Ausartung der Pflanzen hare überhaupt.}

Etwas über das krankhafte Verbalten der Pflanzenhaare.

Ueber die Bildung der Haare an der Oberfläche pflanzlicher Afterorganisationen .

Eintheilung der Aftergebilde in Auswüchse und Missstaltungen 55

Von der Behaarung der Zapfenrosen ( $\mathrm{S}$ q a m matio) -

Von der Behaarung der Verkrüpplungen (Pteromata) - $\quad 56$

Von der Behaarung der Fleischapfen (Folliculi carnosi), der Sackgeschwülste (Bursae) - - - - - -

Von der Behaarung der Fleischgewächse (S a rcomata) - 57

Von der Behaarung der Gallen (Gallac) - _ _ _ _ -

Von der Behaarung der Masern (Tubera) - _ - 58

$\begin{array}{lllllll}\text { Schlussfolgerungen } & - & - & - & - & - & - \\ \text { Literatur der Ptlanzenhaare } & - & - & - & - & - & -\end{array}$

Zweyte Abtheilung. Von den llaaren der Thiere.

Erster Abschnitt. A. Anatomisch-naturhistorische Bemerkungen.

Erstes Hauptstück. Von den Thierhaaren im Allgemeinen.

Definition des Thierhaars _ _ $\quad$ - $\quad$ - 63

Organisation, Form und Gestalt - _ _ _ _ $\quad 64$

Beschreibung eines Tasthaars aus der Schnauze eines Ochsen - -

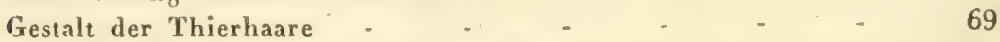

Weichheit, Härte, Glätte und Rauhigkeit _ _ _ 70

Richtung der Thierhaare. Gerade und krause Haare - $\quad 72$ Von der relativen Menge, Länge und Kürze der Haare an ver-
schiedenen Theilen des Körpers -

\begin{tabular}{ccc} 
Verschiedenheit dieser Haare nach dem Geschlechte und dem \\
Alter \\
\hline
\end{tabular}

Von der Mausser der Vögel, und dem Hären der Thiere - 81

Einfluss des Klima und der Jahrszeit auf die Haare der Thiere 85

Veränderungen, welche diese Haare durch dic Lebensart der
Thicre erleiden - 


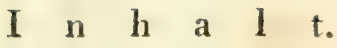

Seite

Von der Farbe der 'Thierhaare

Bezeichnung der verschiedenen Körperhaare $\quad$ - $\quad$ - $\quad$ - 94

Chemische Eigenschaften der Thierhare - _ - 97

Zweytes Hauptstück. Von denHaaren der Thiere insbesondere, d. i. nach denKlassender letztern.

Einleitung -

W i r b e llos e Thiere.

I. Haare der Zoophyten - $\quad$ - $\quad$ - $\quad$ - $\quad$ - $\quad$ - 98

Terminologie dieser Haare - - - . 100

Vorkommen der gewöhnlichen Haare bey den Zoophyten - 102

Vorkommen der Randhare (Cilia) - - - $\quad 10 j$

Vorkommen der Rankenhaare (Cirrhi) - - 105

Vorkommen der Borsien (Setae) - _ _ _ _ _ _ _ _ _

Vorkommen der Hornstacheln (Corniculi) . _ _ - _ -

Vorkommen der Stacheln (S pinae) - _ _ _ 106

Vorkommen verschiedener dieser Arten an cinem und demselben Individuum

11. Haare der Eingeweidewiirmer - _ _ _ _ $\quad 107$

III. Haare der Medusen, Acalephen - - $\quad 108$

IV. Haare der Strahlthiere - $\quad$ - $\quad$ - $\quad$ - $\quad . \quad$ -

V. Haare der Anneliden - $\quad$ - $\quad \ldots \quad 109$

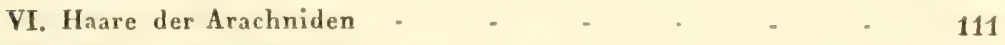

VII. Haare der Crustaceen - _ _ _ _ _ _ -

VIII. Haare der Mollusken und Cirrhipeden - - $\quad 113$

IX. Haare der Insekten nach den einzelnen Grinungen derselben 11'

Thiere mit einer Wirbelsåule.

X. Haare bey den Fischen

XI. Haare der Amphibien - _ _ - 127

XII. Haare der Vögel, Federn - _ - $\quad$ - 128

Von den Federn insbesundere - _ _ _ . 150

Organisation der Feder, Kiel _ _ _ _ _ . 131

Schaft oder Ruthe - $\quad$ - $\quad$ - $\quad$ - $\quad$ - 133

Bart-oder Fasern - - . _ . . 135

Farbe der Federn. - $\quad$ - $\quad$ - $\quad$ - $\quad 137$

Entstehungsweise und Befestigungsart der Federn _. $\quad \mathbf{1 3 5}$

Schlussfolgen $\quad$ - $\quad$ - $\quad$ - $\quad$ - $\quad 139$

XIII. Haare der Säugethiere nach ihren Ordnungen - _ 143

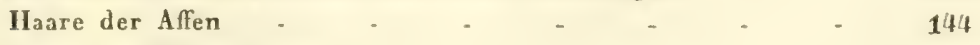

Haare der Fleischfresser - _ _ _ _ _ - 147

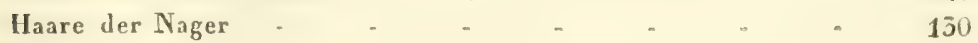

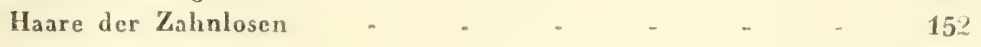

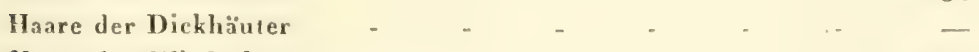

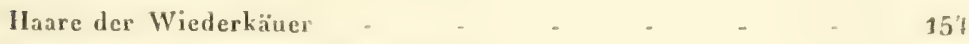

Haare der fischarligen Säugethiere _ _ _ _ . 155 
Drittes Hauptstück. Von der Verschiedenheit der Thierhare nachihrer Textur.

Allgemeine Eintheilung dieser Haare

Seite

A. nach ihrem innern Baue, und

B. nach ihrer Beweylichkeit

157

Besondere Eintheilung der Säugethierbare, als der voll-

kommensten in der Structur

158

159

Von den Wollhaaren

162

Von den Seidehaaren

Von den Borstenhaaren

Von den Hornhaaren

Von den Stachelhaaren

Von den platten Haaren.

Yon den gefleckten Haaren

Von den Tasthaaren

Schlussbemerkungen
165

170

171

179

181

184

188

Zweyter Abschnitt. Ueber den physiojogischen $\mathrm{Z}$ weck der Thierhare.

Einleitung. Eintheilung der Verrichtungen

Erstes Hauptstiick. Von dem Nutzen der Thierhaare im Allgemeinen

Zweytes Hauptstïck. Von dem speciellen Nutzen der Thiere

Eintheilung der speziellen Verrichtungen

Von den Thierhaaren als Bedeckungsmitteln

Von den Thierhaaren als Vertheidigungsmitteln

Von den Thierharen als Zierde des Körpers.

Von den Thierhaaren als Organe des Gefühls _ . _ _ 203

Von den Thicrhaaren als Organe der Bewegung - _ $\quad 210$

Schlussbemerkungen

Dritter $A$ bschuit. Etwas über die Pathologie der 'Thierhare.

Bemerkungen über das Verhalten der Hare in den verschiedenen Krankheiten der Thiere

Bemerkungen über das abnorme Vorkommen der Hare bey den Thieren

Literatur der Thierhane 
Erste Abtheilung.

Pflanzenh a are. 



\title{
Erster Abschnitt.
}

\author{
Anatomische Bemerkungen.
}

Von den Pflanzenhaaren überliaut.

\section{§. 1 .}

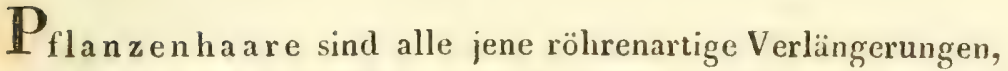
welche auf der Oberfläche verschiedener Pflanzentheile aufsitzen, stets aus einer oder mehreren, ans dem allgemeinen Zellgewebe hervorspringenden Zellen bestehen, und ihrer äusseren Bildung nach den Haaren der Thiere mehr oder weniger ähnlich sind.

\section{§. 2 .}

Jedes Pflanzenhaar ist als eine offenbare Verlängerung des Zellgewebes anzusehen, ist an und für sich selbst nichts anderes, als eine fortgesetzte Zelle. Diess scheint schon M a lpighi gewusst zu haben, indem er sagt*): „es ist wahrscheinlich, dass die Haare Anhängsel, und die letzten Kettenzweige des Zellgewebes seyen."

Es ist aber nicht bloss die Epidermis, wie die meisten Schriftsteller glauben, sondern der gesammte Rindenkörper, der in die Bildung derjenigen zarten Organe eingeht, welche wir an der Oberfläche des gesammten oberirdischen Pflanzenkörpers wahrnehmen, und die wir Haare nennen. Damit soli jedoch nicht behauptet werden, dass die Oberhaut gar keinen Antheil an der Bildung der Haare nehme, sondern ich bin vielmehr der Meinung, dass wenigstens die einfachen Formen derselben aus ihr gebildet werden. Bei den mehr entwickeiten Formen dagegen bildet sie offenbar nur den Ueberzug

*) Opera posthuma. De pilis observationes p. 45. 
über die aus dem Rindenkörper entspringenden, und vorwaltend nach der Länge angereihten, mehr oder weniger regelmässigen Zellen.

Anmerkung. Der Rindenkörper findet sich seiner wahren Iiedeutung nach nur in den höheren ausgebildeten Pflanzen, als den Bäumen und Sträuchern, wo sich sein polarer Gegensatz in der Bil. dung des Holzkörpers äusserlich darstellt. Doch ist nicht zu läug nen, dass sich wenigstens ein Analogon des Rindenkörpers auch in den Monocotyledonen und in den krautartigen Dycotyledonen vorfindet. Ueberhaupt unterscheidet sich der Rindenkörper durch folgende Merkmahle: Seiner fage nach ist zu bemerken, dass er sich unmittelbar unter der Oberhaut ausbreitet, und mit dieser auf das innigste zusammenhängt. Rücksichtlich seiner Struktur besteht er bloss aus Zellgewebe ohne Spiralgefässe; seine Zellen selbst unterscheiden sich von jenen des Parenchyms durch ihren feringern Durchmesser, und durch ihre mehr gestreckte, ja zuweilen auch unregelmässige Form. Ihr Inhalt zeichnet sich durch eine grössere Menge jenes harzigen Extractivstoffes aus, der die grüne Farbe der krautarigen Pflanzentheile hervorbringt. - Man mag nun dieses eigenartige Gewebe von bald grösserer bald geringerer Mächtigkeit Rindenkörper nennen, oder nicht, oder diese Benennung nur für höher ausgebildete Pflanzen, bey denen sich ein förmlicher Holzkörper findet, vorbebalten, so liegt daran nicht viel; denn hier geniigt es damit bloss den Ort z u bezeich. $n$ e $n$, in welchem jene zarten Furtsetzungen der Oberfläche des Pflanzenkörpers, die man mit der allgerneinsten Benennung der II a are belegt, grösstentheils ihren Ursprung nehme n. Die Entstehung der Haare aus der Rinde ist so auffallend, dass sich schwer unterscheiden lässt, wo jene anfangen, und diese aufhört. Meistentheils erhebt sich das Zellgewebe der Rinde mehr oder weniger an dem Orte, wo ein Haar entstehen soll, und wird nach Verschiedenheit der Pflanzen und des Haares entweder gestreckter oder körniger. Dieses Zellgewebe bildet gleichsarn die Unterlage, die Basis, aus welcher sich das zu entwickelnde Haar erhebt. Zuweilen bleibt es bloss bey dieser Production, das Zellgewebe setzt sich in keine haarförmigen Verlängerungen fort, und so entstehen dann Tuberkeln, wie man diess bey der gemeinen Sonnenblume sehr genau verfolgen kann, wo Knötchen mit nicht entwickelten Haaren und solche mit entwickelten vermischt unter einander vorkommen. Eine höhere Metamorphose dieser Grundlage zeigt sich da, wo das Zellgewebe des Rindenkörpers entweder erhaben, oder in sich selbst versenkt, eine mehr körnige Form annimmt, gefärbt wird (bei Echium vulgare und Chaerophyllun bulbosum), und sich auf diese Weise, wie wir später sehen werden, als driisiges, der Ausscheidung eigenthïmlicher Pflanzensåfte ge widmetes Organ darstellt. 
Diess wäre demnach der Bulbus der Pflanzenhaare, ana$\log$ dem der thierischen. Er zeigt sich somit als ein Convolut von mehr oder minder unvollkommenem Zellgewebe, aus dem sich unmittelbar das Haar erhebt. - Eine dritte Metamorphose eben dieser (Grundlage ist jene, wo sich dessen Zellgewebe durch den ganzen Haarkörper hindurch bis an dessen äusserstes Ende hinzielt, und den Haaren auf diese Art eine grössere Steif heit gibt. Diese Form der Abweichung der Grundlage sieht man in den Gabelhaaren der Aspargia hispida.

So verhält sich die Sache bey den mehr vollkommneren Haaren. Bey zarteren, einfacheren und kleineren Haaren hingegen scheinen nur einzelne, und zwar die oberflächlichsten Zellen des Rindenkörpers sich zur Haarbildung erhoben zu haben; - in einigen Fällen endlich mag auch bloss die Epidermis an deren Bildung ausschliesslichen Antheil nehmen.

Was bis jetzt in Bezug auf den Ursprung der Haare gesagt wurde, gilt ganz vorzüglich auch von den Stacheln; denı auch diese bestehen, ihren anatomischen Verhältnissen nach, bloss aus Zellgewebe, und sind ursprünglich nichts anderes, als ein Product des Rindenkörpers, so zwar, dass der Antheil, den letzterer an der Bildung der Stacheln nimimt, noch bey weitem ersichtlicher ist, als in den Haaren. Auch das Oberhäutchen, das bey vielen Haaren als Ueberzug mehr problematisch ist, lässt sich hier ganz deutlich darstellen. Hieraus geht nun klar hervor, dass die Gränzlinie zwischen Haaren und Stacheln keine so feste, eigentlich gar keine wesentliche, sondern nur gradweise verschiedene sey. - *).

\section{§. 3 .}

Nach der verschiedenen Beschaffenheit der sie bildenden Zellen und des in diesen enthaltenen Saftes sind die Pllanzenhaare bald weich, bald hart oder elastisch, bald durch - bald nicht durchscheinend, bald gefärbt, bald farbelos, bald einfach, bald gegliedert, oder aus mehreren Stücken zusammengesetzt etc. Solche aus mehreren neben einander fortgesetzten Zellen bestehende Haare sah und beschrieb schon Kroker ${ }^{* *}$ ) bey Papaver somniferum und dubium, und Rudolphi***) bey Drosera rotundifolia.

*) Siche hierzu Taf. 1. Fig. 1, 2, 3.

*) Dissertatio de plantarum epidermide. Hal. 1800. 8.

***) Inatomic der Pllanacn. Berlin $180 \%$. 
Dic genannten Zellen, aus welchen das Haar besteht, und die bald einfach, bald zusammengesetzt, bald mehr oder weniger spitz, bald in einer horizontalen Linie fortgesetzt, bald neben einander nach aufwärts gelagert sind, scheinen in den meisten Fällen mit einem Safte angefüllt zu seyn, der hier ungefähr zu demselben $Z$ wecke dient, welchen man dem sogenannten Marke der Thierhaare zuschreibt.

\section{与. 4.}

Guettard *) stellte die Behauptung auf, dass die Pflanzenhaare jederzeit eine Art von Fussgestelle haben, welches mehr oder weniger die Ciestalt einer Halbkugel hat. Doch findet sich diess gewiss nicht bey allen Pflanzenhaaren vor, und desshalb baben auch jene Naturforscher nicht Unrecht, die da behaupten: "dass sich bey der Mehrzahl der Pflanzenhare keine deutliche Zwiebel, weder mit freyem noch mit bewaffnetem Auge, bemerken lässt."

\section{§. 5 .}

$\mathrm{Ob}$ Gefässe überhaupt, und welcher Art insbesondere in die Haare eindringen, ist bis jetzt noch von keinem PflanzenAnatomen entschieden worden. Rudolphi**) sah nie, auch hey den glücklichsten Einspritzungen sehr behaarter Pflanzen (wie Sonchus macrophyllus, Cucurbita Pepo etc.), wo die allerfeirsten Gefässe mit der gefärbten Flüssigkeit angefüllt waren, die llaare selbst auch angefüllt, sondern farblos wie bisher, und folgert daraus, dass $S$ prengel Unrecht habe, wenn er glaubt, dass die Haare Verlängerungen der Schraubengänge seyen. Franz v. Paula Schrank *****) ist ebenfalls der entschiedenen Meinung, dass die Haare nicht Anfänge oder Enden der Canäle, der eigentlichen Saftgefässe sind ${ }^{* * * *}$ ), sondern aus dem Zellgewebe hervorkommen, und selbst aus die-

*) Memoires de l'Academie de Paris 1745. p. 263 in 410 und p. 371 in 8 ro.

**) A. a. O.

***) Von den Nebengefässen der Pllanzen und ihrem Nutzen. Halle 179't. S. 87.

****) Dennoch nimmt Me ye n cinen Seitenkreislauf auch in den Haaren an. Siehe Nova acta acad. Lcopold. 2ter Thl, 13ter Bd. Ueber die Saftbewegung der Pflanzen. Auch Hedwig (Sammlung seiner Ab. handlungen Bd. 1. S. 69 u. ff.) will Spiralgefässe in den Haaren der Wurzeln gefunden haben. 
sem bestehen. Ich finde es nicht überflüssig, hier seine Gründe dafür anzuführen: 1. sah er bey Silena noctiflora gerade denselben Bau an den Haaren und an dem Oberhäutchen. 2. Zieht man, von was immer für einer Pflanze behuthsam das Oberhäutchen $a b$, so folgen die Haare mit, was nicht geschehen würde, wenn sie aus der inneren Substanz kämen, oder sie müssten nur eine feine Decke an der Oberhaut zurücklassen, wie das die Stacheln thun. 3. Nach Abziehung des Oberhäutchens bleibt im Innern der Pflanze keine Narbe, keine Spur einer Verletzung zurück, was wieder geschehen müsste, wenn die Haare aus dem Innern der Pflanze entstünden. -

\section{§. 6 .}

Bey den Haaren mancher Pflanzen findet man an ihrem Ursprnnge drü senartige Körper, deren $Z_{\text {weck }}$ und Nutzen noch nicht hinlänglich bestimnt worden ist. So sah ich diess namentlich recht schön bey dem Stachelhaare des Helianthus tuberosus. Wir legten nämlich den kegelförmig vom Blatte aufsteigenden weichen Stachel, nachdem er von seiner mit einem braunröthlichen Kreise umgebenen Basis mitten der Länge nach durchgeschnitten war, unter das Microscop, und fanden, dass die Höhle der genannten Basis unten gegen das Blatt zu am breitesten war, und sich nach aufwärts immer mehr ver. engerte. Diese Höhle war fast bis zur Hälfte mit einer braun. rö̈hlichen, weichkörnigen, also drüsenartigen Masse angefüllt - Wir entdeckten durchaus keine Spur, dass sich diese Masse aufwärts verlängert hätte, obgleich die Wände der Höhle von allen Seiten bis auf eine gewisse Strecke ebenfalls braunröthlich gefärbt erschiencn, welche Färbung sich allmählig in das einfache Weiss des Stachelhaares verlor. Uebrigens ist wohl zu bemerken, dass sich die ganze Oberfläche der Epidermis, aus welcher das Stachelhaar seinen Ursprung nahm, saftgrün darstellte *).

\section{7 .}

Was nun die F orm der Haare betrifft, so kann ich bey dem beschränkten Raume dieser Blätter, bey der Grösse des Gegenstandes, und bey der ungeheueren Arbeit, die diese Sache erforderte, wohl nichts besseres thun, als nach $\mathrm{Paula}$ Schrank's Beyspiel das in gedrängter Kürze zusammenzustellen, was uns der ausserordentliche Fleiss des französischen Natur.

*) Siche Tab, I, Fig. 1, 4, 5 n. 8. 
forschers (Guettard*) in den Denkwürdigkeiten der Pariser Akademie hinterlassen hat. Der unermüdete Mann wollte sich durch die Untersuchung von 5 bis 6000 Pflanzen in den Stand setzen, aus der Beschaffenheit der Haare und Drüsen eine systematische Eintheilung der Pflanzen zu schaffen. - Ich bin zufrieden, wenn ich bey dieser Arbeit meinem Werke die gewïnschte Vollständigkeit, und den geneigten Lesern durch bessere Zeichnungen und Hinzugabe einiger eigener Beobachtungen ein Mittel an die Hand gebe, wodurch sie das Dunkle dieses Gegenstandes um so leichter zu fassen, und nützlicher zu beurtheilen im Stande sind.

$\mathrm{Zu}$ diesem Ende werden die Haare zuvörderst in einfache und zusammengesetzte eingetheilt, je nachdem nämlich entweder nur eine einzelne Verlängerung ohne alle Theilung in Aeste etc, oder mehrere unmittelbar, oder zwar nur eine einzige, die sich aber in Aeste theilt, aus dem Zellgewebe entspringen

Vonden Pflanzenhaaren insbesondere.

§. 8 .

I. Einfache Haare.

Ein einfaches Haar nenne ich dasjenige, welches sich als eine einzelne röhrenartige Verlängerung von der Oberhaut verschiedener Pflanzentheile so erhebt, dass es sich nie in zwey oder mehrere Theile (Aeste) spaltet. - Davon zählen wir folgende Arten :

1. Pfriemenborsten (pili subulati). Sind gerade, kegelformige, oben nach Art einer Pfrieme zugespitzte, übrigens nur wenig steife Haare. Beyspiele: an den Blättern des Sonchus oleraceus, an den Franzen des Rhododendron hirsutum, an den Samen und Umschlagsblättern der gemeinen Möhre (Daucus Carota), an den Samen, Hïllenblättern und Doldenstrahlen der Athamanta Libanotis; endlich wohl auch bey Borrago officinalis, und den verschiedenen Arten von Echium, Pulmonaria, Cynoglossum, Chaerophyllum bulbosum und Synapis arvensis. Siehe Tab. I. Fig. 1, 2, 4.

Anmerkung. Der Unterschicd zwischen $H_{\text {a a }}$ und $\mathbf{B}$ orste ist nich

*) A, a, O. 
resentlich, eigentich nur quantitativ; denn ersteres geht in die Natur der Borste uber, indem es steifer wird. Nach Link kommt diess daher, dass sich bey den Borsten die Zellen seitwärts zusammenzichen, während die Haare nur eine Reihe von Zellen ha. ben. Zur besseren Versinnlichung verglciche man nur das Haar von Antirrhinum majus ruit der Spitze einer Borste von der Sa. menkrone von Inula helenium.

2. Ahlborsten (pili aciculares). Sind nichts anderes als Pfriemenborsten mit einer Handhabe, wenn ich so sagen darf. Sie haben nämlich am Grunde einen etwas länglichen, dicklichen Körper, der sich in ein krystallklares, pfriemenartiges Haar endiget. Beyspiele davon finden sich bey allen wahren Nesselarten. Tab. I. Fig. 5.

5. Zwiebelborsten (pili bulbosi). Diese unterscheiden sich von den vorigen bloss durch eine walzenartige Zwiebel, aus welcher das konische Haar gerade hervorsteigt. Beyspiele: an den Blättern und dem Stengel der rothen Kornblume; auch an dem Stengel von Daucus carota. Tab. I. Fig. 6.

4. Sichelha are (pili falcati). Man versteht darunter kegelförmige, oben fein zugespitzte, übrigens aus einem etwas dickeren, abgerundeten Grunde entspringende, und nach der Seite (sichelartig) gebogene, meist krystallhelle Haare. Beyspiele: an den Blättern des Wiesensalbey, des Abbisses (Scab. succisa), an den Blättern und Stengeln von Scabiosa arvensis, stellata, columbaria, sylvatica, Phlomis nepetifolia, an den Trägern und dem Blumenblatte der Glockenblume. Diese Art Haare findet sich am häufigsten im Pllanzenreiche. Sind diese Haare sehr steif, wie diess gewöhnlich bey den Grasarten der Fall ist, wo man sie an den Rändern der Blätter, an der Unterseite der Blattribben, so wie bey den Syngenesisten am Samen findet, so nennt man sie mit Recht Sichelborsten. Tab. I. Fig. 7.

5. Hakenborsten (pili redunci). Sind zwar durchaus konisch gestellte, aber oben in eine hakenförmig gebogene Spitze auslaufende Borsten. Man findet sie an den Samen und Blättern von Gallium rotundifolium, auf der Oberseite der Blätter der beyden Forskolien (Forskolia tenacissima und augustifolia), dann auch bey einigen Arten des Labkrautes. Tab. I. Fig. 8 .

6. F a denha a re (pili filiformes). Nit diesem Nanen belegt man lange, fast durchaus gleich dicke, aber verhältniss- 
mässig dünne, übrigens cylinderförmige, oben abgerundete, und unten auf einer rundlichen erhabenen Basis ruhende Haare. Beyspiele: am Griffel der Lonicera symphoricarpos, am Stamm und den übrigen Theilen der Rose, besonders aber am Grunde der Samen von Scabiosa atropurpurea und Tragopogon arvense. Tab. II. Fig. 9 .

7. Walzenförmige Haare (pili cylindrici). In ihrer Benennung liegt zugleich ihre nähere Bezeichnung. Sie unterscheiden sich von den vorigen bloss durch ihre grössere Dicke und Kürze. Man trifft sie an der Innenseite des Griffels bey Silena noctiflora, und an den Stempelnarben der meisten Pflanzen; so auch am Griffel der Lychnis vespertina. 'Tab. II. Fig. 10 .

8. Gekräuselte ll a are (pili crispi). Sind verhältnissmässig sehr lange, schlangenartig gebogene, nicht dicke Haare. Nit genauer Noth findet man sie an den Blättern des Weinstockes, und zwar auf der Unterseite in dem Winkel, den die grösseren Ribben mit der Mittelribbe machen; leichter trifft sie das Auge auf den Blättern und dem Stengel der Centaurea sonchifolia, und noch reichlicher an fast allen 'Theilen des'Tarchonanthus camphoratus. Tab. II. Fig. 11.

9. Kn oten ha are (pili nodosi). Diese Haare ähneln ganz einem feinen Faden, der hie und da durch einen Knoten unterbrochen ist. Guettard nannte sie daher auch Poils en corde de St. François. Schrank fand sie bisher nur an den Kelchen der Achyranthes lapacea; ich auch an dem Samen der Oberlippe der Krone von Galeobulolon Galeopsis. Tab. II. Fig. 12.

10. Gliederhaare und Gliederborsten (pili arliculati aut geniculati). Es sind diess kegelförmige, weiche und durchscheinende Haare, welche durch eine Zwischenwand in ihrem weitern Verlaufe so abgetheilt sind, dass das folgende Glied immer kleiner als das voranstehende ist. Die Zahl der Glieder ist natürlich verschieden bey verschiedenen Pflanzen. Sind sie steif, so heissen sie Gliederborsten. Nan findet erstere an den Blättern und den übrigen äusseren Theilen des Lamiunı purpureum, eben so an den Blättern und Stengeln von Arnica Doronicum und Marubium: ferner bey Cirsium acaule (wenn die Haare etwas verwelkt sind), und endlich an der braunen Spreue, womit der Kelch von den weiblichen Blüthen des Xanthium spinosum hedeckt ist, wie uns 
Schrank zuerst berichtet hat. - Von den Gliederborsten kann man sich die beste Vorstellung durch Betrachtung der Haare an den Blättern, Stengeln und Blattstielen der Kürbisse machen. Tab. II. Fig. 13.

11. $\mathrm{Z}$ wischenwandhaare (pili valvulati). Sie kommen den Gliederhaaren sehr nahe, unterscheiden sich aber doch von ihnen aulfallend dadurch, dass, wie uns $\mathrm{Sch} r$ ank sehr richtig bemerkt, ihre Oberfläche stätig fortgeht, und nicht, wie dort, Stufen bildet. Man bemerkt nämlich die kleinen wagrechten Scheidewände erst beim Abtrocknen ganz genau, indem sie im frischen Zustande leicht dem Microscop entgehen. Beyspiele davon liefern uns die Blätter und Stengel der Ajuga reptans und pyramidalis, die Zoten an der Mündung der Blumenröhre der Vinca rosea; ferner die Blumenröbre der Calendula officinalis, der Bart der rothen Samenblume (Tagetes patula Linn.) etc. Tab. II. Fig. 14.

12. Kn öchelh a are (pili torulosi). Sind nichts anders, als wahre Gliederhaare mit Aufgetriebenheit an jener Stelle, wo das Gelenke sich befindet. Malpighi und Schrank geben bloss den Stengel und die Blätter des Lamium album als diejenigen Pflanzentheile an, wo man jene Haare finden kann. Tab. II. Fig. 15.

13. Rosenkranzha are (pili moniliformes). Ihre Beschreibung liegt ganz in dieser Benennung. Es sind nämlich kurzgliederige Haare, deren einzelne Glieder entweder kugeloder eiförmig und scharf begränzt sind. Schrank hat an den Haaren des Stengels und der Blätter des gemeinen Baldgreises $50-40 \mathrm{~K}$ ügelchen, oder vielmehr eiförmige Körperchen an einem solchen Haare gezählt. Auch der Sonchus oleraceus trägt auf dem Stengel, den Blättern und Kelchstücken solche Haare, so wie die Blumen der Melonen, Gurken, Kürbisse und dergleichen Gewächsen, ferner die Anagallis phoenicea an den Trägern rothe und durchscheinende Rosenkranzhaare haben. Tab. II. Fig. 16.

14. Gelenkhaare (pili phalangiformes). Sie unterscheiden sich von den vorigen bloss durch ihre langen, meist ovalen Glieder. Das schönste Beispiel liefert gewiss der Staubbeutel der Tradescantia virginiana. Tab. III. Fig. 17.

15. Seit enzahnha are (pili secundati). Sind kegelförmige, einseitig gezähnte Haare. Beispiel : an den Blïttern der Siegesbeckia orientalis. Tab. III. Fig. 18. 
16. Sägeförmige $\mathrm{H}$ a are (pili serrati). Hier gehen die Zähne von beiden Seiten der Blätter ab. Z. B. beim Blatt der Cnemidostachys serrulata Martii. (Siehe dessen nova genera et species plantarum Brasiliensium. (Tab. 42.) Nicht so eigenthümlich bei der Velosia abietina. (Man sehe ebendaselbst Tab. 3, 4, 6. und bei Ilieraceum Pilosella. Tab. III. Fig. 19.

\section{9 .}

\section{I. Zusammengesetzte Hare.}

Ich zähle hieher alle jene Pflanzenhaare, welche entweder an und für sich schon doppelt oder mehrfach aus einem gemeinschaftlichen Grunde, oder zwar einfach entsprungen sind, sich aber späterhin wie vielfach immer getheilt haben. - Es gehören biezu folgende Arten:

17. Warzenhare (pili verrucati). Sind kurze und feine Haare, welche auf warzenartigen Erhöhungen der Pflanze entspringen. So findet man sie auf Cistus Helianthemum, auf den Blättern und Stengeln des Viburnum Lantana, ferner an den Kelchen, Blüthenstielen und in den Winkeln der Blattribben von Spiraea opulifolia, dann auf einigen Käspappeln, dem Solanum, der Alga marina u. dgl. Tab. III. Fig. 20.

18. Stern förmige Harre (Borsten), (pili stellati). Man versteht darunter steife, aus einem gemeinschaftlichen, ebenfalls über die Epidermis der Pflanze erhabenen massiven Mittelpunkte entspringende, dann parallel mit der Fläche nach allen Seiten verlaufende, und sich in eine scharfe Spitze endigende Haare. Das beste Beispiel hiezu biethet uns das Alyssum dar. S chrank hat solche Haare vom Alyssummontanum, calycinum, und von der Sida mauritiana dargestellt. Man findet sie übrigens auch an den Kelchen, Stengeln, Blattstielen, und an der Unterseite der Blätter bei Lavatera triloba, beim Lavendel, an den wilden Oelbaumsblättern, bei Hieraceum Pilosella und Onosma stellatum. Tab. III. Fig. 21. a. b.

Anmerkung. Man kann die sternförmigen Haare abtheilen in solche, deren Strahlen einfach, und in solche, wo sie getheilt sind. Er. steres findet man bey den Cisten, Croton balsamiferum, argent. eum und tinctorium, Solanum racemosum etc., letzteres bey Alyssum, Clypeola jonthlaspi, an welcher vier Paar zweymahl hinter einander gespaltene Haare sind. - Diese Iaare machen den Uebergang zu den Schuppeu, werden manchmahl wirklich zn Schuppen, wenn sie sich nähmlich ganz mit einander verbinden. 
So sind die Haare bey Croton Eluteria durch ein zelliges Häutchen verbunden, und bilden Schuppen, aus denen am Rande noch lange Spitzen hervorstehen. Bey Croton nitens sind sie bis an die ïusserste Spitze vereinigt, und bilden stumpfeckige Schuppen. Etwas Aehnliches sieht man auch bey Cistus squammatus, und bey Solanum elaeagnoides; so wic dagegen diese Haare bey Croton balsamiferum aus 12-17 langen Strahlen bestehen, wie uns Rudolphi*) genau beschricben hat. - Auch entdeckte derselbe**) im Innern der Nymphea lutea und alba einige sternförmige Haare. Man sieht sie in einem Querschnitte von Nymphea lutea fig. 40. und von N. alba litt. A. Sie sitzen nicht auf der äussern Oberfläche, sondern inwendig in den grossen Zellen des zusaramengesetzten Zellgewebes.

19. Gefiederte Ha are (pili pennali). Sind solche Haare, aus deren Seiten andere feinere Haare entstehen, so dass das Ganze einer Federfahne nicht unähnlich ist. Diess sieht man bei Hieraceum Pilosella und einigen Arten von Lungenkra ut Tab. III. Fig. 22.

20. A estige Haare (pili ramosi). Sind so zu sagen auch gefiederte Haare, nur mit dem Unterschiede, dass sie durchaus dicker, und die abgehenden Aeste in geringerer Anzahl vorhanden sind. Man findet sie an den Blattstielen der Grossularia. Tab. III. Fig. $2 \tilde{\jmath}$.

21. Gabelh a are (pili furcali). Es sind diess steife Haare, die sich gabelförmig theilen. Die Gabeln sind bald zwey-, drey-, bald selbst vierspitzig, wie man diess am Leontodon umbellatum, hispidum und incanum sehen kanu. Die zottigen Träger der Staubbeutel bey dem dreyplätterigen Lycium bestehen ebenfalls aus solchen Haaren; und Bauhin's Alcaea. Bryoniae folio trägt an den Aesten, Blattstielen, Blättern, Blüthen, Stielen, Kelchen und Blattansätzen borstenartige Gliederhaare, die jedoch in Bezug auf ihren Ursprung zu den Gabelhaaren gerechnet werden müssen. - Tab. III. Fig. 24.

22. Hakenasth a re (pili frondosi). Sind weiche, konische, helldurchscheinende, oben zugespitzte Haare, welche aus einem einfachen Stammhaare gleichsam wie die Finger aus der Hand entspringen. So zeigt sie der Filz des Verbascum Thapsus, und der Rosmarinblätter. Tab. III. Fig. 25.

23. $\mathrm{Z}$ w ischenk no pha are (pili ganglionii). Sind fa-

*) A. a. O. p. 112 .

**) Bemerkungen aus dem Gebiethe der Naturgeschichte. 
den-oder kegelförmige Haare mit kugelförmigen Knoten, aus welchen die feineren Haare nach allen Richtungen entspringen. Beyspiele : an den åusseren Theilen von Verbascum Lychnitis und Blattaria und dem Jerusalemischen Salbey (Phlomis). Tab. IV. Fig. 26.

24. Schützen borsten (pili fusiformes). Sie bilden eine warzenartige Erhöhung, aus welcher sich zwei kugelartige Haare horizontal nach entgegengesetzten Seiten verlängern. So findet man sie an den Ecken der Blattstiele und der Aeste des Hopfens, beim Astragalus physodes, falcatus und massiliensis vor. Tab. IV. Fig. 27.

25. Gezähnte Borsten (pili dentali). Man versteht darunter kegelförmige Borsten, die durchaus mit Zähnen besetzt sind. Siehe die Samen des 'Tordylium Anthriscus und das Nectarium von Delphinium elatum. Tab. IV. Fig. 28.

26. Angelborsten (pili hamati). Sind abgestutzte, kegelförmige Körper, mit rückwärts gebogenen steifen Widerhaken an der stumpfen Spitze. So hängen sich nach Schrank die Samen des Bettlerläusekrautes (Myosotis Lappula) mit diesen Borsten an die Kleider der Vorübergehenden an. Auch findet man sie bey Spargia hispida. Tab. IV. Fig. 29.

27. Gezähnte Angelborsten (pili hamoso-dentati). Vereinigen die Eigenschaften der beyden letzten Arten. Schrank fand jedoch den Unterschied, dass bey den gezähnten Borsten die Zähne aufwärts, hier aber nach der entgegengesetzten Richtung stehen. Man findet übrigens diese gezähnten Angelborsten an den Samen der Caucalis leptophylla, und des Cynoglossum officinale. Tab. IV. Fig. 30.

Diesen von Schrank aufgeführten Arten von Pflanzenhaaren reihe ich noch folgende an:

28. S p innenwebförmige $\mathrm{H}$ a a re (pili arachnoidei). Sie bilden an der Oberfläche der Blätter ein förmliches Gewebe, welches sich von einer Spitze des Blattes zu der eines andern hinzieht. So sah ich es bey den Blättern des Sempervivum arachnoideum. Tab. IV. Fig. 31.

29. Keulenförmige $\mathrm{H}$ a are (pili clavati). Einfache Haare, die gegen ihre Spitze zu immer dicker werden; z. B. an dem Staubfaden von Verbascum pulverulentum; überhaupt an den Blumen der Labiaten, des Antirrhinum, der Linaria, Euphrosia etc. Tab. IV. Fig. 32.

30. B ̈̈ s chelha a re (pili fasciculati). Aehneln den vo- 
rigen, kommen jedoch zahlreicher aus einem Punkte hervor. An den Stengeln der Lavatera micans. Tab. IV. Fig. 5う.

Die sogenannten Drüsenhaare (pili glanduliferi) sind ebenfalls einfache Haare, welche einer oder mehreren (?) Drüsen als Stütze dienen. Neuere Botaniker haben sie wieder in folgende Unterarten gebracht:

51. a) Kopfförmige Haare (pili capilati; nach Schrank und Guettard glandulae globosae). Einfache walzen-, kegelförmige, gegliederte oder stätige Haare, die sich oben mit einer kugelförmigen Drüse endigen. Man findet sie häufig z. B. bey Chenopod. viride an der Unterseite der jungen Blätter, weniger zahlreich an den Hopfenblättern, an den Samen der Hasselquistia cordata, an der Corolla des Antirrhinum majus, und der Stapelia reclinata J a qu in., der Digitalisarten u. s. w.; ferner beym Taback, Bilsenkraut, bey den Rosen, Gerauien, Teucrium hircanicum, Scabiosa stellata und atropurpurea, und Arnica Doroniceum; endlich bey dem Hiera ceum amplexicaule, der Madia viscosa, der Siegesbeckia orien talis, dem Hibiscus Abelmoschus, und am Rande der Kelch blätter der Lavradia montana *). Tab. IV. Fig. 34.

32. b) B e cherhaare (pili cupulati). Man versteht darunter ebenfalls einfache Haare, die aber an der Spitze eine hohle Drüse tragen. So findet man sie bey den Kichern. Tab. IV. Fig. 34.

32. c) Vielköpfige Haare (pilipolycephali). Sie gehören zu den zusammengesetzten Haaren, und charakterisiren sich dadurch, dass sich ihre Aeste in eine Drüse endigen, z. B. bey Croton penicillatum; hieher scheinen auch die von $\mathrm{Schrank}$ und Guettard als Kolbendrüsen (glandulae clavatae) bezeichneten Nebengefässe zu gehören, wie man sie bey Passiflora foetida in unendlicher Anzahl und Verschiedenheit findet. Tab. IV. Fig. 35.

A nmerkung 1. L in $\mathbf{k}^{* *}$ ) macht einen Unterschied zwischen den gestielten Glandeln, den kopfförmigen, und namentlich zwischen jenen Haaren, an deren Spitze ein Tröpfchen Saft ausschwitzt, und sagt z. B. dass man vielen Salbeyarten gestielte Glandeln zu. schreihe, da doch nur ein Tröpfchen an der Spitze der Haare

*) Siehe MI a r $t$ in s nov. gen. etc. tab. 2j, 1, 2.

**) Grundlehren der Anatomie und Physiologic der Pflanzen. Güuin. gen 180\%. S. 115. 
hảngt, welches sich abwischen lässt, aber in der Luft so dickfliissig und braun wird, dass man es, tlüchtig angesehen, wohl für eine Driise halten konnte.

A nmerkung 2. In physiologischer Beziehung hat man auch eine eigene Art von Haaren anfgestellt, und sie vorzugsweise absonderndeHare (pili excretorii, s, bulbosi) genannt. Man versteht darunter solche Haare, die auf einer Drüse sitzen, der sie als Absonderungscanal dienen, z, B. bey dem Dictamnus al. bus etc. Als Unterarten hat man folgende angeführt:

a. Pfriemenförmige II a a re (pili subulati), wo eine Drüse unter dem röhrigen, pfriemenförmigen Haare sitzt.

b. Malpighische oder We berschiffchen-II a re (pili Mal. piphiacei), bey welchen auf der Drïse ein horizontal liegen. des Ilaar fest in der Mitte aufsitzt, und an seinen beyden Enden die Fliissigkeit ausflessen lässt; wie bey der Malpighia urens, - Ich zweifle jedoch, dass bey allen pfriemenförmigen Ilaaren eine solche Drïse als Basis dient, so wie ich nicht glaube, dass den sogenannten Schützenborsten (denn dorthin scheinen doch wohl die hier aufgeführten Malpighischen Haare zu gehören, jederzeit eine Drüse zu Grunde liege. -

Anmerkung 3. De Candolle (in seiner Organographie vegetale etc. Paris 1827) theilt die Haare im 10ten Kapitel in 6 Hauptklassen: 1) in die driisigen Haare, 2) in die lymphatischen oder nichtdriisigen, 3) in die corollinischen, 4) in die schuppigen, -5) in die Wimpern- oder Rand., und 6 ) in die Wurzelhaare. Die drisigen Haare sind nach ihm entweder: 1. Drüsentragende (pili glan. duliferi), welche die Stuitzen kleiner Driisen sind, und worunter die drey angeführien Arten unserer Drïsenhare gehören, oder 2. aus. sondernde Haare (pili excretorii), worunter er die Aussonderungscanảle gewisser Druisen, also die kurz zuvor angeführten pfriemen. förmigen und Weberschiffchenhaare begreift. - Mit dem Namen der corollinischen Haare (poils corollins) bezeichnet $\mathbf{D e}$ C andolle alle jene Haare, welche sich auf den Petalen, Perigonien, Staubfäden und Stengeln befinden, ohne Rücksicht auf ihre Form. Diespreuartigen Haare (poils scarieux) sind nach ihm von trockener schuppiger Beschaffenheit, zeigen sich an verschiedenen Theilen lebender Gewächse in einem atrophischen Zustande, und besizen bloss noch die dem Pflanzengewebe eigenen hygroskopischen Eigenschaften. Sie sind also im Pflanzenreiche das, was die Schuppen im 'Thierreiche sind. Man findet sie auf den Blattstielen der Farrenkräuter, an der Federkrone der Compositae und der Valerianeen, auf den Bälgen der Gramineen, auf den Samen mehrerer Apocineen etc. Diese Ilaare sollen vorziiglich zur Verbreitung der einsamigen Früchte der Corapositae dienen, indem sie, sobald sie feucht werden, aufrecht stehen, und sich allmählig ausbreiten, so wie sie vertrocknen. Durch diese Ausbreitung oder 
das Niederlegen stiitzen sie sich entweder auf das Involucrum, oder die angrenzenden Blumen, und da diese Widerstand leisten, so drücken sie auf die ihnen zur Stütze dienende Frucht selbst, heben sie aus der Hülle heraus, und begünstigen so die Zerstrenung der Frucht in der Luft. Die Wimperha are (cilia) zeichnen sich vor den übrigen Haaren bloss dadurch aus, dass sie nicht auf einer Fläche, sondern auf dem Rande derselben entstelen; finden sie sich nur an der Spitze der Blätter einfach, so heissen sie Borsten (setae), die zur Spize (mucro) wird, wenn sie etwas kurz und weich ist. Auch die Wurzelhare haben in Bezugauf die Form nichts Ausgezeichnetes. Alle ibrigen, unter die genannten Arten nicht gehörigen, also bey weitem dic zahlreichsten, machen die lymphatischen Hare aus. Ueberhaupt sind nach De Candolle alle nicht drüsigen Haare lymphatisch, und er bringt die Hauptverschiedenheiten ihrer Form unter folgende Arten: 1) Die einfachen, die nur durch Verlängerung einer einzigen Zelle gebildet werden. 2) Die Fach - Hare (poils cloissonnés), welche aus mehreren, einfach an cinander gereihten, durch Scheidewände getrennten Zellen bestehen. 5) Die ästigen $\mathrm{H}$ a are, deren zahlreiche Zellen nicht nach einer Reihe, sondern nach verschiedenen Richtungen auseinander gehen. 4) Die stachelf örmigen $\mathbf{H}$ a are, welche aus mehreren, aber wie im Zellgewebe zusammengehäufien Zellen gebildet sind.

\section{ร. 10 .}

Das verschiedenartige äussere Ansehen, welches die mannichfaltige Beschaffenheit der Haare überhaupt den Pllanzen gibt, hat in der botanischen Terminologie zu vielerley Benennungen Anlass gegeben, wovon ich hier die vorzüglichsten anführen will:

a) $\mathrm{H}$ a a r im engern Sinne (Pilus) bedeutet ein an der Oberfläche sitzendes, wenig niederliegendes, und etwas steifes Haar.

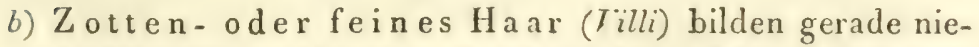
derliegende, zahlreiche, etwas weiche und kaum sichtbare Haare; z. B. Ballota nigra, Anemone pulsatilla, Plantago media u. dgl.

c) Wolle (Lana, lanugo) ist ein der Wolle äbnliches Gewebe, das aus langen, weichen, niederliegenden, oder sich kreuzenden Haaren besteht; z. B. Stachys lanata, Cineraria lanata.

d) Filz (Tomentum) ein der Baumwolle ähnliches Gerebe, 
das aus langen, mitunter krausen und gekreuzten, aber nicht einzeln wie bey der Wolle zu unterscheidenden Haaren besteht; z. B. Verbascum Thapsus, Althaea officinalis.

e) Seide (Sericum). Sehr feine, dicht aufliegende, und der Oberfläche ein glänzendes Ansehen gebende Haare; z. B. Potentilla alba, Convolvulus althaeoides, Alchemilla alpina.

f) W eiches $\mathrm{H}$ a ar, Pflaumenbart (Pubes), eine Menge weicher, weisser Haare, die dem Milchbart der Ziege ähnlich sind; z. B. Oenothera mollissima, Rhus typhina.

8) $\mathrm{R}$ a uh h es $\mathrm{H}$ a ar (Hirsulies), eine Menge langer, zahlreicher und dicht an einander stehender Ilaare; z. B. Hieraceum. aurantiacum, Echium vulgare, Daucus carota.

h) Wimper- oder Rand $\mathrm{I}_{\text {a a }} \mathrm{r}$ (Supercilium s. cilium) ist ein etwas steifes, am Rande irgend einer Fläche stehendes Ilaar; z. B. Sempervivum tectoram, die Corolla der Gentiana ciliata $\mathrm{u} . \mathrm{s}$. w.

i) Bart (Barba). Haare, die etwas büschelförmig, oder in einer regelmässigen Ordnung stehen; z. B. Mesembrianthemum barbatum.

k) Granne (Arista) ist eine Art steifer Haare, eine fadenförmige, am Ende oder am Rücken stehende Spitze, die nicht die Fortsetzung einer Ribbe zu seyn scheint; z. B. die Gluma aristata bey der Gerste, dem. Hafer u. a.m.

l) Steifes Ha ar (Crinis). Gleicht dem Rosshaar, es mag wo immer sich an einer Pflanze befinden.

m) Ha arspitze (Apiculus), ein Haar, oder eine haarförmige Spitze, die am Ende steht, fein, kurz, und nicht sehr steif ist.

7) Pfriemenspitze (Cuspis) ist eine langgestielte, pfriemenartige Haarspitze.

o) Borste (Seta s. mucro). Ein gerades, steifes Haar. Das einfach stehende, ziemlich lange, elastische und zugespitzte Haar geht in die Natur der Borste über, indem es steifer wird; z. B. Phlox setacea, Crepis aspera.

p) Striegel (Striga) entsteht, wenn sich die Borsten der ganzen Länge nach dicht an die Pflanze anlegen; z. B. Borrago officinalis, Symphytum officinale.

9) Haken (Hamus, rostellum, uncus) ein hakenförmig ge- 
liümmtes Haar, oder eine eben so gekrümmte Spitze; z. B. Gallium aparine, Caucalis daucoides.

r) Widerhaken- oder Angelborste (Glochis), ein dünnes, steifes Haar mit zurückgekrümmten oder herabgebogenen Aesten; z. B. Aspargia aspera, Echinospermum lappula.

s) Brennhaar (Stimulus, pilus urens), ein feines, etwas steifes Haar, das eine noch nicht recht gekannte Flüssigkeit enthält, welche auf der thierischen Haut eine eigene Art von Jucken und Entzündung mit einem brennenden Gefühl hervorbringt; z. B. Urtica urens.

Anmerkung 1. Manche Botaniker ählen auch die Dornen und Sta. cheln unter die Haare, ob mit Recht oder nicht, ist bey dem schwankenden Begriff dieser beyden Benennungen näher zu bestimmen. Ich glaubo aus guten Gründen die $S_{t}$ a che ln (aculei) hier nicht ausschliessen zu dürfen, insofern sie nämlich gleich den Haaren der Epidermis und dem Rindenkörper ange. hören; da hingegen die Dornen (spinae), weil sie überall aus Zellgewebe und Spiralgefässen zusammengesetzt sind, und entweder die Bedeutung von verlängerten und zugleich contrahirten Blattnerven, oder von, in ihrer Ausbildung gehemmten Knospen und Aesten haben, nicht hieher bezogen werden können. In Bezug auf das Verhälıniss zwischen der gewöhnlichen l'llanzenhaare und dem Stachel (im angegebenen Sinne) finde ich ganz das gleiche Bewandtniss, wie bey den Thierhaaren und Thierstacheln, wo. von später gehandelt wird.

A nmerkung 2. Der unermiidliche Guettard, dem es vorzüglichum die Classification der Pllanzen zu thun war, kam nach seinen vielen und sorgfältigen microscopischen Untersuchungen der Pflan. zenhare endlich zu dem Resultate: $d$ as bey vielen Familien und Arten e ines Geschlechtes einerley Haregefunden werden. So tragen nach seinen Angaben z. B. diePflanzen, welche Schmetterlingsblumeu haben walzenförmige, die pappelartigen kegelförmige, die mit Lippenblumen Gelenkhaare u.s.w. G ue tt a rd ging wirklich so weit, vorzuschlagen, dass man bey Bestimmung der Geschlechter besonders auf die Beschaffenheit der IIaré sehen sollte, weil er der Meinung war, dass die Arten von einem Geschlechte auch hierin übereinkommen miissten. - Dem istaber nicht so. Zum Beweise dessen hier nur einige Beyspiele: Rhododendron hirsutum hat an den Franzen des Randes sechs wenig gebogene Sichelborsten; Rhodod, ferrugineum ist ohne alle Borsten und Haare, und lihodod. Chamaecistus hat wieder kegelförmige Rand. borsten mit einem bräunlichen Kölbchen an der Spitze. Verbas. cum thapsus, bicolle und nigrum haben ebenfalls ganz verschie. dene Haare. 


\section{§. 11.}

Was das Vorkommen und die Vertheilung der Haare an den verschiedenen Pflanzen und deren Theilen betrifft, so muss bemerkt werden:

1. Dass es kaum eine Pflanze gibt, die man als durchaus haarlos ansehen könnte. Wallroth *) sagt, dass sich auch bey den unvollkommenen Pflanzen Haare vorfinden, und beweisst diess an der Chara. Nach $\mathrm{L}$ a mou reux**) triff man selbst bey den Fucis Haare an; und von den edleren Pflanzen, namentlich aber von allen Landgewïchsen, scheut sich Schrank***) nicht, geradezı zu behaupten, dass sie, einige kryptogamische Pflanzen etwa ausgenommen, durchaus Nebengefäs se besitzen.

2. Eben so wie es demnach beynahe keine völlig haarlose Pflanze gibt, so ist auch absolut kein Theil der Pflanze von der Eigenschaft ausgeschlossen, Haare tragen zu können. Um dieses näher zu beweisen, will ich in dieser Hinsicht die einzelnen Theile, aus welchem die Pflanzen bestehen, durchgehen, und zugleich auf die dabey vorkommenden Verschiedenheiten der hier gefundenen Haare aufmerksam machen.

a) Häufig findet man die W u r zeln, und zwar mit sehr feinen Ilaaren besetzt. Schon Malpighi**t*) schrieb, mit Ausnahme der Zwiebelgewächse, allen Wurzeln Ilaare zu. Schrank will sie sogar an allen Pflanzen gefunden haben, welche er aufs Gerathewohl einer Untersuchung unterzog. Merkwürdig ist jedoch, dass sie sich nur an den jungen Wurzeln und Nebenwurzeln bey ihrem ersten Keimen entdecken lassen, und anfangs so zarten, kleinen Wärzchen gleichen, dass sie nach Sprengel alsbald an der Luft zusammenfallen, und dann selsr feine Bänderchen darstellen. - Letzterer behauptet auch, dass sich die feinsten und zartesten Haare der Wurzelfasern in der Regel nur dann erkennen lassen, wenn der Same auf der Oberfläche der Erde (wie die Lactuca im Winter in Kästen) gesäet wird, oder im Wasser keimt, wo dann die Oberfläche der Fasern mit den feinsten,

*) Ann. botanic, 1815.

**) Annales du Muscum d'histoire naturelle p. 268.

***) А. a. O. p. 58 .

****) De sem. veget, op, tom. II. p. 66, Tab, 1-6. 
wolligen IÏrchen besetzt ist. Dieselbe Bemerkung hat auch Carradori*) gemacht, und er hält diese Haare desshalb für Organe, die zur Einsaugung der Feuchtigkeit der Luft bestimmt seyen, indem sie gleich den Schwämmchen das schon gebildete Wasser einsaugen. - Diese Haare haben übrigens nach $\mathrm{S}$ chrank jederzeit das Eigene, dass sie mehr oder weniger spitz, kegelförmig, dahıer stets einfach, nie ästig, nie gegliedert sind, und keine Becher oder Drüsen tragen. - Wie Wurzel der schönen Amaryllis, die man im Wasser kann wachsen lassen, hat pfriemenförmige Ifaare, am schwarzbeerigen Nachtschatten, beym gemeinen Bilsenkraut und dem glatten Stechapfel finden sich ausserordentlich feine Haare; eben so zeigen sich die Wurzeln aller Gräser sehr behaart, und leicht und schön findet maı sie auch beym Taback, den Arten des Amaranthus und des Sisymbrium. Selbst die Wurzel des Froschbisses, einer Wasserpllanze, und den Bulbus vom Hyacinthus comosus fand Schrank und ich ganz zottig von Haaren.

b) Der Stengel und die Aeste sind meistens mit den grössten, längsten und rauhesten llaaren versehen, und pflegen bis zu ihrer Theilung (an den sogenannten Blattachseln) die meisten Haare zu haben. - Es ist wohl überflüssig, davon Beyspiele anzuführen, da sie sich bereits aus dem Gesagten und dem noch später Anzuführenden leichı abstrahiren lassen.

c) Die Blätter biethen den ausbrechenden Haaren eine grosse Oberfläche dar, sind auch in ihrer Jugend, wie sie aus den Knospen hervorwachsen, last alle zottig, oder mit Seidenhaaren besetzt, und fangen erst mit vollendetem Wachsthume an, glatt zu werden. - Uebrigens bemerkt man an ihnen noch das Resondere, dass sie an ihrer unteren, der Erde zu - und dem Lichte abgewendeten Fläche jederzeit am haarigsten sind, besonders an jenen Stellen, wo die Ribben oder Nerven des Blattes verlaufen.

d) Bey den Organen der Inflorescenz und den eigentlichen Befruchtungswerkzeugen finden wir den oben ausgesprochenen Satz wieder aufs schönste realisirt : sie sind nämlich fast alle mehr oder weniger mit Haa.

*) Degli organi absorbenti delle xadice osscrvaz. prescnt. alla socicta dei Georgofili di Firenze etc. 
ren begajt. Hievon ist selbst die Narbe des Pistills nicht ausgenommen, wie diess S prengel vom Crocus und der Cerbera Manghas durch Zeichnungen dargethan hat. Andere Beyspicle sind theils in dem Vorstehenden schon enthalten, theils werden sie noch nachfolgen. Sogar die Testa der Samen ist nicht frey davon. So hat Cleoma und andere Samen einen Z o p f (Coma) von wirklichen Haaren. Die Samen des T'ordylium syriacum sind mit starken kegelförnigen Borsten besetzt; die von Tordyl. anthriscus haben gezähnte, weiche, etwas gebogene Borsten. Athamanta cretensis zeigt an den Samen weisse, fast fadenförmige Haare. Die Samen von Scandix infesta sind mit ähnlichen Borsten versehen, wie die von Tordyl. anthriscus. Das Ovarium von Alsodea pluysiphora Mart. ist ganz und stark behaart; eben so bey Alsod. panniculata. (Siche Tab. 19, 20. a. a. O.) Bey der Lagetta funifera Mart. (Tab. 39. N. 7) sieht man den oberen Theil des Griffels mit der Narbe, welche gleichsam aus zwey zusammengewachsenen Köplen besteht, ganz mit steifen Haaren oder Borsten besetzt. - Der Samen der Wittelsbachia insignis (Tab. 55. N. 5) ist ganz in Wolle eingehüllt.

c) Selbst die Friichte machen von der allgemeinen Regel keine Ausnahme, und der Pappus oder die Haarfederkrone ist ein so bekanntes und in die Augen fallendes Merkmahl mancher Pflanzen, dass er jedesmal in der Specification desselben genannt wird; z. B. in den Cichoraceen. Auch ist es nichts Ungewöhnliches, dass man die Oberfläche mancher Obstarten oder sonstiger Früchte haarig findet.

Anmerkung. Merkwürdig ist es jedoch, dass die männlichen Befruch. tungswerkzeuge, welche bey den meisten Thieren mit Haaren, oder auf eine andere Art bedeckt sind, in den Blumen frey und nackt stehen, wenigstens sehr selten von Haaren umgeben sind. Diess gilt übrigens bloss von dem Staubbeutel, wo durch die IIaare die Ausstreuung des befruchtenden Pulvers erschwert, oder ganz verhindert wïrde, dagegen dienen sie wieder bey dem Staubwege dazu, den Blumenstaub desto besser aufzusaugen und zu bewah. ren. So findet man an den Seiten der Staubbentel der Veil. chen feine Haare, die wechselweise in einander greifen, und dadurch etwas zur Befruchtung der Narbe beytragen, die nur im Rohre der Staubbeutel Statt finden kann.

5. Es ist wirklich sehr auffallend, dass alle Ilaare, die man bisher an den Narben verschiedener Pllanzen gefunden 
hat, walzenförmig sind. Schrank hat diess vom Verbase. thapsus, Amaranthus cruentus, sanguineus und flavus, der lris, der Primula, den Aurikeln, der Wiesenkresse und dem Panicum verticillatum durch seine Untersuchung dargethan.

4. Nichts ist gewöhnlicher, als dass man an einer Pflanze mehrere Arten von Haaren zugleich antrifft. - Ich will rersuchen, diess durch eigene Untersuchungen zu beweisen:

a) Die Haare des Boretsch (Borrago officinalis) sind, da wir sie oben unter die Pfriemenborsten zählten, ziemlich lang, spitzig, stets einfach, aber in lange Glieder abgetheilt, hie und da knieförmig gebogen, vollkommen durchsichtig, und hangen so fest an der Oberhaut, dass man letrtere mithinwegreisst, wenn man an den Haaren mit einiger Gewalt zieht. An ihrer Basis sind sie breiter und ringsum braunröthlich gefärbt. So fand ich sie an den Stengeln und Blättern; da hingegen sitzen an den Kelchblättchen nicht gegliederte und durchaus gerade Haare.

(1) Der oberste Theil des Stengels von Antirrbinum majus ist, so wie auch die ganze äussere Oberfläche der rachenfơrmigen Blumenblätter mit einer Menge von gerade stehenden (hie und da wohl auch durch Verkrüppelung verkrümmten) sehr kurzen, deutlich gegliederten, weissen, und an ihrer Spitze mit einem bald grösseren, bald kleineren, unregelmässigen, doch meist rundlichen Kopfe (Drüse) versehenen Haaren bedeckt. - Dagegen sieht man die innere Oberfläche der Blumenkrone nach oben mit einem weissen Haarteppich überzogen, welcher aus lauter äusserst zarten, cylinderartigen, aber verschiedentlich unter einander verwickelten, und mit Samenstaub bederkten Ilaaren besteht. Endlich steigen von unten nach aufwärts einige schön citronengelbe Streifen, die von lauter gelben, geraden, sogenannten kopfförmigen Haaren gebildet werden.

c) Lychnis calcedonica hat am Stengel sehr viele lange, weisse und regelmässig gegliederte Haare, die manchmal das Ansehen haben, als wenn länglichte Beeren mittelst dünner Fäden aneinander gereiht wären; die Haare der Blätter dagegen sind gerade, stark und kurz, und an der Hauptrippe in der Mitte des Blattes nur da und dort knollenartig angeschwollen (nodosi), übrigens wie jene am Stiele. An den Blumenblättern haben sie aber das Eige- 
ne, dass sie nicht allein nicht gegliedert sind, sondern sich auch einander nähern, ja sogar förmlich in einander übergehen, und sich wie ungefähr die Wurzeln unter der Erde zu vereinigen pllegen. -

d) Die Kelchblätterhaare der Tradescantia virginiana sind fast gerade, und haben hie und da kleine Knoten, wo sie sich dann nach der Seite biegen. Dagegen sind die Haare am Staubfaden so wie die Corolle schön violett gefärbt, und sehr dentich aber ungleich gefiedert (Gelenkhaare, pili phalangiformes, denn die Glieder nehmen stets an Länge $a b$, wie sie sich der Spitze nähern).

S c hrank*) hat auch eine Menge solcher Beyspiele angefihrt, wovon ich nur einige der interessantesten herausheben will:

e) Bey der Salvia coccinea sind die Blätter, besonders auf der Rückenseite und am Rande, und die Stengel mit weissen Sichelhaaren besetzt, eben so die Aussenseite des Helmes und der Grillel; nebst diesen befinden sich an Stengel noch lange wegstehende Pfriemenborsten.

f) Die Blätter des Lycopus europaeus haben dreygliederige Gliederhaare, eben so, jedoch sparsamer, die Kelche. Die Haare der Blume hingegen, deren Helm davon feinzottig ist, scheinen keine Gliederhaare zu seyn.

g) Au den Kelchen der Silena quinquevulnera triff man lauter Z wischenwandhaare, die jedoch von doppelter Ait sind: borstenförmige und kugeltragende oder sogenannte kopfformige. Erstere sind sehr lang, selbst mitunter halb so lang als der Kelch selbst, und durchaus krystallhell; letztere sind viel kürzer, stellen abgestutzte Kegel vor, und endigen sich an der Spitze in einen undurchsichtigen Kopf, der, wenn man die Blüthe in Branntwein legt, welcher den Kleber auflöst, einen Kaffeebecher mit ziemlich weiter Mündung vorstellt.

h) Das Verbascum thapsus ist an den Stengeln, Blättern, dem Kelche und an den Trägern mit Hakenast- oder hand. fömigen, an dem Fruchtknoten hingegen fast bloss mit Z.wischenknopfhaaren besetzt. Verbascum bicolle zeichnet sich durch Zotten von ungleicher Gestalt an den drey oberen Trägern aus, an den unteren sind blosse Fadenbaare von durchaus gleicher Dicke. Bey den Haaren von

*) A. a. 0.5 .41 . 
Verbascum nigrum ist die Keule kurz, und verschwindet an den unteren Trügern fast ganz.

i) Der Stengel von Antirrhinum linaria hat kurze kugeltragende Gliederhaare, dagegen die innere Seite der unteren Blumenlippe überall Walzenhaare.

1.) An den Kelchen der Verbena Aubletia bemerkt man Sichelhaare, die an den Blättern kurz, steif und kegelförmig sind, und auf einem breiten Fussgestelle sitzen, das davon rauh wird. Der Blumenschlund dagegen ist mit Rosenkranzhaaren geschlossen, weiche auch das Feld, wo sich die längern Staubgefässe befinden, besetzen. An der Aussenseite der Corolla sieht man wieder lauter weiche, kurze Sichelhaare.

l) Diejenigen Haare, welche man an den Kelchen der Siegesbeclia orientalis triff, sind mehrgliederige Gliederhaare von ungleicher Grösse, und hie und da auch Seitenzahnhaare, die bald gerade bald krumm sind.

m) Die Blätter, Kelche und der Stengel der Münze sind allenthalben mit zahlreichen $\mathrm{Z}$ wischenwandhaaren, der Blumenschlund aber nebst einem grossen Theile der Röhre mit undurchsichtigen blassen Sichelhaaren besetzt.

n) Die Primula elatior hat an der Unterseite der Blätter etwas abgestumpfte Glieder, - und kleine, aber dicke, kopfformige Haare. Die Gliederhaare, welche man an den Kelchen bemerkt, sind noch mehr abgestumpft, und am Ende sogar erweitert.

\section{§. 12 .}

Eine nicht unbeträchtliche, und in mehr als einer Hinsicht sehr merkwürdige Verschiedenheit der Haare biethet auch das Alter der Pflanzen dar.

Im Allgemeinen steht die Regel fest, dass eine Pflanze um so reicher an Haaren ist, je näher sie ihrem Ursprunge steht, d. i. je jünger sie ist, je rascher der Trieb der Säfte vor sich geht, und je mehr die Theile noch zusammengedrüngt sind. Daher bekommen Stecklinge, die unter Glasglocken gezogen werden, mehr Haare; daher sieht man in den Knospen jenen schönen, wolligen Ueberzug, der gleichsam, wie S prengel sich ausdrückt, eine mit Haaren gefiederte Wiege für die künftigen Blumen der Früchte darstellt. z. I. bey dem Andropogon arundinaceus Schrad. 
Nit der Entwickelung der einzelnen Theile aus der Knospe, also mit der Bildung der Blätter, Aeste und Blüthen verliert sich die haarige Oberfläche, so dass man bey diesen Theilen nur in manchen Fällen im späteren Alter noch Haare bemerkt. - So wie sich diess auf die genannte Art mit der Knospe verhält, eben so sehen wir auch bey den einzelnen Theilen einer Pflanze mit dem Fortschreiten des Wachsthumes die Haare immer weniger, die Oberfläche immer glatter werden. So sind die ganz jungen Blätter des spanischen Flieders haarig, verlieren aber diese Eigenschaft mit der Zunahme der Entwickelung immer mehr, so dass sie am Ende derselben ganz verschwindet. Bey manchen Pflanzen ist das Glattwerden nur scheinbar, in so fern nämlich der Körper, auf welchem die Hlaare sitzen, an seinem Umfange grösser wird, seine Theile demnach, und mit ihnen auch die Haare, weiter aus einanderrücken, und auf diese Art, ohne an Zahl zu- oder abzunehmen, dadurch, dass sie auf einem grösseren Raume vertheilt sind, dem Anscheine nach weniger werden. - Auch hat Schrank die wichtige Bemerkung gemacht, dass sich die Haare, welche am Grunde (als dem Orte, wo nach D uh a mel's Versuchen das Wachsthum in die Länge zuerst aufgehört hat), noch dicht genug stehen, desto mehr von einander entferneh, je höher der Stengel geworden ist. - Manchmal drängen sich jedoch die oberen Theile wieder zusammen, und dann wiederhohlt sich die Erscheinung in Bezug auf die Haare, wie an den jungen Pflanzen. Diess sieht man sehr schön an dem Hasenkohl, der mit Rosenkranzhaaren besetzt ist. - Oft wachsen IIaare nach, wenn der Theil gleich nicht wächst, und dann bleibt er gleich rauh, oft wachsen keine nach, dann wird er glatter als in der Jugend; dass sic erst im Alter erscheinen, habe ich nie beobachtet, obgleich Deleuze die Erfahrung gemacht hat, dass die Rispe von Rhus cotinus während der Blüthenzeit fast ganz haarlos ist, und dass nach dieser Epoche diejenigen Blumensticlchen, welche Früchte tragen, auch noch glatt, oder wenigstens kaum behaart sind, während bey denjenigen, deren Früchte felılschlagen, viele ausgebreitete Haare entstehen.

\section{S. 15.}

Auch das Klima, der. Wohnort und die Kultur der Pllanzen haben einen wesentlichen Einfluss auf die Entstehung und Bildung der Haare. - In Bezug auf das erste 
ist es erfahrungsgemäss richtig, dass Pflanzen, die in rauhen Klimaten oder auf magerem Boden wachsen, viel haariger sind, als andere, die auf fruchtbarer Erde, oder unter einem milden Himmelsstriche gedeihen. S. G. Gmeli in *) sagt, dass die Pflanzen in Ghilan und dem nördlichen Persien überhaupt viel haariger, wolliger und filziger seyen, als anderswo. Das Cichoreum dulce ist in einer Berggegend, wo es kalt ist, behaart, in Neapel cultivirt, verliert es die Haare; so auch die Sanguisorba und Brassica oleracea maritima. Atich ist es eine ausgemachte Sache, dass die Alpen - und Gebirgspflanzeu ihre häufigeren Haare in dem feuchten und fruchtbaren Erdreich der Gärten verlieren. So ist nach $S$ prengel eine Abart von Thymus Serpyllum durchaus rauh, sobald sie auf dïrren Sand gestellt wird, und das Laserpitium pruthenicum sah er fast ganz seiner Haare beraubt, wenn es auf feuchten Waldwiesen vorkam, oder dahin versetzt wurde. Ein dürrer Standort, oder der heisse Erdstrich, so wie auch gebirgige und windige Gegenden sind daher der Erzeugung der Haare sehr günstig **). - Darüber hat uns $\mathrm{Schrank}$ recht schöne Beyspiele aufgezählt: Aus allen Arten von Colutea ist die aethiopica am besten und feinsten bekleidet, und die ganze Gattung des Silberbaums (Leucadendron) ist in das dürre Afrika verwiesen. Unter den Arten des Wermuths und der Artemisie sind diejenigen haariger, sammtartiger, die in dürren Gegenden vorkommen; die Habichtskräuter der Gebirge, und die Pulsatille und Anemone der Alpen sind am haarigsten und zottigsten, weil jene an den dürrsten Stellen, und diese auf den kalslsten Gebirgen vorkommen. Ranunculus Ficaria, flammula, sceleratus sind sehr glatt, Ranunculus lanuginosus aber sehr rauh, und der Ranunculus

*) In seiner Reise durch Russland.

**) Humbold t sucht diesen Reichthum an Haaren bey den Alpenpflan. zen von dem Reize einer stärkern Elektricität, und von dem Reiz der durch die diinnen Luftschichten (auf Alpen) minder geschwäch. ten und also hellern Sonnenstrahlen herzuleiten, wodurch nämlich die Ausscheidungen, ivie die Secretions-Organe (die IIaare), vermehrt, die Säfte verdickt, und eben die Wirkungen hervorgebracht werden, welche in dem heissen Klima eine grosse Masse von Värme. słoff bey stärkerem Druck der Atmosphäre kaum hervorzubringen vermag. Siehe dessen Versuche iber dic gereizte Muskel. und Nervenfaser. 2ter Bd. S. 145. 
glacialis fein, aber stark zottig. Die drey ersten trifft man mir an feuchten Orten im Gegensatz zu den zwey letzten, welche mehr trockenen, hungrigen Boden lieben. - Uebrigens finden sich dennoch nicht allein auch an Sumpf- und Wasserpflanzen mitunter viele Haare, sondern diese fallen auch $a b$, sobald man ihren eigentlichen Standort mit einem entgegengesetzten, also mit einem trocknen, dürren Erdreich vertauscht. Wenn wir die am Meerstrand wachsenden Pflanzen bey uns in Töpfen halten, und diese im Winter in das Glashaus setzen, so behalten sie ihren filzigen, weissen Ueberzug; wenn sie aber Sommer und Winter über im freyen Lande stehen, werden sie ihn nach und nach absetzen, und endlich eine grüne Oberfläche erhalten. So fand Wahlenberg*) Lathyrus pratensis, Risum maritimum, Ribes rubrum, Salix fusca und trifolium pratense an der Nordsee theils filzig, theils zottig, was in andern Gegenden nicht der Fall ist.

\section{14 .}

Die $\mathbf{F}$ arbe der Haare ist gewölnlich weiss, selten rostfarben (wie beym Ledum pallustre), noch seltner blau (bey Solanum sanctum), oder grün (bey Delphinium elatum). Violet zeigt sie uns die schöne Blume der Tradescantia virginiana. - Die ganz einförmig gebauten Haare des Stengels von Papaver rhoeas sind oben in der Nähe der Blume selbst fast ganz violet, und nur an ihrer Ursprungsstelle weiss; je weiter sie sich aber von der Blume entfernen, desto mehr verliert sich diese schöne Farbe, und die Haare sind schon zwey Zoll unter der Blume fast ganz weiss. Man kann demnach wohI auch behaupten, dass die Haare einer und derselben Pflanze an den verschiedenen Theilen derselben eine Verschiedenheit von Farbe zeigen. - Uebrigens stehen die obigen Benennungen von Sammt, Seide, Wolle etc. mit der Farbe der Haare wohl auch in einiger Beziehung, so wie natürlich die feinsten Haare immer auch den feinsten Farbenstrich an sich haben.

A n merkung. In Bezug auf die Grösse, do i. änge und Dicke der Pflanzenhaare, lässt sich im Allgemeinen nicht viel sagen, indem die Verschiedenheit ins Unendliche geht. Auch ist mir nur cin einziger Fall bekannt, wo ein Naturforscher ein Pflanzenhaar gemessen, und den Befund zur öffentlichen Kenntniss gebracht haf. Hofrath und Profess. Ritter v. Marti u's ${ }^{* *}$ ) legte ein Ilaar von der

*) Flora Gothoburgensis. Pars I. Upsala 1820.

**) Nova acta acaderu, caes. Leopold. Carol, n. c, Vol, 13, p. 265. 
Physiologische Bemerkungen etc.

Gomphrena officinalis unter das Microscop, und mass es mit dem Micrometer; oberhalb seiner am Grunde etwas verdickten Wurzel mass es 0,00j0, an der Spitze 0,00067. Das Haar von der Gomphrena globosa aber hatte 0,00059 Pariser Zoll im Durchmesser.

\section{Zweyter Abschnitt.}

Physiologische Bemerkungen über die Pflanzenhare.

\section{§. 14.}

$$
E i n l \text { e } i t u n g \text {. }
$$

Wenn, wie ich später zu erweisen gedenke, der physiologische Zweck der Haare selbst bey den Thieren und dem Menschen so zu sagen noch ganz im Dunkeln steht, und die Function und der Nutzen dieser Gebilde immer nur mit allgemeinen, unsichern und unzulänglichen Umrissen bezeichnet wurde, so herrscht über diesen Punkt in der Pflanzenwelt nach dem einstimmigen Urtheile aller Sachverständigen noch weit grössere Dunkelheit, ja ich möchte sagen, wahre Finsterniss. - Diess vorausgesetzt, wird der geneigte Leser leicht einsehen, dass ich mich keineswegs berufen fühlen kann, in diese Nacht das gewünschte Licht und die willkommne Aufklärung zu bringen, um so mehr, als ja bekanntlich unsere besten Pflanzenphysiologen hierin bis jetzt vergeblich nach einem richtigen und sichern Standpunkt gezielt haben, von wo aus sie, mit sprechenden Thatsachen und Versuchen unterstützt, das eigenthümliche Leben der Pflanzenhaare überhaupt, und ihre physiologische Bedeutung für das besondere Leben der Pflanze selbst mit jener erfreulichen Wahrheit und Gründlichkeit beleuchten und erklären konnten, die wenig oder gar nichts zu wünschen übrig lässt. - Bey diesem niederschlagenden Geständniss kann ich, so zu sagen, ein Neuling in dieser Sache, wohl wenig Neues von Beleg hinzufügen, und bin in so fern darauf beschränkt, den wissbegierigen Leser einerseits mit allem dem in gedrängter Kürze vertraut zu machen, was uns die vorzüglichsten Naturforscher über diesen 
Punkt bis jetzt hinterlassen haben, und andererseits ihm die Nothwendigkeit fernerer Forschungen ans Herz zu legen; damit es auf diese Art vielleicht möglich werde, durch mehrfache, und mit Liebe und Eifer unternommene weitere Untersuchungen in diesem vielleicht noch unbebautesten Felde der medicinischen Wissenschaften dereinst zu einem erfreulichen und wohlthätigen Resultat zu gelangen. -

\section{§. 15 .}

Die physiologische Wichtigkeit der Pflanzenhaare muss sich, so wie bei allen organischen Gebilden, nothwendis auf ihre anatomischen Verhältnisse, als der materiellen Basis, zunächst und hauptsächlich gründen. Wir müssen demnach, ehe wir in dieser Untersuchung weiter vorschreiten, einen prüfenden Rückblick auf die Organisation der Haare machen, um von da aus dann auf die hier wirkenden Kräfte, und so endlich aut die Function und den Zweck des Ganzen zu gelangen. - Wir haben oben \$. 2 gesehen, dass man die Pflanzenhaare mit allem Rechte für verlängerte Zellen, welche über die Oberfläche der Pflanzen hervorragen, ansehen konne. Ebenso ist daselbst weiter behauptet worden, dass man ihnen alle Gefässe abstreiten müsse, indem einerseits die feinsten und gelungensten Injectionen nie in die Haare eindrangen, andrerseits sich, wie wir weiter unten sehen werden, die ihnen zugeschriebenen Verrichtungen unbeschadet dessen erklären lassen. - Hieraus folgt nun der natürliche Schluss, dass die Pflanzenhaare, in Bezug auf ihre Organisation, zu den einfachsten Gebilden zu zählen, und auf der niedrigsten Stufe igestellt seyen. Sie bestehen aus blossem Zellgewebe, das nach aussen von einer etwas festern Wandung eingeschlossen, und im Innern dagegen viel lockerer gebaut ist. Die aus der letztern Eigenschaft fliessende grössere Durchsichtigkeit führt uns gar oft bey den Pflanzenhaaren anf die Idee eines, so wie in den Thierhaaren vorhandenen Kanals, der gewöhnlich um so deutlicher hervortritt, je fester und dichter bey dennoch gegebener Durchsichtigkeitt der Mitte die äussere Umgebung ist. - Uebrigens ist die Anordnung und Aneinanderreihung der einzelnen Zellen in den Pflanzenhaaren bey weitem nicht so manichfaltig, wie bey den Thieren, und wir vermissen demnach auch dort jene sogleich in das Auge fallenden charakteristischen Verschiedenheiten, wo- 
durch sich hier, nämlich bey den Thieren, so zu sagen, jedes Haar von dem andern, wenigstens gewiss jede Gattung von einer andern trennt. Man könnte sagen, die in der ganzen Natur ausgesprochene Manichfaltigkeit ist bey den Pflanzenhaaren mehr an ihrer Oberfläche und in ihrem Totalhabitus, bey den Thierhaaren dagegen nebst diesen vorzüglich im Innern selbst wahrzunehmen. - Das bisher Gesagte gilt allerdings, wenn von den Pflanzenhaaren im Allgemeinen, oder besser gesagt, im Durchschnitte gesprochen wird; dagegen dürfeır wir eine merkwürdige Verschiedenheit derselben ja nicht ausser Acht lassen, die darin besteht, dass es

1. Haare gibt, welche sich durch ganz besondere Feinheit und Zartheit des Baues auszeichnen, und die desshalb auch ganz durchsichtig sind. (Man kann doch wohl den feinen Wurzelhärchen, oder den eben so zarten als schönen Härchen an der Innenseite mancher Corollen und Staubfäden nicht eine und dieselbe Verrintung mit den Borsten und Stachelhaaren zuschreiben?)

2. Eine weise Vorrichtung der Natur seyn muss, warum sie allerdings die meisten Pflanzen mit oben spitzig zulaufenden Haaren versehen; und dagegen eine weit geringcre Anzahl oben abgestumpfter, zugerundeter, kopff örıiger, mit einem Worte, sogenannter Drüsenhaare erschaflen hat, welche letztere, wie noch später erhellen wird, gewiss so auffallend von den gewöhnlichen Haaren ciffleriren, dass ich es jenen Naturforschern nicht so sehr übel neinmen mag, welche sie ganz aus der Classe der Haare verbannt wissen wollen.

5. Welch ein wichtiger Unterschied liegt endlich noch darin, dass eine nicht unbedeutende Anzahl von Haaren auf einer drüsenartigen Anschwellung, oder auf einem Convolut von kleinen Zellen sitzen, denen sie als Absonderungscanal dienen, wie wir diess an vielen pfriemenartigen und an den sogenannten Malpighischen Haaren ( $($. 8) sehen können; und dass wieder auf der andern Seite eine weit grössere Anzahl von Haaren aufzufinden ist, denen diese drisenreiche Basis gänzlich mangelt ?

Aus Allem diesem geht nun wohl der Schluss hervor, dass die Haare gleich dem Rindenkörper, aus dem sie entspringen, auf der niedrigsten Organisationsstufe, und somit mit Ausnahme des Oberhäutchens unter allen Pflanzentheilen der unorganischen Natur am nächsten stehen. Auch kann man mit 
Recht behaupten, dass sie, in Bezug auf ihre Vitalitätsverhältnisse, ungefähr in demselben Bezuge zur ganzen Pllanze sind, wie das Thierhaar zum thierischen Organismus. Endlich muss ihre so grell in die Augen fallende Verschiedenheit in der eben angegebenen dreyfachen Beziehung jederzeit festgehalıen werden, sobald von ihren verschiedenen Verrichtungen die Rede ist. Auch ist es nicht unwahrscheinlich, dass die Zwiebelund Warzenhaare, so wie jene, welche in auffallendem Grade einer Secretion vorstehen, rücksichtlick ihrer Organisation, deu Thierhaaren am nächsten kounmen.

\section{§. 17.}

Wir können mit voller Gewissheit annehmen, dass die Pflanzenhaare vom Grunde gegen die Spitze w a chsen, und wenn uns auch $\mathrm{Du}$ II amel's Versuche dieses nicht so anschaulich machten, so spricht doch alle Analogie dafür. Dass übrigens ihr Wachsthum nothwendig an das Alter gebnnden sey, ist ebenfalls eine ausgemachte Sache; daher erreichen die Haare nicht allein im Allgemeinen eine verschicdenartige Grösse, sondern diese selbst ist während den einzelnen Lebens-Perioden der Pflanze öfters Veränderungen unterworfen. Im Durchschnitte wachsen sie schnell zu ihrer höchsten Grösse und Ausbildung heran, auf der sie dann einen scheinbaren Stillstand machen, und endlich in die regressive Metamorphose eintreten, d. i. nach und nach immer spröder, saftloser werden, vertrocknen und endlich ganz abfallen. Uebrigens hängt die Entwicklung der Haare nothwendig mit jener der Pflanzenorgane zusammen, an denen sie hervorwachsen, denn die Haare erscheinen nicht eher, als die Entwicklung ihres mütterlichen Bodens bis auf einen gewissen Grad gediehen ist. - Im Winter und unter allen jenen Verhältnissen, die den Tod der Pflanzen, vorzüglich aber auch die Vernichtung des Oberhäutchens nach sich ziehen, gehen auch die Haare zu Grunde, die demnach wegen ihres viel zärtern Baues nicht so unverweslich, als die Thierhaare sind. - Merkivürdig bleibt noch die Veränderung mancher sarter Pflanzenhaare, vermög welcher sie oflenbar in Borsten und Stacheln übergehen. Man bemerkt nämlich an einigen Fackeldisteln (Cactus Peirescia), an den Zweigen und in den Blattachseln büschelförmige Haare, die mit der Zeit immer stärker werden, mehr einzeln stehen, nnd die Natur der Borsten, und endlich selbst der Stacheln annehmen. Das- 
selbe zeigt sich bey den Acacien. - Vom Grau- und Bleichwerden der Pflanzenhaare schweigen die Autoren ganz, und ich muss gestehen, dass ich ebenfalls nichts Aehnliches benbachtet habe; welches übrigens hier um so weniger auffallen kann, da bekanntlich die meisten Pflanzenhaare ohnehin schon von weisser Farbe sind.

§. 18.

Um nun zunächst zu den Functionen der Pflanzenhaare iiberzugehen, theile ich jene zuerst in II a u p $t$ - und N e benverrichtungen ein, und verstehe unter den ersten alle jene Verrichtungen, dic auf die ganze Oekonomie der Pflanze cinen wesentlichen Einfluss haben, wogegen die Nebenverrichtungen den manichfach gestalteten, zufälligen Nutzen bezwecken.

\section{A. Hauptverrichtungen.}

\section{\$. 10 .}

a) Einsaugung gewisser in der Luft, Erde und dem Wasser enthaltener Flïssigkeiten.

Hauptvertheidiger dieser Idee sind: Malpighi, Schrank, Bonnet, Rudelphi und zum Theil auch De C a nd olle. Die Gründe dafür sind:

1. Es leitet uns zuvörderst die nähere Betrachtung der Wurzelhaare auf den Gedanken hin, dass selbe als treue Begleiter, ja als wesentliche Bestandıheile der zarten Wurzeln wohl auch an dem Hauptgeschäfte der letzten, nämlich der Einsaugung, Theil nehmen werden. - Diese Meiuung ist keineswegs neu, denn schon der grosse Malpighi, der die Haare an den Wurzelfasern sehr gut beobachtete, und auch abbildete, hat darauf hingezielt. Er äussert sich hierüber folgendermassen *): Quaenam sint portae, seuhantia orificia, quae propulsum fluidum cribrent et determinata admittant, adhuc dubium. Circa tenellas radices pili copiose $l u$ xuriant hinc inde: sunt autem pili candidae fistulae et gracillimae, minimis orbiculis invicem hiantibus coagmentatae, unde horum orificiis determinatae figurae anologam fluidi partem, ambientium si expressam, admittunt, et ligneis fistulis reddunt. Ubicunque radices a proxima terra per spalium aliquod distant, pili hujusmodi in rete complicantur, et circa

*) Opp. II. p. 84. de pilis. 
frustula luxuriant, el quoddammodo tensi manent. Quoniam tamen non quaecumque bulbosa el radicum genera pilis $p a-$ tenter ditantur, ideo dubitandum occurrit, an in hujusmodi bulbosis percolatio subingredientis liquoris fiat ab exteriore ambiente cuticula, ita ut ab hac in contiguas utriculas, quibus ceparum inpolucra coagmentantur, transilus succedal. Wir sehen hieraus, dass Malpighi noch zweifelhaft blieb, durch welche Oeffnungen die nährenden Flüssigkeiten in die Wurzeln gelangen. In Bezug auf die Behauptung: dass er die Wurzelhaare, vorzüglich bey den Zwiebelgewächsen, vermisst habe, wird er von Schrank*) vollkommen widerlegt, welcher deutlich ausspricht, dass er die Wurzelhaare noch bey allen Pflanzen ohne Unterschied, und namentlich auch bey den Zwiebelgewächsen, gefunden habe. Insbesondere ist Hyacinthus comosus ganz zottig davon. Gie $w^{* *}$ ) glaubt sogar, dass der Saft, ehe er aus der Erde in die Wrurzeln aufgenommen wird, noch sehr verfeinert werden müsse, was auch Schrank für höchst wabrscheinlich hält. - Ein vollwichtiger Grund für die Behauptung, dass die Wurzelhaare wirklich einsaugen, ist gewiss noch der Umstand, dass man durch Versuche ausgemacht hat, dass Pllanzen, denen man die kleinen, sehr behaarten Wurzeln wegnimmt, bey der reichlichst gegebenen Nahrung dennoch so lange kränkeln, bis sie nene Würzelchen getrieben haben. Auch der erfahrne Link 栦), der früher den llärchen der Wurzeln das Vermögen, cinzusaugen, gänzlich absprach, erkannte später seinen Irrthum, der durch einseitige Vergleichung dieser Wurzelhaare mit einigen Arten von liaaren aul dem Stamme und den Blättern entstanden war. Nach seinen Beobachtungen stehen die Haare der Wurzeln nicht allein in len Lïicken des Erdreichs, sondern sie finden sich auch da, wo Erde anhängt, in Menge; sie entstehen sogar mitten im Wasser, und umhüllen dort oft das Würzelchen gleich einer flockigen Wolle. - Endlich sind es zufolge der von S e n e b i ex, Carradori ${ }^{* * * *}$ ) und De Candoll e t) angestellen Versuche

*) A. a. O.p. 5 \%.

**) Anat. of plants, B. 2. p. 82.

***) Nachträge zu den Grundlehren der Anatomie und Pliysiologie der Pflanzen, p. 18.

$* * * *)$ A. a, $\mathrm{O}$.

†) Mem. sur le devellopement des racines, Annal, des sciences naturell, de Genéve 1826. p. 1. 
vorzüglich die äussersten Enden der haarartigen Wurzelanhänge, welche das Geschäft der Einsaugung besorgen, obgltich man bis jetzt keine freyen Saugmündungen entdecken konnte.

2. Der gelehrte B on ne *) hat durch Versuche hinlänglich dargethan, dass die untere Fläche der Blätter bauptsächlich und weit mehr, als die obere, einsange. Da nun aber gerade diese auch vorzugsweise mit Haaren besetzt ist, so spricht es zu Gunsten der Einsaugung durch die Haare.

5. Franz v. Paula Schra $\mathrm{k}^{* *}$ ) glaubte mit Itülfe der Geometrie für die Bestimmungen der Pflanzenhaare ein allgemeines Gesetz gefunden zu haben, zufolge dessen die Haare lediglich zur Einsaugung bestimm wären. Insbesondere stellt er von den kegelförmigen Ilaaren als Resultat seiner Untersuchungen den Satz auf: dass sie vorzüglich bestinmt seyen, Dïnste einzusaugen. Diese Behauptungen suchte er überdiess noch durch einen ganz originellen Versuch unter dem Microscop zu bekräfigen. Er brachte nämlich Pflanzentheilchen mit kegelförmigen Haaren, auch ganze und in der Absicht, damit die Haare mehr in das Auge fielen, zusammengefaltete Blätter unter den Brennpunkt eines zusammen gesetzten Microscops in Wasser, während sein Auge ïber dem ()cularglas ruhte. Die llaare füllten sich, aber nur tropfenweise, und verhältnissmässig grosse Tropfen Lufi füllen die Zwischenrïume zwischen den Wassertröpfchen. Dadurch, dass er dann das Wasser mit Weingeist verdiinute, und den Yersuch nochmal mit frischen Blättern wiederholte, wurde die Füllung nun gleichformiger und stätiger. Ir hielt demnach das von den Hlaaren Eingesogene für verdünntes Wasser, für Dünste. Auf diese Art erklärt sich nun Schrank 1.: warum die Vorsicht den Pflanzen der heissen Länder so viele llare gegebun habe. (Obgleich es in jenen Läudern wenig regnet, falien dnch häufige und mitunter sehr starke Thaue, wodurch dann die Pflanzen aus der fenchten Luft ilure Nalurung einsaugen.) - 2. wesshalb die Pllanzen, die auf dirren Sizndgegenden oder kahlen Alpenfelsen wachsen, so haarig sind.

Sprengel *a*) suchte diese Angaben einisermassen zu wilerlegen, indem er sagte: dass nicht bloss kngelförmige Hhare offenbar eigenthimliche Säfie anslecren, und dass dii:

*) Usage des feuill. p. 47. D u ham el Pliysique desarbres, Vol. I. p. 185.

**) A. a. O. p. 82 .

***) Ueber den Bau und die Natur der Gewächse 1812. 
Gebirgspflanzen nur desswegen behaarter sind, als andere, weil ihr Wuchs gebeugter, die Theile aber zusammengezogener sind. Uebrigens sprach er sich ganz für die Meinung aus, dass Aussonderung die Hauptfunction der Pflanzenhaare sey. Ich werde auf die dafür aufgestellten Gründe zurück kommen. 4. Dagegen trat Rudol phi*) der Idee S chrank's in sofern bey, als er ebenfalls die Einsaugung für die Prinzipalfunction der Pflanzenhaare, und zwar aus nachfolgenden Gründen erklärte :

a) Sehr viele Pflanzen kommen in warmen, sehr trocknen Gegenden, z. B. im südlichen Furopa, auf der Insel Candia, im Orient und den Steppen Sibiriens etc. vor, deren ganzer Bau gedrungen ist, die keine grosse Menge von Säften enthalten, und also nicht viel ausdünsten können. Thre Wurzeln sind nicht gross, und sie haben nur kleine und wenige, unter den Haaren verdeclite, oft kaum aufzufindende, zuweilen gar keine Poren, so dass ihnen also auf diesem Wege die nöthige Flüssigkeit nicht zugeführt werden kann. Rudolphi findet es daher ganz natürlich, anzunelamen, dass ihre Haare die Feuchtigkeit aus der Luft einsaugen, welche die Wurzeln im dürren Sande nicht finden können. -

b) Das Gleiche gilt wohl auch von den auf den Alpen oder trocknen Gebirgsgegenden, in Felsenrissen u. s. w. wachsenden haarigen Pflanzen, denn auch bey ihnen ist anzunehmen, dass sie die ihnen nöthige Flüssigkeit mittelst der Haare aus der Atmosphäre einsaugen.

c) Die im Wasser lebenden Pflanzen, deren Oberfläche haarlos ist, bedurften natïlich der Haare eben so wenig, als der Poren, und desshalb gehen ihnen auch beyde ab.

d) Aus demselben Grunde sind auch fast alle auf feuchten Wiesen und in den Sümpfen des nördlichen Europa wachsenden Pflanzen völlig haarlos. Sie bedurften so vieler Saugwerkzeuge nicht. Eben desshalb finden wir auch keine haarigen Pflanzen in den feuchten Gegenden Amerika's und Asiens.

e) Darum haben alle, mit grossen und vielen Poren versehene Pflanzen keine Haare.

f) Ganz besonders entscheidend scheint die Thatsache zu

*) Anatomie der Pflanzen p. 124-126. 
seyn, dass bey solchen Familien, die sonst gewöhnlich haarlos sind, einzelne Geschlechter derselben in dürre? Gegenden Haare im Ueberflusse bekommen, z. B. bey den Gräsern.

8) Und umgekehrt ist es sehr auffallend, dass so viele im wilden Zustande behaarte Pflanzen in unsern Gärten allmählig und oft ganz diese Bekleidung verlieren. Wir sehen diess an den Alpenplanzen und an den sibirischen Gewächsen, wie sie nach und nach in unsern Gärten glatt werden. Es scheint dagegen eingeworfen werden zu können, dass viele Pflanzen in den Gärten trotz aller Cultur die Haare behalten, allein Rudolphi, beseitigt diesen Einwurf dadurch, dass er sagt: fast alle diese Pflanzen haben einen starken, dichten Filz und eine äusserst dünne Blattsubstanz, so dass diese allein nie bestehen kann; einigen gehen sogar die Poren ganz ab. Hier sind also die Haare wesentlich und immer nöthig, wenn nicht ein ganz neues Blatt und eine gaiz neue Pflanze entstehen soll. Bey jenen Alpengewächsen und sibirischen Pflanzen hingegen hat die Blattsubstanz mehr Wasser, und die Haare dringen nicht so fest ins Parenchym ein. Dagegen kann eingewendet werden, dass diese saftigen Gewächse aber auch oft olne alle Haare sind, häufig die heissesten Klimate und die trockensten Gegenden bewolnnen, und einige von ihnen dennoch in der blechernen Büchse oder auf dem Bette des Treibhauses dann noch fortwachsen, wenn manihnen die Wurzel weggeschnitten hat. Se h rank antwortet darauf: diess geschieht durch die mittelst der Hautdrïsen bewerkstelligte Einsaugung aus der Atmosphäre.

h) Alle Pflanzen aller Klimate dünsten aus, und dennoch gibt es ja viele, die keine Haare besitzen.

Durch diese Gründe hich es $\mathrm{Rudol}$ phi für völlig bewiesen, dass die Haare eben sowohl einsaugen, als die Poren. Doch gibt er eine Verschiedenheit zwischen beyden zu, indem er sagt, dass die Poren, besonders die sehr grrossen der fleischigen und saftigen Gewächse reichlicher einsaugen, wesshalb) diese Gewächse auch die Wurzeln länger enthehren können, als die haarigen. Diese bedürfen dagegen keincr so reichlichen Einsaugran: und es fih!t ihnen das lockere P'urenclym 
der fleischigen Gewächse, das diesen als ein Behälter für das Eingesogene dient. -

5. Die Narbe des Pistills ist dazu da, um den befruchtenden Samenstaub aufunehmen und zu dem Fruchtknoten zu leiten. Sollten nun die Haare an der Oberfläche der Narbe nicht wenigstens Theil an diesem Geschäfte nehmen? Sollten sie daher nicht auch zur Einsaugung dienen? -

6. Viele junge Blätter z. B. der Buche, sind bey ihren Entstehen, und noch eine Zeitlang nachher haarig, und werden dann glatt. Diess scheint nur desshalb so eingerichtet zu seyn, weil sie erst aus der Luft trinken mïssen, bis die durcl:wärmte Erde ihnen durch die Gefässe mehr Nahrung zuschicken kann.

7. Ueber die Art und Weise, wic diese Einsaugung von Statten gehe, lässt sich nur wenig sagen. Dennoch wissen wir durch eine genauere Einsicht in die Organisation der Haare, dass die von ilınen angesngenen Dünste zuerst in das mit demselben in Verbindung stehende Zellgewebe, und aus diesem in die eigentlichen Gefïsse kommen. Dieser Satz folgt zunächst aus dem $§ .2$ näher bezeichneten Ursprung der Haare. - Auch ist es höchst wahrscheinlich, dass die ebenfalls oberflächlich liegenden, und innigst mit dem Zellgewebe der Oberhaut verbundenen Hautdrüsen an diesem Geschäfte einigen Antheil nehmen. -

8. Den so eben angefiihrten Thatsachen entsprechend, glaubt D e Can dolle (a.a. O.), dass lie Haare der Verdünstung ein natürliches linderniss entgegen setzen, indem sie die parenchymatösen Theile gegen die Wirkung des Sonnenlichtes schiitzen, welches doch das Hauptagens der Verdïnstung ist. Daher fehlen die Haare in der Regel auch allen Pflanzen, welche wenig oder gar keine Spaltoflnung besitzen, wic den Fett - und Wasserpillanzen und jenen schattiger Orte; wogegen sie bey den, der Sonne ausgesetzten Pflanzen sehr hätfig sind.

*) Anmerkung. Nach Link lässt sich das Resultar von Schrank's Versuchen über die wirkliche Einsaugung der Ilaare auf die Krafi der Capillarität zuriick fiilıren. Auch fehlen den Haaren nach seiner Meinung die Spalı̈flnungen nicht, sondern sind nur schwer zu linden. Z. B. bci Salvia canariensis, officinalis, Phlomis fruticosa, Marubium cinercum, Cistus ladaniferus, Cineraria maritima, Arctotis calendulacea u. a. m. - Obschon übrigens Link mehr 
fiir Excretion, als dem Haup'geschäfte der Pflanzenhaare zu stimmen geneigt ist, so spricht er ihnen dennoch das Vermögen einzusaugen nicht ganz ab, und bezieht sich in dieser Hinsicht aut die haarigen Papillen am Stigma dex Pflanzen, die wie ein keulenför miges Haar gestaliet sind, und unstreitig zum Einsaugen dienen. Auch in seinen Nachträgen zu den Grundlehren der Anatomie und Physiologie der Pflanzen p. 37 behat ptet er, dass die Narben-und Wurzelhaare gewiss zur Einsaugung bestimmt sind.

§. 20 .

b) Aussonderung eigener, in der Pflanze bereiteter, flüssiger Stoffe.

Nichts desto weniger gibt es doch auch eine Menge 'Thatsachen und Beobachtungen, welche datür sprechen, dass viele Pflanzenhaare zur Aussonderung bestimmt sind. Ich werde hier die wichtigsten derselben zusammenstellen, so wie sie von Sprengel, Kieser, Link, Duhamel, Moldenhawer und Senebier vertheidigt werden:

1. Schon Malpighi war mit der blossen Einsaugung der Haare nicht zufrieden, sondern hielt es *) für sehr wahrscheinlich, dass sie als Fortsetzungen der Querschläuche des Zellgewebes zur Absonderung gewisser Feuchtigkeiten bestimmt sind. Er sagt dort: Tenellas igitur vegetantium partes, pilis hirtas ita mirati sumus, ut adhuc nos laleat, an plantas tutelae gratia pilosas reddiderit natura, an vero turgentis alimoniae incongrua portio sub harum forma erumpat ct digeratur. Gemmarum itaque foliola ila mollibus pilis cooperiuntur, ut probabile sit, ipsorum formam de facili custodiri; dum autem vegetando auctiora fiunt, pili quoque proceriores redditi ut plurimum contubescunt, unde satius videtur, plures hujusmodi pilos foliorum vegetationi inservire. Perdurant autem fortasse in nonnullis plantis exarati pili ob materiae conditionem, qua excitantur. Cum enim probabile sil, pilos esse appendices utriculorum transpersalium, cumque ipsorum quasi catena sideantur, ideo contentus, in iis humor aeri exposilus, cum libere pateat, si natura sua volatilis sit, vel aquosus facillime exhalat et digeritur, unde membranae utriculorum superstites laxam et mollem compagem relinguunt.

*) Opp. tom. II. p. 58 . 
2. D uhamel*) hält es für unläugbar, dass eigenthümliche Flüssigkeiten durch die Haare ausgeschieden werden. Er machte an einer Martinia aus Louisiana, deren Blätter, Blüthen und Früchte mit sehr feinen Haaren besetzt sind, die Beobachtung, dass an den Endspitzen dieser letztern einige Tropfen eines durchsichtigen, riechenden und schmierigen Saftes hängen, der nicht aus der Pflanze selbst ausschwitzt. -

Auch aus Bonnet's Versuchen erhellet, dass die Einsaugung vorzüglich in dem Parenchym $\mathrm{z} w$ is chen den Rippen und Adern des Blattes vor sich gehe. Nun aber befinden sich bekanntlich die meisten Haare a uf den Blattrippen, also scheint e.s, dass selbe nicht besonders zur Einsaugung bestimmt sind.

3. Den sprechendsten Beweis für die Ausdünstung der l'liantenhaare liefert aber das unläugbare Factum, dass man an den Haaren mancher Pllanzen Tröpfchen eines eigenthümlichen Saftes findet. So behauptet Sprengel, und vor ihm schon Schrank, dass die Haare der weiblichen Narbe offenbar das Oel absondern, das zur Aufnahme des Samenstaubes bestimmt ist, und El. Bjerkander **) hat deutlich bemerkt, dass bey behaarten Blättern am Morgen jedes Haar vam Grunde bis an die Spitze mit grössern und kleinern feinen Tropfen bekleidet ist, und dass Pflanzen, die unter Glasglocken gehalten werden, aus ihren Haaren die Saftröpfchen ausscheiden, z. B. Fragaria vesca und Equisetum fluviatile. Diess kann man bey jedem Steckling beobachten. - Es handelt sich also hier hauptsächlich um die physiologische Bestimmung der sogenannten Drüsenhaare, deren z. B. die Passillora foetida eine grosse Menge an verschiedenen Theilen hat, und die beständig einen klebrigen Saft, an welchem kleine Insecten hängen bleiben, ausschwitzen. Dieser Saft ist im Wasser auflöslich, und färbt die Auflösung weingelb. - Die Kölbchen auf den Haaren oder kegelförmigen Randborsten bey Rhododendron Chamaecistus enthalten alle ein Gummiharz, das sich zum Theil in Wasser, zum Theil in Weingeist auflöst. An der Nicotiana rustica fand ich jedes Haar an der Spitze mit einem ovalen, helldurchsichtigen, grünen Köpfchen versehen. Ein ausserordentich feines Häutchen schloss einen Tropfen Flüssigkeit in sich, der sich bey dem geringsten Drucke aus

*) Physique des arbres. Vol. I. p. 183.

**) Sehwedisché Abhandlungen, 1773. P, 68. 
demselben entleerte. Als ich die Pflanze dann über Nacht ins Wasser brachte, hatten sich die Köpfchen ganz entleert, und waren, so zu sagen, verschwunden, indem sich der enthaltene Saft mit dem Wasser vermischte. - Rudolphi hält jedoch diese Drüsenhaare nicht für Haare, sondern für gestielte Drüsen, welche die Feuchtigkeit absondern. Gleicher Meinung mit ihm ist auch $\mathrm{Schrank}$ und selbst Link*). Ich meinerseits finde zwischen einer sogenannten gestielten Drüse und einem kopfförmigen Haare keinen wesentlichen Unterschied; so wie ein Haar, welches, wie Link sagt, an seiner Spitze bloss ein Tröpfchen Feuchtigkeit trägt, in diesem Augenblicke wohl schwerlich von einer gestielten Drüse unterschieden werden kann. - Was aber die von Bjerkander und S prengel angegebene Tropfensammlung der unter Glasglocken stehenden Erdbeerstauden oder Melonenranken betrifli, so kommt selbe nach $\mathrm{Rudolphi}$ auch nicht von einer aus den Haaren abgeschiedenen Flüssigkeit, sondern kann theils ein aufsteigender Thau seyn, der sich an die Pflanzenhaare hängt, theils nach Schrank ein wirkliches 'Thränen; die Pflanze dünstet nämlich auf der Oberfläche aus, und die Materie sammelı sich an den Haaren. Ich kann diesen Streit nicht entscheiden.

Anmerkung. B aster glaubt, dass ans diesen durch die Haare aus. gesonderten Feuchtigkeiten die Bienen jenes unvollkommene Wachs verlertigen, womit sie die überflissigen Oeffnungen an ihren Körben verkleben.

4. Viele kegelförmige Haare führen einen mehr oder wewiger klebrigen, schmierigen, riechenden oder geruchlosen Saft aus. Streicht man z. B. die Blätter des gelben Tabacks gelinde mil der Hand, so wird sie davon etwas schmierig und stark riechend. Dasselbe kann man auch bey hoher Temperatur bey den kegelförmigen Zivischenwandhaaren des Geranium inquinans beobachten; die Finger werden davon schmutzig, pomeranzengelb und fettig.

5. Selbst $\mathrm{L} \mathrm{ink}{ }^{* *}$ ) gibt zu, dass sehr viele Haare, ohne Glandeln zu tragen, oder ohne kopfförmig zu seyn, einen klebrigen Saft ausschwitzen, der an vielen Salbeyarten, dem Antirrhinum maj. u. a. als ein Tröpfchen auf der Spize hervor-

*) §. 4. Anmerkung zu Nr. 5.

**) A, a, O, p. 121 . 
quillt, dort etwas erhïrtet, und irrig für eine Glandel angesehen wird. An den Cisten sah er die Seiten oft durch jene klebrige Feuchtigkeit zusammengeklebt. In den Haaren der Boraginen sieht man eine weiche erhärtende Masse, welche auch oft cinzelne Zellen in der Warze an der Basis färbt; und in den Haaren von Echium stockt oft eine bräunlichgelbe Masse absatzweise ${ }^{*}$. Aus den abgeschnittenen Haaren der Kichererbsen (Cicer arietinum) sickert die Kleesäure im freyen Zustand: mit etwas Aepfel- und Essigsäure aus. - Nesselhaare, wenn sie in der Haut stecken bleiben, verursachen durch den in ihnen enthaltenen ätzenden Saft heftiges Brennen, und der Grad dieses Biennens richtet sich nicht nach der Länge oder der Steifheit der Haare, sondern nach dem Grade der ätzenden Beschaffenheit des Saftes. Die Urtica urens brennt während ihrer Blïthenseit darum weniger, weil der Trieb der Säte mehr in die Blïthe geht, - Dr. D a niel major **) beobachtete im Jahre 1676 die noch nicht geöffneten Rosenknospen mit dem Microscop, um die wahre Beschaffenheit der gelbrothen Iaare oder Wolie an dem Samenhehältniss, der Blumendecke und dem Stiele zu cotdecken. Er land, dass es keine spitzig zulaufende Haare, sondern gleichsam umgekehrte Fläschchen, oder mit Saft angefuillte kolbenformige Röhrchen seyen; die sich bald in einen runden, bald lïnglichen Bauch endigen, und einen öligen Saft in sich enthalten. Als er etwas ron dieser Wolle abschabte, und auf glühende Kohlen warf, so verbreitete sich ein ganz schwacher Rosengeruch. - Nach Guettard enthalten die llaare der Nesseln, der Nalpighia u. a. an ihrer Basis eine mit scharfer Flüssigkeit gefüllte Blase, welche sich mittelst des sehr feinen, die liaare durchkreuzenden Cauals in den gestochenen Theil ergiesst, so wie das Gift in die Zähneder Schlangen. -

6. Moldenhawer *w*) glaubt, dass die Function der Wurzelhare in der Vermelirung der Obertiäche der Wurzel, und in der Ausschwitzung einer Fliissigkeit bestehe, welche wenigstens zum Theile als ein Aullösungsmittel des chemischen Prozesses benützt wird, durch welchen die nährenden Bestandtheile des Bodens zur Anuahme in der Wurzel vorbereitet, und

*) Siche Tab, I, Fig. 4 .

**) Siehe den 8ten Theil der Wahrnehmungen der kais. Akad, der Natur. forscher.

***) Beyträge zur Anatomic der Pllanzen. Kiel 1812. p. 139 
der Natur jeder Pflanze assimilirt werden. Und in dieser Hinsicht wäre es der Speichel des Thierreiches. Ferner erklärt er hieraus die Thatsache, dass verschiedene Pflanzen durchaus nicht gedeihen, wenn sie von den Wurzeln gewisser Nachbarn belästiget werden, obgleich weder Mangel an Nahrung, noch Beschattung oder Tropfenfall Statt findet; daher die Aehnlichkeit jener ausgeschwitzten Feuchtigkeit mit denı Speichel der Thiere, welcher bekanntlich, wenn er von zwey verschiedenen Thieren genommen wird, nicht selten dem einen schädlich wird; endlich findet er in dieser Annahme einen Grund für die grössere Feuchtigkeit des Erdreiches in der Nähe stärkerer Wurzeln.

7. Nach Sprengel pllegen Pflanzen, die in freyer Luft. stark getrieben werden, den Ueberfluss des Nahrungssaftes stets durch die Ilaare auszuleeren. Auch behauptet er

8. Dass die Menge der llaare mit jener der Spaltöffnungen im ungekehrten Verhältnisse stehe, dass demnach platte Theile um so melir Poren haben, gerade als wenn diese beyden Gebilde entgegengesetzte Functionen hätten. Dagegen kehrte Pudolphi diesen Satz so um, dass er sagte: wo viele llaare sind, die cinsangen, bedurfte es nicht so vieler und grosser Poren; wo diese aber sind, waren jene nicht nöthig, da beyde einsaugen.

9. Wie bekannt ist die Oberfläche einer Pflanze um so haariger, je stïlier der Trieb der Säfte ist, und desshalb finden sich auch bey jungen Plianzen immer die meisten Haare. Da nun aber auch die Ausdünstung in demselben Verhältnisse, d. i. mit dem vermehrten Säfteandrang nothwendig zunehmen muss, so scheinen die llaare ollenbar auch zur Ausdünstung zu dienen. Endlich

10. Nag wohl auch die Analogie dafür spreclen, inden beym Nenschen die llaare vorzüglich da gedeihen, wo eince reichliche Absonderung vor sich geht, z. B. am hopf, in der Achsclgrube, der Schaangegend, auf der Brust u. s. w.; obgleich es leicht zu erweisen ist, dass weder die Thier- noch Menschenhaare bloss zur Ausdünstung bestimmi sind.

Anmerkung. Link stellt in seinen kritischen Bemerkungen und Zusäizen zu' Kurt's Sprengel's Werk: iiber den Bau und die Natur cier Gewächse pag. 27. die Frage auf: Ob viclleich alle Hare, welche Querwände in Verlaufe, oder in der Nähe ler Basis haben, zur Absonderung; hingegen alle, denen dieso 
Querwände fehlen, zur Finsaugung bestimmt seyen? Ihm ist diess sehr wahrscheinlich, weil die Haare an den Wurzeln keine Spur von Querwänden zeigen, die Haare am Stamme u. s. w. aber, wenigstens in der Nähe der Basis immer damit versehen sind. So sah L ink auch Querwainde bey allen Haaren, die offenbar klebrige und riechende Stoffe absondern. Diese Einrichtung scheint ihm auch sehr der Natur gemäss zu seyn: einsaugende Haare müssen die Flüssigkeit schnell durchlassen, damit eine Menge von derselben in das Gewiohs tritt; absondernde Haare hingegen können Querwände haben, damit der Stoff beym Durchschwitzen durch dieselben seine gehörige Beschaffenheit und Mischung erhalte. -

Bey dieser grossen Verschiedenheit der Ansichten scheint mir nach genauer Erwägung und Vergleichung der beyder Seits angeführten Thatsachen, der Schluss am wahrscheinlichsten: dass einige Haare zur Einsaugung, andere zur $A$ l, sonderung gewisser Flüssigkeiten dienen. $\mathrm{Ob}$ es auch solche gäbe, welche beyden Functionen vorzustehen im Stande sind, ist schwer zu entscheiden.

Anmerkung. Treviranus hält die Haare für mehr zufällige Organe der Epidermis, als die Poren. Sie enthalten noch ihm Luft und Saft, und stehen in Bezug auf Absonderungen aus dem $\mathbf{P}_{x-}$ renchym nicht in so unmittelbarer Verbindung wie die Poren, indem sie nicht nur auf der Oberhaut stelien, sondern wirklich Verlängerungen derselben sind, Siehe dessen vermischte Schrifien 4. Bd. 1329.

\section{B. Nebenverrichtungen.}

\section{ร. 21.}

1. Einige Haare dienen den Pflanzen, auf denen sie vorkommen zum Schutz und zur Bedeckung zarter Theile. Auf diese Idee werden wir geradezu durch den Umstand geführı, dass die weise Natur immer die zartesten Theile so sorgfältig mit Haaren verwahrt hat. So sehen wir diess bey den Blättern in der Knospe u. s. w. Schon (irew *) hat bemerkt, dass die Haare den jungen Pflanzen dazu dienen, die noch unentwickelten Theile vor dem wechselweisen Drucke zu schützen. Daher verlieren sich die Haare an den Blättern mancher Pflanzen, sobald sich diese entfaltet haben, wie wir diess :m der Rothbuche sehen; bey andern faillt die haarige Bekeidung, durch welche sie gegen die Strenge des Winters

*) A, a, O, IY, Bd, Ch, I. 
geschützt wurden, mit der wiederkehrenden warmen Jahrszeit hinweg. Am auffallendsten ist dieser Zweck der Haare bei der Blattknospe der Rosskastanie, únd bey manchen $\mathrm{Na}$ delblättern zu erkennen, z. B. bey den Fichten und der Magnolia grandiflora, wo jedes junge Blatt eine zarte, behaarte Hülle, wie eine Scheide besitzt, die sich in der Folge abstreift *). - Dass die steifen Haare, Borsten und Stacheln ebenfalls zum Schutze der Pllanzen dienen, ist zu einleuchtend, als dass man es nicht einsehen musste. Auch hat uns Schrank**) den Nutzen der Hakenborsten bey den rerschiedenen Arten der Forskohlien auf diese Weise zu erklären gesucht, indem er eine Fliege sah, die den Kleber auf dem Blatt anfischlürfen wollte, aber mit dem Rüssel an einigen Hakenborsten hangen blieb und starb. - Linné ist der Meinung, dass die Haare mehr gegen die Wärme als Kälte schützen, und sucht durch einige Beyspiele zu beweisen, dass die grosse Hitze, und auch der schädliche Einfluss des Windes dadurch abgehalten würden. Es sind aber nicht allein viele in den wärmsten Gegenden wachsende Pllanzen glatt und kahl, wie die meisten fetten Gewächse, die Faclieldisteln, Euphorbien, Ficoiden u. s. w., sondern man findet auch in kältern Gegenden mehrere, welche mit liaare besetzt, oder gar mit einem wolligen Ueberzuge bedeckt sind. Fast alle, die an dem Lfer des Meeres wachsen, und wo meistens halte Winde herrschen, sind von der Art; daher man wohl eher zugeben mag, dass die Haare iiberhaupt, und besonders wenn solche dicht stehen, und unter einander verwickelt sind, oder ein besonderes Gewebe ausmachen, den Pllanzen mehr zum Schutz gegen die Kälte als gegen die Wärme dienen. Solche weiche, lange und lirause Haare halten, wie De Candolle sagt, um die zarten Organe herum eine gefangene Luftschichte zurück, und hindern so gleich den Thiterpelzen das Durchdringen der äusseren Temperaiur.

Auch gegen die äussere Feuchtigkeit schützen die Haare in manchen Fällen, welches man am besten bemerkt, wenn man stark behaarte Blätter ins Wasser taucht, wo dann die behaarte Fläche dennoch trocken bleibt. Eben so spricht dieBeobachtung, dass die meisten haarlosen Flächen der Pflan-

*) Rudolphi a, a, O. p. 126 .

$\left.{ }^{*}\right)$ A. a, O. p. $68 \simeq 71$. 
zen durch irgend eine andere Vorrichtung, z. B. durch einen blaugrünen Staub, Wachs, oder andere klebrige und schleimige Stoffe gegen die Feuchtigkeit geschützt sind, dafür. Endlich dienen viele Haare auch zum Schutze gegen die Insecten. Diess zeigt sich vorzüglich bey den Blüthenkelchen der Labiaten, wo der Eingang in die Röhre gewöhnlich durch eine zahllose Menge kleiner, feiner Ilaare vertheidiget wird. Noch auffallender ist diess bey den steifen, stärkern, hakenförmigen und Stachelhaaren zu sehen, wovon ich schon oben ein Beyspiel angeführt habe.

2. Einen nicht unbedeutenden Nutzen haben die Haare auf das Befruchtungsgeschä ft verschiedener Pflanzen. So tragen die feinen Haare an den Seiten der Staubbeutel bey den Veilchen dadurch, dass sie wechselweise in einander greifen, otwas zur Befruchtung der Narbe bey, die, wie Schrank behauptet, nur im Rohre der Staubbentel, uind vor dem endlichen Durchbohren und Ueberwachsen derselben vor sich gehen kann. Auch sondern die Haare der weiblichen Narbe offenbar das Oel ab *), das zur Anfnahme des Samenstaubs bestimmt ist. Endlich dienen einige Haare den Samen zur leichtern Verbreitung dieser letztern, z. B. die Hakenborsten bey den Arten von Gallium, Bidens, Verbesina alata etc., ferner die Angelborsten an den Samen des Cynoglossum virginicum. Wenn diese Samen von den vorbeygehenden Thieren abgestreift werden, so sind jene Haken die dienlichsten Wittel, wodurch sie sich anhängen, weiter getragen, und endlich wieder abgestreift, und so an ganz andern Orten glcichsam wieder ausgesäet werden. - Bey andern Pflanzen dienen wiede die Haare ihrer Geschlechtstheile bloss dazu, um die Oberfläche zu vermehren. Diess scheint z. B. der Fall bey dem haarigen Bart unter der kleinen Narbe der Wicke zu seyn; diese

*) Amici (Annales des sciences naturelles, Par Andouin, Brogniart et Dumas. Paris 1824. Seite 65) sah bey der Portulaca oleracea in den feinen Härchen der Narbe Saftkörperchen auf - und absteigen; als ein Korn Pollen, welches auf einem solchen Haare lag, platzte, fuhr eine Röhre heraus, die sich an die Seite des Haares anlegte, und Körnchen enthielt, die theils aus ihr, theils aus der Pollen ka. men, unregelmässig sich bewegten, und nach drey Siunden verschwunden waren. -

Bey Ophrys insectifra silat der Pollen als dichte Masse auf Driisenhaaren, welche mit dem Fruchtknoten zusammenhangen. - 
Hare hindern durch ilıre besondere Stellung den Verlust des Samens, indem sie ihn gleichsam zwingen, in der Nähe der Narbe zu bleiben. - Der eigenthümliche Bau der Befruchtungswerkzeuge des $\Lambda$ conitum neomontanum scheint in dem ersten Augenblick für dieses Geschäft sehr naclitheilig eingerichtet zu seynn, und dennoch wird bey näherer Beleuchtung die Fructification eher dadurch befördert, als gestört. Denn die aus den Spalten hervorquillenden kleinen Oeltropfen sammeln sich durch die grosse Annüherung der Griffel und Narben zu einem grössern Tropfen; die Träger stehen mit ihrem breiten Theil überall mit den Stempeln in enger Verbindung, an ihrem pfriemenförmigen Theil aber sitzen engstehende zerstreute Fadenhaare, welche die Narben bedecken; und weil die Träger selbst in ihrer Jugend verschiedentlich gebogen sind, nach und nach aber, und schr einzeln, gerade auswachsen, so entsteht nach Schrank eine Bewegung der llaare, wodurch immer Blüthenstaub zur gemeinschafilichen Narbe gebracht wird, abgesehen von dem, dass die ziemlich langen Haare überdiess noch anderer mechanischer Bewegungen fähig sind *).

5. Manchmal beste ht der Nutzen der Haare bloss darin, die Oberfläche der Pllanze rauh zu machen, und dadurch einerseits diese selbst zu schützen, andrerseits die Möglichleit einer genauern und andauernden Berihrung zwischen ihr und andern zu erzielen und zu erleichtern. Diess schen wir schön realisirt bey dem Hopfen, welcher durch seine Sehützenborsten an den Blattrippen, Blattstielen, jungen Aesten und Stempelu die Reibung zwischen der Pflanze und der Stange vermehrt, sich also an letztere um so fester anlilebet, und zugleich die unmittelbare Berührung zwischen der feinen Substanz der Pflanze und Stange hindert.

4. Ich stehe keinen Augenblick an, zu behaupten, dass die llaare mancher Pllanzen zur Zierde derselben beytragen. Wer gibt nicht gerne zu, dass der fcine sammtartige Ceberzug in manchen Blumenkronen die Zartheit und Llegan\% derselben ungemein erhöhe? Wer sieht den Staubfaden der Tradescantia ohne herzerhebende Bewunderung an? und deunoch sind es bloss die violetten Gelenkhaare, die ilum diesen Reiz verleiben. Ich zweifle auch nicht, dass der seidenartige Ueberzug so vieler Pflanzen zur Erhöhung ihres an-

*) Siehe Baierische Flora n. 816. Tab. 111. Fig. 1. 2. 
muthigen Baues wesentlich beytrage, so wie die silberweissen oder goldgelben IIärchen die Pracht so vieler rachenförmigen, zweylippigen und glockenartigen Corollen ungemein steigern.

\section{Dritter Abschnitt.}

Etwas über das krankhafte Verhalten der Pflanzenhaare.

I. Ueber krankhafte Ausartung der Pflanzenhaare überhaupt.

§. 22.

Wie der ganze Organismus, jedes seiner Systeme und Organe in seinen normalen Verrichtungen gestört, und der Entwickelung der Krankheitserscheinungen einen fruchtbaren Grund und Boden abzugeben vermag, so wird es uns nicht wundern, wenn selbst jene zarten Gebilde, die wir eben ihrem manichfaltigen Baue und ihren Verrichtungen nach in Betrachtung gezogen haben, ebenfalls krankhaften Veränderungen unterworfen seyn können. Nicht weniger die Zartheit ihrer Struktur, als ihr physiologischer Einfluss auf die Oekonomie des pllanzlichen Lebensprozesses lassen erwarten, dass ihre pathologischen Zustände ungeachtet der Kleinheit ihres Wesens nicht unbedeutend seyn können, und allerdings in die Erscheinung fallen müssen.

Wir wollen hier nicht die sämmtlichen krankhaften Zustände, denen die Pflanzenhaare während ihrer Entwickelung, und dem allmähligen Auf:hören ihrer Functionen unterworfen, und wozu wir in den bewährtesten pflanzenphysiologischen und pathologischen Schriften kaum leise Andeutungen zu finden im Stande sind, in Erwägung ziehen; sondern uns lediglich auf ein einziges Geschlecht von Haarkrankheiten der Vegetabilien beschränken, das wir in den Pflanzensystemen unter dem Namen Erineum (Phyllerium) aufgeführt finden. 


$$
\text { §. } 23 .
$$

Bevor wir in die weitere Erörterung dieser krankhaften Erscheinung eingehen, glauben wir folgende Bemerkungen voraus schicken zu müssen:

Es ist bekannt, dass der pflanzliche Organismus von dem thierischen potentiell verschieden ist, dass, so wie in jenem Plasticität herrscht, dieser seine höhere Stellung durch Bewegungsfähigkeit offenbart. Diesem Grundverhältnisse folgt auch die Krankheitserscheinung in beyden Organismen. Diese als einen eigenartigen, niederen Organismus mit Lebenskraft begabt erkennend, können wir demnach in der Pflanzenwelt nur unter der plastischen Form als Afterorganisation (Krankheitsorganismus) erscheinen sehen, während sie in der Thierwelt mehr in bewegter Gestalt als Krankheitsprozess zur Entwickelung gelangt. Dadurch nun, dass die Krankheit der Vegetation sich vorzugsweise in der Form als ein geschlossener Organismus, welcher, obgleich niederer Art, dennoch das Wesen mit jedem andern Organismus gemein hat, darstellt, ist es gekommen, dass viele Krankheiten der Gewächse in den Pflanzensystemen Eingang fanden. So finden wir z. B. die Exantheme als niedere Krankheitsorganismen in den Systemen der Pilze abgehandelt, und ein gleiches gilt von der eben zu erörternden Krankheit. Es fehlt nicht an Schriftstellern, welche in klareren oder dunkleren Andeutungen die $\mathrm{Hy}$ podermien und Phylleriaceen für Krankheiten der Gewächse oder für krankhafte Produkte derselben erklären. So findet sich in den Schriften von Persoon, Strauss, Nees v. Esenbeck, Link u. m. a. mehrere Stellen, die wir als Belege hiezu anführen könnten. Am deutlichsten hierüber spricht sich Fries*) in der Einleitung zu seinem vortreflichen mycologischen Werke aus, wo es unter andern heisst: "Infimae quoque formae (fungorum) vix nisi exanthemala et partes plantarum in functionibus turbatae et liberlate in vegetatione compotes factae v. gr.Phylleria;" - dann "Infimae formae (fungorum) sunt: Exanthemata et partes plantarum in statu morbosn v. gr. Phylleria, Sclerotium, Clavus e. s. p. ;" weiter heisst es: "Vidimus eadem ratione in plantis vegetis cellulas discretas clongari, et hoc modo oriuntur pili plantarum. Infimae quoque Mucedineae sunt tantum

*) Systema mycologicum. Vol. I. 1821 p. XXI et seq. 
pili plantarum in statu morboso, v. gr. Phylleria; " und wo er von den Phylleriaceen selbst handelt, sagt er: "Sunt. slatus morbosi vestitus plantarum. Evidentissime hoc monstrant Phyllerium Gei, Rubi, quae nil nisi pili foliorum aggregati el paululum mutati."

Wenn wir nun fragen, worin denn die krankhafte Ausartung der Pflanzenhaare, die unter der gewöhnlichen Benennung Erineum bekannt ist, bestehe, so müssen wir Folgendes erwiedern :

Es ist entweder ein auf seiner tieferen Entwickelungsstufe stehen gebliebenes Haar, das sich durch seine Kürze, durch sein knopf-oder keulenförmiges, nicht selten sogar verzweigtes Ende (Grumaria Kunz) auszeichnet; oder es ist ein verlängertes, erweitertes, spiral gewundenes oder manichfaltig verbogenes Haar (Phyllerium Fries), das eine höhere Entwickelung, ein mehr Selbstständigwerden beurkundet. Erineum alneum Pers. (Rubigo alnea Nees) mag vom ersteren, Erincum alnigenum Kunz (E. alneum Nees) *) von letzterem als Beyspiel dienen. Zwischen beyden, nämlich der Grumaria und dem Phyllerium steht jene Form die Fries Taphria nennt. Sie besteht aus sehr kleinen keilförmigen Fäden, die sich zwischen einem Aggregat von seidenartigen Haaren bilden. So z. B. das Erineum gryseum Pers., welches sich an Eichenblättern findet. Alle diese Formen von Erineum haben das Eigenthümliche, dass sie sich nur an bestimmten mehr oder weniger ausgebreiteten Stellen entwickeln, wo sie im letzteren Falle dicht zusammen gedrängt ein haufen - oder kissenförmiges Ansehen gewinnen. Nicht selten ist dabey die Blattsubstanz, die ihnen zur Unterlage dient, mehr oder weniger aufgelockert und vertieft.

\section{S. 24 .}

Das bey der Bildung der Erineen Merkwürdigste, worauf wir bey der Bestimmung ihrer Grundursache gewiss mit Recht das meiste Gewicht legen dürfen, ist der Umstand, dass sämmtliche Erineen sich nur an Plättern bilden, und alle übrigen Pflanzentheile, selbst wenn diese auch grün gefürbt und blattartig sind, und einen Haarüberzug haben, frey lassen. Eben so verdient es besondere Be-

*) Tab, IV. Fig. 35 . 
rücksichtigung, dass sie sich nur an Blättern vollkommener Pllanzen (Dycotiledonen) zeigen, und fast ausschliesslich nur an Blättern von Bäumen und Sträuchern vorkommen. In unseren Gegenden sind es besonders die Amentaceen, als: Alnus glutinosa und incana, Populus nigra und trcmula, Quercus robur, ilex, acgilops und faginea, Carpinus belulus, Fagus syloatica, Betula alba und viridis, dann viele Arten von Acer, als: A. campestris, platanoides, pseudo-platanus, opulifolius, mons pessulanus, ferner Prunus padus, Mespilus oxycanta, Pyrus malus und domestica, Sorbus aucuparia, Tilin vulgaris, parvifolia und argentea, Juglans regia, Aesculus hypucastanus, Rhamnus catharlica, Vilis vinifera, Rubus corylifolius, Ribes rubrum, und die beyden einzigen krautartigen Geum urbanum und Asclepias sinceloxicum, deren Stengel jedoch ebenfalls einen namhaften Holzkörper besitzen, und die sich somit den strauchartigen Gewächsen nähern. Doch scheint diese krankhafte Erscheinung an Blättern gleich den Hypodermien sich nicht allein auf die gemässigte und kältere Zone zu beschränken, sondern selbst in den heissen Himmelsstrichen vorzukommen. Hierin sind jedoch ganz natürlich meine Erfahrungen äusserst beschränkt. Demungeachtet hat uns Schlechtendal mehrere neue Arten von Erineum bekannt gemacht, die den Blättern von grösstentheils ansehnlichen Bäumen eigen sind, welche im mittleren Amerika und den westindischen Inseln wachsen. Es sind: Avincennia nilida, Bucida Buceras, Dombeya punctata, Chrysophyllum microcarpon, Callophyllum Calaba, Cinchona cordifolia, Capparis laurina, Qualea, Celastrum, Melastoma, durchaus Bäume, deren Laub mit netzförmig verzweigten Adern versehen ist. Jüngst hat noch $\mathrm{Holl} *$ ) ein Erincum (Grumaria) auf den Blättern von Laurus indica entdeckt.

Was die Verbreitung der Erineen nach der Hohe betrifft, so erscheinen sie noch in der subalpinen Region. So traf ich sie dort noch auf Alnus incana, Acer pseudo-platanus, Belula alba und Sorbus aucuparia. Die ihnen eigenthümliche Region scheint aber in unsern Breitengrade die untere und obere Bergregion (Regio Juglandis et Fagi), die da bis 4000 , in den Apeninnen auf 5000, in Sicilien auf 6000 Fuss steigt. In Mittel-Amerika und den westindischen Inseln ist es

*) Verzeichniss der anf der Insel Madeira beobachteten Pflanzen. Flora. 1830. 
die Region der Cinchonen und Melastomen in einer Höbe von $5000-8000$ Fuss.

Die Zeit ihrer Erscheinung fällt nach meinen Beobachtungen in den Anfang des Monats Juny, wo die Ausbildung der Blattsubstanz im Einklange mit der ihr eigenthümlichen Function das höchst erreichbare Mass und die grösste Energie erlangt hat. Indess dient zur Beachtung, dass um diese Zeit nicht nur vollkommen entwickelte, sondern auch (obgleich seltener) jüngere, ja selbst kaum entfaltete Blät'rr mit jener Krankheit behaftet werden. Ihre Dauer reicht gemeiniglich bis zum Blätterfalle am Anfange oder zu Ende des Herbstes, kurz vor welcher Zeit man sie am häufigsten und am vollständigsten entwickelt antrifft.

Viele Erineen sind in ihrer Jugend weiss, und erhalten erst später eine dunklere, gelbrothe und braune Farbe, was von der grösseren oder geringeren Ausbildung des Färbestoffes abhängt, welcher in grumosen Massen des Innern jedes einzelnen ausgearteten Haares angehäuft ist. Ich habe die Bemerkung gemacht, dass bey Verletzung der umkleidenden Haut, die, wie wir später schen werden, dieselbe ist, welche die Zellen der Epidermis bildet, die dunklere Färbung nach dem Zutritt der atmosphärischen Luft alsogleich bewerkstelliget wird. Offenbar hat demnach die dunklere Farbe in der höheren Oxydation ihren Grund.

\section{§. 25 .}

Es wurde früher schon angegeben, dass die Erineumbildung in einer krankhaften Metamorphose der Haare liege, und dieselbe auch näher bezeichnet. Wir kehren hier nochmals darauf zurück, weil wir auf einen Umstand stossen, der diese Ansicht nicht nur zweifelhaft machen, sondern selbst vernichten könnte. Dieser ist die Bemerkung, dass die Erineumbildung auch an solchen Blättern Statt findet, die gänzlich aller Haarbedeckung ermangeln, wie dicss z. B. an den Blättern von Populus tremula, Juglans regia u. s. w. der Fall ist. Wollte man einwenden, dass auch diese Blätter in ihrer Jugend mit sehr kleinen, wenn gleich spärlichen Haaren versehen seyen, so würde es doch immer schwer seyn, die Erscheinung des dichten Polsters auf diese Weise zu erklären, in welcher Form z. B. das Erineum Juglandis später hervortritt. 
Meines Bedenkens scheint die Sache einer anderen, näher liegenden Erklärung fähig.

Ich verweise hier auf den anatomisch - physiologischen Theil, wo gezeigt wurde, in welcher Verbindung die Haare mit der Oberfläche des Pflanzenkörpers überhaupt, und zunächst mit der Epidermis stehen. Dort wurde gesagt, dass dic Pflanzenhaare auf ihrer tiefsten Stufe und in ihrer ursprünglichen Bedeutung allein der Epidermis angehören, ja nichts anderes seyen, als in der entgegengesetzten perpendikulären Richtung ausgedehnte einfache Zellen der Epidermis; dass ferner erst die höher ausgebildeten Haare im Rindenkörper selbst wurzelten. Es wurde daher auch ihre Function grösstentheils jener der Epidermis gleichgestellt.

lch glaube nun, dass die Erineumbildung nicht nur allein in krankhafter Umbildung der bestehenden oder sich entwickelnden Haare bestche, sondern auch auf krankhafte Umänderung der Epidermis überhaupt ausgedehnt werden müsse. Für diese Meinung haben mich nicht nur allein theoretische Gründe bestimmt, sondern auch die an mehreren Erineumarten gemachte Beobachtung, dass die ursprüngliche Bildung derselben aus perpendiculär verlängerten und verschiedentlich geformten Epidermiszellen bestehe. Namentlich habe ich dieses bey Erineum (Grumaria) alncum und Erineum (Ply.llerium) acerinum beobachtet. Ferner gibt es eine Art von Erineum, jenes nämlich, welches $S \mathrm{chlechtendal}$ im ersten Bande der Linnea als Evincum ribium beschreibt, dass ich auch schon früher häufig in den Umgegenden. Wiens gefunden habe, aber als von Blattläusen herrïhrend, für eine Art von Excrescenz hielt. Hier, so wie in einer ähnlichen Missbildung an den Blättern von Amygdalus persica, welche bisher noch nicht beschrieben wurde, geht der Bildung von Erineum eine auffallende blasige Auftreibung der Blattfläche nach aufivärts, die sich nicht selten durch eine gelbrothe Farbe auszeichnet, voraus. An den Pfirsichblättern lässt sich selbst später an der Unterseite kaum etwas wolliges erkennen, obgleich ich niclit anstehe, diese Missbildung auch hierher zu zählen. Hier leidet offenbar die Oberhaut selbst mit dem unterliegenden Paren. chym (Mesophyll.).

Es wird demnach entsprechender seyn, die Erineumbil. dung nichtinur auf die krankliafe Metamorphose der Haarbedeckungen zu beschränken, sondern auch die Oberhaut und 
sclbst das Blattparenchym in den Bereich dieser Krankheitserscheinung zu ziehen.

\section{§. 26.}

Un endlich auf den Grund dieser krankhaften Veränderung oder auf den Krankheitsprozess selbst zu gelangen, dürfen wir einen Umstand nicht übersehen. Es wurde bereits bemerkı, dass nur die Blätter und zwar fast ausschliesslich von dicotyledonischen Bäumen vom Erineum befallen werden; es ist aber eben so merkwürdig, dass nur die Unterseite derselben die Grundlage ihrer Erzeugung bildet.

Da aber vorzugsweise nur die Unterseite der Blätter mit Poren versehen ist, und, wie ich an einem andern Orte erweisen werde, diese nichts anders als die Stomata der Athmungshöhlen der Pflanzen sind, so scheint sich wohl ungezwungen zu ergeben, dass die fragliche Krankheil mit der Alhmungsfunction der Vegetabilien im Causalnexus stehe.

Ditss dieses der Fall auch bey den Hypodermien sey, will ich hier nur beyläufig erwälınen, ohne den Unterschied beyder Krankheiten in Erwägung zu ziehen.

Auf jeden Fall liegen der Hy podermien-, Xylomenund Erineum-Bildung specifisch verschiedene Krankheitsprozesse zum Grunde, deren Erforschung ich schon seit mehreren Jahren meine Aufmerksamkeit schenke. Die Resultate derselben werden sich aber für eine besondere Schrift eignen.

II. Ueber die Bildung der Haare an der Oberfläche pflanzlicher Afterorgani$s$ ationen.

\section{27.}

Es ist bereits erwähnt, wie das mehr oder minder Behaartseyn von Pllanzen, denen ursprünglich entweder gar keine llaare zukommen, oder die zu den behaarten gezählt werden, von äusseren Einflüssen, insonderheit von der Beschaffenheit des Bodens und dem Feuchtigkeitsgrade der Atmosphäre abhïnge, und wie diese allerdings pathologisehen Zustände der Pllanzen aus den gestörten functioncin einzeluer Organe erklärt werden können. 
Nicht minder wichtig, und die Bedeutung der Haare nicht weniger erhellend, scheint mir noch die Betrachtung, welche wir der Bildung der Haare an der Oberfläche pflanzlicher Afterorganisationen schenken wollen. Der Leser wird darin wenigstens die hauptsächlichsten Punkte angegeben finden, die ihm für weitere Untersuchungen über diesen bisher so wenig beachteten Gegenstand von einigem Nutzen seyn dürften.

\section{28.}

Ich theile die Aftergebilde der Pflanzen in zwey Ordnungen, wovon die erste die Ausw ü chse (Excrescentiae pluntarum), die zweite die Missstaltungen (Deformitates plant.) in sich fasst. Beyde Ordnungen in mehrere Gattungen zerfallend, begreifen unzählige Arten in sich, deren hauptsächlichste wir nun in Kurzem durchgehen wollen, um am Ende einige allgemeine Resultate beyfügen zu können.

\section{§- 29 .}

Die unterste Form der Pflanzenauswüchse ist jene, die von der ursprünglichen, den verschiedenen Pflanzenarten eigenthümlichen Form am wenigsten abweicht. Wir nennen sie Zapfenrose, Sqammatio. Da sich diese krankhafte Metamorphose nur entweder an den Spitzen oder Seiten mit Blätter versehener Zweige, oder an den Kätzchen oder Traubenbliithen einiger Pflanzen ausbildet, folglich nur in einer niedern Jmstaltung genannter Organe besteht; so ist begreillich, wie die normale Behaarung dieser Theile auch in der krankhaftenUmänderung derselben sich so viel als möglich gleich bleibt. So sehen wir z. B. die Zapfenrosen der Buchweide, Squammatio Salicis helicis, der Stieleiche Squammatio Quercus pedunc. unbehaart, während jene der weissen Weide Squammatio Salicis albae, des deutschen Ginster Squammatio Genistae germanicae, der Natterwurz Squammatio Echii pulgaris u. dgl. behaart sind. Indess findet diess nicht überall statt; denn es gibt Zapfenrosen, welche mit Haaren versehen werden, obgleich den normal gebildeten Pflanzentheilen der Art, worauf sich dieser Auswuchs bildet, keine zukommen. Beyspiele dieser Art geben die Zapfenrosen an den Blüthenkätzchen der Salix tii anda, wo die verdickten Staubfïden ringsherum mit einem dichten Filz von Ilaaren bedeckt sind; dann die den Erdbce. 
ren ähnlichen Auswüchse an den Blüthen des Sisymbrium sylvestre und an den Zweigen von Asperula cynanchica u. s. w.

Am auffallendsten unter diesen Formen von Auswüchsen beurkundet die krankhafte Production der Haare eine Varietät der Zapfenrose des Feldbeyfusses Squammatio Artemisiae campestris. Ihre scbmalen filzigen Blättchen, welche die vielen an einander gehäuften einkammerigen Zellen des Mittelpunktes decken, geben dieser Zapfenrose das Ansehen eines Bedeguars.

\section{§. 30 .}

Die ziveyte Stufe der Auswüchse, die Verkrüp pluíngen, Peromata, bestehen wie gesagt in ungleichförmigen verschieden gestalteten Auftreibungen der Blattlächen, oder in Verdickungen, und zugleich Verdrehungen (Contorsiones) der Stengel- und Blattstiele vieler Bäume, Sträucher und anderer krautartiger Pflanzen, und sind weit seltener mit krankhaft erzeugten Haaren besetzt. Meist sind diese heller oder röthlich gefärbten blasigen Auftreibungen der Blattfächen wenigstens oben unbehaart und glatt.

\section{§. 31 .}

Desto mehr sind die beyden darauf folgenden Gattungen von Auswüchsen mit Haaren versehen. Die Fleis chzapfen (Folliculi carnosi), kleine warzen - oder zäpfchenförmige, innen hohle Geschwülste an der Oberseite der Blätter sind grösstentheils mit kleinen dichten Haaren sammtartig überzogen, wie es sich an den Fleischzapfen von Tilia europoea, Acer campestris und platanoid., Ulnus glut., Carpinus betul. und besonders von Fagus sylvatica findet.

Die S a ck ge s ch w üls te (Bursae), von den Fleischzapfen nur durch den grössern Umfang verschieden, sind ebenfalls meist und besonders, wenn sie noch nicht vollständig entwickelt sind, mit Haaren überzogen, wie diess z. B. der Fall mit der grossen Sackgeschwulst der Rüster ist. Es gibt jedoch auch Auswüchse dieser Gattung, deren Oberfläche glatt ist. Beyspiele dieser Art geben die Sackgeschwülste, die auf den verschiedenen Arten von Pistacia vorkommen; eben so jene Sackgeschwulst, die auf Puxus sempersis. angetroffen wird. 


\section{§. 32.}

Die folgende Stufe der Auswüchse nehmen die Fle is ch$\mathrm{gew}$ ëchse (Sarcomata) ein. Da diese von der einfachen Aftermembran, als welche sich diese Form in einigen Pflanzen darstellt, bis zur beynahe vollsändig individualisirten Afterorganisation (wie in den Fleischgewächsen des Rubus caesius, der Serratula arvensis, des Cornus sanguinea u, a. m.) die verschiedenartigsten Formen durchgeht, so ist es wohl natürlich, dass hievon die Production der Haare zum Theil bedingt wird. Im ersten Falle, wo die Aftermembran immer von andern angeschwollenen und manichfaltig missstalteten Pflanzentheilen umgeben und bedeckt wird, folgt wie bey den Zapfenrosen die Behaarung der übrigen Pflanzentheile. So sind die Fleischgewächse von Ferbascum, Teucrium chamaedry's behaart, während die von Scrophularia nodosa u. a. m. glatt bleiben. Eben diess gilt von den Fleischgewächsen, die sich in dem Fruchtboden mehrerer Distelarten bilden, welche daher immer mehr oder weniger mit Haaren, Schuppen oder Spreublättchen bedeckt sind. Die am vollständigsten entwickelten Fleischgewächse sind, wie jene, die wir früher anführten, selten oder gar nicht behaart.

\section{§. 35.}

Was nun die am meisten individualisirten Auswüchse, die Galle n (Gallae), betrifft, so finden sich in ihren verschiedenen Abstufungen solche, die durchaus glatt, glänzend und wie mit einem Firniss überzogen erscheinen; andere, die sparsamer oder dichter; endlich noch andere, die so sehr mit Haaren überzogen sind, dass sie dadurch ein ganz fremàartiges Ansehen erhalten. Alle Schildgallen, besonders die rauhen der burgundischen Eiche, und die Seidengallen (Galles en boutons soyeux $)^{*}$ ) und Gallae capillatae **) sind mit Haaren überzogen. - Die Nabelschildgallen (Galles en champignon ${ }^{*}{ }^{*}$ ) sind sogar mit sternförmigen Haaren bedeckt. Ein Gleiches gilt von manchen Apfelgallen. So beobachteten wir an den noch jungen Gallen des Gundermans (Glechoma hederac.) sehr deut-

*) Rea um. Mem. XII. PI. 40, Fig. 13, 14, 15. p. 446.

*) M. Il a I $\mathrm{p}$ igh i Op. de gallis p. 20, Fig. 16.

${ }^{* * *}$ ) R c a um. Mem。 XII, PI, 12, Fig, $8-10$, p. 424. Malpigh, a, a, 0 . p. 20. Fig. 15. 
liche und bedeutend grosse Zwischenwandhaare. Dagegen sind Knopperngallen meistens glatt. Unter allen haben jedoch die Bedeguargallen die meisten Haare, und zwar gehören dieselben zu den Asthaaren, die so stark und lang sind $(1-1 \%$ Zoll), und zugleich so dicht neben einander stehen, dass diese Form von Auswüchsen ein durchaus wolliges Ansehen erhält. Hierher gehören die bekannten Bedeguare der Rosa canina und der Quercus pedunculata.

\section{§. 34.}

Endlich verdienen noch die Masern (Tubcra) rücksichtlich ihrer Bedeckung einer Erwähnung. Behaart kommen zuweilen die Muttermäler und Warzen vor. Die Baummasern sind stets ohne Haare.

\section{§. 35 .}

Aus diesem Allem geht hervor:

1. Dass sich fast auf allen Gattungen von Pflanzenaus. wüchsen an der åussern Oberfläche Haare entwickeln.

2. Dass diese Haare selbst von verschiedener Form, und zwar von der einfachsten bis zur entwickelsten vorkommen.

5. Dass die Pflanzenauswüchse besonders in ihrer Jugend gleich andern Pflanzentheilen behaart erscheinen.

4. Dass endlich die Entwicklung der Haare an pflanzlichen $\Lambda$ fterorganisationen nicht lediglich von der Behaarung der gesunden Pflanzentheile, woraus jene hervorkeimen, abhängt, obwohl sie zum Theil davon bedingt wird.

\section{§. 56 .}

Literatur der Pflanzenhaare.
a) Ueberhaupt.

A dans o n familles des plantes. 1763. I. Theil. p. 256-258.

B onnet usage des feuilles. p. 47.

De Candalle principes elementaires de botanique. Paris 181j. p. 53.

- A. P. Organographic végétale etc. Paris 1827. Ins Dcul. sche iibersetzt von Dr. C. F. Mleis ner, 1828. 
D) uhamel physique des arbres, Vol. I. p. 183-187.

Gr ew Anatomie of plants, Bd, 2. p. 33. 34, 82, Bd, 1. Ch. IV. und Bd. IV. Ch, I, und II.

Gue 2 t a r d Memoires de l'academic de Paris 1745. p. 263. in 4. und p. 371. in 8 .

II edwig Sammlung seiner Abhandlungen. Bd. 1. p. 69.

- - de fibra vegetab. p. 9.

Ki efer Anatomic der Pflanzen. Jena 1815. 8.

K roker Dissertatio de plantärum epidermide. Halae 1800. 8.

L a m ouroux, Annales du Museum d'histoire naturelle. p. 268.

L in né Fundarmenta botanica. p. 314.

L ink's Grundlehren der Anatomie und Physiologie der Pflanzen. Göt. tingen $180 \%$.

- - Nachträge zu den Grundlehren der Anatomie und Physiologic der Pllanzen. Götting. 1809.

- - kritische Bemerkungen über Kurt Sprengel's Anleitung zur Kenntniss der Gewächse. Halle 1812.

MI a ighi Opera omnia. Anatome plantarum. Londin. 1675. p. 45. und de pilis obs. p. 93.

M ol den hawer's Beyträge zur Anatomie der Pflanzen. Kiel 1812.

Richard Achille nouveaux elemens de botanique, appliquée à la me. decine etc. Paris 1812.

Rudolphi Anatomie der Pllanzen. Berlin 1807.

Franz von Paula $S$ chrank. Von den Nebengefässen der Pflanzen und ihrem Nutzen. IIalle 1794.

K. Sprengel's Anleitung zur Kenntniss der Gewächse. Halle 1802.

- - Ueber den Bau und die Natur der Gewächse. IIalle 1812.

Wenderoth's Lehrbuch der Botanik. Marburg 1821.

b) Abhandlungen über einzelne hicher geh ̈̈rige Gegenstände.

De Candolle iber dic IIaare der Drusa in Annal. du Mus, d'hist, nat. Vol. 10. p. 469.

II a Il'sche allgemeine Litteraturzeitung 1808. Bd. 3. p. 12. Ueber Aus. diinstung der Haare.

II e $n$ schel von der Sexualität. p. 482.

I. edermiiller's microscopische Gemiiths. und Augenergölzung. 1761.

4. p. 156-157. Ueber die Gestalt der Haare.

- - die Haare an den Samen der Rosen. Ebendas. Fig. c. 1, m.; von Cardutis nutans, p. 176 Tab, 89. Fig. d, c, und 17.7. Tab. 31. Fig. c. d. c. 
Martius. Nova genera et species plantarum Brasiliensium. Monachii 1820. 4 .

- - in Novis actis acad. caes. Leopold. Car. n. c. Vol. 13. p. 265 Messung eines Haares.

M e yen über dic Saftbewegung der Planzen in den Zellen. Siehe Acta acad. Leopold. Car. n, c. 13. Bd.

M i r bel Haare der Labiaten in Annales du Museum d'histoire naturelle. Vol. 15. p. $221-223$.

Rudol phi Bemerkungen aus dem Gebieth der Naturgeschichte über die Haare der Nymphaea lutea und alba. Fig. 40 und Litt. A.

Scherer's allgemeines Journal der Chemie. Bd. 2. pag. 270. Ueber die Natur der Flüssigkeit, welche die Haare von Cicer arietinum ausschwitzen.

Senebier physiologie vegetale. Vol. 1. p. 449. Ueber denselben Ge genstand.

Wallroth anni botanic. 1815. Ueber die Haare der Chara.

In Martii nova genera etc. und in $H u m b o l d t ' s$ und Kunth's $A$ b. handlung ïber die Mimosen finden sich seltsame Haare abgebildet. 


$$
\text { Zweyte Abtheilung. }
$$

T h i e r h a a r e. 



\section{Erster Abschnitt.}

\section{Anatomisch - naturhistorische Bemerkungen.}

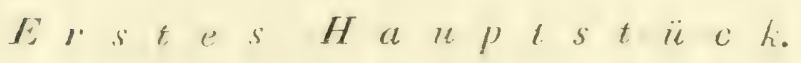

Von den II aren der Thiereim Allgemeinen.

\section{§. 57 .}

Definition der Thierhare.

Die grosse Manichfaltigkeit derjenigen Gebilde im Thierreich, welche wir mit dem allgemeinen Namen der Haare belegen, macht es einigermassen schwer, die generischen $\mathrm{Ei}$ genschaften derselben in einer schulgerechten D efi n i ti on zusammenzustellen. Indem ich daher, um unnütze Wiederholungen zu vermeiden, auf die weiter unten folgende, ausführlichere, und so viel möglich das Ganze umfassende Bestimmung des Begriffes von Mlenschenhaaren verweise, mit welcher denn auch das Thierhaar im Allgemeinen fast ganz übereinkommt, will ich hier nur anführen, dass man in der Zoologie alle jene Gebilde unter die Haare zu rechnen pflegt, welche sich als hornartige, fadenförmige, mit dem breitern Ende aus der allgemeinen Bedeckung der Thiere entspringende, oben allmählig spitzig zulaufende, und aus einer äussern festern, und einer innern lockerern Substanz bestehende Verlängerungen charakterisiren.

Anmerkung. 1. Diese Definition passt auf alle Haare des Thierreichs. Wer sie als zu allgemein verwerfen möchte, dem muss ich erwierlern, dass sie durch jeden, die Eigenthümlichkeiten eines Thierhaars noch näher bezeichnenden Zusatz gewiss an Allgemeingültigkeit verlieren, und daher unpassend seyn würde. So hat man z. B. den allerdings für die Haare der meisten Thiere gültigen $U_{m-}$ stand, dass sie mit einer mehr oder weniger dicken $Z_{\text {wriebel in }}$ 
und unter der Lederhaut entspringen, ebenfalls da und dort in den allgemeinen Begrift von Haaren aufgenommen, allein gewiss mit Unrecht: indem es, wie wir in der Folge sehen werden, viele Haare gibt, denen dieses Merkmal ganz abgeht, und die man doch, wie gesagt zu allen Zeiten und an allen Orten unter die Haare gezählt hat, und fortan zählen wird.

A nmerkung. 2. Naturphilosophisch hat man das Thierhaar ein Haargefäss genannt, welches bloss Schleim führt, aber sich einzeln über das Fell hinaus verlängert. (Oken's Naturph. 2ter Thl, p. 89).

\section{§. 38 .}

\section{Organisation, Form und Gestalt der Thierhare.}

Die genauere anatomische Untersuchung der Haare unrerliegt bey den Thicren im Allgemeinen weit weniger Schwierigkeiten, als bey den Pflanzen, und selbst beym Nenschen. Am besten eignen sich zu solchen Untersuchungen die Stacheln des Igels und Stachelschweins, die Borsten des Elens, des Wildschweins, die Knebelbärte und Tasthaare der Seehunde, Katzen und andrer Fleischifresser.

Um nun in der weitern Auseinandersetzung und Beschreibung der Organisation der Thierhaare überhaupt ein Schema zu haben, das, so wie es sich durch seine höchste Vollkommenheit auszeichnet, zugleich auf alle ührigen mehr oder weniger passt, selbe wenigstens immer unter sich begreift; so handle ich zuerst von denjenigen 'Theilen, aus welchen ein, auf der höchsten Stufe der relativen Vollkommenheit stehendes Thierhaar zusammengesetzt ist; und da ich aus Gründen, die ich weiter unten auseinandersetzen werde, die eigentlichen Tasthaare der Säugthiere als die vollkommensten betrachte, so ist meine erste Aufgabe, diese in ihre Theile zu zerlegen, d. i. anatomisch zu beschreiben.

Man unterscheidet aber an jedem Tasthaar folgende Theile: 1. den $\mathrm{Balg}$ sammt der in ihr enthaltenen Wurzel oder Z wiebel des Haares, 2. den Schaft, Cylinder, oder auch das $\mathrm{H}$ aar im engern Sinne.

\section{§. 59 .}

Beschreibung des Balges und Cylinders.

Folgendes ist die genaue Beschreibung des Balges eines Tasthaars aus der Schnauze eines Ochsen: 
Ein solches grosses Tasthaar beginnt mit einem ovalen, $1 \%$ Linie langen, und $1 / 2$ Linie breiten, weissen und festen Körper, dem Balge, der mit seinem untern, stumpfzugespitzten Ende in der Fetthaut wurzelt, von hier aus die Lederhaut ganz durchdringt, und bis an die Oberhaut reicht. Dieser Balg ist durch Zellgewebe an die Fetthaut, das Corion, und an die Oberhaut befestiget, und zwar an letztere am schwächsten. Rein präparirt, d. h. von allem umgebenden Zellgewebe befreyt, erscheint er weiss und derb, am untern Endtheil aber durch einige Fortsätze mit den vorbeystreifenden Nerven und Gefässen verbunden. - Schneidet man nun den Balg ein, so kommt man zunächst auf die äusserste feste Haut, von der so eben schon die Rede war; und hier entdeckt man jetzt, dass diese Haut ein ungefähr $1 / 4$ Linie dickes, übrigens aber gleichartiges, festes Gewebe hat, das sie zu einer Haut sui generis stempelt. Ganz mit Unrecht hält sie Gaultier für eine Fortsetzung der Lederhaut, indem er glaubt, dass sie durch eine Einsackung dieser letztern entstanden sey; in gleichem Sinne sucht er auch die einzelnen Theile des Hautorgans in dem Haarbalge wieder zu finden. Die beyden Flächen des letztern glänzen in frischen $Z$ ustande, und geben ihm so die Aehnlichkeit mit einer fibrösen $\mathrm{Mem}$ bran. Uebrigens ist diese Haut keineswegs ganz geschlossen; sondern bildet eine Art von Säckchen, das jedoch oben eine grössere, unten aber mehrere kleinere Oeffnungen hat. Erstere wird ganz genau von dem aufiärts durchdringenden Haar, die untern aber von den eintretenden Nerven und Gefässen sammt ihrem Zellgewebe verschlossen. - Schneidet man den Balg der Länge nach auf, so sieht man, dass diese erste Haut mit ihrer innern Oberfläche an einen etwas durchsichtigen, sulzartigen, verschiedentlich roth gefärbten Körper stösst, mit dem sie durch sehr feine, unzählbare Querfädchen zusammenhängt. Trennt man aber auch diese Fäden, so quillt ein dünnflüssiges Blut heraus, nach dessen Abfluss der ganze Theil ein weissgelbliches Ansehen bekommt. Es scheint jedoch, als wenn diese blutige Flüssigkeit sich nicht allein in den als Querfäden erscheinenden Haargefässen, sondern auch in den Zwischenräumen derselben befinde, und zwar so, dass ihre Menge nicht immer gleich gross, und daher die Farbe des ganzen Theils bald melir, bald weniger roth, bald selbst gelblich sey. Sind alle jene Fäden ge- 
trennt, so kann man den ganzen Körper sammt dem darin steckenden Anfang des Haars abgesondert herausbringen, und der Sack bleibt leer zurück. - Der genannte Körper (corpus conicum nach Gaultier) hat dann eine cylindrische, längliche Figur, und hängt wahrscheinlich auch durch kleine Fäden mit dem Haare selbst zusammen, das er umgibt. Genauer betrachtet, schien er mir, wie aus einer sehr feinen, griesigen Nasse zu bestehen, die jedoch nicht an allen Stellen gleich gut als solche unterschieden werden konnte. Sie reicht übrigens so weit, dass sie die ganze Höhle des Balges vollkommen ausfïllt, und scheint besonders oben und unten mit demselben fester zusammenzuhängen; wenigstens fand ich bey der Herausnahme dort allzeit einen grössern Widerstand; sonst liess sie sich leicht über das Haar wegstreifen. Auch glaube ich an ihrem untern Ende, worin die eigentliche Wurzel des Haars steckt, unter dem Microscop einige Unebenheiten - etwa abgerissene Gefässe oder Nerven? - beobachtet zu haben. - Wahr ist es, dass dieser ganze Körper desto fester wird, je länger er der Luft ausgesetzt bleibt. Wass seine Farbe betrift, so habe ich ihn in der Mehrzahl bey schwarzen Haaren weiss und weissröthlich, bey weissen meist röthlich, doch auch weissgelblich, bey spätern Untersuchungen wieder beynahe durchaus blassröthlich gefunden, so dass mich diese Beobachtungen ganz in Dunkeln rücksichtlich eines ursächlichen Zusammenhangs zwischen der Farbe der Наare und dieses Körpers liessen. - Ich vermuthe, dass dieser Körper im lebenden Zustande wo nicht ganz, doch halbflüssig sey*), und es scheint, als wenn aus ihm eigentlich das Haar entstehe. Ich bin übrigens nicht im Stande, das nach Wunsch zu beweisen, was ich nur ahnen möchte, dass er nämlich von der innern Oberfläche des Sackes - die vielleicht seröser $\mathrm{Na}$ tur ist - secernirt werde. Wenigstens ist mir diese Annahme viel wahrscheinlicher, als jene, nach welcher er von unten durch die eintretenden Gefässe exhalirt wird; und ich fiude mich jetzt, wo ich so glücklich war, bey dem Tasthaar einer Katze die Zwiebel bis in ihre innerste Substanz ausgespritzt zu sehen, um so mehr zu dieser Meinung berechtigt, als sich aus diesem Präparat ergibt, dass die innerste Seite - also jene,

*) He usinger will bey der Hufeisennase diese Flüssigkeit durch das Microscop sogar in lebendiger Bewegung gesehen laben 
welche dem eingeschlossenen Haar zunächst liegt - viel röther, gefässreicher erscheint, als die, welche unmittelbar an die innere Oberfläche des Balges stösst. Denn als ich in jenem eingespritzten Haarbalge, nachdem er getrennt und aufgeschnitten war, den gelatinösen Körper auch herauszulösen suchte, schien es mir, als bilde letzterer selbst wieder einen geschlossenen Sack, der oben das Haar, und unten die eintretenden Gefässe und Nerven hindurchlässt, und wie gesagt, an seiner innern, dem Haare zngekehrten Fläche mit viel reichlichern Gefässen versehen war, als an der entgegengesetzten mit dem Balge zusammenhängenden Seite, welche kaum ein blassröthliches Ansehen hatte. - Dem zu Folge wäre also diese sulzartige Masse nichts anderes, als eine während des Lebens von der so eben beschriebenen innern Oberfläche des Balges secernirte Flüssigkeit, die nach dem Tode coagulirt, und sich als Sulze darstellt.

Anmerkung. Spätere Untersuchungen haben mich vollkommen in der Ansicht bestätigt, dass 1. dit zahlrcichen Fäden zwischen der innern Fläche des Balgs und dem conischen Körper wenig. stens in der Mehrzahl Gefässe seyen; 2. nur dann aus dern anfgeschnittenen Balge eine blutige Flüssigkeit sich ergiesse, wenn dabey einige dieser Fäden zerschnitten werden; 3 . diese Gefässe von der innern Wand des Balges ab. und zum conischen Körper hingehen, um dort die gelatinöse Masse abzusondern.

Schneidet man auch diese sulzartige Masse entzwey, oder streift man sie sanft mit einem f́einen Messer hinweg, so sieht man ihre innere Fläche mit einer feinen glatten Haut überzogen, die zugleich den Haarschaft unmittelbar umgibt, bis er die Oberhaut durchbohrt. (Gaultier, der den conischen Körper für eine Fortsetzung des Malpighischen Schleimnetzes hält, glaubt diesen feinen Ueberzug des in dem Balge steckenden Haares für eine Fortsetzung der Epidermis erklären zu können). - Wird auch dieses Häutchen entzwey geschnitten, so erscheint das eigentliche $\mathrm{Haar}$. Es beginnt mit einer stumpfen Spitze, die mir zwar getheilt zu seyn schien, an der ich jedoch stets vergebens jene 5-10 Fäden, von denen so viele Autoren reden, gesucht habe. Dieses nennt man die Wurzel oder Zwiebel des Haares. Sie ist immer von weicherer Consistenz als das Haar selbst, und nähert sich gewissermassen dem gallertartigen Körper, in welchem sie steckt; ferner ist sie hohl, und schliesst einen weichen, wahrscheinlich mit 
Gefässen und Nerven versehenen Körper in sich, den man den Ha arkern, Haarkeim zu nennen pllegt.

Das Haar im engern Sinne, oder der Haarschaft, Haarcylinder, steigt als eine mehr oder weniger runde Röhre gerade nach aufwärts, durchbohrt zuerst den Balg, dann die Leder - und endlich die Oberhaut, unter welcher letzterer es cine sehr kleine Strecke schief fortläuft, und kommt jetzt an der äusseren Oberfläche des Körpers zum Vorscheine, wo es nach Verschiedenheit der Umstäude eine verschiedene Gestalt, Richtung und Farbe u. s. w. erhält.

Der Schaft eines ausgebildeten vollkommenen Haares besteht aus einer doppelten Substanz; nämlich einer äussern, hornartigen, meist festen, und einer innern, gewöhnlich zelligen oder blätterigen Substanz. Erstere wird die Horn- oder Pinden-, letzterc, die (weil sie durchsichtig ist), auch den sogenannten Canal bildet, die M a rksubstanz genannt. Wir werden später auf die mancherley Verschiedenheiten sowohl der einen, als auch der anderen Substanz zurückkommen. Vergleiche Tab. V. Fig. 36-41.

Anmerkung. 1. Die Epidermis gihı bestimmt dem Haar keinen Ueberzug , sondern hefret sich nur an dasselbe an, wenn es aus dem Corion heraustritt, wie ich diess bey den Menschenhaaren ausführlich beweisen werde.

Anmerkung. 2. Die genannten Theile, aus welcher das ganze Haarge. bilde zusammen gesetzt ist, biethen natuirlich in den verschie. denen Thiergattungen auch grosse Verschiedenheiten dar, welche sich übrigens erst aus der spätern Betrachtung und Eintheilung der mancherley Haararten ergeben werden. Hier sey nur im Allgemeinen noch bemerkt, dass das, was ich oben mit dem Namen: Haarbalg belegte, und fortan belegen werde, nicht allein an Grösse und Gestalt, sondern auch an Consistenz seiner Substanz u. s. w. mächtig differire, und überhaupt nach dem Grade der nöthigen Feinheit von der derben Beschaffenheit des Horns bis zu der eines zarten serösen Säckchens vorkomme. - Was ferner die gelatinöse, pulpöse Masse, den sogenannten konischen Körper betrifft, so würde man sich sehr täuschen, wenn man ihn bey allen Haaren, noch mehr aber, wenn man ihn iiberall so ausgebildet z.u finden glaubte, als bey dem eben beschriebenen Tasthaar des Ochsen; indem es sogar Fălle gibt, wo er so zu sagen ganz zu fehlen scheint, wie z. B. in den Stachelhaaren; geschweige der mancherley Verschiedenheiten an Menge, Farbe, Durchsichtigkeit u. s. w. die sich in dieser Hinsicht bey verschiedenen Thie- 
ren aussprechen. In Bezug auf den Haarschaft wird aus dem Nach. folgenden zur Genüge einleuchten, dass gerade dieser Theil des Ilaars die meisten Abweichungen in Rücksicht auf Gestalt, Richtung, Weichbeit, Härte, Farbe u. s. wo darbicthe; und da ich in der unten folgenden Haupteintheilung des Haargebildes ohnehin wieder in die genauere Auseinandersetzung der anatomischen Beschaffenheit eines jeden einzelnen Haartheiles - also auch nothwendig des unter allen am meisten verschiedenen Haarschaftes - eingehen muss, so verspare ich mir hier jede genauere Beschreibung, als welche gewiss zu allgemein, und daher für specielle Fälle nicht wohl anwendbar ausfallen mïste.

§. 40 .

Gestalt der Thierhaare.

Die grosse Manichfaltigkeit, welche wir in allen Theilen der unendlichen Natur bewundern, spricht sich auch bey den Thierharen in Bezug auf ihre Gestalt dentlich aus. Dennoch finden wir, wenn wir das Ganze in seinen Theilen vergleichen, den Satz durch die Erfahrung bewährt, dass die runde Gestalt als allgemeiner Typus, als Normgestalt für das Haar angenommen werden müsse, an welche sich sodann die übrigen nach Massgabe der grössern oder geringern Aehnlichkeit anreihen lassen. So finden wir, um hier nur einige Beyspiele zu geben, rücksichtlich welcher wir übrigens auf die Abhandlung über die Haare der einzelnen Thierklassen verweissen, bey den Robben Borstenhaare, welche von zwey Seiten zusammengedrückt und platt sind, daher zwey Flächen und zwey Ränder haben, wovon der vordere dadurch, dass sich das Haar halb um seine Achse gedreht hat, in gleichen Entfernungen eingedrückt ist. Auch unterscheiden sich hier die kleinen, mehr nach hinten stehenden Borsten von den grös‘eren dadurch, dass sie ganz regelmässig spiralformig gedreht, und also nicht, wie die grösseren, abgeplattet sind. Bey-den Stachelhaaren, die im Ganzen allerdings, vorzüglich bey einer nur oberflächlichen Ansicht die runde Normgestalt haben, finden wir dennoch den Haarschaft oberflächlich durchaus fxin gerieft, oder mit nach der Länge hinlaufenden Rinnen, welchen dann wieder eben so viele parallel laufendeLeisten entsprechen, auf eine ïberraschend nette Art versehen. Iläufig ist die Gestalt der Körperhaare eyrund, oft cylindrisch, 
kreisrund, oft auch ganz platt. Die verschiedene Art von Umbeugung auf der einen oder andern Seite verändert natürlich ebenfalls die Gestalt, und so entsteht, wie z. B. beym Rebe, das wellenförmige IIaar. Noch auffallender beobachtet man dieses bey den Wollhaaren, die nicht allein abwechselnd links und rechts gebogen, sondern auch an den Biegungstellen regelmässig verdünnt sind. Bey den Seidenhaaren finden wir wieder die spiralförmige Gestalt vorwaltend. - Viel bedeutender ist aber die Abweichung von der Urform in den sogenannten schuppenförmigen Haaren, deren Name schon andeutet, dass sie so zu sagen den Uebergang zu den Schuppen machen, und deren Verschiedenheiten wir späterhin kennen lernen werden. Eben so werden wir sogar auf Haare kommen, die Widerhaken zu besitzen scheinen, wie beym Goldmaulwurf (Chrysochloris aurata), bey manchen Insectenhaaren, den Stacheln des Urson (Hy-strix dorsata) u. s. w. - Bey den Insecten finden wir pfriemen-pyramidenförmige, drey bis viereckige, und vorzüglich solche Haare, die mit wahren Fortsätzen, also mit Seiten - oder Randhaaren, versehen sind, woraus sich denn wieder eine grosse Manichfaltigkeit der Gestalt ergibt. Fanz ausgezeichnet ist auch die Gestalt der Haare an den Schmetterlingsflügeln, die häufig immer breiter werden, je weiter sie gegen die Spitze kommen, wo sie dann endlich in breite Blättchen oder Schüppchen übergehen.

Anmerkung. Wenn With of unter vielen Tausenden von Haaren, die er unter dem Microscope betrachtete, kaum vier sah, welche soit Knoten versehen waren, so kann man diess wohl mit Recht zum abnormen Zusiande reclinen.

§. 41 .

Weichheit und Härte, Glätte undRauhigkeit der Thierhate.

Auch in dieser Beziehung kommt der Beobachter wieder auf so zahlreiche Verschiedenheiten, dass es schwer ist, selbe durch allgemeine Andeutungen näher zu bestimmen. So finden wir unter den Säugethieren Haare von knorpelartiger Härte, wie z. B. die Stacheln, und wiewohl im geringeren Grade auch die Borsten. An die letzteren reilıen sich dann die gewöhnlichen Haare mit ihren mancherley Abstufungen an, und zuletzt 
schliesst die ganze Reihe die zarte Wolle und das feine Seidenhaar. Nur wenige Vögel besitzen jene steifen Borsten - und Ilornhaare, die wir viel häufiger bey den Säugethieren antreflen; und es scheint unentschieden, ob man das feine Gefieder, welches den Leib des zarten Jungen vor der Bildung der eigentlichen Federn bedeckt, zu den Haaren oder den letzteren zühlen soll. Die Fangarme der Cirripeden, welche von den neuesten Naturforschern gleichfalls als haararlige Verlängerungen bezeichnet werden, sprechen sich als blosse pyramidenförmige Fortsätze der Epidermis, welche zudem im Innern hohl zu seyn scheinen, durch besondere Weichleit vor allen Haaren der übrigen Thiere aus. Diesen zunächst stehen sodann in dieser Beziehung die Borsten der Anneliden, und bey den Crustaceen finden sich beyde Haararten vereiniget, oder besser gesagt, gleichzeitig vorhanden. Die Insecten haben gewöhnlich Haare von ausserordentlicher Weichheit; ferner haben sie Borsten und selbst Stacheln, so dass sie sich auch hierin durch das Haargebilde ganz besonders charakterisiren. Auffallend ist endlich der Bau der Arachniden durch die Anzahl und Stärke der einzelnen vorzüglich die Extremitäten besetzenden Haare und Borsten. - So ungefähr finden wir es in der Regel; es ist jedoch leicht begreiflich, dass die Härte und Weichheit des Haares noch überdiess von einer Menge zufälliger Einflüsse, als von der Lagerung, der Cultur der Haare, dem Klima, der Lebensart, selbst dem Geschlecht und Alter der Thiere abhängen, was ich jedoch hier bloss allgemein andeuten will, da dieselben Umstände theils später, theils bey den Menschenhaaren ausführlicher besprochen werden sollen. Die Glätte und Rauhigkeit der Thierhaare steht wohl meistens auch mit ihrer Feinheit und Härte in genauer Verbindung, obwohl wir auch hier wieder auf mancherley Ausnahmen stossen, indem manches Borstenhaar die gewöhnlichen Körperhaare an Glätte iibertrifft. Nebst den eigentlichen Stachelhaaren möchten wohl die Schuppenhaare in Bezug auf Rauhigkeit oben anstehen, so wie dagegen die äusserst feinen, seideglänzenden Haare mancher Schmetterlinge und einige Arten der Seidenhaare bey Sängethieren wohl alle übrigen Haare an Glätte übertreffen. Zwischen diesen beyden Extremen erblicken wir dann das ganze Heer der übrigen Thierhaare, in deren nähere Betrachtung wir uns jetzt nicht-weiter einlassen wollen. 


\section{Richtung der Thierhare.}

In Bezug auf die Richtung der Haare gilt bey den Thieren das Gesetz: dass sie fast immer abwärts hängen, und zivar so, dass eines immer das andere bedecke, damit auf diese Art die ganze Haut durch den haarigen Ueberzug vollkommen geschützt, und das Ablaufen der Feuchtigkeiten u. s. w. bestmöglichst befördert werde. Tysson hat sogar als ein Kennzeichen, das dem Menschen und einigen Affengattungen besonders eigen sey, das angegeben: das b beyder Haare auf den Schultern abwärts, und an den Armen a ufwärs gerichtet seyen. Indessen ist es doch eine ausgemachte Thatsache, dass z. B. die Haare des Faulthieres und Ameisenfressers an den vorderen Theilen des Leibes rückwärts, hingegen auf dem Kreuze und den Dünnungen vorwärts gerichtet sind. Ueberhaupt aber ist die Richtung der Haare unter sich je nach den verschiedenen Gegenden des Körpers, wo sie wachsen, wieder sehr verschieden, je nachdem es nämiich der besondere, nicht auf blossen Schutz vor Regen u. dgl. zu beziehende Zweck erheischt. So legen sich die Haare an den Extremitäten gewöhnlich rück-, ein- und etwas abwärts, während die Rücken- und Bauchhaare flach abwärts laufen. - Viele Thiere haben auf dem Rückgrath, d. i. längs der Rïickensäule stärkere, längere, mehr gerade rückwärts laufende und hervorragende Haare. Dagegen biethen die Haare am Kopfe und Halse wieder mancherley Richtungen dar. Manchmal laufen sie strahlenförmig auseinander, wie diess z. B. auf dem Scheitel jenes Affen der Fall ist, den $\mathrm{B}$ u f fo $\mathrm{n}$ eben desshalb auch die Chinesermütze nannte, weil er nämlich oben auf dem Kopfe lange Haare hat, die vom Centrum aus nach allen Punkten des Umkreises gerichtet sind, so dass sie gleichsam eine Haube machen, die einer chinesischen Plattmütze nicht unähnlich ist. - Hieher gehören denn auch noch die so verschiedenartigen Figuren, welche sich aus der besonderen Zusammenstellung und Richtung mehrerer Haare an einem und demselben Körpertheile bilden. Auf diese Art sehen wir Bärte, Zöpfe, Schwänz", Halsbinden, Nähte, Mähnen u, dgl. m. cntstehen. So gibt 
cs einen Aflen (Makak), der einen Zopf auf dem Haupte, einen Wanderu, der einen langen, geraden Bart bey übrigens schwarzen Haaren des Leibes hat, der das ganze Kinn sammt den Backen bedeckt, und ein wenig kraus ist. Jedermann kennt die Bocks - und Ziegenbärte. - Der Hirsch hat an beyden Seiten der Stirn das Haar in Büscheln, wie diess auf der Mitte der Stirne bey dem Pferde beobachtet wird. Beym Luchse steht ein Büschel Haar von den Spitzen der Ohren gerade aufivärts; und an der Spitze des Schwanzes vom Elephanten findet sich ein Büschel dicker borstenartiger Haare. Wer kennt nicht die Knebelbärte der Katzen und andrer Raubthiere? Und welche ausserordentliche Verschiedenheit bieten uns nicht die vielartigen Schwänze der Thiere dar? - Bey den Pferden, Hunden und andern Thieren stossen die Haare in entgegengesetzter Richtung an einander, und bilden Nähte (Suturae). - Das bisher Gesagte gilt fast ausschliesslich von den $\mathrm{S}$ ä u g et h i eren. Steigen wir wieder unsere Leiter herab, so bieten sich uns auch bey den Haaren der übrigen Thierklassen verschiedenartige Richtungen dar. So ist es gewiss merkwürdig, dass sich das Haargebilde da, wo es sich bey den $\mathrm{V} \ddot{g} \mathrm{geln}$ auf eine obwohl untergeordnete Art ausspricht, fasst durchgehends büschelförmig gestaltet, und dass die Haare der Cirripeden, Anneliden und Crustace en meist eine gerade Richtung behaupten, sich jedoch durch die ihnen eigends zukommende Beweglichkeit, und die daraus entspringende öftere Verändernng der Richtnng ganz besonders charakterisiren. Was sollen wir übrigens von dem räthselhaften Haarbüschel halten, welches aus einer eigenen $\mathrm{Ver}$ tiefung in der Schale der Füsse unsrer Flusskrebse hervorkommt, und sich dann an die entsprechende Kieme, gleichsam selbe umarmend, anlegt? - Welch bewunderungswerthen, so äusserst zierlichen Bau sehen wir nicht durch die verschiedeuartige Richtung der Insectenhaare hervorgebracht? Mau betrachte nur die ungeheure Anzahl von Raupen, welche Manichfaltigkeit, welche Nettigkeit und Eleganz in der Vertheilung und Richtung ihrer Haare? Ich will hier nur auf die, wie mit einem Pelz versehenen Bärenraupen, und auf die mit den oft wunderschönsten Büscheln versehenen sogenannten Borstenraupen aufmerksam machen. Es ist unmöglich, im Allgemeinen all' das Schöne und Bewundernswerthe hier anzuführen, was in dieser einzigen Beziehung nur das Heer der Schmetter- 
linge, der Zweyflügler u. a. m. dem aufmerksamen Auge darbiethet, und unwillkürlich fühlt man sich durch diese unbegreifliche Manichfaltigkeit in der Natur zur vollen Bewunderung des höchsten Schöpfers angezogen!

Ich habe bisher bloss von der Richtung der Haare in ihrer (resammtheit, nämlich als Decke des Körpers gehandelt, und es hleibt mir daher noch übrig, etwas Weniges über die Richtung der einzelnen Haare, in so fern sie nämlich gerade oder kraus, steif oder umgebogen sind zu bemerken. Ohne mich in die Ursachen dieser Eigenschaften weiter einzulassen, welche eigentlich bey den Menschenhaaren einer genauern Würdigung unterzogen werden sollen, will ich mich in Bezug auf das Gesagte nur auf Folgendes beschränken : die Rauhigkeit, Steifheit, Härte und das Gekraustseyn der Haare stehen zu einander in demselben wechselseitig gleichen Verhältnisse, wie die Weich-, Zart- und Feinheit mit dem Geradseyn der Haare. Denn es ist wirklich eine ausgemachte Thatsache, dass in der Regel cin Haar um so stärker, steifer und härter ist, je krauser es ist. Das Gegentheil gilt im Allgemeinen wohl auch von dem geraden, obgleich es viele Beyspiele von sehr rauhen und doch ganz geraden und andererseits von sehr feinen und doch krausen Haaren gibt. Wir werden uns also nicht wundern, dass wir die meisten krausen Haare bey jenen 'Thieren finden, die in der kalten Zone wild, und öfters in Mangel leben; da wir hingegen in dem gemässigten Himmelsstriche jenes feine, zarte, lange und gerade Haar unter den Thieren antreffen. Indessen gibt es auch hiervon wieder mancherley Ausnahmen, die dann ihre Erklärung in besondern gleichzeitigen Nebeneinflüssen finden können. Ueberhaupt sind krause Haare in dem Thier- und Pflanzenreich ungleich seltner, als beym Menschen, obgleich sie für alle Schafarten ein gemeinschaftliches Merkmal ausmachen. Ich werde spüterhin bey der Abhandlung über die Menschenhaare auch auf den Satz zurückkommen, dass das krause Haar ein Zeichen der körperlichen Stärke sey; hier bey den Thieren kann ich den Schluss nur dann als gültig betrachten, wenn dieses einzige Zeichen - das krause Haar - noch mit andern zusammentrifft, von denen man über ihr ursächliches Verhälıniss mit der Körperstärke nicht in Zweifel seyn kann; mit einem Worte: krause Haare an und für sich bezeichnen eben so wenig Stärke, als gerade Schwäche des Körpers ausdrücken; sonst müsste das Schaf den Löwen weit an Stärke 
ühertreflen, was doch offenibar eine absurde Behauptung wäre. -

\section{43 .}

Relative Menge, Länge und Kürze der Haare an verschiedenen Theilen des Körpers.

Bey den Sä ug e thi eren kann man wirklich als allgemeine Regel annehmen, dass immer jene Körperseite am behaartesten ist, welche vorzugsweise den verschiedenen Einflüssen der Witterung, äussern Beschädigungen u. s. w. entgegensteht. Dessbalb finden wir an der der Erde zugekehrten Körperhälfte im Allgemeinen nicht allein weichere, zartere, biegsamere, sondern auch kürzere und weniger Haare, als an dem Rücken, wo sie steifer, länger, dicker und zahlreicher sind. A ristoteles ${ }^{*}$ ) hat in dieser Hinsicht schon bemerkt, dass der Mensch weit mehr Haare auf dem Kopfe, aber an den übrigen Theilen weniger als die Thiere hat; ferner dass bey ihm mehr die untere Seite, bey jenen mehr die oberen Körpertheile bebaart sind. - Obgleich man aber den Thieren im Durchschnitte das Haupthaar im eigentlichen Sinne absprechen muss, so gibt es dagegen doch wieder einige, die ziemlich lange Kopfhaare haben, wie z. B. manche Affen. Ausser den Affen, den Elephanten, dem Strauss, dem Sagittarius und dem afrikanischen N!adenfresser (Crolophaga Ani) soll kein Thier an beyden Augenliedern Wimpern haben. Da diesen Vögeln auch die Nickhaut abgehen soll, so vermuthet Slaben, dass diese Augenliedhaare jene ersetzen **). Verschiedene Thiere, vorzüglich die Fleischfresser, tragen Knebel-, Schnauzbärte. Ueberhaupt finden sich mit einigen Ausnahmen, Haare an allen Oefinungen der Haut, z. B. am Maul, der Scham, am After, den Obren, Augen, der Nase etc. Dagegen fehlen sie da, wo das Gefülıl fein seyn muss: in der flachen Hand, den Lippen, der

*) Tract. de partibus lib. 2. cap. 14. 15. der Historia animalium.

**) Baster's zweyte Abhandlung von den Jecken der Haut bey den Thieren elc. in den Abhandlungen der Harlemer Gesellschaft 2. Bd. p. 309 . 
Eichel u. s. w. Obgleich übrigens die Zeugungstheile der Thiere, und namentlich der Säugethiere, keineswegs haarlos sind, so ist es doch eine allgemein bekannte Sache, dass die hier sich vorfindenden Haare sich durch besondere Feinheit auszeichnen. Auch das hat Aristoteles schon bemerkt, dass ausser dem Dasypus alle Thiere auf der hohlen Hand und im Plattuss keine Haare haben. Ersterer allein hat unter den Füssen, und innerhalb der Backen, der Mysticetus aber inı Munde statt der Zähne borstenähnliche Haare. Bey ma; chen 'Thieren ist ảer Schwanz sehr behaart, z. B. bey den Eichhörnchen, dem Dachse, Fuchse, Pferde; bey andern ist er wieder fast ganz kah̆l, z. B. bey einigen Mäusen. Bey Simia Maimon, wo er einem Schweinsschwanze ähnelt, ist er oben sehr wenig behaart, und an der untern Seite (wie diess bey den meisten Thieren eintrifft) fast nackt. Der Schwanz des. Tarsers ist nur an seiner Spitze sparsam mit Haaren besetzt, der des Phalangers ganz nackt. Bey manchen Thieren endigt er sich in einen Schopf, wie beym Löwen und dem Zebra. Aristoteles hat daher nicht ganz Recht, wenn er sagt: die Schwänze der Thiere seyen mehr oder weniger haarig, je nachdem es ihr Körper selbst ist. - Auch bey den Haaren der Füsse stossen wir auf grosse Verschiedenheiten, indem wieder einerseits manche Thiere so reichlich mit Haaren versehen sind, dass man die Füsse gar nicht sehen kann, wie die Bären, andern dagegen alle Haare an diesen 'Theilen fehlen z. B. den Fledermäusen. Endlich sind einige durchaus am ganzen Körper sehr stark behaart, wie die Bären, der Dachs, dessen Haare so lange sind, dass man die Ohren kaum sieht, und der Bauch die Erde zu berühren scheint; da hingegen wieder andere, z. B. der Elephant, das Gürtelthier, das Rhinoceros, das Nilpferd und überhaupt die Seesäugethière theils nur wenige Haare besitzen, theils alle entbehren. Wo die Haare durch ihr vereinzeltes Hervorkommen auf einem übrigens ganz nackten Orte, oder durch ihre Mlenge und Länge besonders in die Augen fallen, da entstehen dann die sogenannten $B$ är te, $Z$ öp f c, Schöpfe, Schwänze, Halsbinden, Mähnen, Nähte u. dgl., die natürlich den Thieren mitunter ein ganz eigenthümliches, so zu sagen charakteristiches Aussehen geben. - Es ist gewiss eine bemerkenswerthe Erscheinung, dass sich bey den Vögeln, mit Ausnahme des gleich in den ersten Tagen nach der Geburt zu beobachtenden, und späterhin durch die Federn ganz verdrängten Flaumes, das eigentliche Haargebilde nur nuch bey 
einigen Gattungen unter der Gestalt von Büscheln am Halse darstellet. - Die Haare der Mollusken, Cirripeden, Anneliden und Crustaceen geben ebenfalls durch ihre ganz besondere Zusammenstellung zu eigenen Benennungen Anlass. So werden wir weiter unten auf Kränze, R a ndhaare, Rückenhaare, Bündel, Schwanz- und Kopfstacheln u. s. w. stossen. Uebrigens ist zu bemerken, dass alle diese Thiere in Bezug auf die Menge und Länge ihrer Haare den Säugethieren, und auch den Insecten weit nachstehen, welch' letztere bey dem, dass es auch unter ihnen manche Familien gibt, die entweder ganz haarlos, oder nur sparsam mit Haaren bedeckt sind, dennoch eben so häufig eine ungeheure Menge, und in Bezug auf ihren kleinen Körper sehr lange Haare besitzen, so dass sie davon ganz rauh werden. Die Borsten-, Büschel- und Bärenraupen zeigen uns schon durch ihren Namen hinlänglich an, dass die verschiedenartige $\mathrm{Zu}$ sammenstellung ihrer Haare jener der Säugethiere manchmal sehr nahe kommt, und man kann wirklich mit Recht behaupten, das jene Benennungen auf die Haare keiner Thierklasse so gut passen, als gerade auf sie. - Uebrigens wissen wir, dass es ganze Klassen von Thieren - wie die Amphibien gibt, denen im strengen Sinne alle Haare fehlen. In dieser Hinsicht sagt Aristoteles: (histor. 1. 1. c. 6.) pilos habent, quae pedestrin eademque vivipara sunt; cortice integuntur, quae noiparn; squammas vero pisces habent.

\section{§. 44.}

Verschiedenheit der Thierhaare nach dem Geschlechte und dem Alter.

Dass sich die Haare auch nach dem Geschlechte der Thiere verschiedenartig verhalten, sehen wir bey manchen derselben auffallend bestätigt. So ist die $\mathbf{F}$ ar be der Haare bey den Männchen der meisten Thierklassen manichfaltiger, gesättigter, feuriger, glänzender und schürfer begränzt. Diess sieht man besonders bey den Insecten, namentlich den Schmetterlingen, ferner den Vö g el n, vorzüglich den Singvögeln. So ist z. B. Kopf und Hals beym Männchen der Ortolane olivengrün, und beym Weibchen mehr aschgrau. Etwas Aehnliches zeigt sich bey den Spechten, bey vielen Wasservögeln, 
und unter den Sumpfvögeln ist das Weibchen der Beccassinen viel heller und blasser gefärbt. Selır auffallend zeigt sich dieser Unterschied auch bey den Landvögeln, wie wir täglich an unserm Haushahn und Pfauen, Fasan, Birkhahn, Rebhuhn u. a. m. bemerken. Auch unter den Säugethieren erweist sich dieses Gesetz, besonders bey den wildlebenden. Ueberdiess spricht sich bey den Thieren wie beym Menschen die Regel aus, dass sich das männliche Geschlecht durch reichlichern, noch mehr aber durch einen stärkern Haarwuchs vor dem weiblichen Geschlechte auszeichnet: so hat der llengst eine weit stärkere Nähne, als der Wallach und die Stute; Ochsen, Widder und Schweine männlicher Art (Eber) sind mit steifern, stärkern, und man kann wohl auch sagen, häufigern Haaren versehen, als Kühe, Mlutterschafe und Mutterschweine. So sind viele männliche Vögel mit Federbüschen auf dem Kopfe geziert, welche entweder dem Weibchen ganz fehlen, oder wenigstens viel kleiner sind. Dasselbe zeigt sich auch bey den Schwanzfedern, z. B. bey der Gans, Coracias garrula, Phasianus argus u. a. m. Bekannt ist der längere und stärkere Bart der Böcke. - Endlich zeichnen sich die männlichen Thiere häufig durch ganz eigenthümliche, dem Weibchen ganz. mangelnde Haare aus. Der Löwinn so wie der weiblichen Phoca jubata fehlt die Mähne des Männchens $\mathrm{u}$. dgl. m. So hat auch der Haushahn besondere lange Schwungfedern an der Seite des Schwanzes; so ist dic Zeichnung, der Glanz und das Vermögen zur Aufrichtung der Schwanzfedern beym Truthahn und Pfauhahn viel ausgezeichneter, zum Theil auch ganz eigenthümlich; beym Birkhahn sind diese Federn bogenförmig gestellt, so dass sie dem Schwanze die Gestalt einer Lilie geben. Columbus cristatus hat einen von der Wange und Kehle herabhängenden Federkragen; Olis houbara einen IIalskragen von bunten Federn, nur der Truthahn am Halse ein Büschel steifer Haare, so wie die männliche Trappe einen bartähnlichen Streifen dünner Federn vom Schnabel bis unter die Augen. Unter den Säugethieren hat endlich auch nur der Steinbock (masc.) einen Bart.

Noch ungleich wichtiger und in die Augen fallender sind die Veränderungen der Haare, welche sie durch das Alter erleiden. Doch muss im Voraus bemerkt werden, dass auch diese Veränderungen beym Menschen weit merkwürdiger sind, als bey den Thieren. - Nach Heusinger's 
Beobachtungeu ist bey einem Kuh - Fötus über drey Monate noch keine Spur von Haaren zu sehen; bey einem viermonatlichen sah er kurze Barthaare, Augenbraunen und zwey Haare unter dem Auge; sonst war alles nackt. An einem KuhFötus von 25 Wochen sind die Barthaare, Augenwimpern und Augenbraunen lang und vollkommen ausgebildet; auch sieht man an den Spitzen der Ohrniuscheln, oberhalb der Klauenkränze, an der Schwanzspitze und in der Mitte der Hörnerstellen kleine Haare; eben so fangen sie auch an, über dem Kniegelenke hervorzubrechen. Oberhalb der bereits herausgetretenen Haare finden sich Hautstellen, wo man sie unter der Oberhaut liegen sieht; noch weiter nach dem Körper hin hat die Haut das Ansehen, als wäre sie von Rauch schwarz gefärbt, wogegen sie am Körper und an den obern Theilen der Extremitäten und dem Schädel noch ganz glatt und ungefärbt ist.

Bey der Geburt der Thiere sind die Haare an einigen Stellen des Körpers schon mehr oder weniger stark entwickelt, an andern hingegen kommen sie entweder erst in einer spätern Lebensperiode zum Vorschein, oder die bereits erschienenen verlängern sich dann mit dem fortschreitenden Wachsthum. Ersteres streitet mit der Angabe von Aristoteles: dass nur der Mensch pilos postgenitos, alle Thiere dagegen nur congenilos haben. Hiermit stimmt auch des trefllichen Glisson's Meinung *) ganz überein, nach welcher die ältern Böcke einen stärkern Bart, und der indische Hahn bey seiner Reife zur Zeugung um den vordern und hintern Theil des Halses einen gewissen Cirrum erhalte. - Bey den Säugethieren ist das erste Haar unvollkommen, und zum Theil ron kurzer Dauer; so hat z. B. der Igel bey der Geburt nur Spuren von Stacheln, die überdiess weich und den gewöhnlichen Haaren ähnlich sind. Auch der Seehund hat anfänglich bloss ein langes, weiches und gelblichgraues Haar, und wagt sich nicht eher, als bis er dieses abgeworfen hat, ins Wasser*). Nit dem herannahenden Alter der Thiere gehen auch ihre Haare jene eigenthümliche Metamorphose ein, die ich beym Menschen ausführlicher beschreiben werde: sie werden grau. Aristoteles sagt zwar, das sich diess weit seltner bey den Thieren, als beym Menschen ereigne, mit Ausnahme des Pfer-

*) Tractat. de partibus continentibus in genere Cap. 6-10.

**) B urdach's Physiologie als Erfahrungswissensch. 3. Bd.p. 136-13\%. 
des. Doch sehen wir diess durch die tägliche Erfahrung widerlegt, indem auch andre Thiere, z. B. schwarze Hunde u. s. w. manchmal recht auffallend grau werden. - Die meisten jungen Hasen haben auf dem Scheitel einige weisse Haare, der S tern genannt. Diess Merkmal vergeht aber gewöhnlich nach dem ersten Hären; bey einigen aber bleibt es bis ins hohe Alter.

Bemerkenswerth sind hier auch noch die auffallenden Veränderungen, welche in der Zeit der Fortpflanzung (Brunst) an dem Haargebilde der Thiere beobachtet werden, und welche nebst andern Erscheinungen den Satz bewahrheiten: dass die thierische Hautbildung in dieser Zeit ihren höchsten Gipfel erreicht. Es sind nämlich im Allgemeinen die Haare der Säugethiere in der Brunstzeit am glattesten, dichtesten und lebhaftesten gefärht, und das Gefieder der Vögel ist dazumal am weichsten, glänzendsten und buntesten. Insbesondere aber erscheinen manche eigenthümliche Bildungen der Männchen bloss während der Brunstzeit, und verschwinden nachher wieder. So wird bey den Vögeln das Männchen von Loxia ory $x$ in der Brunst hochroth und am Bauch und Kehle glänzend schwarz, während es nach derselben wie das Weibchen eine graulichbraune Farbe hat; die Ohrfedern des Fasans werden grün, und der Kampfluahn bekommt einen Federbusch am Hinterhaupt und Halse, den er nachher wieder verliert. - Auch die Farbe der Haare wird durch die in dieser Periode verstärkte Absonderung an den Zeugungstheilen bey manchen Thieren verändert; so färbt sich der Hirsch und Rehbock am Bauche schwarz, und die Haare am Zeugungsgliede des Damhirsches werden nicht allein immer scliwärzer, sondern auch grösser, je weiter die Brunstzeit vorrückt, so dass sie endlich eine Quaste bilden. Beym Fuchse färbt die zähe, angenehm riechende Feuchtigkeit, welche von einer Drüse am Zeugungsgliede ausgeschwitzt wird, die umstehenden Haare gelb u. dgl. m. -

Dagegen nehmen weibliche Thiere im höhern Alter nicht selten einen männlichen Typus an, der sich auch in den Haaren ausspricht. So bekommen weibliche Giraffen im Alter die männliche Farbe der Haare, Pferde die männliche Mähne, Enten die kurzen Schwungfedern des Männchens, Fasane den Glanz und die Lebhaftigkeit der Farbe ihrer Männchen. 
Eine der wichtigsten Erscheinungen an den Haaren der Thiere ist jene diesen eigene Metamorphose, vermög welcher sie gewissermassen auf dieselbe Art eine ganz neue Haardecke für den Körper, wie die Schlangen und andere Amphibien eine neue Haut erhalten. Man nennt diese Erscheinung bey den Säugethieren das Hären, bey den Vögeln aber insbesondere die Ma user. -

Ueber den eigenthümlichen Process, welcher zur Zeit des Härens in den zum Haar gehörigen Theilen vor sich geht, hat uns noch Niemand so klaren Aufschluss gegeben, als Herr Professor Heus inger*). Es ist zwar leicht möglich, dass meinen Nachforschungen über diesen Gegenstand in den ältern Schriften etwas entgangen ist; allein ich zweifle selbst in diesem Falle keineswegs, dass die uns von Heusinger kund gegebenen Erfahrungen immer das grösste Interesse und Lob verdienen, und da sie so ganz dem Gange der Natur gemäss zusammengestellt sind, so nehme ich keinen Anstand, das Wichtigste davon hier mitzutheilen. - Nachdem Herr Prof. Heus inger die anatomische Beschreibung aller zum Haar gehörigen Theile geendet hat, kommt er zur eigentlichen Entwickelungsgeschichte derselben. Um zu dem gewünschten Resultat zu gelangen, rupfie er einem Hunde täglich einige Tasthaare aus, und tödtete denselben nach dem Ausrupfen der letzten. Die Ergebnisse seiner alsdann gemachten Beobachtungen stelite er unter folgende sechs Punkte zusammen:

1) Gleich nach dem Ausrupfen zeigt sich ein Blutstropfen in der obern Oeffnung des Balges; öffnet man diesen letzteren 10-12 Stunden nach dem Ausrupfen der Haare, so findet man die fleischige Substanz am Haare angeschwollen und blutreich.

2) Drey Tage nach dem Ausrupfen findet man diese Substanz wieder ziemlich in ihrem gewöhnlichen Zustande (doch ist diese Zeit nicht immer gleich). In der Mitte derselben findet sich eine schwärzliche bröckliche Masse, die von dem Boden des Balges bis zur Mitte der fleischigen Substanz in die Höhe reicht.

3) Fünf Tage nach dem Ausrupfen zeigt sich bereits ein et-

*) Meckels Archiv für Physiologie 7. Bd. 4tes Heft. p. 555. 
was mehr als zwey Millimeter langes Haar in dem Balge, dessen Zwiebel dicht auf dem Boden des Balges liegt.

4) Nun dauerte es noch eine geraume Zeit, ehe das Haar auf die Oberfläche des Körpers gelangte; war es aber einmal ausgebrochen, so wuchs es schnell, und erreichte in drey Wochen seine naturgemässe Grösse.

5) Aber auch in der Zwiebel des Haares ergaben sich während dieses Processes eigenthümliche Veränderungen. Denn wenn ein Haar durch ein anderes ersetzt werden soll, so wird die Zwiebel ganz blass; bald darauf bildet sich neben ihr ein schwarzes Kügelchen, welches kurze Zeit nachher eine kleine Hervorragung zeigt, die sich sodann schnell in den Haarcylinder verwandelt. Dieses neue Haar wächst dicht auf dem alten liegend, kommt ganz dicht neben diesem nach aussen zum Vorscheine; aber man unterscheidet es ganz leicht durch seine viel grössere Dünne, und dunklere Farbe.

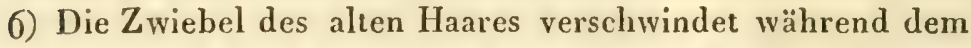
ganz, und bald darauf auch der untere Theil des Haares selbst immer mehr; ist es bis an die äussere Oeffnung des Balges geschwunden, so fällt dann der äussere Rest des Haares ab, doch erst, wenn ảas neue Haar seine gehörige Länge und Stärke hat. -

Die Regeneration der übrigen Körperhaare geschieht ganz auf dieselbe Art, wie ihre erste Bildung im Foetus, und wie diess so eben von den Barthaaren des IIundes gezeigt wurde. Man kann diess im Frühjahr bey jedem härenden Thiere beobachten. Gerade die Stellen, an denen sich die Haare im Foetus zuerst bilden, fangen in der Regel auch zuerst an sich zu regeneriren: der Schwanz, das Kreuz, die Gegend um den Mund und besonders die Stellen oberhalb der Nägel. Sollen demnach an einer Stelle die Haare gewechselt werden, so setzen sich nach Heusinger neben den ganz blassen, fast verschwundenen Zwiebeln der alten Haare kleine Pigmentkügelchen in der Lederhaut ab, bald darauf sieht man diese aus einer äusseren und inneren Substanz gebildet, sie werden grösser, und es verlängert sich die äussere Substanz in den Haarcylinder, der unter die Oberhaut gelangt, hier eine Zeitlang liegen bleibt, diese endlich durchbricht, und nach aussen erscheint, während die alten Haare ausfallen. - 
Uebrigens ist die Zwischenzeit von einer Härung auf die andere nicht bey allen Thieren dieselbe. So ist z. B. das Kamehl mit seinen feinen Haaren alle Jahr in weniger als drey Tagen einer allgemeinen vollkommenen Härung unterworfen, sn dass es um diese Zeit ganz kahl aussieht, und mit einem Kleister überschmiert werden muss, damit seine Haut gegen die Stiche der Insecten geschützt werde. Bey andern Thieren geschieht das Hären bald früher, bald später, und selten allgemein, sondern nur stellenweise.

Beydem Ma us er n der Vögel löst sich die Oberhaut an den Füssen, dem Schnabel und an andern unbefiederten Stelien in Form von Platten, an den befiederten Stellen aber unter der Form von Kleye ab. Auch hier sind beym Abfallen der alten meist schon die Keime der neuen Federn vorhanden. In beyden Fällen aber, d. h. sowohl beym Hären als bey der Mause entstelit ein Jucken in der Haut, wodurch das Thier aufgefordert wird, dem Ausfallen der Haare und Federn in etwas nachzuhelfen. Diess geschieht bey den Säugethieren durch Kratzen, Reiben an Bäumen und andern festen Körpern, Walzen auf dem Boden, Ablecken mit der eigenen Zunge, wo dann nicht selten die Haare auch verschluckt werden u. s. w. Die Vögel kratzen sich theils mit dem Schnabel und den Füssen, theils rütteln sie mit dem Schnabel die Federn auf, indem sie damit in demselben hin und her fahren. - Uebrigens ist während dieser beyderseitigen wichtigen Veränderung nicht allein das Leben überhaupt, sondern namentlich die animale Sphäre desselben bedeutend aliẹnirt und herabgesetzt. So bedarf das Hausvieh bekanntlich während dieser Y'eriode einer sorgsamern Pflege, und bessern Fütterung; die Vögel, welche ïberhaupt in der Nauser still und traurig werden, müssen wärmer gehalten, und ebenfalls, vorzüglich gegen das Ende der Periode, reichlicher gefüttert werden. Solche, bey denen die Mauser schnell vorüber geht, wie z. B. wilde Gänse und Enten, können eine Zeit lang gar nicht fliegen, was bey andern, die langsamer, oder zweymal im Jahre mausern, darum nicht der Fall ist, weil die Federn an verschiedenen Stellen nur nach und nach, und die einander entsprechenden Federn beyder Seiten gleichzeitig ausfallen*). Hieraus ergibt sich also, dass Burdach den

*) Eurdach's Physiologie als Erfahrungswissenschaft 3ter Bd. p. 524 526. 
Process der Häutung (wozu denn auch das Hären und Mausern gehört), recht treffend eine wiederhohlte Enthüllungr des Thieres nennt, wo die Oberbaut sammt ihren Verlängerungen mit den Eyhüllen, und das Thier mit einem Neugebornen; die Frühlingsmauser der Vögel aber und dic Erlangnng eines neuen Geweihes mit einer neuen Pubertät zu vergleichen, und die ganze periodische Regeneration eine Verjüngung zu nennen ist *).

Was nun noch die $\mathrm{Z}$ eit dieser Regeneration betriff, so beginnt letztere meist erst nach Vollziehung des Zeugungsgeschäftes. So geschieht das Wechseln der Haare bey den Säugethieren mehr oder weniger deutlich im Herbste, im Frühling aber vor demselben, gleichsam als wenn dieser Process zur neuen Vollziehung des Zeugungsgeschäftes vorbereiten sollte. So bekommen die Hirsche nach der Brunst zuerst das Winterhaar, dann wechseln sie das Geweih, welches sich jedoch erst nach dem Erscheinen des Sommerhaars vollkommen ausbildet. Alle Vögel mausern sich im Herbste nach vóllendeter Ausbrütung und Erzichung der Jungen, und zwar die mcisten im Julius und August, einige im September, und noch andere, wie z. B. die Wildenten erst im December. - Indessen haben die äussern Verhältnisse, namentlich die Jomesticitäı der Thicre auf diesen periodischen Haarwechsel grossen Einfluss. So erscheint das Häreu bey unsern Hausthieren, sobald sie durch mehrere Generationen ihrer ursprünglichen Verhältnisse entwöhnt worden, nicht mehr so regelmässig; während dagegen andere Thiere, die man gerade zu zähmen anfängt, in der warmen Stube sich zu derselben Zeit hären, und ihre larbe wechseln, wie wenn sie noch im Freyen lebten. Dasselbe gilt auch rücksichtlich der Mauser bey Vögeln, die man aus einer kalten oder warmen Zone zu uns bringt; so wie auch nach Naumann's Beobachtung männliche Singvögel, die man vom Frühjahre an in einem dunkeln Orte hält, bey der nächsten Mauser ihr volles Gefieder nicht wieder bekommen, und späterhin ganz kahl werden.

A nmerkung. Es ist bemerkenswerth, dass so wie bey dem Zahne die Krone, beym Haare die Spitze zuerst, die Wurzel aber zuletzt gebildet werde. Daher findet man oft noch nicht ganz ausgewachsene Haare ohne Wurzel. Ist die Wurzel aber schon voin Anfange

*) Burdach ebendaselbst p. 528. 
der Haarbildung sehr gross urid breit, dann ist sio auch sehr weich, und verlängert sich in den Haarschaft.

(Vergleiche hiemit 'Tab. V. Fig. 42-45.)

\section{45.}

Einfluss des.Klima und der Jahreszeit auf die Hàấre der Thiere.

Auffallend ist der Einfluss, welchen das $\mathrm{Kl}$ im a auf die Beschaffenheit der Haare in mehr als einer Hinsicht hat. Es zeigt sich diess sowohl bey Thieren, die in einem gewissen Klima geboren sind, und fortwährend in demselben lebcn, als auch bey solchen, welche erst in dasselbe wenigstens durch einige Zeit hindurch versetzt wurden. - So ist im kalten Norden das Haar dick und rauh, im warmen Süden schöner und seidenartiger; obgleich auch diess, wie wir gleich selyen, werden, seine Einschiränkung leidet. Das nordische Schaf hat spröde, und sehr grobe das spanis he und persische zwar sehr spröde, aber zugleich ungemein feine Wolle. Buffon sagt: „das wilde Schaf und jenes der sebr heissen und kalten Länder hat keine Wolle, sondern Haare; das grosse Schaf am Senegal und in Indien ist ohne Wolle, und hat ebenfalls nur ein kürzeres oder längeres Haar, das nach Verhältniss der Hitze des Klima's mehr oder weniger spröde ist. Ein sehr heisser Himmelsstrich scheint daher die Sprödigkeit der Haare zu befördern. Es zeigt sich diess am besten dadurch, das die Wolle der spanischen und persischen Schafe, wenn diese, in sehr heisse Länder versetzt werden, in eine ziènilich spröde verwandelt wird." - Auch bey unseru Schafen ist die Wolle kein wesentlicher Charakter, sondern hängt grösstentheils von dem gemässigten Himmelsstriche $a b$, indem dieselben Schafe in heissen Ländern nur Haare haben, obgleich ilıre Wolle bey uns nichts weniger als haarartig ist. Ueberhaupt zeigt sich die Wirkung des Klima's auf die Haare am auffallendsten bey den Hausthieren. Im Norden werden ihre Haare lang und steif, z. B. beym sibirischen Hunde; in dem spanischen und syrischen Klima werden sie, wie schon gesagt fein, seidenähnlich; wie wir diess bey den Merinos von Spanien, den Ziegen von Syrien, den Katzen und Kaninchen von Angora, den Jilaltheserhïndchen u. a. m. sehen. In sehr warmen Ländern werden sie dünne, oder gehen ganz in Verlust, wie diess-der guineische 
Hund (den man fälschlich den türkischen nennt), die afrikanischen Schafe, ja selbst schon die italienischen Schweine u. dgl. beweisen. Im kalten Norden werden bey manchen Thieren die Haare auch fein, aber zugleich dicht, nicht spröde, z. B. beym Hermelin, den Füchsen, Zibelinen, Hasen, Bären u. s. w. Noch muss ein Unterschied gemacht werden zwischen dem Einfluss eines sehr warmen und eines sehr milden Klima's. So haben die Ziegen unter sehr mildem Himmelsstriche nicht so sehr Haare als vielmehr Wolle, denn das Haar der angorischen Ziege ist schöner und feiner, als die Wolle unserer Schafe. Die spanischen Katzen haben rothe, schwarze und weisse, aber durchaus sehr feine Haare; die Schöpsen, Ziegen, Hunde und Kaninchen haben in Spanien und Syrien die schönste Wolle, die schönsten und längsten Haare, die angenehmsten und manichfaltigsten Farben; dagegen haben alle Pferde aus den morgenländischen und mittägigen Gegenden: die türkischen, arabischen, persischen, und die Pferde aus der Berberey weit struppichtere und kürzere Haare, als die andern.

Im Allgemeinen stehen die Thiere warmer Zonen an Menge der Haare jenen, die in kältern Klimaten zu leben gewohnt und genöthiget sind, weit nach. Diess sehen wir an den Bären, Füchsen, Dachsen, Eichhörnchen u. a. m. im Gegensatze z.u dem Elephanten, dem Gürtelthier, Rhinoceros u. dgl. Selbst unsere Hunde sollen in warmen Gegenden ganz kahl werden. So erzählt uns schon Adrianus Spigelius *), dass man aus Indien eine Art Hunde gebrach habe, die ganz haarlos waren, das Kinn ausgenommen, und fügt hinzu: dass der sehr gemässigte llimmelsstrich und die seltene Trübung des Himmels durch Wolken die Haare bey diesen Thieren entbehrlick mache. Aus derselben Ursache glanbt er auch, dass die Schweine in Italien weniger Borsten haben, als die in Deutschland und den Niederlanden. Von Island dagegen sagt er: dass die llaare der dortigen Hunde so lang sind, dass sie den Löwenmähneu gleichen. -

Im Allgemeinen ist das Winterhaar im Vergleich zu dem Sommerhaar um so mehr verschieden und wärmer, je kälter das Klima ist, und in ganz warmen Ländern verändert sich das Haak gar nicht. So ist das Winterhaar unserer Pferde vom Sommerhaar nur wenig verschieden, während es in Norwegen sehr

*) De humani corporis fabrica 1545. 
lang und zottig wird. Wärmer wird es dadurch, dass zu den Sommerhaaren noch neue hinzukommen, welche theils länger, dichter und starrer, theils, wie z. B. beym Bisamochsen, weicher, kürzer und krauser werden. - Nach der kürzern oder längern Dauer des Winters ist auch die Dauer des Winterhaars kürzer oder länger. So dauert es bey unsern Alpenhasen $6-7$, in Norwegen 8-9, in Lappland 10 Monate, und in Grönland das ganze Jahr hindurch. - Doch erscheint es viel früher, als die Kälte eintritt, denn unsere Alpenhasen und Schneehühner erhalten es schon im October, und ihr Sommerhaar schon im Nlärz. Daher sagen die Jäger einen harten Winter vorher, wenn das Wildpret eine ungewöhnlich dicke Haardecke bekommt.

Noch auffallender erscheint der Einfluss des Klima auf die Farbe der Haare bey einer und derselben Thiergattung, je nachdem sie unter einem kalten, gemässigten oder heissen Himmelsstriche lebt. So wissen wir von dem Hermelin, dem Eichhörnchen, dem Bären, Fuchsen, Hasen, dass sie im hohen Norden theils schneeweiss, theils, wie z. B. das Eichhörnchen, wenigstens grau gefärbt, während sie bey uns, in dem gemässigten Klima von gelblichbrauner, schwarzgrauer oder rother Farbe sind.

Selbst die verschiedenen Jahreszeiten kündigen sich durch offenbare Veränderungen an den IIaaren mancher Thiere an. So ist es eine allgemein bekannte Thatsache, dass die eben genannten Thiere im strengen Winter in den hohen Alpen die Farbe ihrer Haare gerade so ändern, wie ich diess so eben von ihnen, in den hohen Norden versetzt, angegeben habe, und dass sie im Sommer ihre vorige Farbe wieder erhalten *). - Bey andern Thieren werden die ohnehin hellen Farben im Winter noch heller oder bleicher; so verändert sich das dunkelbraune bey Rennthieren und Rehen in grau; das schwarzbraune des Elenns in hellbraun mit grau gemischt; das röthlichbraune des Hirsches in graubraun. - Degegen gibt es auch Thiere, bey welchen die hellern Farben im Winter dunkler werden, diess sehen wir bey Flussottern, Steinmardern, Steinböcken, Damhirschen, beym Iltis, grossen Wiesel u. m. a. Ich kann nicht entscheiden, ob Dr. Daniel J a cob

*) Lep us apud Suecos acstale cincreus, hieme semper albus (Linné. Fauna suecica p. 8). 
Wagner's*) Behauptung: „dass bey den weissen Hasen die Hare bloss an den Spitzen der Ohren, bey den Murmelthieren die Spitze des Schwanzes, bey den Schneehühnern bloss die beyden äussersten Schwungedern mitten im Winter schwarz würden" wahr sey. - Auch auf die Farbe der Federn bey Vögeln haben die Jahrszeiten einen mächtigen Einfluss. Ein starker Winter gibt den Vögeln, die einfärbig waren, verschiedenfarbiges Gefieder; einige Federn werden mehr oder weniger schwarz, und gehen ins Weisse über, wie diess beym Raben, Sperling und den Tauben zu sehen ist. Jas Schneehuhn, die Slerna caspia, Limosa melanura und limosa, so wie mehrere andere Vögel ändern ihre braune, graue oder schwarze Farbe im Winter in die weisse um. Aber kein weisser Vogel wird nach dem Ausspruch des Aristoteles schwarz.

\section{§. 46 .}

Veränderungen, welche die llare durch die Lebensart der Thiere erleiden.

Welche Veränderungen die verschiedene Lebensart der Thiere in dem Colorit ihrer Haare hervorbringen, wird sogleich bey den allgemeinen Beobachtungen über ihre Farbe näher angegeben werden. Aber abgesehen davon hat die Lebensart der Thiere einen unverkennbaren Einfluss auf fast alle übrigen Eigenschafien ihrer Haare. Wer weiss nicht, dass wilde Thiere sich in ibrem ganzen Aeusseren von den zahmen unterscheiden? Und sollten daran die Haare keinen Antheil nehmen, sie, die gerade unter allen Organen des Körpers jenen gewaltigen und manichfachen äussern Einwirkungen am meisten ausgesetzt sind? - Wir sehen daher, dass dic Haare im Allgemeinen um so zarter, feiner, um so weicher und länger sind, je weniger das Thier der rauhen Witterung Preis gegeben, und je mehr es, wie fast alle unsere Hausthiere gegen Kälte und Nässe geschützt ist. Wie sehr unterscheidet sich das Haar eines von seiner Dame leider of mehr als ihr eigenes Kind geliebtes, und eben desshalb auch ver-

*) Acta acad. cacs. L c o pold. Carol. n. c. 'l'um. XIX. 
weichlichtes Schoosshündchens von dem Zottenpelz eines Wolfs - und Schäferhundes? Wie himmelweit differirt ein Polarhund von einem sogenannten guineischen? Während letzterer ganz nackt ist, schützt jenen sein langes, dichtes und dickes Haar vor den Stürmen seines rauhen Klima's, denen er fortwährend ausgesetzt ist. Ein ähnliches Verhältniss liess sich wohl auch bey der Katze, dem Pferde, dem Rindvich, kurz bey allen unseren Hausthieren, ja sogar bey dem Geflügel, im Vergleich zu ihrem Naturzustand, nachweisen. - Um hier nur etwas von dem Unterschied der Borsten des wilden von denen des zahmen Schweines zu sagen (worauf ich späterhin ausführlicher zurückkommen werde), führe ich an, dass die wilden Schweine zwischen ihren Borsten noch ein kürzeres sehr biegsames, und nach Verschiedenheit der Theile, an denen sie wachsen, oder des Alters der Thiere bald gelbliches, bald aschgraues, ja selbst schwärzliches, sehr weiches, und beynahe wie Wolle krauses Haar haben, welches den siam'schen und unseren zahmen Schweinen gänzlich mangelt.

Auch das Element, in welchem sich die Thiere melir oder weniger aufzuhalten pflegen, spricht sich in der Form und Bildung ihrer Haare aus. So haben z. B. die Wasserhunde viel dichtere und dickere Haare, als die andern. Die Mäuse, welche sich in Scheunen aufhalten, sind mehr aschgrau gefärbt, als solche, die sich in Häusern finden lassen. Der Landbär hat längere, feinere, geradere und dichtere Haare, als der Eisbär und Waschbär; Thiere, welche ihre längste Zei in finstern und unterirdischen Ilöhlungen zuzubringen genuthiget sind, sind auch meist kurz und feinhaariger, als solche, die frey in der Natur herumspringen. Einen deutlichen Beleg dafür haben wir an den Haaren der Haus - und Feldmaus. Wie auffallend unterscheiden sich die Haare eines Pudels und eines sogenannten Pinschers, dem keine Witterung zu seinct: Excursionen zu schlecht ist, von denen eines Mops oder Bologneserhändchens, das nur bey der schönsten Tageszeit seiu Lager von Eiderdunen verlässt, um mit seiner Herrinn eine kleine Spazierfahrt zu machen?! So kannte ich einen von $\mathrm{Na}$ tur schön gebauten, nnd mit herrlichen Gaben ausgestatteten Bastard von einem Mopse und einer Jagdhündinn, der, obgleich er, wie gesagı, eine sehr zarte Haut, und ganz feinco Haar in seiner Jugend hatte, dennoch nit der Zeit das rauheste 
struppichste Fell bekam, das ich je an einem solchen Thiere bemerkt habe, und warum? weil dieser Hund mit Hintansetzung aller Leckerbissen der feinern Lebensart unserer Stubenhunde, sein einziges Vergnügen in der freyen Natur fand, manchınal ganze Wochen nicht zu Hause kam, und um nur seinen Hang nach Freyheit und Begattung nach Wunsch zu befriedigen, allem Ungestüm der Witterung, ja manchmal dem nagendsten Hunger trotzte, und jede noch so gut zubereitete Speise verachtete, wenn sie seiner nur an rohe Fleischnahrung gewöhnten Nase durch fremdartige Zusätze nicht zusagte. -

Gewiss ist auch die $\mathrm{Nahrungswe}$ ise der verschiedenen Thiere zu berücksichtigen, wenn von der verschiedenen Beschaffenheit der Haare die Rede ist. Der vortreffliche Glisson*) gibt unter den Ursachen des Abfallens der Haare unter andern auch den Mangel an Nahrung an, indem er sagt: Diess tritt besonders bey den Thieren im Winter ein, und ist wahrscheinlich eine Hauptursache, dass die Haare am kommenden Frühjahre, wo alles neu gestärkt ist, ausfallen. Aristoteles sagt schon, dass eine reichliche Nahrung das zartere Haar stärkt, und das steife erweicht. - Aus demselben Grunde mag es zum Theil herrühren, dass die wilden - vor allem aber die Raubthiere, die doch manchmal Mangel an Nahrung leiden, auch steifere Haare bekommen. - Wirklich scheint auch bey den Thieren die Qualität der Speisen die Eigenschaften ihrer Haare zu modificiren. So mögen gerade die wilden Thiere, da sie von einer viel roheren Nahrung leben, eben desshalb auch gröbere, steifere Haare bekommen, als unsere Hausthiere, die wir nach und nach durch Verzärtelung unserem verfeinerten Geschmack in Auswahl der Speisen nichts nachgeben sehen. - Von der wirklich sonderbaren Wirkung des Wassers auf die Haare der Thiere fand ich nur bey $\mathrm{Ari-}$ stoteles**) einige Bemerkungen: "Das Wasser, so sagt er, hat Einfluss auf die Farbe der Haare einiger Thiere. So nannte

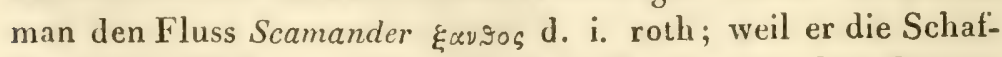
heerden roth fïrbte. Vorzüglich soll sich diess bey bunten Farben gezeigt haben. - Ja selbst die Temperatur des Wasscrs macht hierin eine verschiedene Wirkung: heisses Wasser

\footnotetext{
*) A. a. 0 .

*) Hist, lib, III, Cap. 12.
} 
macht weisse, kaltes schwarze Ilaare. An einem andern Orte*) sagt er hierüber: "Der Einfluss des Wassers auf die Farbe der Haare erstreckt sich sogar auf dic Kleinen. Ich habe beobachtet, dass manchmal schwarze Jungen von weissen Heerden gezeugt werden, wenn diese von jenem Wasser getrunken hatten. Das Wasser des Psychrus in Assyrien, in der Umgegend von Antandros, bildet zwey Flüsse, wovon der eine die Heerden weiss, der andere schwarz macht. Der Scamander macht sie

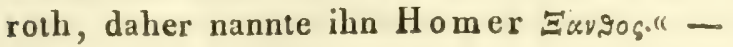

\section{47.}

Farbe der Thierhaare.

Was die F a r be der Thierhaare betrifft, so will ich hier gleichfalls nur einige allgemeine naturhistorische Bemerkungen machen, indem ich in jeder übrigen Beziehung auf jenen Paragraph verweise, wo ich ausführlich von der Farbe der Menschenhaare handle.

Unter allen Thieren stehen in Bezug auf Schönheit, Manichfaltigkeit und Zartheit des Colorits ihrer äussern Bedeckungen unstreitig die Vögel oben an. Einen prachtvollern Schmuck konnte ihnen der Schöpfer nicht geben. Nichtsdestoweniger biethet uns auch das übrige Thierreich noch eine grosse Manichfaltigkeit der Haarfarben dar. - Ueberhaupt scheint der Satz richtig zu seyn, dass die Farbe der Haare um so bunter und lebbafter sey, je näher die Thiere der heissen Zone leben, und je mehr sie schon zu Hausthieren umgeschaffen worden sind. Denn wenn gleich der heisse Süden nicht vorzugsweise schwarzgefärbte Thiere hervorbringt, so findet doch bey den Thieren etwas Aehnliches, wie beym Menschen statt : dem Norden gehören die einfach weissen und lichten Haare; dem Süden die braunen und dunkelgefärbten zı, wie ich diess beym Einfluss des Klima's auf die Beschaffenheit der Haare schon angezeigt habe. - In Bezug auf den Unterschied zwischen wilden und zahmen Thieren sagt $B$ uffon, dass die Lage, Grösse und Figur der Flecken sowohl, als die Farben bey jedem Hausthier insbesondere mehr oder weniger manichfaltig sind. - Uebrigens lassen sich die verschiedenartigen Far-

*) Gen, lib, V. Cap, 6 . 
ben der Thierhaare nicht leicht in einige Ordnung bringen, denn die Natur scheint hier absichtlich die grösste Manichfaltigkeit vor Augen gehabt zu haben. - Aber nebst dem Himmelsstrich hat auch die Lebensart, und die verschiedene Vermischung der Raçen den grössten Einfluss auf die Farbe der Haare. Denn ganz anders werden sich die Haare eines und desselben Thieres färben, wenn es beständig allen Witterungsveränderungen Preis gegeben ist, anders wieder dann, wenn es als Hausthier davor gesciützt ist. - Nach Buffon's Angabe ist das Gelbrothe, Dunkelbraune, kurz das Rothfahle die gemeinste, so zu sagen die natürlichste Farbe der wilden Thiere, und die braune, verschiedenartig gemischte und manichfach schattirte Farbe meistens bey den Pferden und andern Hausthieren zu finden. Die wilde Katze hat viel gröbere Farben, als die zahme; dasselbe gilt vom Auerochsen, Büffel, und unserm zahmen Rindvieh. Unter allen Säugethieren scheint indess der llund die verschiedenfarbigsten Haare zu besitzen. Zur Bezeichnung gewisser Haarfarben bedient sich auch der Sprachgebrauch eigener Ausdrücke; so sagt man z. B. von dem Tiger und dem Zebra, dass sie gestreift; vom Leopard, Jaguar und Panther, dass sie gefleckt sind. Die Genette und den Serval heisst man punktirt, die Hyäne und den Ozelot nennt man gefleckt und gestreift. - Es gibt unter den Thieren einige Arten, die alle einerley Farbe haben, wie z. B. die Löwen, die alle rothfahl sind; bey vielen andern ist diess nicht der Fall, z. B. beym Rindvieh, den Hunden; Ziegen etc.

Noch ist zu bemerken, dass die Farbe der Haare auch nach den Gegenden des Körpers verschieden sey; und hier gilt das Gesetz: dass die Haare an bedeckten, oder den äussern Einflüssen weniger ausgesetzten Theilen fast immer heller gefärbt sind, als an den entgegengesetzten. Den Beleg dafür liefern die Rücken - und Bauchhaare. Die Haare des Agouti sind ausserordentlich manichfaltig gefärbt: denn am Unterkinnbacken ist das Haar gelb, unter den Beinen und auf den Füssen schwarz; an beyden Seiten des Hinterns schön hochgelb, auf dem übrigen Leibe aschgrau, und an der Wurzel der Haare braun; unter dem aschgrauen ist das Ilaar schwarz oder schwärzlichbraun, ïber den Schwänzen gelb oder pomeranzenfarben, und an den Spitzen immer schwarz. So sehen wir also schon hier ein Beyspiel, dass es bey den Thieren ara nichte Ungewöhnliches ist, dass die einzclncu Ilaare, je 
nachdem man sie näher oder entfernter von der Wurzel betrachtet, auch ein verschiedenartiges Colorit halsen. Aehnliche Beyspiele liefern uns die langeu Haare des Bibers. Diese sind nämlich, auf $2 / 3$ Länge von der Wurzel entfernt, aschfarbig, übrigens braun, roth, durchscheinend und glänzend, so dass sie verschiedene Farben spielen. - Indem sich nun bey solchen Verhältnissen die gleichfarbigen Stücke der einzelnen Haare in einer gewissen regelmässigen Ordnung auf- und aneinanderlegen, entsteht das gestreifte, gefleckte und gebänderte Aussehen. - Häufig unterscheidet man sogar eine doppelte, ja dreyfache Lage von Haaren aufeinander. So hat der Wolf zuerst starke, harte und gelblichbraune Haare; unter diesen befinden sich aber kürzere, weichere und aschgrau gefärbte. Die Genette ist schwarz gefleckt auf einem Grunde, in dem das Graue und Feuerrothe abwechselt. Das Zibeththier hat kurze und dichte Haare, die eine Art rom aschfarbigem Wollhaar, welches noch viel kürzer ist, bedeckt, und verschiedenartig weiss-grau, braun und schwarz durcheinander gefleckt ist. Wenn man die rothfahlen langen IIaare des Tigers auseinanderbiegt, so sieht man deutlich, dass von ihnen andere Haare von einer hellern, falben Farbe bedeckt werden, unter denen man wieder andere findet, die weisslicht sind, und zarte gelbliche Sprenkel haben. Dasselise kann man auch bey den meisten llausthieren beobachten.

Der kleinste Theil der hehaarten Thiere bringt die bleibende Farbe der Haare gleich mit auf die Welt. So wechselt der männliche Vogel, wie wir gesehen haben, erst später die Farbe des Gefieders, und mehrere Säugethiere erhalten die bleibende Farbe ibrer Haare erst nach einem halben oder ganzen Jahre. In der Regel wird zwar die Farbe etwas dunkler, als sie bey der Geburt war, doch gibt es auch Vögel und Säugethiere, deren IIaare Anfangs dunkel sind, und sich erst späterhin (doch nieht erst im Alter) bleichen; so geht die Farbe bey mehrern Falken aus röthlichbraun in aschgrau, bey Cathartes perenopterus aus dunkelbraun in schmutziggelb, und endlich in weiss über. Die Füchse haben bey der Geburt eine dunkelaschgraue Farbe, die späterhin braunroth wird; so kommen viele Mäuse, und so auch die Fledermaus und Fischotter fast schwarz auf die Welt, und ihre Haare färben sich erst allmälig heller. - 
Anmerkung. 1. Schon II omer legte denjenigen Thieren, welche eine

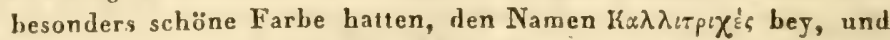
wir heissen heut zu Tag den Affen Mangabay wegen seines weis. sen Haarkragens um den Hals $\mathbf{S}$ im ia Callitrix.

Anmerkung. 2. Man hat vielfälig behauptet, die Farbe der Haare stünde rait jener der Haut in geradem Verhältniss. Indess läugnet schon Aristoteles dieses Factum bey Thieren, während er es bey'm Menschen zugibt. Glisson *) sagt: die Haare haben dieselbe Farbe, wie die Haut; diess sieht man bey gefleckten Schweinen, deren Haut, sobald man die Haare mit siedendero Wasser iberbrüht, und herabgeschabt hat, ebenfalls so gefleckt erscheint, wie die Haare es waren. Cuvier leitet desshalb die Farbe der Haare zum Theil von der des Schleimgewebes ab, weil in den Thieren mit verschiedenartigem Pelzwerk die durch die Haare gebildeten Flecken ähnliche Flecken in der Haut andeuten, welche von den erstern bedeckt werden.

\section{§. 48.}

Ueber die Bezeichnung der verschiedenen Körperhaare.

Nur die Haare des Menschen haben nach ihrem verschiedenen Standorte eigenthümliche und so manichfache Benennungen erhalten, wie wir in der Folge sehen werden. Bey den Thieren gibt es deren nur eine kleine Anzahl, z. B. H a u p thaare (Coma), Wimpern (Cilia), A u gen braunen (Supercilia), B art (Barba), Kn e bel b art (Myslax) etc., weil die Haare ausser der Bedeckung ihrer Haut und des dadurch gegebenen Schutzes gegen die Unbilden der Witterung u. s. w. lange nicht jene besondern Nebenzwecke haben, wie beym Menschen. - Ich weiss auch, die schon oben angeführten Benennungen einzelner Haarfiguren, wie z. B. des B a rtes, Sch opfes, der Mähne, der Halsbinde, der Kopfhaube, der Haar$\mathrm{kr}$ one, $\mathrm{H}$ a arzot te, und des Sc $\mathrm{h} w$ an zes ausgenommen, keine andern aufzuweisen, ob ich gleich nicht zweifle, dass in der Sprache der Thierheilwissenschaft, besonders bey unsern Haussäugethieren, und namentlich beym Pferde, noch viele solcher Namen gang und gebe seyn werden, die uns hier nicht besonders bekümmern können. Es versteht sich übrigens von selbst, dass wir uns bey Bezeichnung der Haare immer dadurch am verständlichsten machen werden, dass wir uns an die Theile

*) A, a. 0 . 
halten, an denen sie vorkommen; z. B. Kopf-, Hals-, Rükkenhaare u. dgl.

Man könnte wohl hier die Frage aufwerfen, ob vielleicht den Thieren an einigen Stellen Haare zukommen, wo sie den Menschen mangeln, oder umgekehrt? - Obgleich den Säugethieren, als den behaartesten unter allen, mehr ein Ueberschuss als Mangel an Haaren in dieser Beziehung zugeschrieben werden muss, so fehlen ihnen doch z. B. die Schamhaare, die beym Menschen so bedeutend sind; denn wir finden die Zeugungstheile dieser Thiere unter allen Theilen ilıres Körpers am nacktesten. Auch haben alle Thiere, einige wenige ausgenommen, am Kopfe nur kurze, und daher eigentlich keine Kopf haare. Eben so fehlen ihnen zwar die Augenbraunen und Wimpern nicht durchaus, sind jedoch bey weitem nicht so hervorstehend, wie beym Menschen. Auch die Achseln und Weichen, wo der Mensch vorzugsweise mehr und grössere Haare, als an andern Stellen besitzt, sind bey den Thieren im Allgemeinen nicht mehr als letztere behaart. Freylich muss man bey allem diesem nicht vergessen, dass der Mensch nicht durchaus so stark behaart ist, wie das Thier, wesshalb bey ihm dann die mindeste starke Behaarung sogleich grell in die Augen lällt. - Dennoch gilt auch der umgekehrte Fall, dass nämlich den Thieren Haare zukommen, die der Mensch nicht besitzt; wir sehen diess an den Schwänzen: und auch die sogenannten $\mathrm{K} \mathbf{n} \mathrm{eb}$ elbärte einiger Thiergattungen lassen sich schwer mit den Barthaaren des Menschen in einerley Verhältniss stellen, wie wir späterhin noch deutlicher einsehen werden. Die Haare des äussern Gehörganges sind bey ihnen gleichfalls viel zahlreicher als beym Menschen. - Endlich habe ich zum Theile schon früher gesagt, dass das Gürtelthier *) so wie der Vison und Pekou (1/ustela $V$ ison et canadensis), ferner der Blaufuchs (Canis lagop.) Haare unter den Zehen ${ }^{* *}$ ), der Wallfisch aber statt der Zähne borstenähnliche Haare im Nunde habe.

*) Einer genauen Untersuchung der erst neulich aus Brasilien hier angekommenen wohlerhaltenen Gürtelihiere zufolge, besitzt keines derselben eigentliche Sohlenhare, sondern es wachsen dieselben nur am Rande der Fusssohle, und beugen sich gegen letztere um, so zwar, dass diese Thiere wirklich auf ihren Haren gehen. Dasselbe gilt auch von ihren Haaren innerhalb der Backen.

**) Curier's Thierreich 1. Th. 
Anmerkung. So wie man lingst davon abgekommen ist, dass der Ma u l w r f keine Augen habe, so weiss man also auch, dass die Haut da wo die Angen liegen, durchbohrt sey, und ein wahres Augenlied bilde. Uebrigens ist die Spalte noch durch lange Haare gedeckt, welche sich untereinanderkreuzend, einen dichten Streif bilden.

\section{§. 49 .}

Ghemische Eigenschaften der Thierhaare.

Die Haare aller Thiere, sie mögen als gewöhnliche Haare, oder als Wolle, Borsten, Stacheln u. dgl. erscheinen, geben bey der chemischen Untersuchung ungefähr gleiche Resultate. Der Wirkung des Feuers in freyer Luft ausgesetzt, schmelzen oder fliessen sie anfänglich, wie Cuvier sagt, indem sie zugleich aufschwellen (wie z. B. die Eiderdunen), geben nachher eine weisse Flamme, und verwandeln sich in eine schwarze, sehr schwer in Asche zu verwandelnde Kohle. - Was jedoch das genaue chemische Verhalten der Haare bey den einzelnen Thiergattungen betrifft, so findet man die Analysen derselben in John's chemischen Tabellen weitläufig angefülırt, auf welche ich hiemit verweise, indem ich später, in der Abhandlung der Menschenhaare, diesen Gegenstand einer genauern Würdigung unterziehen werde. 


$$
\text { Zweytes } H \text { a uptstück. }
$$

Von den Haaren der Thiere insbesondere, d. i. nach den Klassen der letztern.

$$
\begin{gathered}
\text { S. } 50 . \\
\text { Einle } \quad \text { it } t u n g .
\end{gathered}
$$

Oben, 5. 37, habe ich zwar versucht, eine Definition für das zu geben, was man Thierhaar zu nennen pflegt, und diese so allgemein aufgestellt, dass sie für alle Thierhaare passt. Nichts desto weniger wird sich mancher meiner Leser wundern, da und dort in den Schriften gelehrter Nänner von Haaren zu lesen, die durchaus nicht in dem oben aufgestellten Begriff untergebracht werden können. So sagt uns z. B. der berühmte Cuvier, dass man die meisten Schuppen der Amphibien für sehr platte Haare nehmen könne; und Professor Heusinger*) eifert uns an, die brennenden Farbenstoffe vieler Pllanzenthiere, die Farbenschuppen der Schmetterlingsflügel, die nackte Haut der guineischen Hunde, endlich das Hautorgan der Amphibien und Fische für nichts anders als in der Ausbildung gehemmte Haare und Federn, oder wie im letztern Falle für das ganze, sammt dem Pigmente unter der Oberhaut liegen gebliebene Hautorgan zu halten. Von der andern Seite trägt man wieder Bedenken, die Borsten, Dornen und Stacheln des Pflanzen- und Thierreichs den Haaren beyzuzählen. Bey dem schwankenden $\mathrm{Zu}$ stande, in welchem sich also die Terminologie dieser so weit verbreiteten Organe befindet, wird es vielleicht Manchem sehr auffallen, dass ich den $\mathrm{Z}$ o o p h y ten, Eingeweidwürmern, Strahlthieren, Mollusken und Cirripeden, und endlich selbst den Fischen Haare zuschreibe. Ich kann vor der Hand bloss hierauf aufmerksam machen, indem ich mir vorbehalte, zu gelegenerer Zeit auf die wissenschaftlichen Gründe zurück zu kommen, auf welchen jene sowohl als

*) In M e ckel's Arch. a. a. O. 
meine, Manchen vielleicht zu weit herbeygehohlt scheinenden Ansichten, bey näherer Betrachtung dennoch sicher beruhen können.

\section{A. Wirbellose Thiere.}

\section{§. 51 .}

\section{H a a re der Z Z o p hyten.}

Diese bewunderungswürdigen Thiere, deren Körper entweder völlig, oder wenigstens grösstentheils aus einerley Masse, oder von verschiedenartigen Substanzen zusanmengesetzt ist (Zonphyla monohyla et helerohyla der Neuern), haben zwar nicht alle, aber doch die grösste Anzahl derselben gewisse äussere Ansätze, Arme, Fühlfäden u. dgl., welche meistens um den Mund, nicht selten an den Endtheilen und an den übrigen Punkten der Oberfläche theilweise und einzeln, oder auch wie wir später sehen werden, unter mancherley Gruppirungen festsitzen. Diese An - oder Fortsätze sind nun von einer auffallenden Verschiedenheit, denn entweder können sie als wahre Verlängerungen der ohnehin fast einfachen Substanz des Körpers betrachtet werden, oder nicht. Im ersten Falle scheinen sie eigentlich nicht wohl in den Bereich dieses Werkes zu gehören, wenigstens gewiss mehr im letztern Falle. Denn das bewaffnete Auge bemerkt an verschiedenen Orten der äussern Oberfläche dieser noch immer räthselhaften Thiere besondere, von den andern auffallend verschiedene Verlängerungen, die beym ersten Anblicke schon auch den Ungeübtesten auf die Idee bringen, dass diess Haare sind. Obwohl ich nun in diesen Verlängerungen mit Ausnahme ihres Standpunktes und ihrer Figur in anatomischer Hinsicht fast keine anderweitigen Eigenschaften entdecken konnte, wodurch ich sie mit den Haaren der höhern, und namentlich der Säugethiere in nähere Beziehung zu bringen im Stande gewesen wäre, und da besonders in Bezug auf die chemischen Bestandtheile der Haare dieser und andrer Thiere eine grosse Verschiedenheit obwaltet; so fühle ich mich doch, gestützt auf den Schluss der Analogie, welche uns der Ort 
ihres Vorkommens, und ihre Figur an die Hand gibt, so wie auf die Angaben und Benennungen, welche diesen Verlängerungen von den berühmtesten Naturforschern der ältern und neuern Zeit beygelegt wurden, um so mehr dazu geneigt, sie für eigenthümliche, von andern allerdings sehr verschiedene Haare zu balten, und als solche meinem Thema einzuverieiben, als je bekanntlich auch unter den Haaren der übrigen Thierklassen beträchtliche Verschiedenheiten obwalten. $\mathrm{Zu}$ diesen Bestimmungsgründen kommt nun noch der besondere Umstand, dass gerade die Haare der $\mathrm{Z}$ o o $\mathrm{ph}$ y ten rücksichtlich ihres höchst einfachen Baues, und ihrer ausserordentlichen Feinheit den passendsten Jebergang von den Pflanzen- zu den Thierhaaren, und demnach ebenfalls ein Glied jener grossen Kette ausmachen, durch welche beyde Naturreiche so innig mit einander verbunden sind.

Allein so auffallend auch bey dem ersten Anblick die Aehnlichkeit dieser Gebilde mit llaaren überhaupt ist, so lässt doch die ausserordentliche Kleinheit jener Thiere über die eigentliche Organisation ihrer Haare, fast möchte ich sagen, blosse Vermuthungen zu, nach welchen selbe den späterhin näher zu beschreibenden Haaren der Cirripeden, Anneliden und Crustaceen am fïglichsten anzureihen sind. Was also von jenen gesagt werden wird, kann einstweilen mit den nöthigen Einschränkungen auch hier für gültig angenommen werden. - Ich beschränke mich daher jetzt darauf, die Verschiedenheiten dieser Haare in Bezug auf die äussere Form und Gestalt, ihren Standpunkt, die Art der beobachteten Bewegung u. dgl. anzugeben, und das Gesagte gleichzeitig mit Beyspielen, die aus den einzelnen Arten dieser Thiere entnummen sind, zu erläutern. Ïch folge hier grösstentheils den иm die systematische Bearbeitung der Zoophyten so hoch verdienten $\mathrm{Otho} M$ ii lle $\mathbf{r}^{*}$ ) und $\left.S \mathrm{chweigger}{ }^{* *}\right)$.

Letzterer ***) hat die háarförmigen Ansätze der $\mathrm{Z}$ oophyten in zwey Hanptabtheilungen gebracht, nämlich

*) Mílleri O. F. Animalcula infusoria fluviatilia et marina. Opus posthumum cura Fabricii, Havniae 1786.

**) August Frid. Schweigger's Handbuch der Naturgeschichte der sceletlosen, ungegliederten Thiere. Leipzig $18 \geq 0$.

***) A, a. O. p. 164 . 
1) In solche, die olne bestimmte Ordnung beweglich sind (Monohyla ciliata vibratilia), und

2) in solche, wo sich einer nach dem andern so bewegt, dass sich bey rascher Bewegung alle Haare im Kreise zu drehen scheinen (Monohyla ciliala rolaloria).

Noch allgemeiner könnte man die Haare der $\mathrm{Z}$ oo phyten in bewegliche und unbewegliche abtheilen, und dann bey den erstern die eben angegebene Eintheilung von $\mathrm{Sch}$ weig ger geltend machen. Denn es gibt gewiss In f u sorien, deren Haare noch nie in willkührlicher Bewegung gesehen wurden, und die daher auch den eigentlichen Haaren der böheren Thierklassen näher stehen. Es ist natürlich sehr zu bedauern, dass uns das Messer hierüber gar keinen näheren Aufschluss geben kann, indem man schon grosse Mühe hat, diese Theile unter einem guten Microscope nur nach Wunsch wahrzunehmen und zu beobachten. Ich bin daher auch nicht im Stande, etwas über die materielle Verschiedenheit der beweglichen und unbeweglichen Haare dieser Thiere anzuführen.

A nmerkung. In der Unterabtheilung $\mathrm{Z}$ oo $\mathrm{phy}$ a heterohyl a fin. det man bloss bey Ceratophyta tubulosa, Genus Plumatella Lam., Tentacula ciliata plura quam octo; und bey der Cerat, $t u b$, Gen. Electra Lamour, ein os ciliat $\mathrm{um}$.

\section{§. 52.}

Die specielle Terminologie der Ilaargebilde dieser Thierklasse lässt ebenfalls noch Manches zu wünschen übrig, indem auch hier mitunter höchst willkührlich vorgegangen wurde. Wie leicht zu erachten, hat man die einzelnen Benennungen aus den in der Pflanzen - und übrigen Thierwelt angenommenen entlehnt, und wir kommen daher wieder auf zum Theil schon bekannte Namen zurück; dennoch findet sich da und dort etwas Eigenthümliches. Um nun in dem Nachfolgenden nicht missverstanden zu werden, will ich mich im Voraus über das erklären, was ich unter den vorkommenden $\mathrm{Ha}$ a rbezeichnungen verstanden wissen will.

1) Crinis s. pilus ist ein mehr oder weniger langes, dem Anschein nach weiches Fädchen an der Oberfläche des Thierleibes, welches keine eigentliche Substanzverlängerung zu seyn scheint. 
2) Cilia sind ähnliche Fädchen, die an irgend einem Rande sitzen, Randhaare.

5) Cirrhis. Cirri sollten nach der gewöhnlichen Bedeutung dieses Wortes Haare seyn, die sich gleich Raknen um sich selbst, oder um andere Körper herumschlingen. Hier aber wird unter Cirrhus ein etwas stärkeres llaar verstanden, das, wenn auch nur wenig, gebogen ist. Nach $M$ üll er sind Cirri: corpora, pilis, ciliisque pauciora, corniculisque longiora, basi latiora, inter se distantia.

4) Seta oder Borste ist ein gerades, rundes, dickes und steifes Haar.

5) Corniculus nennt Müller ein hartes Haar, dessen Spitze beweglich ist.

6) Spina und Aculeus, d. i. Dorn und Stachel, werden auch hier, wie in der Botanik, häufig mit einander verwechselt, und zwar um so leichter, da hier von dem dort geltenden Unterschied kein Gebrauch gemacht werden kann. Im Allgemeinen wird man nicht irren, wenn man unter beyden Benennungen eine starke und sehr spitzige Borste versteht.

Anmerkung 1. Man plegt die $\mathrm{Haare}$ auch $\mathrm{R}$ adi $\mathrm{i}$ zu nennen, wenn sie, wie bey vielen Infusorien, am Rande des scheibenförmigen Thieres herumsitzen.

Anmerkung 2. Die Haare (crines) mancher Trichoda können auch Cilien genannt werden, unterscheiden sich aber von den Cilien der Vorticellen und Brachionen offenbar dadurch, dass diese bey beständiger Bewegung, die oft mehrerc Minuten dauert, in heftige Schwingungen oder Drehungen gerathen, jene aber nur hie und da mit unterbrochener Bewegung zittern, vibriren. Solche Cilia vibratilia finden sich hauptsächlich bey den Arten vom Genus Leucophra; Cilia rotatoria aber bey den Vorticellen und Brachionen.

Einfache $\mathrm{H}$ a are (Criness. pili) treffen wir nicht nur in grosser Menge und in Gesellschaft von Cilien und Borsten, sondern sogar mit Stacheln an einem und demselben Thiere, namentlich aber in dem Genus Trichoda.

Cirrigibt es bey den Vorticellen und Himanthopus.

Bursten kommen wieder häufig mit Cilien und gewöhnlichen Haaren gesellt vor, besonders im Ge nus Vorticella.

Hornartige Hare (Corniculi) trifft man vorzigglich im Genus Kerona, und $S t a c h e l n$ sind bey den Brachionen aı häufigsten. 


\section{§. 55 .}

1. Pili, crinos, gewöhnliche, oder sogenannte einfache Haare.

Diese sind in dem Genus Trichoda so häufig, dass M ü ller letztere einen Formis inconspicuus, pcllucidus, crin'tus nennt, und sie nach Beschaflenheit der IIaare in drey Unterabtheilungen: ccaudatae, caudalae und subcaudatae (pilis posticis) bringt. Man sieht schon daraus, dass auch hier in der Vertheilung und Lage der Ilaare eine grosse Verschiedenheit Statt finde. So haben Trichoda urnula, semiluna, trigona, tinea, nigra, Proteus, scrsalilis, Poëta, usula, trochus, grrinus, anas, Linter, angulus nur an der vor̀deren Spitze gewöhnliche Haare.

Trichoda cometa ist vorne mit einem ziemlich starken Haarschweife begabt; Floccus hat hinten drey mit Haaren besetzte Papillen, so auch Pubes an der stumpfén Spitze ganz kleine, nur in agone mortis zu erkennende Haare. (In diesem Nomente streckt das Thier diese Haare mit aller Kraft aus der Spitzenspalte hervor, und bewegt sie beym Einziehen des letzten Wassertropfens hefig.) Die Bulla hat vorne und hinten 3-4 zitterude Hare. Bey der Gallina ist die stumple Spitze ganz behaart, der kleine Schwanz aber nur mit wenig Härchen besetzt. - Bey dem Cursor finden sich vorne und hinten Haare. Erstere bewegen sich alle zugleich, und das Thierchen weicht nach jeder fiinften Schıvingung der Haare etwas zurück; die hintern Haare bewegen sich einzeln. Die krummen sind länger als die geraden, und hängen von dem gekrümmten Rande herab. - An den Einschnitten oder Lippen sind behaart: Forceps, forfex, index, navicula; an den Rändern: Succisa, farcimen, rrinita und barbata. Die Sinuala hat bloss am Rande des Sinus fluctuirende Haare. Gibba hat pili antici und ventrales. Patens ist an den Rändern seiner Grube behaart. Anas trägt unter der Spitze des Halses einige wenige, ungleiche pilos hyalinos. Bey der Trichoda angulus dienen die an dem einen Ende sichtbaren Haare zum Theil als ein Zeichen, dass das Thier eigentlich nur einfach, aber winkelartig gebogen ist. - Am Halse behaart ist die Mclitea und Vermicularis. Die Ciliata trägt rückwärts einen Haarkamm; Increnila zeigt an der Basis auf jeder Seite ein kaum merkbares, vibrirendes Haar. Grandinella 
hat $2-j$ oder mehrere schwer zu unterscheidende Cilien, die sie entweder in zwey Bündel, oder auf dem ganzen Rande der Oeflnung ausbreitet. Granata ist in der ganzen Peripherie behaart, und zeigt entweder seinen ganzen Radius, oder drückt die langen Haare in einen Bündel zusammen. Die Globularis nennt $\mathrm{M}$ üller: undique radiata. Ihre Radii kommen nicht bloss vom Rande, sondern von der ganzen Oberfläche. Und dennoch sah Müller nie eine Bewegung bey ihr. - Praeceps ist anssen lang, und stark behaart. Bey der Fimbriata bildet der Rand der Spitze ein Segment eines Zirkels, welches mit einer Reihe vibrirender IIaare versehen ist. Diese entstehen innerhalb des Zirkels, und haben in Bezug auf jene ähnlicher Thiere eine abweichende Lage, denn hier scheinen sie auf beyden Blättern, auf jedem nämlich die Hälfte davon, zu sitzen. -

\section{§. 54 .}

2. Cilia, Randhaare.

Von ihnen bekommt das Genus Leucoplrra das Kennzeichen: permis undique ciliatus. Bey diesen Thieren sind die Haare ein Hauptmittel zur Bewegung. So hat Leucophra confictor zwar nur sehr kleine Cilien, und dennoch dreht sich durch Hülfe dieser die ganze Masse kreisförmig herum. Die L. mamilla hat grössere gekrümmte Cilien, die ihr nicht allein zum Drehen, sondern auch zum Schwimmen dienen. Bey Virescens finden sich bogenartige Cilien. An der Lursata sind gar dreyerley Arten: vorne rolantia, vorne und seitwärts fasciculata, und am ganzen Körper flucluantia. Die Posthum zeigt ihre Cilien nur bey langsamer Bewegung, und wenn fast alles Wasser verdünstet ist. Die $L$. vesiculifera streckte ihre Radii erst hervor, als sie in agone lag. Globulifera, Postulatu, Turbinata und Nolata sind fast an der ganzen Oberfläche behaart. Bey langsamer Bewegung legt die Signata ihre Cilien an den Körper an, aber beym senkrechten Stande des letztern schwingen sie plözzlich überall. Der conische Körper der Cornuta ist fast überall behaart; die Cilien an der Seite sind sehr klein, die vorderen aber dreymal länger, und bewegen sich in eirem, nie aber, wie in der Polymorpha in zwey Zirkeln. Uebrigens schwingen die einen wic die anderi nach Belieben des Thieres. Unter den Vorticellen hat die $\mathbf{T} i$. ridis cilia antica und sphaeroidea; die Cicuta an beyden Seiten 
und an beyden Enden einen kleinen Einschnitt, in welchem zwey ganz ausserordentlich kleine Haare sich bewegen. Bey der Bursata sitzen rings um die Papille am Rande der Oeffnung kleine Cilien, die entweder alle zugleich zittern, oder theils an den Körper zurückgeschlagen ruhen, theils hervorstehend sich bewegen. Bisweilen sind sie auch zurückgebogen, und bilden einen Haken, oder machen steife Spitzen an beyden Seiten der Papille. - Spularium hat wenige lange, excentrische Cilien, die nicht am Rande, sondern aus der Scheibe strahlenförmig hervorkommen. Dieses merkwürdige, gleichsam doppelte Thier macht mit seinen Cilien verschiedene Schwingungen im Kreise herum, und fährt sehr schnell durchs Wasser, wo man dann die Cilien kaum wahrnehmen kann. - Die Polymorpha, das wunderbarste Thierchen unter allen, der wahre Proteus der Infusorien, hat bald gestreckte Cilien, bald bewegen sich selbe in Bündeln; bald sieht man an einer Seite ein hakenförmiges Glied, wobey sich aber dennoch die entgegengesetzten Cilien stark bewegen, bald ist dieser Theil gleichsam geöhrt (auriculata), stumpf oder zugespitzt, oder gerade, lässt entweder einen kleinen Fortsatz (Pedicellum,) oder von der Seite einen Cirrum heraus, was jedoch seltuer ist. - Das rotirende Organ in der Nasula umgibt die Mitte des Körpers; vorne sieht man auch ringsherum Cilia rolantia; die in der Mitte liegenden sieht man aber wegen der heftigen kreisförmigen Bewegung nur von beyden Seiten und gleichsam wie in eine Spitze vereint. Zwischen diesen mittleren und vorderen Cilien ist noch ein dritter auch mit Cilien begabter Theil, die aber einen kleinen Bündel bilden. Socialis und Flosculosa sind mit besonders schönen Discis ciliatis versehen. - Diese manichfaltige Bildung der Cilien findet sich auch, nur mit andern Haaren vermischt, in den einzelnen Arten der Brachionen; so z. B. in dem dreyfachen Drehorgan von Brachionus Bakeri. Zwischen den Tentakeln dieses Thieres ragt ein ganz durchsichtiges Züngchen herab, dessen kopfförmige Spitze mit Cilien besetzt ist. Auf beyden Seiten sieht man ausserhalb den Seitenzähnen runde, mit Cilien besetzte Körperchen, und in dem Körper selbst neben dem gezähten Riande des Schildes zwischen den grössern Zähnen und Fühlfäden eine querlaufende Reihe doppelter Cilien. Die Bewegung aller dieser Cilien gewährt dem Auge das schönste Schauspiel. 


\section{55 .}

3. Cirri, Rankenha are.

Bey dem äusserst lebhaften Genus: Himanthopus verliünt sich z. B. bey acarus die Spitze unten in eine Reihe: langer Cilien. Oben am Bauche kommen wenigstens vier lange gekrümmte Cirri hervor, welche sammt den Cilien bey nach aufwärts gerichtetem Kopfe und Bauche in steter Bewegung sind. - Die Vorticella cirrata hat an beyden Seiten einen cirrum ventralem.

\section{56 .}

$$
\text { 4. Setae, Borsten. }
$$

Diese finden sich selten einzeln, sondern neist in Gesellschaft von Cilien, gewöhnlichen Haaren und Stacheln vor.

Trichoda augur hat unter seinen drey Füssen einen Borstenbündel, welcher von der Nitte des Körpers bis über den Hintertheil hinabhängt.

Trichoda fixa ist das trägste unter allen Thieren dieser Gattung, indem man durchaus weder an den äussern noch innern Theilen eine Bewegung wahrnehmen kann, ungeachtet es rings am Rande mit feinen, ungleichen, kaum sichtbarem Borsten (setae hyalinae) versehen ist, und einen sonderbaren Schwanzfaden hat.

Vorticella stellina ist ein sehr schönes rundes Thierchen, dessen äusserster, ganz durchsichtiger Rand ganz kleine Borsten hat, die einen Radius bilden. Diese verschwinden bey der kreisförmigen Bewegung ganz, und es bleibt am Rande bloss ein schimmernder durchsichtiger Streif zurück. -

$r$. Palella trägt an der Spitze ihres Kopfes zwey sehr liurze, auseinanderstehende, grösstentheils aber vereinte Borsten. -

\section{§. 57 .}

5. Corniculi, Hornstacheln.

Von ihnen heisst das Genus Kerona: corniculata. K. rastcllum hat weder Cilien, noch gewölnnliche Haare, sonderu hornartige Stacheln, die man in einer dreyfachen Peihe am 
Bauche sieht. Sie werden entweder alle zugleich, oder einzeln bewegt, und dienen wohl auch zu Füssen.

\section{§. 58 .}

6. Spinae, Mucrones, Stacheln.

Brochionus lamellaris hat an der Spitze seines runden, einfachen, doppeltgegliederten, beweglichen Schwanzes zwey Stacheln, die etwas gebogen werden können.

\section{§. 59 .}

7. Verschiedene dieser Haararten an einem und demselben lndividuum.

Trichoda ignila hat unter seiner Spitze nach hinten eine Reihe spielender Cilien, unter diesen zwey Borsten, die bey der Bewegung der Cilien zusammengezogen und hervorgestreckt werden. - Die Trichoda ambigua hat an ihrem tubulus Cilien, und am Körper Borsten. Tr. lunaris, bilunis, tigris, Ratlus, Pocillum und Paxillus sind mit feinen Härchen, am Schwanze aber mit starken Borsten versehen. Tr. longicauda ist vorne abgestumpft und behaart, und endet an ihrem langen, zweygliederigen Schwanze mit zwey Borsten. Tr. Pellionella trägt vorne Haare, hinten Borsten. Eben so die Erosa. Rostrata hat lange Cilien und vier fussartige Borsten. - Cimex zeichnet sich vorne durch umgebogene Haare, und hinten durch gerade Borsten aus. Eben so verhält sich's mit der Tr. Cicada.

Kerona, Haustrum. Sein vorderer grösserer Theil besteht bloss aus einer weissen, durchsichtigen, hohlen, am Rande mit langen Cilien ringsum besetzten Haut; der hintere Theil zeigt in seiner Mitte $6-7$ bewegliche, über den Rand hervorragende Borsten, und innerhalb des innern Pandes gegen der Mitte zu ragen zwey Haken oder Hörner hervor. Das Thier zittert mit den Ilaaren, und bewegt sich so im Wasser.

$K$. Patella hat eine schildkrötenähnliche Gestalt, 5-6 in doppelter Reihe gestellte borstenartige Füsse, unten Haare von verschiedener Länge, und ausser dem Schilde ragen 6 - 7 Borsten hervor, die ebenfalls zu Füssen oder Rudern dienen. 
K. Mytilus ist an beyden breiten Extremitäten behaart, vorne mit zwey Hörnchen, hinten mit zwey Borsten versehen. -

Vorticella longisela hat zwey sehr lange Schwanzborsten, und vorne nur sehr kleine Cilien.

Die Brachionen, deren Organismus schon mehr zusammengesetzt ist, tragen auch mehr oder weniger fast alle Haararten an sich. So ist Brach. cirratus an beyden Seiten seines conischen Kopfes mit einem Bündel Haare geziert, und hinten tehen ebenfalls auf beyden Seiten des Körpers ziwey steife Borsten geracie hervor. Mit ähnlichen Borsten endigt auclı der Schwanz.

Brach. tripos zeichnct sich durch zwey Haarbündel an den vordern Seitentheilen, durch zwey vordere und eine hintere stachelformige Spitze, ferner durch Cilien, die das doppelte Drehorgan rings ungeben, und endlich durch zwey Schwanzstacheln aus.

\section{ร. 60 .}

II. Haare der Eingeweidewürmer.

Einige Species dieser Thiere haben längst dem ganzen Körper Borsten, und stehen in dieser Hinsicht einigen Anneliden, und namentlich den Regenwürmern sehr nahe. So hat z. B. Pentastoma denticulatum der Quere nach in Linien stehende Borsten. Andere Entozöen sind mit stachlichen Ansätzen des Körpers versehen, die von einer auffallenden Härte sind. Wir sehen diess an den Stachelkränzen der Kratzer, Acanthocephala, der Nestelwürmer, C'estoidea und Blasenwürmer Cystica. Die Kratzer zeichnen sich besonders durch ihren einziehbaren, reihenweise mit Haken besetzten Rüssel aus; mittelst dessen sie sich an die benachbarten Theile befestigen, und selbe reitzen können. Distoma Lima ist der ganzen Länge nach mit feinen Stacheln besetzt. - Unter den Blasenwürmern, welche alle llaken besitzen, findet man diese besonders schön an dem Riüssel der Quese (Coenurus), des Blasenschwanzes (Cyslicercus), und des Blumenkopfs (Anthocephalus) in der Form eines Kranzes zusammengestellt. - Es ist wohl zu bemerken, dass diese Stacheln meist beweglich sind, und dass es sogar Beyspiele gibt, wo sie ganz zurückgezogen, und in kleinen Höhlen verborgen werden können, z. B. im Pcn 
lasloma proboscideum. - Auch machte Bremser bey den Bandwürmern und mehreren Arten von Echinorynchus die interessante Bemerkung, dass sie im ersten Alter keine Stacheln besitzen, sondern diese erst später hervorkeimen.

\section{§. 61 .}

\section{Haare bey den Mudusen, Acalephen.}

In dieser Klasse finden sich nur haarähnliche Fäden, welche man mehr den Fühlfäden, als den Haaren zuzählen kann. So hängen an dem wolligen gelben Rande der grossen Aeste der Berenice auroma lange, rothe Haare; und die vier Arme der Cyanea lösen sich gleichfalls in Haare auf. -

\section{§. 62.}

\section{Haarebey den Strathlthieren.}

Ausser den Fühlfäden bey den Actinien stehen zu beyden Seiten der Rinne der Strablen bewegliche Stacheln, die offenbar zur Ortsveränderung dienen. Tiedemann hat in sciner Preisschrift: Ueber den Bau der Röhrenholothurie p. 36 . -- 59, dic Stacheln der Asierias aurantiaca genau beschrieben. Sie hat nämlich fünf lanzenförmige Strahlen, deren Ränder mit pflasterförmig liegenden Knochenstücken bedeckt sind, auf welchen sich starke bewegliche Stacheln einlenken. Nebstden ist die ganze Oberfläche nit kleinen abgestutzten und gezähnten Stacheln besetzt.

Auch M üller*) hält die fleischigen, glatten, nicht stechenden Spitzen an der Oberfläche der Asterias pulsillus für noch weiche Stacheln. - Die meisten Stacheln treffen wir aber bey den Echiniden an, deren Schale mit warzenförmigen Erhabenheiten versehen ist, auf welcher kalkartige Stacheln articuliren, deren Basis vertieft, und auf den Erhabenheiten eingelenkt ist. Da sie das Thier nach Willkühr bewegt, so will Lamark**) in der Gattung Cidariles den Gelenkkopf mit einem Loche versehen beobachtet haben, durch welches die Muskeln zu dem Stachel gelangen. Schweigger

*) Zoologia danica p. 64 .

*) Hist. nat. des animaus sans vertébres III, pag. 73. 
war nicht so glücklich; und offenbar sind die Warzen gewiss an den meisten Gattungen nicht durchbohrt. - Uebrigens unterscheiden sich die Stacheln auch durch Gestalt, Grösse und Farbe. Pallas*) beschreibt sie im Echinus calamarius hohl, an der Spitze offen und sagt, dass sie aus über einander liegenden Lamellen und netzförmiger Kalksubstanz bestehen. Heusing er**) glaubt ebenfalls bey Echin. saxatilis diese Lamellen und nadelförmige Kalkkrystalle gesehen zu haben.

\section{Haare der Anneliden.}

Die Haare und Borsten, die wir häufig in dieser Klasse antreffen, und die man vorzüglich an der Aphrodite aculenta untersuchen kann, sind meist cylindrisch, manchmal jedoch auch platt, wie z. B. bey Amphitrile auricoma. S a vign y ***) theilt sie in vier Arten: 1) soies subulés; 2) s. acicules; 3 ) $s$. à crochets; 4) s. à palettes. H eusing er ${ }^{* * * *}$ ), der sie nur an dem Regenwurme und der Aphrodile aculeata untersuchte, beschreibt sie so: „Die Spitze ist dicht, der Rest der Borste ist aber mit einer verhältnissmässig sehr weiten Höhle versehen, welche wciter wird bis zur Basis der Borste, wo sie ganz offen ist. Hier fand er weder eine zwiebelartige Anschwellung, noch eine Spur eines Balgs. - Das Merkwürdigste bey diesen Borsten ist, dass sie mil eigenen, in den $\mathrm{Z}_{\text {wi- }}$ schenräumen der Längenmuskeln liegenden Muskeln begabt sind, so dass sie eingezogen und herrorgestreckt werden können. - Die Borsten irisiren in der Regel eben so, wie die ganze Oberhaut dieser Thiere. - Die Stärke derselben ist rerschieden, von der eines feinen Menschenhaars, bis zu der ciner starken Schweinshorste." -

Diese Borsten sind in Büscheln vereinigt, deren ich an den beyden Seitenrändern ungefähr 56 zä̆ılte. In der Mitte stehen die dicksten, und sie nehmen nach den beyden Enden

*) Spicileg. zoologie. X. p. 32. tab. II. fig. 8. a. O.

*) A. a. O. pag. 262.

***) Recherches pour servir à la classification des annelides. Auch in Annales generales des sciences physiques. Vol. V. pag. 72.

***) A. a. O. pag. 248 . 
an Dicke und Stärke ab. Ein jedes solcher Büschel besteht nur gewöhulich aus 16-18 einzelnen Borsten, die an Grösse und Feinheit stufenweise abnehmen, so dass die grössten immer am höchsten, und zugleich nach dem äussern Körperrande des Thiers zu, dann in zwey melır unterhalb und einwärts stehenden Absätzen die übrigen feinern nach dem Grad ihrer Zartheit und Kürze stehen. Eine dieser Borsten ist immer die grösste, und von dieser gilt denn auch die angegebene Beschreibung am besten. Alle aber sind durch eine zähe Haut in ein Büschel vereinigt, welches viel Aehnlichkeit mit einen Pfeilköcher hat. Auch schillern alle. - Nach einwärts setıen sich ringsherum feine Muskeln an die stumpfe Spitze fest, welche von der Haut zu kommen scheinen.

(Das Ganze macht die Tafel V. Fig. 46-48 anschaulich.)

Die Substanz ist spröde, leicht zerbrechlich, etwas faserig. - Obgleich keine chemische Analyse derselben vorhanden ist, so spricht doch der Umstand, dass sie beym Verbrennen einen dem der Säugethierhaaren ganz ähnlichen Geruch verbreiten, sehr zu Gunsten ihrer nahen Verwandtschaft mit jenen. - Nur wenige Anneliden sind übrigens, wie die Aphroditen mit gewöhnlichen Haaren bedeckt, welche nebst den zum Gehen dienenden steifen Haaren oder Borsten noch eine grosse Menge anderer, langer, biegsamer, metallisch glänzender Haare von meergrün schillernder Farbe haben. - Endlich ist noch bemerkenswerth, dass die Kiemen der Anneliden durch eine Art von Werg oder Filz bedeckt sind, durch welche das Wasser durchsickert*).

'Treviranus**) gibt überhaupt dreyerley Arten von willkührlichen Bewegungsorganen der Aphroditen an, wovon die zwey letzten zum Haarsystem gehören, die erste aber aus den genannten Borsten besteht, welche reihenweise an den Füssen (40-41 Paare) sitzen. Die zweyte Art besteht auf jeder Seite des Körpers in zwey Reihen von Stacheln, die kammförmig aus dem wergartigen Rückenfell hervorragen. Zur dritten Art gehören lange, metallisch glänzende Haare, von welchen die meisten auf jeder Seite in zwey Büscheln vereinigt, und wovon die neben den Füssen sitzenden mit einem Bü-

*) Cuvier's Vorlesungen tiber vergl. Anatomie, Uebers: v. Meckel. Leipzig 1809 pag. 611.

**) Zeitschrift fiir Physiologie 3. Bd, pag. 166. 
schel kürzerer, schwärzlicher Haare verbunden sind. - Was übrigens Treviranus weiter von dem innern Zusammenliang der Borsten mit den in der Bauchhöhle liegenden Theilen sehr genau angibt, konnte ich bey meinem Specimen, das schon viele Jahre im Weingeist aufbewahrt war, nicht mehr erkennen. -

\section{§. 64 .}

\section{Haare der Arachniden.}

Schon viel auffallender tritt das Haargebilde in dieser Klasse hervor. Wir schen es namentlich in seiner zweyfachen Gestalt als gewöhnliche, und als steife IJaare (Borsten) hier zugleich erscheinen. - Auch scheinen sie sich schon mehr den Haaren der höhern Thierklassen anzureihen, indem sie gegen ihre Basis dicker werden, obgleich man ihnen noch leine eigentliche $Z_{\text {wiebel }}$ zuschreiben kann. In der Mehrzahl sind die Haare sehr weich und saftig; wie dieser Saft in sie gelange, kann ich nicht bestimmen. Vielleicht lässt sich die Art ihres Ursprungs noch am besten mit der vergleichen, welche ich weiter unten von den Haaren der Insecten angeben werde.

Eine grosse, sehr schädliche, braunzottige, westindische Winkelspinne ist, den Brustschild ausgenommen, stark mit Haaren bewachsen. Margrave und B lankaart sagen, dass die Ilaare dieser Spinnen so fein wie Seide anzufühlen wären, und $\mathrm{P}$ is o schreibt ihnen eine brennende Kraft zul, wenn sie auf die Haut eines Menschen kommen*).

Vergleiche Taf. V. Fig. 49.

\section{ร. 65 .}

\section{Haare der Crustaceen.}

Diese Klasse von Thieren zeichnet sich in Bezug auf die Ilaare vor allen übrigen dadurch aus, dass sie ein äusseres und inneres Hfaargebilde besitzt. Zu dem ersten rechne ich die haarförmigen Fortsätze an den Schalen, die in Rücksicht auf Grösse und Anzahl unendlich verschieden sind; ferner ähnliche Fortsätze von hieher gehörigen Thieren, deren Schale jedoch noch

*) Rös el's Insectenbelustigungen. 
keinen Kalk enthält, und deren Oberfläche mit einer feinen Haut überzogen ist, von welcher aus sich diese Haare fortzusetzen scheinen, z. B. bey Cypris, Lynceus u. m. a., die davon oft ganz behaart erscheinen. - In Portunus puber, Dromia Rumphii ist aber auch die ganze Schale behaart, und unser Flusskrebs trägt fast am ganzen Leib, nämlich an den äussern Kinnladen, Füssen und den Rändern der Schalenschilder, Randhaare. Baster fand 4erley Haare bey den Krebsen: 1) gezähnte, wie eine kleine Säge an den Armen, 2) gefiederte am Schwanze und an den Schwimmfüssen, 5) sehr steife und borstenähnliche an den innern Lippen, und endlich 4) am Ende cylindrische und spitzig zulaufende an den Lauffüssen*). - Iclı stimme He u sing e ${ }^{* *}$ ) gerne bey, wenn er diese Haare für blosse Fortsätze der Oberhaut annimmt, und die Kalkschale unter ihnen aus dem Grunde für durchbohrt hält, weil bey der Schalenwechselung sich auch in diesen Haaren neue Haare bilden, die der alten Schale abgeworfen werden, und weil die neue Schale mit eben solchen Haaren wieder besetzt ist. - Ausser diesen, in Bezug auf Zartheit immerhin den Haaren im gewöhnlichen Sinne beyzuzählenden, finden wir bey den Crustaceen auch noch stärkere, dickere Fortsätze, die wir dann Stacheln nennen, und die, weil sich in ihnen die Kalkschale oft selbst bis in die Spitze, die häufig noch hornartig bleibt, fortsetzt, sich schon von den Haaren etwas mehr entfernen.

Was nun das innere $\mathrm{Ha}$ argebilde betrift, welches man, einige Aphroditen ausgenommen, noch in keiner Thierklasse beobachtet hat, und das meinens Wissens zuerst von $\mathrm{H}$ e u sing e $\mathrm{r}^{* * *}$ ) an der Respirationshaut unsrer Flusskrebse aufgefunden und beschrieben wurde; so habe ich diesen Gegenstand ebenfalls einer genauern Untersuchung unterzogen, und werde die Resultate, da sie theils etwas vollständiger als die von Herrn Prof. Heusinger sind, theils auch von diesen etwas abweichen, hier kurz nachfolgen lassen:

An der Stelle, wo die Schale eines Fusses durch die sogenannte Respirationshaut mit der entsprechenden Kieme zusammenlängt, sieht man an der inneren Seite dieser Schale ein ovales Grübchen, das nur nach einer Seite hin eine flache Aus-

") A. a. O. p. 337.

$\left.{ }^{* *}\right)$ A. a. O. p. 253.

***) A, a, O. p. 254. 
schweifung in dem ringsum aufgeworfenen Rande zeigt. Dieses Grübchen ist mit einer sehr grossen Anzahll von ausserordentlich kleinen graulichen Bläschen, die dicht neben einander liegen, immer befeuchtet sind, und höchst wahrscheinlich genau der Anzahl Haaren entsprechen, besetzt und angefüllt. Denn jenseits dieses Grübchens, d. i. also an der äussern Seite der Schale, steigt aus einer, mit einem nur wenig erhabenen Rande eingefassten Vertiefung ein kleines Büschel in einander verwickelter Haare heraus, und breitet sich, gegen die entsprechende Kieme hingewendet, und selbe gleichsam innig umflechtend, auf ihr so aus, dass man die einzelnen Haare, Behufs der genauern Untersuchung des Ganzen, mit Schonung und behutsam aus den Kiemenblättchen losmachen und entwirren muss. - Diese Haare sind übrigens von braungelber Farbe, und hängen, wie ich mich sattsam überzeugt habe, unmittelbar mit den genannten Bläschen (ihren Zwiebeln?) zusammen. Aueh scheinen_sie etwas gewunden zu seyn, wesshalb sie unter dem Microscope lichtere und dunklere, der. Länge nach schief laufende Streifen bilden.

Vergleiche Tab. VI. Fig. $50-54$.

§. 66 .

VIII. Haare der Mollusken und Cirripeden.

An der lederartigen Substanz auf den Seiten, wo die Crattung Chiton keine kalkigen Schalen hat, befinden sich lange haar- und stachelartige Fortsätze; wenigstens nehmen sie Cuvier und Blainville für Haare oder Borsten. - Swammerdam *) fand die das Gehäuse der Embryonen lebendig gebärender Schnecken äusserlich bekleidende Oberhaut mit vielen borstigen Härchen besetzt. Bey den Cirrhipoden stehen längs dem Bauche zahlreiche mit sehr vielen kleinen Gelenken versehene Borstenfäden, in 10 - 12 Paare gereihet nach Art der Füsse oder Flossen.

Am genauesten beschreibt He usinger ${ }^{* *}$ ) das Horngewebe der Fangarme der Girripeden. Er behauptet, dass diese Girri nur mit einer dünnen, ungefärbten, aber harten

*) Bibl. nat. p. 75 .

**) A. 2. O. p. 242. 
Epidermis überzogen sind, und dass sich inwendig eine weiche, muskulöse Substanz befindet, auf der eine blauschwarze Pigmentschichte liegt. Sie sind, wie gesagt, hornigt, gegliedert, und an ihrem inneren Rande mit Haaren besetzt. In der Anatifa laevis sollen sich an dem äusseren Rande kurze, einzelne, mit blossen Augen nicht sichtbare Ilaare, am innern hingegen zwey Reihen von längern Haaren befinden. Heusinger hält diese Haare für pyramidenförmige Fortsätze der Epidermis, die hohle, glatte, an der Spitze geschlossene Canäle darstellen, in welche letztere sich ein Faden der innern weichen Substanz eine Strecke weit fortsetzt. Nach Andern befinden sich Muskeln in ihren Höhlen.

\section{§. 67 .}

\section{Haare der Insecten.}

Bey den Insecten erreicht das $\mathrm{H}$ a argebilde schon einen viel höhern, ja man kann sagen den höchsten Grad von Ausbildung unter den wirbellosen Thieren, und zeichnet sich vorzüglich in manchen Ordnungen dieser Klasse, und in gewissen Lebensperioden jener Thiere um so mehr durch Ueppigkeit aus, je weniger die äussere Haut ein Streben zur Verhärtung zeigt. - Wir können dasselbe unter einer zweyfachen Verschiedenheit betrachten, in so fern nämlich die haarförmigen Fortsätze unmittelbar aus der Oberhaut entspringen, aus der sie demnach auch zusammengesetzt sind, wie z. B. bey den Raupen u. s. w.; oder in so fern sie, höher organisirt, aus mehr Hornsubstanz und Pigment, ja sogar aus einem Zellgewebe, dass die innere Höhlung ausfüllt, wie bey manchen Käfern, z. B. Melolontha solstitialis, bestehen. Es ist wohl der Bemerkung werth, dass die höhere Organisationsstufe der Insectenhaare so zu sagen gleichen Schritt mit der Ausbildung der Insecten selbst halte, und dass demnach die eigentlichen Haare nur den vollkommnen, die aus blosser Epidermis zusammengesetzten aber fast ausschliesslich den unvollkommnen Insecten zukommen. Im Grunde sind aber die Haare der meisten Insecten verzweigt, und nähern sich daher in dieser Beziehung den Federn.

Es herrscht ïbrigens in Bezug auf das Vorkommen dieser Gebilde eine ausserordentliche Verschiedenheit unter den 
Insecten, so dass wir ganze Ordnungen in verschiedenen $\mathrm{Ab}$ stufungen bald mehr, bald weniger, bald ganz behaart, andere wieder durchaus haarlos finden. Doch haben die Insecten gewöhnlich nicht an allen Theilen des Körpers Haare; einige bloss am Kopfe, wo sie denselben Dienst leisten, wie die Schleussen derFedern; bey andern ist das vordere Bruststück ganz mit Haaren bedeckt; bey andern wieder nur der hintere Theil ihres Rückens. Auch an den Beinen oder Schenkeln, an den obern und untern Flügeln der Insecten entdeckt man häufig viele Haare.

Die äussere Gestalt derselben ist natürlich sehr manichfaltig, wie uns der unermüdete Reaumur ${ }^{*}$ ), ferner Lyonet $\left.{ }^{* *}\right)$, De Geer ${ }^{* * *}$ ), S wammerda m****), Rössel t), $\mathrm{L}$ a $\mathrm{tr}$ eill e tf) u. a. m. grösstentheils durch getreue Abbildungen gezeigt haben. In der Regel sind diese Haare gerade, häufig ästig, oder mit zahlreichen Nebenhaaren versehen - federartig. Uebrigens sind sie fast durchgehends steif und brüchig, und dieser Umstand macht die Stiche mancher Insecten, und namentlich mancher Raupen sehr lästig, und ist die Ursache, warum man sie ehemals sogar für giftig gehalten hat. Sie sind zwar gewöhnlich ausserordentlich fein, doch gibt es auch viele ron so beträchtlicher Dicke und Stärke, dass man sie füglich Stacheln nennen könnte. Kle e mann t+t) beschreibt eine westindische Raupe, deren Haare an Härte dem Eisendraht nahe kommen: ein jeder dieser Stacheln theilt sich manchmal in mehrere Ziveige, die so klein sind, dass man sie mit blossen Augen gar nicht beobachtet. - Doch ist die Theilung verschiedener Zweige keineswegs gleich, sondern geschieht manchmal in drey, manchmal in vier Aestchen. Auch ihre Stellung ist häufig verschieden; denn bey einigen Insecten sind

*) Memoires sur l'histoire naturelle des Insectes. Vol, I. p. 197 u, f.

**) 'I'raité anatomique de la Chenille, qui ronge le bois de Saule etc. p. 69. - Und dessen Remarques sur la telologie des Insectes de M. Lesser. Torn. I. p. 108.

**) Abhandlungen zur Geschichte der Insecten. Uebersetzt von Götze. Leipzig 1776.

****) Biblia naturae.

i) Histoire naturelle generale et particulière des Crustacées et des Insectes. Tom. 2. p. $60-67$.

i) Insectenbelustigungen a. a. 0 .

Ht) Beytrïge zur Natur- und Insectengesehichte, 1ster Thl. p. 20. 
sie rings um einen Ring in einer krummen Linie gelagert, bey andern wieder schief, etwa auf zwey Linien Entfernung, aber immer in so bestimmt gleichen Zwischenräumen gestellt, dass keine Kunst sie hätte genauer abmessen können. - Ihre verschiedene Zusammenstellung hat auch hier zu ähnlichen Benennungen Anlass gegèben, wie ich schon oben im Allgemeinen angedeutet habe, und später noch ausführlicher darstellen werde.

Die $\mathbf{F}$ arbe der Insectenhaare ist an und für sich so manichfaltig, dass man in dieser Beziehung kaum allgemeine Regeln aufstellen kann. - Es verdient jedoch einer besondern Erwähnung, dass sie sich nicht allein bey allen mit vorrückendem Alter, sondern auch bey denen, die ihre eigenen Häuschen von Schalen zu machen geschickt sind, verändert. Wenn diese nämlich ihre Einpuppung beginnen, so essen sie fast nichts mehr, und in ihren Haaren gehen manchmal recht auffallende Veränderungen vor sich. So haben uns gute Beobachter Raupen beschrieben, deren Haare sehr weiss waren, sich aber in jener Metamorphose binnen einigen Stunden zu schwarzen umänderten. - Da viele dieser Haare wie schon gesagt, blosse Fortsätze der Oberhaut sind, so ist es leicht begreiflich, warum sie mit derselten zur Zeit der Häutung ausfallen, und zugleich durch neue ersetzt werden, welche die alten sogar an Länge übertreffen.

Ich will nun die Linnéischen Ordnungen der Insecten einzeln kurz durchgehen, und die freylich nur in einer sehr kurzen Zeit gesammelten Beobachtungen anführen:

Die meisten Käfer haben an den Seitenrändern ihrer Bauchschilder, an der unteren Seite des Thorax meistentheils büschelförmige, feine, mit der allgemeinen Kërperfarbe übereinstimmende Härchen. Im Allgemeinen trifft man diese am häufigsten an den Rändern des Schildes, der Füsse, der Bartspitze, und hauptsächlich in der Nähe des Afters, im Ganzen aber mehr an der Unterseite des Körpers an. So sind sie z. B. ochergelb beym Scarabacus nasicornis, Ilercules und Actaeon; bey dem Maykäfer (Melolontha vulgaris) befinden sich hinter dem Halsschilde viele Haare, und an der unteren Fläche des Leibes zwischen den Füssen ist er dicht mit gelbbraunen Haaren besetzt. Eben so stehen auf dem Halsschilde und selbst auf dem Kopfe verschiedene, aber kürzere Härchen. - 
Ich habe übrigens diese Haare von Scarabaeus nasicornis genau unter dem Microscope untersucht, und gefunden, dass sie undurchsichtige, mit dem Schilde gleichgefärbte, derbe und daher nur mit einem sehr feinen Canal begabte Fortsätze sind. Die Undurchsichtigkeit und die Kleinheit oder gänzliche $A b$ wesenheit des Canals tritt um so deutlicher hervor, je dichter die Rindensubstanz - das Horngewebe - angehäuft ist, und wenn man melirere Haare von verschiedenen Käfern untersucht, kommt man wohl häufig auch auf solche, die den Canal recht deutlich zeigen. - Doch hat Heusinger*) ganz recht, wenn er behauptet, nie einen Balg mit Bestimmtheit wahrgenommen zu haben, denn es scheint wirklich, dass das Haar mit seiner breiten Basis, ohne eine $\mathrm{Z}$ wiebel zu bilden, unmittelbar aus der Oberlläche des Körpers entspringe; wesshalb denn auch beym Ausreissen derselben immer eine kleine runde Oeffnung in letzterer zurückbleibt.

Unter den Halbflüglern (Hemiptera) zeichnet sich das ganze Geschlecht von Gryllus dadurch aus, dass sie an ihren Füssen auf beyden Seiten eine Reihe ziemlich starker, aber kurzer, mit den Fussbedeckungen gleichfärbiger Stacheln besitzen, die bey den grössern, ausländischen Grillusarten ungleich stärker sind, als bey den europäischen. Auch die Mantis hat an ihren Füssen viele solche stachelförmige Haare. Rea umur**) hat auch Blattläuse abgebildet, deren ganzer Körper mit einer weichen, feinen, wolligen Substanz bedeckt ist.

Viel ausgezeichneter, reichhaltiger und manichfaltiger, überhaupt auf der höchsten Stufe seiner Bildung tritt das Haargebilde bey den $\mathrm{S} c \mathrm{hmetterlingen}$ hervor. Denn ihre llaare bekleiden nicht nur den ganzen Körper als eine dicke, wollige Decke; sondern sie erscheinen hier auch in den manichfaltigsten Gestalten und Farben.

Alle Schmetterlinge, sagt De Geer***), haben unter und vor dem Kopfe zwey rauhe Theile, welche Reaumur Bärte nennt, und zwischen welchen der Saugrüssel zusammengerollt liegt. So verschieden die Arten der Schmetter-

*) A. a. O. p. 257.

$\left.{ }^{*}\right)$ A. a, O. T, III, Tab, XXXI, Fig, 21, 27, Tab, XXXVI, Fig, 1, 4, $5,10,11$.

***) A. a. O. 1ster Thl. p. 50 . 
linge sind, so verschieden sind auch die Gestalten ihrer Bärte. Bey einigen sind sie kurz und dick, bey andern länger und dünner. Einige sind gerade, andere bogenförmig, und sehen wie zwey Hörner aus. Reaumur hat viele Verschiedenheiten beschrieben. De Geer selbst beschreibt die merkwürdigsten Bärte dieser Art an der Phalaena pyralis tentacularis Linnei. - Fast bey allen Phalaenen sitzen am Halskragen zwey glatte, sehr haarige Theile, die gleichsam wie zwey Ohren aussehen, und an den Seiten flach anliegen.

Die R a upen bieten in jeder Hinsicht die grösste Manichfaltigkeit der Haare dar; denn der grösste und auffallendste Unterschied ist bey ihnen unstreitig der, dass einige glatt und olne Haare, andere hingegen rauh, und mit vielen an Länge, Zahl und Stellung verschiedenen Haaren bewachsen sind. - Einige Haare sitzen auf den halbkugelförmigen Erhabenheiten, und bilden auf jeder derselben eine Art von Büschel, bey andern kommen sie unmittelbar aus der glatten Oberhaut hervor. - Wenn sie recht dickhaarige Büschel bilden, so heisst man die Raupen vorzugsweise: Bürstenraupen. Diese Bürsten sind entweder oben abgestumpft und viereckig, wie bey der Phal. bomb. fascilina und pudibunda (welche letztere auch einen merkwürdigen rosenrothen Haarschweif am letzten (Gelenke hat); oder abgestumpft und cylinderförmig, wie bey der Antigua und Gonstigma; endlich trifft man sie entweder, wie bey den meisten Bürstenraupen, auf dem Rücken, oder auch zugleich am Bauche, wie bey der Antigua. Einige solcher Raupen haben nur wenige Haare an sich, und der grösste Theil der Haut ist glatt; man nennt sie halbbehaarte. Andere Verschiedenheiten hat Herr v. R e a m ur angeführt. De Geer beschränkt sich bloss auf die Haarraupen, welche auf gewissen, insgemein halbrunden Buckeln dicke Haarbüschel laben. Von diesen Buckeln, und folglich auch von den darauf sitzenden Haarbüscheln hat R e a u mur sogar behauptet, dass sie ein generisches Kennzeichen abgeben könnten. Denn man findet Haarraupen, die einander an Farbe und Gestalt sehr ähnlich sind, und die man kaum für andere Arten halten würde, wenn man sich nicht die Mühe nälıme, die insgemein ungleiche Zahl der behaarten Buckehn zu berechnen. - De Geer kennt übrigens keine Llaarraupen mit Buckeln und Haarbüscheln, die sich in Tagvögel verwandeln, sondern es waren lauter $\mathrm{Nachtvög} \mathrm{cl}$. 
Anmerkung. Was den Ursprung dieser, Birstenhaare betrift, so habe ich mir Mühe gegreben, der Sache genauer auf die Spur zu kommen. Zwar hat schon Lyone ${ }^{*}$ ) die Haare der Weidenraupe diessfalls sorgfäliger untersucht, und ähnliche Resultate, wic ich gefunden und abgebildet; denn es heisst dort über den Ursprung jener Haare: „Les poils sont enchassés dans un anneau ou cy"lindre tres court, ecailleux et brun, qui s'éleve un peu au des„sus de la peau, et en perce les deux membranes ou tuniques; "le poil passe par cet anneau, et m'a paru communiquer par la "racine avec un tegument molasse, qui tapisse la peau en de"dans, et sur lequel les nerfs forment un tissu reticulaire. J'ai "cru même voire plus d'une fois des petits nerf's de ce tissu s'in"troduire dans la racine d'un poil." Auch hat er die hohlen, mehr stachelartigen Haare mit einer 2,744000 maligen Vergrösserung, die Wurzeln selbst aber, von denen er spricht, nicht deutlich abgebildet. - In der neuern Zeit finde ich ebenfalls in He rold's Entwicklungsgeschichte der Schmetterlinge **) Härchen an der Raupenhaut abgezeichnet, die mit deutlichen kugeligen Wurzeln aus jener Haut entspringen, ohne dass sich jedoch der Verfasser darüber auch nur im geringsten ausgesprochen hätte. - Allein mit allem diesem ist die Sache nicht allein an und fir sich nicht erschöpft, sondern auch für viele Leser unverständlich. - Ich wählte mir daher die Phalaena bombyx Caja, die sich von allen ähnlichen durch Schönheit und Ueppigkeit ihres Haarwuchses auszeichnet, zur Untersuchung, und fand, dass die Anzahl der einzelnen Haare (im Büschel) ganz genau der Menge von kleinen Wärzchen entspreche, welche sich an der äussern Oberfläche jener früher genannten halbkugeligen Erhabenheiten befinden, und dass die Haare selbst unmittelbar aus diesen Wärzchen entspringen, jedoch so, dass man erstere abstreifen und herausreissen kann, ohne dass dadurch die Warze etwas an Umfang verlöre, oder überhaupt zerstört würde. - Um nun auf die innere Structur und Organisation dieser Wärzchen zu kommen, war ich bemüht, die Haut der Raupe umzukehren, um die innere Oberfläche jener warzigen Erhabenheiten genauer sehen zu können. Aber hier war nir die dunkelblaie Farbe dieser schillernden Oberfläche sehr hinderlich. Nichts desto weniger fand ich eine dem Umfang der halbkugelförmigen Erhabenheit ganz. angemessene, ja man kann sagen, genau entsprechende, ovale Grube mit einer Menge von rundlichen Vertiefungen wie punktirt, welche natïrlich nichts anderes, als jene Wärzchen waren. Gegen das Licht gehalten waren jene Stellen, die ich bereits ihrer Haare beraubt hatte, in Bezug auf die andern, die noch mit Haren

8

*) A. a. O. p. 69 .

*) Casscl und Marburg 1815, und zwar auf der 6. - 12. 'Tafel. 
bedeckt waren, lichter und durchscheinend, doch nicht durchsichtig. - Es ist also klar, dass diese Bürstenhaare aus den Haarpapillen, (denn für solche halie ich die angeführten Wärzchen auf den halbkugelförmigen Erhabenheiten) unmittelbar entspringen, und dass hier schon eine Andeutung auf die höhere Struc-

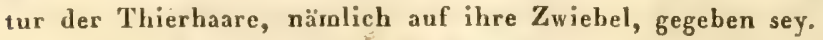

Vergleiche Tab. VI. Fig. $56-59$.

Ich gehe nun zur Betrachtung der Haare, die wir a: den R a upen der Tagrögel (Papiliones) finden, über.

Alle Raupen, aus welchen die Tagvögel der ersten Klasse nach Rössel entstehen, tragen auf ihrer Haut dornenähnliche Borsten oder Stacheln mit spitzigen Nebenästen, wesshalb man ihnen auch den Namen: Dornenraupen gegeben hat. Auch haben diese Papilionen statt des dritten Paares Füsse ein Paar kurze und stumpfe, aber ganz mit Haaren überzogene Pfoten ohne Klauen, deren sie sich als Hände bedienen, indem sie inmer ihren Kopf und Bart damit putzen. Die genannten Dornen sind entweder einzeln stehend, oder büschelformig, und die erstern sind immer entweder nit Seitenstacheln versehen, oder ganz glatt, oder theilen sich oben gleichsam in mehrere Spitzen; manchmal haben sie ganz das Ansehen eines Fichtenbäumchèns im Kleinen, wie z. B. bey der Raupe des C. album; bey Phalaena Prorsa ähneln sie einem Hirschgeweihe. Auf eine ähnliche Art verhält es sich bey der Atalanta und Cardui, die Raupe der Pophia hat gerade Pfriemen mit sich meist entsprechenden Seitenstacheln. Papilio Crategi ist am Leibe über und über haarig.

Die Tagvögel der zweyten Klasse nach Rössel haben Raupen oline Dornen; nur einige sind, und zwar sparsam mit Härchen verselıen, wie z. B. Machaon, Podalirius.

Der Citronenpapilion (Pap. Rhamni) hat eine überaus feine seidenartige Haardecke an seinem Leibe, und zum Theile auch an seinen Flügeln, so auch Didyma (gen. Fritilltria) und mehrere andere Papilionen. Da jedoch der Bau dieser Haare von dem der Nachtschmetterlinge wenig oder gar nicht abweicht, so verspare ich mir die Beschreibung derselben bis dahin.

Unter den Abendvögeln ist bey Euphorbiac zwischen dem Vorder - und Hinterleib oben auf dem Rücken ein breiter Wulst von zarten, weisslichen Härchen; und die sehr feinen Körperhaare der Splinx Convolsuli mas. sind unten viel 
dicker, und werden gleich darauf sehr dünn - sind also keulenförmig - ohne sonst etwas Eigenthümliches zu haben.

Die Raupen der Nachtvögel der ersten Klasse nach Rössel (eigentlich der Abendvögel nach Linné) sind alle haarlos, und haben eine höckrige Haut. Die der zweyten Klasse aber sind theils mit steifen (z. B. PFr. B. Salicis und Lubricipoda); theils mit weichen Haaren (Phal. B. potatoria) besetzt. Andere haben wenig solcher Haare, oder sind ganz glatt (Phal. noct. pyramidea). Die haarigen haben auf dem Rücken entweder Bürsten (Ph. B. fascilina), die bald gross, bald klein sind; oder aus Haaren zusammengesetzte Zapfen (Phal. noct. Psi. Linn. und quercifolia), Spitzen (Phal. B. Salicis) und Hörner (zur Seite des Kopfs bey der Phal. B. fascilina), welche bey einigen auch hinten und vorne zur Seite stehen; andere tragen viele erhabene Knöpfe mit Haaren besetzt, wie Caja, Dispar, Pavonia minor u. dgl. Erstere, nämlich die Raupe der Phalaen. Bombrx Caja ist ganz ausgezeichnet hä rig. Vom Kopf an sind die drey ersten Gelenke mit lauter gelbrorlien Haaren besetzt, und von eben solchen geht ein gelbrother Streifen an jeder Seite des Leibes unten am Bauche bis an den hintersten Absatz. Die übrigen Haare alle, wovou die lïngsten und auf den mittelsten Absätzen emporstehenden fahl, aber $1 / 2$ Zoll lang sind, sehen schwarz aus, und die äussersten Spitzen fallen ins Nausgraue. Die Raupe gebürdet sich wie ein Igel, wenn man sie an den Haaren berührt, denn sie rollt sich sogleich zusammen. Uebrigens fallen die Haare leicht $\mathrm{ab}$, und erregen eben so leicht Kitzel und Jucken auf der Haut des Berührenden. Wenn sich die Raupe einpuppt, so webt sie, wie viele ihres Gleichen, alle ihre Haare mit hinein, wovon sodann dass Gespinnste so dich wird, dass man nicht durchsehen kann; der Schmetterling dagegen bat bloss an der Unterseite des vordern und hintern Leibes sehr viele mennigrothe Haare. - Die Haare der Raupe von Phalaena Cossus bilden solidere starke Stacheln. Die Raupe von Phal. B. Pini ist an allen ihren Rändern und Enden haarig. - Im Allgemeinen haben die Schmetterlinge dieser Klasse alle einen runden gewölbten und haarigen Rücken, und an dem mittlern und hintersten Paar der Füsse eigene Stachelspitzen. Unter mehrern andern habe ich vorzüglich die Haare der Phalaina B. quercus untersucht, wobey ich dann gefunden, dass die ausserordentlich feinen Haare, welche ant 
Rande der Flügel sitzen, beym ersten Anblick gegliedert zu seyn scheinen, was sich aber bey genauerer Beachtung als optische Täuschung erweist; indem diese Haare oberflächlich ausserordentlich fein schuppig sind, und sich von dem Schüppchen der Flïgeln nur durch ihre runde, stachelartige Form unterscheiden. Uebrigens fand ich mehrere, die sich oben an der Spitze ganz wie die Haare mancher Säugethiere bis auf eine gewisse Strecke spalteten, wodurch sie dann wieder den Schüppchen der Flügel nahe stehen. Tab. VI. Fig. 62 ist ein Glied von dem Hinterfuss, welches ganz mit braungelben Haaren bedeckt ist, dargestellt, und Fig. 63 ist die Ansicht eines einzelnen Haars unter dem Compositum abgezeichnet, wo man ebenfalls mehrere dunklere unả hellere unregelmässige Streifen (fasst wie bey den Schuppenhaaren der Säugethiere) im Kleinen sieht, die wie gesagt beym ersten Anblick auf die Idee bringen, dass das ganze Haar fein gegliedert sey, yas sich aber nicht bestätiget. Einen ganz ähnlichen Bau fand ich auch an den Flügelhaaren bey Papilio Rhamni. Doch schien es mir, als hätte ich unter den weissen seidenartigen Körperhaaren einige gesehen, die einen durchsichtigen Canal hatten. Unter vielen beobachtete ich hier bloss ein einziges gespaltenes Haar. -

A nmerkung. 1. Die Puppen von haarigen und Biirstenraupen sind auch mit IIaren besetzt, und die meisten bilden sich von ihren eigenen Haaren während der Einpuppung das sogenannte Ge-

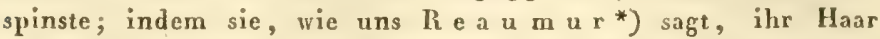
gleichsam ausziehen, oder vorne an, dem Körper mit den Zähnen abbeissen, und vermittelst ein wenig Speichel, oder irgend einer andern klebrigen Feuchtigkeit, sich ein Gehäuse daraus bauen: Einige der Nachtschmetterlinge machen sich auch aus ihren feinen Haaren einen dünnen, aber festen Filz, worin sie ihre Eyer legen. Noch andere Schmetterlinge legen letztere in einer gewundenen finie um, ein diinnes Aestchen, und bedecken sie dann mit ihren feinen Haaren**).

Anmerkung. 2. Es gibt viele Raupen, welche ganz baarig aus dem Ey kriechen, im Alter aber beym Abhäuten ganz kahl werden; während wieder andere ihre Haare durch ihre ganze Lebenszcit biehalten.

*) A. a. O. Tom: I. pag. $503-24$.

**) Elsendaselbst Tom, 11. Tab. III. Fif. 15, 16, 17. 
Fast alle Libellen (Ncuroptera), namentlich aber die Depressa tragen an ihren Füssen feine Härchen. Ich fand diese Haare wie die feinste Seide ganz durchsichtig. An dem langen Hinterleibe sind sie so fein, dass man sie mit blossem Auge kaum bemerkt. Die Haare an den Füssen sind doppelt, feine und borstenartige; letztere sitzen cilienartig an den Rändern der Füsse; die Flügel sind ganz haarlos. Das Insect ist in seinem Larvenzustande voll Haare an der Oberfläche, und vollendet als Wassernymphe trägt sie auch am Rande des Bruststücks ihres Vorderleibs, und am $\mathrm{Kopfe}$ ringsherum solche feine Härchen.

Die Haare an den Füssen der Apis terrestris (Hy menop(era) fand ich den Raupen - und zwar den Bürstenraupenhaaren sehr ähnlich; auch sind sie mit starken Seitenstachelı versehen, gefiedert oder ästig. Die schwarzen Brusthaare ähneln theils den jetzt genannten, grösstentheils aber sind sie feiner, kürzer, und mit viel zahlreichern Seitenästen versehen, die oft fast die Dicke des Stammes haben. Uebrigens sind sie ruthen - oder reiserförmig, wïhrend die Fusshaare nur gewöhnlich ästig sind. - Die Haare der Apis mellifica weichen in threr Bauart von den jetzt beschriebenen nur durch ihre goldgelbe Farbe, grössere Feinheit und Durchsichtigkeit ab. Der Leib der Sirex Gigas ist mit vielen kurzen Haaren bewachsen, welche die schwarze Farbe dieses Insectes matt machen. -

A nmerkung. Ich habe die Ursprungstelle der Hare an der Apis tarrestris untersucht, und gefunden, dass sich die Einpflanzungsart dieser Haare von der bey den Raupenharen angegebenen nur durch giössere Feinheit der einzelnen Haarpapillen und der ihnen entsprechenden Vertiefung an der innern Seite der Haut unterscheiden.

Die Fliegenarten (Diptera) sind alle mehr oder weniger im ausgebildeten Zustande behaart, und zwar an allen Theile-n ihres Körpers mit Ausnahme der Flügel. An den Füssen sind sie wie Cilien in grosser Anzahl gestellt; eben so am ganzen Rande des Rückentheils vom Leibe. Ganz am Hinterleib stehen borstenartige mit feinern Haaren gemischt hervor. An der hintern Fläche des Kopíes, wo er mit dem Brusttheile zusammenhängt, ist ein schöner, fast kreisrunder Seidenbart, dessen Haare jedoch, obgleich viel feiner als die ülorigen, nicht durchsichtig sind. Selbst ihr Fresswerkzeug ist mit vielen ausgezeichneten Borsten besetzt. - Nicht zu übersehen ist es, 
dass es in dieser Familie viele Arten gibt, deren Fühlhörner mit sehr zarten und höchst beweglichen Haaren besetzt sind. Auch die Raubliege (Asilus crabroniformis), hat einen filzigen Unterleib, die Schwebfliege (Bombylius) einen borstigen Schnabel mit horizontalen Klappen, welche wieder borstenartige Stacheln enthalten. - Eben so zeichnet sich das Genus Culex durch einen mit borstenartigen Stacheln bekränzten Mund aus. Culex pipicns hat viele solche Haarborsten an den zwey Fühlhörnern, den zwey Bartspitzen, und an der Schneide des Saugestachels. -

Der F loh (Aptera), kitzelt uns bey seinem Herumspazieren auf unserm Körper grösstentheils desshalb, weil er an dem obern und dickern Theil seiner sechs Füsse viele starke und steife Haare von ungleicher Länge hat. Nebst diesen besitzt er hinter sich stehende, steife und harte Haarspitzen an den zwölf Absätzen seiner Rückenfläche. Der Scorpion ist ebenfalls an allen seinen Extremitäten haarig.

Was nun noch die haarige Bedeckung der Insectenflügel betrifft, so macht uns schon Fabricius ab Ayuapendente* ${ }^{*}$ ) auf die mehlige Materie aufmerksam, die er für eine Art feiner Wolle hielt, und die man nach seiner Angabe vorzüglich auf den Flügeln der Schmetterlinge und Grillen so ausgebreitet findet, dass man sie mit den Fingern fühlt, und sie an diesen hängen bleibt. Malpighi hat die Sache ganz kurz abgehandelt. Desto mehr haben sich die neuern Entomologen um diesen Gegenstand verdient gemacht, und unter diesen vor Allen R e a u m u $\left.r^{* *}\right)$, De Ge e ${ }^{* * *}$ ), L yon e t****), Rössel †), und Heusingertt). -

Ist man so glücklich, den farbigen Staub, welcher die Flïgel der Schmetterlinge bedeckt, mit den Fingern vollkommen rein wegzuwischen, so erscheint der Flügel durchsichtig und olne Farbe. - Der abgenommene Staub zerfällt unter dem Hicroscop in Haare und Schüppchen. Erstere erscheinen als bohle Cylinder, werden manchmal breiter, je weiter sie

*) Opera omnia anatom. et physiologica p. 445. de pilis.

**) A. a. O. und Vol, I. p. 197, u. s. w。

***) A, a. O. Bd. I. p. 55, 57, 60, u. s, w.

+****) A. a. O. Tom. I. p. 108.

†) A. ง. O. Tagvögel CI. I, b. und dessen Nachträgen CI. I. 8. p. 62。

ii) A. a. O. p. 250. 57. 
gegen die Spitze kommen, und gehen so unmerklich in Schüppchen über. Sowohl diese, als die Haare selbst, sind an ihrer Basis hohl, und stecken mit diesem hohlen Stiele in jenen Kleinen, regelmässig in dem obern Blatte des Flügels stehenden Oeflnungen, durch die man dann zu kleinen Bläschen oder Bälgen kommt, welche zwischen beyden Blättern des Flügels liegen. - Heusinger hat diess auf der IV. Tafel Fig. 21, 22 dargestellt. Bey Fig. $23-27$ sind einzelne Schüppchen zu sehen, wie sie an Breite allmälig zunehmen, und sich in diesem Verhältnisse auch oben in mehrere Spitzen theilen, so, dass daraus ersichtlich ist, wie das Haar auf dem Schmetterlingsflügel nur ein gradweise verschiedenes Gebilde von den Schüppchen ist, und so zu sagen in die letztern übergeht. -

B. Thiere mit Skelet oder mit einer Wirbelsäule.

๑. 68 .

\section{Haare bey den Fischen.}

Nanchen meiner Leser wird es auffallen, dass ich bey den Fischen und Amphibien von llaaren spreche. Da ich jedoch schon in dem Vorhergehenden den Begriff von Haaren viel weiter ausdehnte, als gewöhnlich geschieht, so kann ich nicht umhin, auch die Stacheln mancher Fische in diesen Bereich zn ziehen. - Man findet nämlich bey einigen Familien dieser Thierklasse, welche insgemein mit Schuppen gedeckt ist, auch solche, bey denen sich ein Mittelgebilde zwischen Schuppen und Zähnen einfindet. Dieses reihet sich nun in Bezug auf äussere Gestalt, Vertheilung, chemische Bestandtheile und $\mathrm{Z}_{\text {weck }}$ in vielfacher Hinsicht an jene Organe an, die wir sonst Haare zu nennen pflegen. Nichts destoweniger will ich hier nicht übergehen, dass die Abwesenheit eines Canals wenig für eine Analogie mit Haaren, so wie auf der andern Seite auch der starke Zusatz von Kalkerde gegen die den Haaren eigenthümliche Mischung spricht. Indessen kommt es hier doch immer nur auf gradweise Verschiedenheit an; in der 
Wesenheit passen beyde Gebilde gut zu einander; desshalb will ich auch das Nöthigste hierüber anführen.

Blainville*) sagt über die Stacheln der Tetraodonten und Diodonten Folgendes: "Die Lederhaut ist in diesen Fischen gewöhnlich dick, und wie es scheint, sehr ausdehnbar; sie ist sehr faserig, und ihre Fasern kreuzen sich nach allen Richtungen. In dieser Lederhaut sind die Stacheln, womit die Haut bewaffnet ist, befestigt, sie sind kalkig-hornartig, sehr hart, dreyseitig, und ihre Basis ist durch drey $A$ pophysen vergrössert, von denen die vorderste die grösste ist, und mit einigen Muskelfasern in Verbindung steht. Ueber der Lederhaut befindet sich ein perlmutterartig glänzendes Pigment, und eine sehr feine Oberhaut. Im Zustand der Ruhe liegen die Stacheln wie Haare, und sie sind fast verborgen in einer Scheide, die die Haut um sie bildet, und nur durcb die Auftreibung des Körpers und den kleinen Muskel, der sich an sie heftet, werden sie aufgerichtet."

Bey den Selachiern findet man diese Stacheln zuweilen von solcher Feinheit, dass man sie nur durch Streichen bemerkt. In der Regel sind sie spitzig. Die Stacheln der Raja clavata sind durchscheinend, und entstehen aus nach innen ausgehohlten Buckeln oder rundlichen Erhabenheiten, die nach B aster's**) Untersuchungen einen Kern (Zwiebel?) in ihren Höhlen enthalten. - Im Diodon Atinga und maculatus sah Heusinger deutlich die Oberhaut über die Stachel fortgesetzt. - Noch gibt es bey den Fischen sägeförmig gezähnte Stacheln, wie z. B. im Schwanze des Trygon Adanson und anderen Rochen. Auch in dem Geschlechte der Rotzfische fand $\mathrm{B}$ aster bey zwey Arten borstenähnliche Haare, nämlich bey Blennius crislatus zwischen den Augen einen Kamm von feinen schwarzen Haaren, und bey Blenn. maxilla superiore longiore unter den Nasenlöchern kleine Borsten. - Wenn wir also das Ganze kritisch betrachten, so werden wir finden, dass das Stachclgebilde der Fische viele Aehnlichkeit mit den Haaren, noch besser aber mit den Stacheln der andern Thiere habe. - Die

*) A. a. O. p. 148.

**) Job Baster over de Bekledselen van de Huid der Dieren. Verhandlingen van de Holland'sche Maatschappye te Harlem Bd. VI. Tab. XV. Fig. II. - und Baster de squamis piscium Opuscula subseciva Vol. I. 
angegebene Einpflanzungsart, die mitunter gegebene, und offenbar durch lockeres Zellgewebe vermittelte Durchsichtigkeit, und ihr Zusammenhang mit Muskeln entschuldigen es hinlänglich, wenn man sie in die Reihe der beweglichen Haare stellt.

Anmerkung. Ich trage selbst kein Bedenken, auch die Barthaare und Fühlfäden der Fische für modificirte Haare zu halten. Er. stere befinden sich in der Gegend des Mundes, und heissen Cirrhi; letztere findet man oben und an den Seiten des Kopfes, und heisst sie Tentacula. Denen, die von den Seitentheilen des Körpers kommen, hat man sogar den Namen der Finger (D) : giti) gegeben. - Die Zahl der Bartfäden, welche weich sind, ist nicht überall gleich. Cuvier gibt vom Stockfisch und den ïbrigen Gadusarten nur ein Paar, bey der Seebarbe zwey, im Karpfen vier sehr kurze, eben so viel in der Barbe, $6-8$ in den Schlammpeizgern und mehreren Welsarten an. Der Seetenfel, der Krötenfisch u, a. $\mathbf{m}$. haben eine grosse Menge sol. cher Bartfäden im Umfange der Lippen. - Die Fühlfäden der Fische sind von verschiedener Gestalt. Im gefleckten Froschfisch (Lophius histrio) ist der obere Bartfaden $Y$ getheilt, und seine Aeste werden durch eine Fleischmasse zusammengehalten; die übrigen sind lang und kegelförmig. - In dem Geschlechte L ophius sollen diese Organe willkührlichen Bewegungen fähig seyn. - Bey den Arten von Blennius und Scorpaena sitzen die Fühlfäden über den Augbraunen. - Die sogenannten Finger machen schon den Uebergang zu den Flossen. -

5. 69 .

XI. H a arederAmphibicil.

Dieses ist die einzige Klasse der Thiere, in welcher sich gar nichts findet, was mit einem Haar grosse Aehnlichkeit hätte. Denn wemn uns auch $\mathrm{Cuvier}{ }^{*}$ ) sagt: dass man die meisten Schuppen sehr platte Haare nennenkönnte, und Heusinger diese Schuppen auch für plattgedrückte, in der Entwickelung gehinderte, oder ganz unter der Oberhaut liegen gebliebene Haare erklärt; so soll diess wohl nur darauf hinweisen, dass beyde Theile, Haare und Schuppen in Bezug auf ihre Lage, ihren Nutzen und ihre chemischen Bestandtheile viel Analoges haben, ohne dass ich mich desshalb bewogen finden konnte, die letztern in diese Abhandlung aufzunehmen.

*) Vorlesungen 2. Bd, p. 607. 
XII. Ha a $r e d e r \quad V \quad b g \in l$.

F e d e r n.

Im Allgemeinen wird die Bedeckung der Hautoberfläche bey den Vögeln durch die F edern vermittelt; dennoch gibt es einerseits Vögel, von denen man bebauptet, dass sie mit wirklichen Haaren versehen seyen; und andererseits wird angegeben, dass jeder Vogel zu einer gewissen Lebensperiode einzig und allein mit Haaren bedeckt sey. - In der ersten Beziehung trifft man einige wenige $V$ ögel, gleichsam nur ausnahmsweise, an welchen Haare beobachtet werden. Doch glaube ich, dass diese bey genauerer Betrachtung zweckmässiger ha arähliche Federn genannt wïrden, indem ihnen nur der Bart oder die Strahlen abzugehen scheinen. Hieber gehört der männliche Puter, welcher sich durch ein Büschel Haare, die er am Halse trägt, auszeichnet. Diese Haare erscheinen bey ihm erst im dritten Lebensjahre, und ähneln viel den Pferdehaaren, in mancher Beziehung selbst denen des brasilianischen Schweines, und könnten überhaupt den Hornhaaren der Säugethiere angereiht werden; ihre deutliche Theilung, die immer in der Mitte anfängt, bringt sie auf der andern Seite den Borsten der Schweine nahe. Sie sind übrigens urreieckig, wenigstens bald mehr, bald weniger deutlich der Länge nach gerieft, an der Wurzel und Spitze gelbweiss, sonst schwarz und wegen ihres dichten Horngefüges undurchsichtig. Ein Querdurchschnitt zeigt einen weissen, der Oberhaut ähnlichen Ueberzug, worauf eine schwarze Hornmasse folgt, die in dünne Scheiben geschnitten röthlichgelb durchscheinend ist. Ueber die Existenz eines Kanals bin ich nicht ganz im Reinen. - Auch der Strauss und Kasuar zeigen Federn, die in Haare überzugehen scheinen, und im Alter bekommen viele Vögel unter und zwischen den Federn Haare, wie man diess täglich bey allen Hahnen und Hennen beobachten kann. Doch sind auch diess wahrscheinlich nur bartlose Federn. - Ein gleiches Bewandtniss hat es auch mit jenen Haaren, die an den Augenliedern, um die Schnabelöffnung und am Halse vieler Vögel, namentlich der Raben (unter denen die kleine Kaap'sche oder Purpurkrähe drey Loll lange 
haben sollj, der Geyer, Eulen, Spechte, des Ziegenmelker, (welcher an beyden Seiten des Schnabels einen Knebelbart aus langen, steifen, borstenähnlichen Haaren hat), vorkommen. Und sollten die von Baster ${ }^{*}$ ) beschriebenen und abgebildeten Wimperhaare des Sagittarius und der Crotophagi ani, wovon der erste an dem obern Augenliede 30 ungemein grosse und dicke, am untern Augenliede aber nur 14 viel dünnere und kleinere Haare besitzt, hievon eine Ausnahme machen?

In Bezug auf jene Haare, welche man bey allen Vögeln zu einer gewissen Lebensperiode antrifft, behauptet $\mathrm{Cuvier**)}$, dass jeder junge Vogel, so wie er aus dem Ey kriecht, und in den ersten Tagen nach seiner Geburt überall, nur die Gegend des Unterleibes ausgenommen, mit mehr oder weniger dichten Haaren, bedeckt sey. Diese Ilaare treten zu 10-12 Bündeln zusammengestellt hervor, und sind an Farbe und Dicke verschieden. Sie sollen in einen Balg eingeschlossen seyn, welcher das Rudiment oder die Scheide der F eder zu enthalten scheint (?) weil man, wenn nach einigen Tagen die Feder nach Aussen in Gestalt einer schwärzlichen Röhre erscheint, sieht, dass das gemeinschaftliche Bündel Haare an ihrer Spitze hängt, und selbst in das Innere der Scheide dringt. Yerkwürdig ist es, dass diese Haare in dem Miasse ausfallen, als die Feder sich weiter ausbildet, und dass sich später, wenn zur Zeit der Mauser neue Federn erscheinen, keine Spur von Haaren mehr findet.

Der F l a u m (die D u n e n), mit welchem alle Land-, Sumpfund Wasservögel aus dem Ey kriechen, besteht aus weichen Fäden, welche auf der Spitze der eigentlichen Federn sitzen, und durch deren Hervorkeimen verürängt und auf eine Art ausgestossen werden, wie die liilchzähne von den blcibenden. Bey den Wald- und Singrögeln ist der Flaum am unrollkommensten, bricht erst einige Tage nach der Enthüllung des Fötus hervor, und dauert nur 8-14 Tage, wo diese Vögrel schon Flugliraft besitzen. Dagegen bringen die Ra ubvögel ihren Flaum schon mit auf die Welt, und behalten ihn auch länger. Bey den Land- und S umpfrögeln ist er im Ganzen dicht, insbesondere bey den hühnerartigen Vögeln, und dauert 4-5 Wochon. Seine Farbe ist hier meist braun, gelb und

*) A. а. 0 .

**) Vorlesungen 2. Bd. p. 588. 
schwarz gestreift; bey den W asservögeln meist gelb und grünlich, und von $4-8$ wochentlicher Dauer. - Die eigentlichen Federn erscheinen zuerst an den Flügeln, hierauf am Rücken und Schwanze, denn am Bauche, und zuletzt am Kopf und Halse; so bekommt z. B. der Pfau die ersten Flügelfedern schon am dritten Tage nach seiner Enthüllung, seinen Federbusch am Kopfe aber erst in vier Wochen. Diese ersten Federn werden, sobald der Vogel sein Wachsthum vollendet hat, bald gewechselt, obgleich es auch manche Vögel, wie z. B. Wachteln und Truthühner gibt, welche erst im kommenden Jahre mausern ${ }^{*}$ ).

\section{§. 71 .}

$$
V \text { o } n \text { de } n \text { F edern. }
$$

Die den Vögeln ausschliessend zukommende allgemeine Hülle ihres Körpers nennt man das Gefieder. Dieses bedeckt den Vogel grösstentheils, doch sind der Schnabel, die Augen, die Fusswurzeln und Zehen nackt; und ausser diesen Stellen gibt es noch einige, die, obgleich mit Federn bedeckt, dennoch kahl sind, weil aus ihnen selbst keine Federn hervorwachsen. Solche nackte Stellen bilden meist Linien, die von einem Theil zum andern laufen, z. B. vom Oberkiefer nach dem Auge, von den Ohren am Halse hinab nach den Schultern, von dem Brustbein bis zum After u. s. w.

Ausserdem mangeln die Federn manchen Vögeln an gewissen Stellen, wie z. B. den Geyern und Truthähnen am Kopfe, dem Strausse am Unterschenkel, den Fettgänsen selbst an den Flügeln. Umgekehrt sind wieder bey den Eulen selbst die Zehen mit Federn besetzt.

Die einzelnen Theile, aus denen das ganze Gefieder besteht, heissen die Federn; und diese erscheinen wieder unter zweyerley Arten, nämlich als eigentliche Federn, und als haarartige Federn oder Junen.

*) Ueber das Leben der hochnordischen Vögel, von Fr anz Fab er. Leipzig 1826. 8. p. $201-207$.

Joh. Andreas Na u mann's Naturgeschichte der Vögel Deutschlands, nach eigenen Erfahrungen entworfen. Leipzig 1822. 8. mit Kupferı. I. p. $104-111$. 
Am Körper sind alle Federn in Linien geordnet, die einander unter spitzigen Winkeln schneiden (in quincunce); ferner liegen sie dachziegelförmig in der Richtung von vorne nach hinten übereinander. - Bekannt ist die Benennung der $S c h w u n g-$ und Steuerfedern, welche wieder in secundïre oder kleinere, und in primores oder grössere abgetheilt werden. -

Es folgen hier nach $\mathrm{C} \mathrm{u} v \mathrm{i}$ er einige Beyspiele von den Ilauptverschiedenheiten der Federn, ohne jedoch anf die ausserordentliche und kaum zu beschreibende Manichfaltigkeit ihrer Farbe Rücksicht zu nehmen: der Kasuar hat verschiedene Federn, die man im Grunde alle Fla umfedern ohne Fahne nennen könnte. Die fünf Federn, welche an seinen Flügeln sitzen, haben Aehnlichkeit mit den Stacheln des Stachelschweines, wogegen die übrigen Federn sich wieder an die Rosshaare anreihen, da sie ohne Strahlen sind. - Es ist merkwürdig, dass diejenigen Federn, welche die Haube verschiedener Vögel, z. B. des Pfa uenreihers (Ardea paronina) des Buschreihers (Ardea garzetta) u. m. a. bilden, spiralformig um sich selbst gewunden, und dass ihre Strahlen bloss feine Haare sind. Noch interessanter sind die Federn der Nachtraubvögel, indem sie sich durch ihre Weichheit, durch den langen, seidenähnlichen Flaum, womit ihre Strahlen bedeckt sind, und welcher auch den Flug dieser Vögel so leise als möglich macht, auszeichnen, u. s. w. -

Nach dem auffallenden Glanz hat man Seiden-, A tlas-, Metall-und Edelstein-Federn unterschieden, welche letztere sich so bewunderungswürdig schön am Kopf und Hals des brasilianischen Kolibri mit der goldenen Kehle, und mit der rothen Kehle zeigen.

$$
\begin{gathered}
\text { S. } 72 . \\
\text { Organisationderlieder. }
\end{gathered}
$$

Eine Feder (im naturphilosophischen Sinne) ist im Grunde nichts Anderes, als ein verzweigtes oder zusammengesetztes, und zu dem höchsten Grad seiner Ausbildung gelangtes Haar. Im gervöhnlichen Sinne versteht man darunter einen individuellen, selbstständigen Theil des Gefieders, der mit dem einen Ende in der Haut steckt, aus welcher sich dann der röhrenförmige, immer dünner werdende, und an beyden Sei- 
ten mit einer Reihe von Fäden besetzte Schaft in die Atmosphäre erhebt.

So gross auch die Verschiedenheit der Federarten ist, so kommt ihnen doch allen die Grundstructur zu, indem sich bey allen dieselben wesentlichen Theile einer Feder überhaupt vorfinden. Um nun diese letzteren genau darzustellen, nehmen wir eine Schwungfeder des Huhns zur Hand, um sie anatomisch zu betrachten.

Eine solche Feder besteht aus folgenden Theilen:

1. Der Kiel, die Röhre, auch die Spule (Scapus, calamus, tubus). Diess ist jener Theil der Feder, welcher in der Haut verborgen steckt. Er bildet eine durchscheinende, mehr oder weniger cylinderförmige hornige Röhre, von verschiedener Länge. Man unterscheidet an ihm ein oberes und unteres Ende, welche sich beyde in dem Mittelstück vereinigen. Das untere Ende (nach Heusinger und Andern das Grübchen), nach Fr. Cuvier der untere $\mathrm{Nabel}$ ), ist stumpf zugespitzt, und hat an der etwas vertieften Stelle eine Oeffnung, an deren Rand der Kiel eigentlich beginnt, und deren Mitte oder Boden von einer dünnen, glatten, trockenen aber starken Haut verschlossen ist, welche ihrerseits wieder mit dem Rande fest zusammenhïngt, und die man als den Anfang der nachher zu beschreibenden Seele betrachten muss. - Da, wo sich der Kiel an die innere Fläche des Schaftes anschliesst, und wo der zu beyden Seiten des letztern stehende Bart zusammenläuft, befindet sich eine zweyte, durch den äussern Ast der Seele verschlossene Oeffnung, welche man die äussere Oeffoung der Seele, oder den obern $\mathrm{Nabel}$ zu nennen pllegt. Der Kiel selbst hat zwey Flächen, eine innere und eine äussere, welche beyde mit einer hornartigen Substanz überzogen sind, die man wenigstens Aussen die Scheide des Kiels genannt hat. Im Innern zeigt der Kiel eine gleichförmige hornige Substanz, die jedoch häufig Längefasern besitzt, wogegen die Fasern der äussern Fläche quer und ringfürnig sind. Schneidet man den Kiel auf, so zeigt sich ein trockener, häutiger, aus lauter ïbereinander liegenden Zellen bestehender Cylinder, welcher die Seele, oder auch die innere Membran des Kiels genannt wird. Die unterste dieser Zellen grenzt an den untern Nabel, oder an das Grübchen, die darauf folgenden sind sehr kurz, indem sich ihre obern und untern Wände nicht selten berihhren: zuletzt nach oben erweitern sich die Zellen wieder, 
nnd werden länger. Alle Zellen sind mittelst durchlaufender Fi: den mit einander verbunden. - In der Gegend des obern Nabels theilt sich die Seele in einen äussern und innern Ast, wovon ersterer die äussere Oeffnung der Seele, oder den genannten obern Nabel verschliesst, und auf der innern Fläche des Schaftes in dessen Furche als ein bräunliches Fädchen erscheint. Der innere Ast aber setzt sich in den Schaft fort, und endiget sich in dessen Mark. - Endlich ist noch am Kiel der häutig e Ring zu bemerken, worunter man jenen schmalen Ifautheil versteht, der beym Ausrupfen derFeder am Kiel sitzen bleibt, und die Grösse des in der Haut verborgenen Theils vom Kiel anzeigt.

Fr. Cuvier ${ }^{*}$ ) hat an den Schwungfedern, und an den Federn überhaupt zwey Arten von Kielen bemerkt, wovon die eine massir, die andere bis in die Spitze hohl, oder mit einem Canal versehen ist. Bey den Kielen der ersten Art hürt die Seele am obern Nabel auf, indem sie sich an denselben heftet; bey den Kielen der zweyten Art ist sie gleichfalls an diesen Nabel geheftet, setzt sich aber durch die ganze Lünge des Kieles fort. Diese Länge ist übrigens sehr verschieden, natürlich grösser an den Schwung- und Schweiffedern, und kleiner an den Körperfedern und Dunen. Bey manchen Federn, z. B. bey denen am Hypochondrium des Paradiesvogels beträgt die Länge des Kiels kaum $1 /$; , bey andern z. B. bey den Flügeldeckfedern des Flamingo über $1 / 3$ der ganzen Federlänge. Im Allgemeinen gilt nach W e n zel **) nur, dass der Kiel der Schwanzfedern länger, als jener der Schwungfedern ist.

\section{§. 73.}

2. Der Schaft, oder die Ruthe (Rhachis) ist der zweyte Ilauptheil der Feder, und als eine Fortsetzung des Kiels anzusehen. Er fängt gewöhnlich mit zwey, beym Truthahn mit drey spitzigen, oder abgerundeten weissen Schenkeln an, und bildet einen mehr oder weniger länglichen Kegel, dessen eine, die obere Fläche, convex, die andere, untere Flä-

*) Memoires de Museum d'histoire naturelle. 7ieme année. cah. 5. Auch in Froriep's Notitzen aus dem Gebiet der Natur. und Heilkunde. 15. Bd. p. 135.

**) Wenzel C. und J. Bemerkungen ïber die Structur der ausgewach. senen Schwung und Schweiffedern, Tuibingen 1807. 8. 
che, platt und gefurcht ist. An die beyden Seitenflächen setzen sich die Strahlen an. - Wo der Schaft mit dem Kiel zusammenhängt, haben beyde einen gleichen Durchmesser, der jedoch beym Schafte immer mehr abnimmt, indem dieser allmählich in eine Spitze übergeht. Gewöhnlich ist der Schaft nach der Länge gekrïmmt, die obere Fläche plattet sich gegen die Spitze zu mehr und mebr ab, die untere Fläche hingegen ist, und zwar bey den meisten Vögeln nur einfach, im Pfau doppelt gefurcht, und diese Furche nach der Stärke der ganzen Feder mehr oder weniger breit und tief, nach Wenzel bey den wälschen Hühnern am stärksten. - Iın Ganzen besteht der Schaft aus zwey Substanzen, nämlich aus einer äussern Umhüllung, und aus der innern Substanz. Erstere ist glänzend, der Substanz des Kiels ähnlicher, an der obern Fläche am dicksten, an den Seitenflächen am schwächsten. Sie ist ebenfalls hornig, doch weit dünner, als jene des Kiels, und letztere setzt sich auf dor obern Seite des Schaftes weiter fort, als auf der vordern oder untern. Nach Meckel*) wird übrigens der Schaft nicht bloss von aussen mit einem hornähnlichen Ueberzug bekleidet, sonderu es ist auch die innere Fläche seines Schenkels von einer, dicht am Anfange des Schnabels "nach innen zu abgehenden Lamelle des Kiels bedeckt, die sich durch die ganze Höhle desselben und des Schaftes bis zum Ende des letztern fortsetzt, so dass die ganze Masse des Schaftes eigentlich von der Hornsubstanz des Kiels eingeschlossen ist.

Auch die Dicke der Wände des Schaftes ist verschieden, denn die hintere Wand ist weit dicker, als die andere, und an ihrer innern Fläche gerieft. Die vordere Wand ist bedeutend dünner, und die Seitenwände sind ebenfalls verhältnissmässig sehr schwach. -

In der Gegend des obern Nabels fängt die mit der vordern Wand des Schaftes in Berührung stehende zweyte oder innere Substanz, die Kork - oder Marksubstan z (Substantia rhachidis, s. suberosa, s. interna) an. Man vergleicht sie nach Cuvier am besten mit jener Substanz, die man in den Stacheln des Stachelschweines findet. Sie ist gewöhnlich nach ihrer ganzen Länge durch eine Linie getrennt, welche von der Rinne der unteren Fläche des Schaftes ausgeht, und mit

*) Anmerkung zu Cuvier's Vorlesungen im 2. Bd. p. 596. 
welcher zuweilen auf der Rückenseite eine vertiefte Linie parallel geht.

Obschon sich aber im Innern des Schaftes diese lockere Substanz befindet, so ist der Schaft doch mehr oder weniger hohl. Die Weite dieser Höhle nimunt gewöhnlich bis zur Mitte des Schaftes ab, und bleibt sich dann bis zum Ende gleich, nämlich fein, haarförmig. Nach Meckel steht die Länge dieser Höhle bey der ausgewachsenen Feder nicht mit der Länge des Schaftes in Verhältniss, ist aber bey den hochfliegenden Vögeln am längsten, und bey den niedrig fliegenden am kürzesten, ja beynahe ganz obliterirt.

Gewöhnlich ist der Schaft so zu sagen, viereckig, doch geht diese Gestalt mehr und mehr in die runde über, je feiner, zarter die Federn sind. Je biegsamer die Feder überhaupt, desto lockerer ist die Marksubstanz, und desto dünner und elastischer die Hornsubstanz. - Uebrigens unterscheidet sich der Schaft vom Kiel schon durch seine Undurchsichtigkeit, welche bloss von der Marksubstanz herrührt.

\section{74 .}

3. Der dritte Haupttheil der Feder ist der Bart, die Fasern (Radii, telae), welche mit dem Schafte zusammen die Fahne (Vexillum) ausmachen. Nach Andern wird Fabne und Bart für gleichbedeutend gehalten. Der Bart besteht aus vielen einzelnen Strahlen, welches kleine Blätter von Ilornsubstanz sind, und auf den beyden Seiten des Schaftes, mehr gegen die obere Fläche zu, neben einander, und zwar gewöhılich dichter gegen die Spitze hin, und seltener um den Anfang des Schafies herum sitzen. - Indem sie blätterartig an einander liegen, nehmen sie unter einem nach der Spitze des Schaltes zu mehr oder weniger spitzigen Winkel ihren Ursprung. Genauer betrachtet kommen auch aus ihren Rändern viele sehr feine, bald einfache, bald wieder verzweigte Strahlen hervor, die man Nebenstrahlen, Bartfäden (Barbules) nennt. Sind, wie man es wohl bey Falco fulsus, Diomeda exulans, Buceros galeatus u. m. a. trifft, diese letztern ebenfalls wieder mit Strahlen besetzt, so werden diese Stra hlender dritten Ordnung genannt. Uebrigens hat ein jeder Stralıt einen Schaft (Strahlenschaft), der hier freylich bloss aus einem hornartigen, breit vom allgemeinen oder Hauptschaft entsprin- 
genden, und sich allmählich verschmälernden Blättchen brsteht. Ferner besitzt er zwey Ränder, einen innern und einen äussern, die den gleichgenannten Flächen des Schaftes entsprechen; endlich zwey Flächen, eine obere, gegen die Spitze des Schaftes gekehrte, und eine untere, dem Kiel zusehende. Alle Strahlen greifen, so wie sie neben einander liegen, hakenförmig in einander, so zwar, dass sie auf der Seite nach dem Kiele zu kürzer und mehr anliegend, gegen die Spitze des Schaftes aber länger sind, und mehr abstehen. Hängen die Strahlen sehr fest aneinander, so verwachsen sie wohl auch ganz, und stellen so die schuppenförmigen Federn dar, wie wir sie auf den Flügeln der Pinguine treflen. In jedem Fall aber lassen sie den Durchzug der Luft nicht zu. Sonst bietet auch die Beschaffenheit der Strahlen und Nebenstrahlen grosse Verschiedenheiten dar. So gibt es Federn, deren haarartige Strahlen gar keine Nebenstrahlen besitzen, andere wieder, wie z. B. die grossen Kasuarfedern, deren Nebenstrahlen nicht in einander greifen. Ist der Strahlenschaft schwach und dünn, und sind nebstbey die Nebenstrahlen lang, so hängen solche Strahlen frey herab, weil sie nicht in cinander eingreifen, und man heisst sie dann lose oder Flaumstrahlen. Dicse trifft man bey jeder Schwungfeder in der Gegend des obern Nabels, und bey vielen Körperfedern besteht oft $1 / q$, ja selbst die Ilälfe aus solchen Flaumstrahlen. Es ist merkwürdig, dass beym Stransse eigentlich alle Federn nur Flaumstrahlen besitzen. Unter dem Microscop scheinen die Strahlen aus einem bald dichten, bald lockern Zellgewebe $z u$ bestehen, und ziemlich gleichformig zu seyn. Nicht so verhält es sich mit den Nebenstrahlen, vorzüglich den Flaumstrahlen, denn hier erscheint der Bau viel manichfaltiger.

Insbesondere verdient es gewiss aller Aufmerksamkeit, dass die meisten Nebenstrahlen Anschwellungen oder Knötchen bilden, die wieder selbst in einem und demselben Vogel in Bezug auf dichteres Beysammenstehen, Gestalt u. s. w. vielartig abweichen. In der Regel sind sie undurchsichtig, und ragen üher das cylindrische und durchsichtige Stiick des $\mathrm{Ne}$ benstrahls hervor. In Rücksicht auf die Gestalt der Knötchen fand $\mathrm{He}$ us in ger*) cylindrische und herafömige bey sehr vie-

*) A. ค, 0, p. 214. 
Len Vögeln; dreyseitige, pyramidenförmige bey den Enten, scheibenformige bey den Tauben, in der Mitte getheilte beym Pfau und Eichelraben, getheilte und zugespitzic bey den Enten, Rohrdommeln und Pfauen; N e ckel dagegen platte, nach dem Hauptstrahle hin zugespitzte, und nach dem freyen Ende breitere, in den Ordnungen Picae und Passeres; viereckige, scheibenförmige, stark hervorspringende, aber allmählich kleiner und rundlicher werdende bey den Tauben. - Uebrigens bestehen auch diese Knötchen aus einer dichten Hornsubstanz.

Diesen merkwürdigen Bau der Nebenstrahlen, und dic larauf begründete wesentliche Verschiedenheit der Dunen von den Konturfedern hat Nitzsch entdeckt und beschrieben *).

\section{§. 25 .}

$$
\text { F a r b e d e r F e der. }
$$

Lis ist unmöglich, die ausserordentliche Manichfiltigkeit der F a rbe zu beschreiben, womit der grosse Schöpfer den Körper der Vögel aul die bewtinderungswürdigste Art geziert hat; man wird ganz hingerissen von der Schönheit und Pracht der gefiederten Welı!

Im Allgemeinen hängt die Farbe der Feder von jener der Strahlen ab, indem der Kiel und Schaft in der Regel we. nig oder gar nichts dazu beytragen. Heusinger theilt die Farben in matte, metallisch glänzende und irisirende. Die $\mathrm{Fe}$ dern der ersten Art haben einen beynahe gleichen Bau; die Strahlen der metallissh glänzenden sind meist sehr hart, und nach $\mathrm{A}$ udebert ${ }^{*}$ ) auch specifisch schwerer, als die matten. Die merkwürdigste Sache ist jedoch die, dass die versehie. deneFärbung hauptsächlichvonderverschieden. artigen Beschaffenheit, Gestalt, Lage, Mengeund Grösse der beschriebenen Knötchen in den Neben. strahlen abhängt, wie diess bey Heusinger, noch mehr aber in den Untersuchungen von $\mathrm{A} \mathrm{u} d \mathrm{e} b$ e $\mathrm{r} t$ und Nitzsch weilläufiger auseinander gesetzt wird. - Nebstbey scheint jedoch auch die Hornsubstanz des Kiels und des Bartes

*) In Voigt's neuem Magazin. Bd. II. p. $-595-417$.

*) In der Einleitung zur Ilistoirc naturelle des Colibris par A u de. bert et Vieillatect. 
selbst auf die Farbe Einfluss zu haben; wogegen der Clanz derselben theils von der relativen Stellung der gefärbten Theile, theils von der färbenden Substanz selbst abhängt.

\section{§. 76.}

Entstehungsweise und Befestigung der Feder.

Die genaue Untersuchung über die Art und Weise, wie die Feder entsteht, gehört desshalb zu den schwierigsten, weil sich die hieher gehörenden Organe dem Beobachter nie in ihrer Vollständigkeit darstellen; indem sie selbst in ihrer Entwickelung so aufeinander folgen, dass das eine schon abstirbt, während das andere entsteht. Diese Schwierigkeit, verbunden mit dem Mangel an guter Gelegenheit haben mich bisher abgehalten, diesen Gegenstand durch eigene Beobachtungen zu erläutern, und so bin ich also genöthigt, in Kürze nur das mitzutheilen, was andere Autoren und namentlich Al b er t M eck el*), und Fr. Cuvier**) in der neuesten Zeit hierüber erfahren haben.

Ersterer gründete die Geschichte der Entwickelung der Federn auf Beobachtungen an der jährlichen Mauser, und beschreibt sie also: „Auf dem Boden einer röhrenartigen Grube der Haut, in welcher die Feder wurzeln soll, schwellen die Hautgefässe an, und ergiessen eine seröse Feuchtigkeit untér der Epidermis. Der peripherische Theil dieser Feuchtigkeit gerinnt zu einer Membran, der Scheide, welche ein mit Flüssigkeit gefülltes Bläschen darstellt, und an seinem Boden eine Oeffnung, das Gefässloch, hat, durch welches Verlängerungen der Hautgefässe eindringen. Indem diess Gebilde wächst, und gegen die Oberfläche sich verlängert, wird es oval: der nach der Oberfläche zu liegende Theil spitzt sich zu, der Boden bleibt das breitere Ende, und die Scheide bekommt die Form einer Walze mit kegelförmigem Ende. Die eingetretenen Gefässe bilden mit einer gallertartigen Walze, an deren Oberfläche sie sich netzartig ausbreiten, den Kern der Feder (die Z wiebel nach Dutrochet). An seiner Oberlläche ist der Kern mit eyweissstoffiger Flüssigkeit bedeckt, welche

*) In dern Archiv für die Physiologie von J, Ch. Reil XII. Bd, p. $37-96$.

*) A, a, o. 
als Bildungsstoff der Feder dient. Zwischen Kern und Schei de bildet sich nun dicht am Gefässloch cine Schichte halbdurchsichtiger Kügelchen, die sich in Reihen ordnen: je zwey solcher Reihen werden durch eine dazwischen sich bildende Masse vereint, und stellen eine Faser der Fahne dar. An den Seitenrändern jeder Fahne setzen sich einfache, kurze Reihen von Kügelchen $\mathrm{ab}$, welche die $\mathrm{Z}_{\text {weige }}$ der Fahne, oder die Fäserchen bilden. Alle Fasern sind mit dem freien Ende gegen die Spitze, mit dem angehefteten gegen die Wurzel gerichtet. An der innern Oeffnung des Gefässloches verdichtet sich die körnige Mlasse zu einem ovalen Streifen, an dessen Seitenrändern die Fasern der Fahne sich ansetzen; dieser Streifen verlängert sich bald zu einer Platte, welche aus Längefatsern bestehend, hornartig, nach der Spitze cier Scheide zu schmäler wird, gegen das Gefässloch aber mit einem Ringte sich endet: es ist der Kiel, und zwar ist die Platte scin Fahnenstiel, der Ring aber das Rudiment seines röhrigen Theiles. An der entgegengesetzten Fläche bildet sich der Schaft als ein lockeres Gewebe, von den Seitenrändern der Kielplatte in zwey Leisten hervorwachsend, welche sich verdicken, in der Nittellinie zusammentreflen, und so mit der Kielplatte eine geschlossene Höhle bilden, in welcher der Endtheil des gallertartigen Kernes enthalten ist. Nachdem die Fahne sich entwickelt hat, wächst der Ring des Kiels zu einer Röhre aus, welche an der Wurzel nur eine Oeffinung zum Eintritte der Gefässe hat. Die zwey Leisten des Schaftes wachsen ein Stück in den Ring oder den Anfang der Kielröhre hinein, jedoch so, dass zwischen ihnen eine Oeffnung, das Luftloch bleibt, zum Eintritt der Luft, die sich im Gewebe des Schaftes und in der Kiel. röhre verbreiten soll. Die Fahne hat sich zuerst von der Spitze ans entwickelt. So stirbt denn auch der Kern mit seinen Gefäs. sen von der Spitze aus gegen die Wurzel ab, und verwandelt sich in einen Schlauch; ein Stück nach dem andern trocknet und schrumpft zu einem Trichter eiu, so dass der Kern nun als Federseel, wie eine Kette in einander gesetzter Trichter erscheint. Die Scheide wächst anfangs gleichförmig mit ihrem Inhalte, und tritt aus der Hautgrube hervor, erreicht dann oben das Ziel ihres Wachsthumes, berstet an ihrer Spitze, und lässt nun die Fahne austreten. Diese, vorher von der Rüickenseito her gegen die Bauchseite zusammengerollt, entfaltet sich nun. Die Scheide aber bleibt am Kiele als ein membranöser 
anhichender Ueberzug sitzen, der beym sogenannten Ziehen der Feder in Schuppen abfällt."

Dagegen entsteht nach F. Cuvier die Erzeugungsk a j s el der Feder aus einer Hautwarze, jedoch so, dass man erstere nicht als ẹine blosse Entwickelung der letztern ansehen kann. - Zuerst zeigt sich diese Kapsel als ein Cylinder, auf welchem sich oben ein Kegel befindet, der jederzeit früher abfällt, als die Feder vollkommen ausgebildet ist. Unten wird die Kapsel durch eine faserige Haut verschlossen, die in der Mitte eine Oeffnung hat, wodurch die ernährenden Gefässe in das Innere dringen, und die dem untern Nabel der Feder entspricht. Der ganze äussere Theil der Kapsel besteht anis einer membranösen Hülle, welche man Scheide nennt. Diese ist oben fester als unten, weil sie dort aus einem! weisslichen, undurchsichtigen, weichen, dem Ansehen nach knorpligen, unten aber aus einer weichen fibrösen gelblichen Membran besteht. Auf ihrer Nitte bemerkt man der ganzen Länge nach eine gerade schmaie Linie, welche sich durch ilire hellere Farbe auszeichnet. Schlitzt man nun diese Scheide atuf, so erscheint die erste, oder ïussere gestreifte Membran der Kapsel, welche an ihrer äussern Seite glatt, an der innern aber glatt oder gestreift ist, nach der Beschafienheit der von ihr bedeckten Theile. Nimmt man auch diese hinweg, so kommt schon der Bart von unten nach oben eingeschlagen zum Vorschein. Doch sind Anfangs bloss die endständigen Strahlen sammt der Ruthenspitze gebildet; die übrigen Theile aber noch fast olne allen Zusammenhang. Die Nebenstrahlen liegen dicht längs den Strahlen hin. Trennt man die vollkommen ausgebildeten und festen Strahlen, so lindet man zwischen je zweyen immer eine feine Membran, welche Fr. Cuvier die transversale Scheidewand, oiler auch Scheidewand schlechtweg nennt. Diese selbst ist aber nur ein Theil einer zweyten oder innern gestreiften Membran, welche sich zwischen der innern Fläche der von den eingeschlagenen Bartfäden gebildeten Röhre, und dem Kern der Kapsel befindet. Letzterer erhält den Namen der $\mathrm{Z}_{\text {wicbel, }}$ und ist von der innern gestreiften Membran eingehüllt. Die Zwiebel ist der wichtigste Theil der Kapsel, denu sic allein scheint Gefässe und Nerren zu bekommen, und aus ihr entspringt die ganze Feder. - Die vielen Veränderungen, welche die $\mathrm{Z}_{\text {wiebel während des } \mathrm{W} \text { achsthumes der }}$ 
Feder erleidet, machen auch ihre Untersuchung höchst schwierig, und wieder nur an melirern in der Entwicklung begriffenen Federn möglich.

Nach F. Cuvier's Beobachtungen ist die Zwiebel als ein doppeltes Organ zu betrachten, und besteht von dem Puncte, wo der Schaft und die Strahlen entspringen, bis zu dem, wo sie endigen, also von der ursprünglichen Spitze der Feder bis zum obern Nabel, aus einer vordern und einer hintern Portion. Von dem obern bis zum untern Nabel ist sie in allen ihren Theilen einfach und gleichförmig, und communicirt hier einzig mit dem Kiele. In der Entwicklung zeigt sich derjenige Theil der Zwiebel, aus welchem Bart und Schaft entstehen, zuerst; sobald aber der am meisten rorgeschobene Theil seine Bestimmung erfüllt bat, trocknet er till, und verschwindet zum Theil. - Cebrigens entsteht die Zwiebel gleichzeitig mit dem änssern Theil des Schaftes, dem Barte und seiner Membran, und sondert auch gleich Anfangs die verschicdenen Substanzen ab. Nittlerweile entwickelt sich die Kapsel, die Scheide wirft ihre Haube ab, die Spitze des Schaftes schicbt sich hervor, die ersten Strahlen entfalten sich, und ihre Häute fallen durch die Berührung der Atmosphäre und die Reibung als Staub ab. Diess wiederholt sich so lange, als Schaft und Bart sich ausbilden; nach diesem Zeitpuncte wird die Zwiebel einfach, die Strahlen kürzer. Sobald die Erzeugung der letztern aufhört, wird die Liornsubstanz der äussern Ruthenflächı. rings um die $\mathrm{Z}$ wiebel her in grössere Menge abgesetzt, und so fängt sich der Kiel zu bilden an, der in Grunde aus der Vereinigung der Scheide mit der hornigen Substanz entsteht. Zuletzt verkürzt sich die Kapsel ganz, der Kiel rückt dieser" Verkürzung nach, und endigt sich in eine mehr oder weniger stumpfe Spitze, in deren Nitte sich der untere Nabel befindet. Auf diese Art gebildet, steckt nun die Feder mit dem K. örper ihres Kiels in einem hïutigen, ziemilich festen Balge-der sogenannten hörnernen Scheide - welche oben mit der Oberhaut vereinigt, den angeführten häutigen Ping bildet, und unten am Grübchen aufhört. Diese hörnerne Scheide umgibt dest Kiel innig, geht beym Ausreissen der Foder jederzeit mit, und ist jene erste Haut, welche beym soge:nannten Ziehen der Feder abgestreift wird. Der mit diescx Scheide umgebene Kiel steckt in einem eigenen Canal, welcher aus der Oberhaut, der etwas verdickten uad zïhen Lederhat t, 
und einem feinen Epithelium zusammengesetzt wird. Nur oben und unten ist die Verbindung dieser Theile mit der Scheide des Kiels innig und fest. Doch ist zu bemerken, dass das Grübchen stets frey bleibt, d. i. von keinem dieser Theile bedeckt wird, sondern mit dem unterliegenden Zellgewebe, apeneurotischen Fasern und Muskeln in Verbindung tritt. Letztere sind es nun auch, wodurch die Feder verschiedentlich bewe g t wird.

Anmerkung. Heusinger hat gewiss ganz recht, wenn er sagt: dass die Dunen. und Körperfedern in einer ähnlichen Beziehung zu einander stehen, wie die Wollhaare zu den Stammharen bey den Säugethieren. Schon die Befestigungsart der erstern an den Körperfedern spricht deutlich dafuir.

\section{§. 77 .}

Schlussfolgen.

Da ich oben die Feder als ein verzweigtes oder zusammengesetztes, und zu dem höchsten Grad seiner Ausbildung gelangtes $\mathrm{Haar}$ bezeichnete, so muss ich jetzt diejenigen Gründe zusammenstellen, welche mich dazu berechtigten.

1. Zuvörderst haben sowohl Haare als Federn einen und denselben mütterlichen Boden, aul welchem sie entstehen und wachsen.

2. Hat der Vogel im ausgebildeten Zustande nur Federn, und gar keine Haare an seiner Oberfläche.

5. So sehr auch der Bau der Federn von dem der Haare in mancher Hinsicht abweicht, so ist doch beynahe kein Theil der Feder, den man nicht mit einem ähnlichen Theil des Haars vergleichen könnte. So entspricht z. B. der angegebene Canal, in welchem der Kiel steckt, dem Balge der Zwiebel in den Haaren, das Grübchen des Kiels der Haarwurzel, der Kiel selbst dem noch im Balge steckenden Anfangstheil des Haarschaftes, der Federschaft dem freyen Theil des Haarschafts, die Seele und das Mark des Schaftes der Marksubstanz des Haares; die Fahne mit ihren verschiedenen Strahlen den im Thierreich (namentlich bey den Insecten) häufig vorkommenden ästigen Haaren. Selbst das gesellschaftliche Vorkommen der Dunen und Federn findet sein Aequivalent in dem Vereintseyn mancher fei- 
ner Körperhaare mit den Stammbaaren der Thiere, z. B. der Mäuse, Kaninchen u. a. m.

4. Zwischen dem Hären der Säugethiere und der Mauser der Vögel ist wohl kein wesentlicher Unterschied.

5. Auch in den chemischen Bestandtheilen kommen die Federn den Haaren auffallend gleich, denn auch hier ist der Hornstoff der vorwaltende Bestandtheil.

6. Die eigene Verbindungsart der Federn mit Apeneurosen und Muskeln reiht das Federgebilde recht passend an die beweglichen Haare der Strahlthiere, Anneliden u. s. w.

7. Die physiologische Beziehung der Feder stimmt im Allgemeinen mit jener des Haars überein.

8. Endlich erscheinen hie und da, wiewohl unregelmässig, statt der Haare Federn. So kamen zu Naccoomp in der irländischen Grafschaft Cork ein Paar schwarze Kaninchen zur Welt, welche statt der Haare mit Federn bedeckt waren. Der Bart des Federstoffs bestand jedoch nicht aus Flaumen, sondern aus sehr feinen Haaren. -

So sehr nun auch diese Gründe für meine obige Definition sprechen, so muss ich doch auf der andern Seite zugeben, dass in Bezug auf die erzeugenden Organe sowohl, als auch auf die Art der allmähligen Entwicklung zwvischen Feder und Haar eine nicht zu verkennende grosse Verschiedenheit obwalte. Denn während das Haar aus seinem Balge entsteht und wächst, finden wir bey der Feder ein immer vergehendes, und sich immer wieder neu bildendes, eigenthümliches, von der ausgebildeten Feder so zu sagen ganz getrenntes, und bloss zur Erzeugung der Feder bestimmtes Organ, — nämlich ilire erzeugende Kapsel - welche sich durchaus mit nichts Achnlichem der Haare vergleichen lässt, und dennoch, wie leicht einz.usehen, für die Entstehung und Bildung der Feder von der höchsten Wichtigkeit ist.

Vergleiche Tab. VI. Fig. 64 und Tab. VII. Fig. $65-68$.

$$
\begin{aligned}
& \text { §. } 78 . \\
& \text { XIII. Haare der Süugethiere. }
\end{aligned}
$$

Wir betreten nun ein Gebieth, wo das Haargebilde einen so hohen Grad von Ausbildung und eine so allgemeine Verbreitung erhalten hat, dass der gewöhnliche Sprachgebrauch, wenn nämlich bloss von Haaren im Allgemeinen die 
Rede ist, immer die Haare der Säugethiere darunter versteht. Und in der That treffen wir hier das Haar nicht allein in seiner Organisation - also eigentlich in Hinsicht seiner Qualität - sondern auch in seiner Ausbreitung - also in quantitativer Bezie-

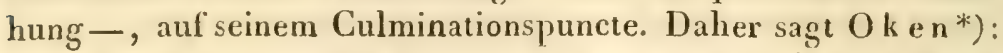
„Da die Säugethiere die höchsten Thiere sind, so kommt ihnen auch die vollkommenste Bedeckung, das Haar, vorzugsweise $z u$, und es ist für sie so wesentlich, dass sein Daseyn oder Mangel entscheiden kann, ob ein Thier zu den Säugethieren zu zählen sey oder nicht, z. B. das Schnabelthier, in welchem dieZitzen noch problematisch sind. Denn kaum mag es ein Säugethier geben, das ohne aller Haare ist. Daher der Spruch: Alle Säugethiere haben Haare, aber nicht alle haben Körperhaare."

Nirgends sehen wir diese grosse Manichfaltigkeit von Haararten, wie hier. Aus diesem Grunde ist es nothwendig das Haargebilde der Säugethiere, nach dem Beyspiele des verdienten Herrn Professors He us inge $\mathbf{r}^{* *}$ ) in einige Unterabtheilungen zu bringen. - Vorerst muss jedoch bemerkt werden, dass das Haargebilde der Säugcthiere als ein Theil des Horngewebes der äussern Haut unter mehreren Formen vorkomme. So gehen die Fasern der äussern Schwiele in der Haut der Cetaccen in das Haargebilde über, indem sie hohl werden; so bildet das Horn des Rhinoceros, in welchem die Fasern des Nagel - und Ilorngebildes ebenfalls hohl werden, den Uebergang in das Haargebilde, und in den Wallfischzähnen findet sich eine ähnliche Annäherung an Horn und Haar. -

Um nun vorerst von den mancherley Arten von Haaren, die wir bey Säugethieren finden, eine allgemeine Uebersicht zu geben, will ich die einzclnen Ordnungen dieser Klasse durchgehen, und diejenigen Thiere anführen, deren Haare in irgend einer Beziehung etwas Merkwürdiges an sich haben; ohne jedoch jetzt schon auf die innere Textur Rücksicht zu nehmen.

\section{§. 79 .}

Erste Ordnung. Affen oder Vierhänder.

Die Vierhänder stehen, wie in so vielen andern Beziehun-

*) Naturph. III. 3. p. 331.

**) A. ง. 0. p. 176 . 
gen, auch rücksichtlich der Haare dem Nenschen am nächsten. Denn obgleich ihre Kopfhaare gewöhnlich nicht länger als die übrigen sind, so beugen sich doch die Haare des Vorderarms gegen den Ellenbogen, im Orang - Utang und einigen andern Arten aber gegen die Hände hin. - Das von Tysson angegebene Kennzeichen, das nur den Affen und dem Menschen eigen seyn soll, und ebenfalls von der Richtung der Haare genommen ist, wurde schon oben $\S .42$ für unhaltbar erklärt. Ich werde nun das Merkwürdigste anführen, wodurch sich manche Affenarten in der fraglichen Hinsicht auszeichnen:

Der Orang-Utang (Simia Satyrus), ist an seinem ganzen Körper mit langen rothbraunen Haaren, so wie der Gibbon ( $S$. longimana) besetzt. Die des Letztern sind jedoch viel gröber. Unter den Meerkatzen zeichnet sich die grossbartige (Cercopithecus latibarbus) durch den breiten, flügelartigen Bart, und durch ein Haarbüschel am Ende des Schwanzes aus. Der blaumaulige Affe (Cer:op. Cephus) fällt sehr durch den gelben Haarbüschel unter jedem Ohr nach dem Gesichte zu, und durch den hellbraunen Streif über die Oberlippe, der die Form eines Schnurrbarts hat, auf. Die gekrönte Mleerkatze (Cere. pilea$t u$ s) hat ihren Namen von den langen Haaren, womit ilire Stirne geziert ist; der Pelz der grauen Meerkatze (Cercop. sabaeus) ist schön gelblich, olivengrau, unten schmutzig-weiss, und an den Backen stehen lange weissliche Haare. Der Backenbart des Mangabey (Cercop. Aethiops) ist bald heller, bald dunkler, grau oder weisslicht. Der Cercop. fuliginosus hat weisse obere Augenlieder, und bey dem Radiatus geht das Haar auf dem Scheitel strahlig auseinander nach Art einer Mütze. Letzteres findet man auch bey der davon genannten Chinesermütze (Cercop. sinicus). - Auf dieselbe Art hat der Colobus polycomos, der gemähnte Stummelaffe, seine Benennung von den langen graulichen Haaren, die vom Kopf bis auf die Schultern herabfallen. - Die Schwanzhaare des Rhesus (Inuus Rhesus), stehen borstenartig ab. Der Wanderu zeichnet sich, wie schon gesagt, durch seine granliche Nähne und weisslichen Bart aus, womit der Kopf eingefasst ist. - Merkwürdig sind auch die Haare des Bärenhundskopfs (Cynocephalus ursinus), besonders in Bezug auf ihre Farbe. Im Ganzen spielt sein Fell aus dem Schwarzen ins Grünlichte; Backenbart, Schultern und Seitentheile sind heller, auf dem Kopf ist die grüne Farbe vor- 
herrschend. Um den Hals hat er eine Nähne, das Gesicht ist nackt, und der ins Graue spielende Backenbart geht nach hinten; der Schwanz endigt mit einer starken Haarzotte. - Sehr fein und lang sind die Haare des J)rills (Cyocephal. leucophacus). Bey dem Mandrill (Cy-noreph. Mormon) finden wir am Kinn einen gelben, kleinen, spitzigen Bart; und auf seinem Kopfe bilden die Haare eine Art von Wulst, welche ihm ein rautenförmiges Ansehen geben.

Unter den Brüllafien gibt es einige, deren einzelne Haare verschiedenartig gefäıbt sind. So ist es beym strolıfarbenen Brüllafien (Stenlor stramincus) an der Wurzel braunlicht und an der Spitze strohfarben; und bey dem Guariba haben die Spitzen der kastanienbraunen Ilaare Goldglanz. - So ist auch die obere Seite des Schwanzes beym Klammeraffen, und seine Spitze braungrau, die Stirnhaare hat er nach hinten, die Scheitelhaare nach vorne gekehrt. - Das weiche, krause (Woll-) llaar mancher Affen hat zu einer eigenen Uiurabtheilung Anlass gegeben: Wollhaarafle (Lugoltrix). Unter den Sajou haben einige selr auffallende liaare. So das Haar des gemähnten (Cebus cirriferns), welches an der Stirn sehr lang ist, und ein Hufeisen bildet; des bärtigen (Cebus barbatus), der dreyerley Farben, überhaupt langes und weiches llaar, und an den Backen einen langen Bart hat; des geschäkten (Ceb. variegatus), dessen Koplhate dreyfarbig: an der Wurzel braun, dann roth, und an der Spitze sehwarz sind. Die Sagoine (Callitrix) zeichnen sich durch ihre schönen hare aus. II umboldts Nachtalle (Aotus Itumboldii) hat an der Spitze weisse, silberglänzende Haare. Mian liann sich des Lachens kaum erwehren, wenn man sieht, mit welcher Sorgfalt der Händetrinker (Pitheci( Chiropoles) sein Wasser mit der hohlen Hand schöpft, um nur seinen Bart nicht nass zu machen. Der Mönch (Pilh. Monachus) hat seinen Namen von seiuer nackten Sirne. Ausgezeichnet sind auch die Schwanzhare des rothbärigen Schweifalten (Pithec. rufibaba), inden sie nach der Schwanzspitze zu immer kürzer werden, woher der Schwanz zugespitzt erscheint. Bey dem gelbköpfigen Schweifalien (Pithoochroccphala), sind die Stirnhaare der Länge nach gescheitelt. Unter den Maki's nenne ich noch den schwarzen (Lemur niger) wegen seiner langen fliegenden Laare am llalse. Der kleine westindische Alle, welchen $\mathrm{B} u f f$ on Mico nennt, hat in Gesichte und an den langen Ohren schön zimnoberrothes llaar. Endlich muss 
ich noch bemerken, dass bey vielen Affen das (resïss schwielig und ganz haarlos ist, z. B. beym Pavian.

80.

\section{Zweyte Ordnung. Fleischfresser (Carnipora).}

Die Handflügler, (Chiroptera), haben meist ein feines kurzes Haar; jenes des kleinsten fliegenden llundes (Ptcropus minimus) ist hoch fuchsroth und wollig. Die Arten des Hundsmauls (Molossus) zeichnen sich durch ihr vielfarbiges Haar aus. Die Flughaut der ägypticchen Spaltnase (Niclinomus (lesypliucus) hat einen behaarten Streif. So gehen auch von der Nase der Brillennase (Phy-llostoma perspicillatum) zwey weisse Streifen zu den Ohren, und bey der gestreiften Blattnase (Phy-llost. lincatum) vier iiber das Gesicht, und einer über den Rücken. - Bey den Galtöopitheken ist auch die Haut an den Seiten des Schwanzes, und an den Ohren mit Haaren besetzt. - Gewöhnlich finden sich bey den Fledermáusen nur sehr wenig Haare auf der Flïgel-, Nasen - nnd Ohrenhaut. Bey der fiulufliegenden Fledermaus (T'espertilio proterus) ist die untere Seite der Flughant längs dem Arme lin sehr stark behaart; eben so auch bey der Leisler'schen Fledermaus; dagegen ist die obere Ilälfte der Schwanzflughaut auf der Riuckenseite bey der Kuhl'schen Fiedermans mit dichten Haaren besetzt. - Die schnauzbärtige Fledermaus (V́cspertilio mystacinus) hat ihren Namen ron dem langen, dichten, weisshaarigen, längs der Oberlippe laufenden Bart, der über die Unterlippe hinaushängt. Eben so erklïrt sich die benennung von der Halsband- (Colluris), der schöngezeichneten (Pictus), der starkbehaarten (Lasiurus), und der langhaarigen Fledermaus (Villosissimus). - In Bezug auf den innern Bau der hieher gehörigen Haare verweise ich auf die unten folgende genauere Beschreibung der Seidenhaare.

In der zweyten Familie der Fleischfresser oder der Raubthiere, nämlich bey den Insectenfressern (Insectivora, Subierranea) kommen wir zuerst auf den Igel, dessen Körper mit Stacheln und Ilaaren so besetzt ist, dass erstere den ganzen Rïcken, letztere den Banch einnehmen. Das Ausfiihrliche iiber diese Stacheln wird weiter unten folgen. - Bey der Spitzmaus steht auf jeder Seite des Körpers 
unter den gewöhnlichen Haaren eine Reihe von gröbern, zwischen welchen nach $\mathrm{C} u$ vier eine riechende Materie ausschwitzt, die in einer eigenen Drüse abgesondert wird. Die Wasserspitzmaus (Sorex fodiens) hat überdiess an den Füssen eine Reihe steifer Haare zum Schwimmen. - Der Pelz des afrikanischen Goldmaulwurfs (Chrysochloris aurata) gibt einen schön metallischen, kupferrothen Schimmer, der nach dem Einfall des Lichts bald mehr ins Grüne, Jald ins Rothe spielt, und dessen einzelne Haare sich durch ihre Randhäkchen auszeichnen. - Die Borstenigel (Centcles) unterscheiden sich von den andern Igeln besonders auch dadurch, dass sie zivar, wie diese mit Stacheln bedeckt sind, sich aber nicht so vollkommen zusammenrollen können, und dass zwischen den Stacheln sehr viele Borsten stehen. - Das Haar des Maulwurfs ist so fein, kurz und dicht, dass die Haut davon eine sammtartige Beschaffenheit erhält. Uebrigens ist es aschgrau bis ins Schwarze, mit verschiedenen Schattirungen nach dem verschiedenen Einfall des Lichts.

Sohlengänger, Plantigrada. Die Haare der Bären sind lang, nicht gar dick, und viel feiner, als die des Igels. Aufenthalt und Lebensart äussern auf sie den bekannten Einfluss; denn der Eisbär hat ganz weisses, langes, glänzendes Haar. Das des langrüsslichen (Ursus longirostris Tiedem.) ist ebenfalls lang, schwarz, glänzend, aber abweichend von dem der übrigen Bären zackig. - In die Familie der Z e h e n gänger (Digitigrada) gehören mehrere Thiere, deren Haar zum 'Theil zum edlen Pelzwerk gezählt wird. Man kann diese Haare nach $\mathrm{Cuvier}$ in zwey Unterabtheilungen bringen, nämlich in feine und rauhe; die feinen sind wiederum doppelt, entweder sehr fein, kurz, und wie untereinander gemengt; oder länger und steifer. Unter die erstern zählt man die Haare des Wiesels, Marders, Zobels, Hermelins, lltis, der Fisch- und Meerotter u. a. m. Zu den Haaren der zweyten Art gehören jene des Zibeththiers, der Katzen und Hunde. Unter den Iltis wird die Haut des Tigeriltis (Mustela sarmatica) wegen ihres artig-gefleckten Ansehens zu Pelzwerk gesucht. Das Hermelin hat das Besondere, dass es alle Winter regelınässig weiss wird. Der Zobel hat vorzüglich stark behaarie Füsse. Der Vison und der Pekou (Mustela Vison und Mustela canadensis), welche beyde in Nordamerika leben, haben Haare unter den Zehen. Unter den Stinkthieren zeich- 
nen sich die amerikanischen Arten alle durch ihren langen, dickbehaarten Schwanz aus. Die Meerotter (Lutra marina), deren Pelı schwarz, und glänzend wie Sammt ist, liefert das allerkostbarste Pelzwerk. - Jedermann kennt die mancherley Arten von Hunden, die sich denn gerade wieder durch ihre Haare so wesentlich und auffallend unterscheiden. - So wie es eine Hundsart (die türkische, eigentlich guineische) gibt, die keine Haare hat, eben so ist der in Merico lebende sogenannte nakte Wolf ganz haarlos. - Der dreyfärbige ( $\mathrm{Ca}$ nis cinereo-argenteus), der Silberfuchs (Canis argentalus), und der Blaufuchs (Canis lagopus), haben ihre Namen von ihren Haaren. Der letztere ist im Sommer schwärzlich, im Winter meist weiss. Auch sind seine Fussballen meist behaart. - Die Civette (Tiverra civelta) hat über dem Rücken und Schwanz eine. Mähne von schwarzen steifen Haaren, welche sich in die Höhe sträuben können. - Der Schwanz der Hyänen ist langhaarig und buschig. - Bekannt sind die Auszeichnungen des Löwen durch seine Mähne über Hals und Schultern, und durch den Haarbüschel am Schwanze, von welchem sich in der neuesten Zeit bey der Section eines in der Menagerie zu Paris gestorbenen Löwen wieder die Angabe der Alten in so fern bestätiget hat: dass sich nämlich, wie auch schon Blum e $\mathrm{nb}$ a $\mathrm{ch}$ behauptete, an der Spitze des Schwanzes ein kleiner Nagel in der Nitte des Büschels schwarzer langer Haare vorfindet. Es ist eine hornartige Bildung, zwey Linien lang, und hängt durch ihre Basis bloss an der Haut, nicht an den Schwanzwirbeln, kann also allerdings dem Haarsystem eingereiht werden. - Tiger, Panther, Leopard, Unze biethen mitunter die schönsten Varietäten von Haarzeichnungen dar, unter welchen die des getropften Panthers (Felis guttala) die seltenste ist. - Der Lucbs trägt auf seinen Ohren einen schwarzen Haarpinsel.

Die Lebensart der A mphibien-Säugethiere machte es nothwendig, dass ihnen der Schöpfer nur kurze, dichte und anliegende Haare gegeben hat. Als Ausnahme hiervon erwälıne ich des rauhen Seehunds (Phoca hispida), dessen Haare nicht glatt anliegen, sondern borstig sind. - Der seidenartige Sechund (Phoca scricea) hat feines, seidenartiges, weisses Haar. Auch die Haare des hasenhaarigen ( $P h$. leporina), die aufrecht stehen, und in einander verwebt sind; so wie des gestreificn (Phoc. fasciata), die kurz und borstig sind, weichen in sofern 
von der allgemeinen Regel ab. - Der gemähnte Seelöwe (Phur. jubata) zeichnet sich durch seine zottige Halsmähne aus. Das Wallross ist mit gelblichen kurzen Haaren bedeckt.

Die Beutelthiere (Mursupialia) haben in ihren Haaren nichts Ausgezeichnetes. Die Lippen des Känguruh mit dem Schnurbart (Halmalurus lubialus) sind gelbweiss mit schwarzem Schnurbart. Das Fell des Wombat (Plascolomys ursinus) ist grobhaarig, nnd an der Oberlippe hat er ebenfalls einen starken Schnurrbart.

\section{§. 81 .}

\section{Dritte Ordnung. Nager (Glires).}

Wir treilen in dieser Ordnung abermals die verschiedensten Arten von Haaren an. Im Allgemeinen sind sie theils kurz, weich und fein, theils lang, rauh und steif, bis zu wahren Stacheln. So ist uns der Biber durch sein nützliches Haar allgemein behannt. Doch sind nicht alle seine Maare so wollicht, sanft, mitunter seidenartig, und nacl: Art der Wolle in Zöpfe getheilt, sondern er hat auch feste und lange llaare. Es ist bemerkenswerth, dass sein Pelz desto dunkler ist, je kälter die riegend seines Aufenthaltes. - Die Stachehatten (Lonrheres) habeu rauhe, platte, breite Haare, velche sich mit einer harten Spitze endigen, und so platte Stacheln bilden. Die abweichende Stachelratte trägt überdiess noch an der Schwanzspitze ein Büschel borstiger Haare. - Der Pelz des Coypu (Iydromys Cospus) wird wegen seiner langen, weichen, und kürzern, sehr feinen Wollhaare zu Hüten beuützt. - Unter den Mäusen zeirl_net sich die Perlmaus (Hus striatus) durch ihre zwölf weiss punctirten Linien, die längs dem Rüclien laufen, und lie gestrichelte Maus (Nus barbnus) durch zehn weise I.inien ebendaselbst aus. Der schuppice Schwanz der rothuasigen Mlaus (Mus pyrrhorhinos) ist an den Ringen mit liorsten besetzt. Interessant ist dic lieobachtung bey dem semeinen Hamster (Cricetus vulgaris), dass sich im Winterschlaf die Erstarrung sogar auf seine Haare ansdehnt, und sie steif macht. - Die Blindmaus (Spalax typhlus) hat das Eigene an sich, dass die Haut ïber den Augen ebenfalls ganz behaart ist. - Die Haare des Ziesel (Arclomys cilillus) haben ein wellenförmiges Ansehen, weil sie graubraun mit schwarz gemischt sind. - Bey den 
Fichhörnchen stehen die langen Schwanzhaare, wie die Bärie einer Feder wach beyden Seiten; mehrere von ihnen haben an den Ohren lange Haarbüschel. Uebrigens füllt der Pelz des europäischen Eichhorns (Sciurus whlgris) desto mehr ins Graue, je nördlicher sein Aufenthalt ist. An dem borstenarigen Eichhorn (Sciurus selosus) finden sich feine Schwanz- und borstenartige Lürperhaare, und bey dem Levaillant'schen sind sie sogar hart und stachlicht. - An merkwürdigsten siod aber die IIaare der Stachelthiere (Hrstrix), wesshalb sie schon in den frühesten Zeiten ein Gegenstand ärztlicher und naturhistorischer Untersuchungen wurden, wie ich weiter unter beweisen werde. - Diese Thieve baben nämlich lange und spitzige Stacheln am obern 'Theile ihres Körpers. - Das gemeine Stachelschwein (IY)strix cristata) ist auf dem Rücken allenthalben mit sulchen schwarzweissen Stacheln besetzt, die wie Federkiele hohl sind; auf dem Kopf steht eine IIähne von längern Haaren, der untere Theil des Körpers ist schwarz behaart, und der Schwanz hat an seiner Spitze offene Stacheln, welche auf dünnen Stielen stehen, und so wie die auf dem Rücken ein starkes Rasseln machen, wenn sie das Thier sträubt, und an einander schlägt. - Die Stacheln des Urson (IJ-strix dorsala) habea feine Widerhäkchen, und fallen leicht aus. Der Schwanz der Hystrix fasciculata endigt in ein Büschel von Stacheln, die ganz platt sind. Die Haare dieser Thiere sind zackig mit kurzen Stachelı. Am Schwanz des langschwänzigen Stachelthieres (Hrstrix macroura) sitzt an Ende ein Büschel ganz knotiter, silberglänzender Stacheln. - Bey dem listigen Stachelthiere (II rstrix insidiosa) bedecken die langen, zottigen, blassgrauen Haare seine Stacheln; und das halbstachelige (Hystrix subspinosa) hat gewellte, gedrehte Stacheln. - Am Hasen finden wir den innern Theil der Lippen und die Fusssohlen auch mit Haaren versehen. Der veränderliche Ilase (Lepus rariabilis) ist im Sommer dunkler von Farbe, (spielt mehr ins Branne,) im Fiühjahr fast silbergrau, seine Schwanzhaare sind länger und graulich, und der Bauch isı weiss; im Winter ist er reinweiss mit schwarzen Ohrspitzen. In Grönland soll er, wie der Eishase (Lepus clacialis), im Sommer ebenfalls weiss seyn. - Das Haar des Aguti ist schön, dick and steif, 'und verschiedenartig gefirbt. Bey dem gemeinen Aguti (Dasypros1a) sind die Haare am ganzen Leibe kurz, rauh, glinzend, auf dem Kreuze viel länger und borstenartig. 


\section{§. 82 .}

\section{Vierte Ordnung. Zahnlose (Edentata).}

Die hieher gehörigen haben im Vergleiche zu den übrigen Säugethieren im Allgemeinen nur wenig Haare, obwohl wir sogleich auf Ausnahmen von dieser Regel stossen werden. Nichts desto weniger bieten uns auch diese Haare eine grosse, Verschiedenheit dar. So ist das Haar des dreyzehigen Faulthieres (Bradypus tridacty-lus) auf dem Scheitel, dem Rücken und an den Extremitäten lang, grob und schlaff, nach $\mathrm{Cuvier}$ wie dürres Gras, und gibt dem Thier ein trauriges Ansehen. - Die Gürtelthiere (Dasypus) haben ausser den Schuppen, zwischen diesen am Kopfe und Rücken noch dünne, kurze und steife Haare, welche den Elephantenhaaren ähnlich sind, aber mit dem Alter ansfallen. Nach Aristoteles findet man beym Dasypus selbst unter den Füssen und innerhalb der Backen Haare, wovon schon früher die Rede war. Der sammthaarige Tatu (Dasypus sillosus) hat weiche, sammtartige braune Haare. - Der grosse Ameisenfresser (Myrmecophaga jubata) trägt lange, breite, geradestehende Haare, der zweyzehige (M. didac(4) la) nur eine feine Wolle. - Selbst die Schuppenthiere sind nicht ganz haarlos, denn zwischen ihren Schuppen stehen feine Borsten. - Hieher gehört auch der Ameisenigel (Echidna), welcher gleich dem Igel stachlich, an dem untern Theile jedoch auch borstig und haarig ist. - Auch zwischen den Schuppen des Schnabelthieres (Ornithorhynchus) stehen, sonderbar genug, winkelartig gebogene, kurze, am Ursprung plattgedrückte, borstenartige, und auf seinen Zehen breite, zweyschneidige Haare; so dass wir also behaupten können, dass auch in dieser Ordnung, gegen die Aussprache mancher Naturforscher, keine ganz haarlosen Thiere vorkommen.

\section{§. 85 .}

Fünfte Ordnung. Dickhäuter (Pachyderma).

Die Viel hufer sind im Allgemeinen nur mit wenig Haaren versehen; so z. B. der Elephant, der nur wenige steife, horstenartige Haare auf seinem Körper hat. Man trifft sie 
manchmal nur auf dem Rüssel, an den Augenliedern und an dem Schwanze. Dieser Haarquaste am Schwanze bedienen sich die vornehmsten Indianer, und insbesondere die Frauenzimmer als eines besondern Zierrathes; von einem lebenden Thiere abgeschnitten, ist sie ein Werkzeug vielfachen Aberglaubens. Bey jenem Elephanten, der in der Menagerie zu Schönbrunn lebt, traf ich dreyerley Haare: die längsten und dicksten an der untern Fläche des Rüssels nahe am Munde, etwas feinere, aber fast eben so lange da und dort am Körper, Rücken u. s. w., und wirklich haarförmige oder gewöhnliche Haare an der Ohrgegend, wo sie büschelartig standen; am Schwanze waren gar keine vorhanden. So verhält es sich auch mit dem Exemplar, das im hiesigen Museum steht. Diese Borsten sind gewöhnlich schwarz, und in ihrer ganzen Länge gleich dick, weil ihnen die Spitzen fehlen. Die längsten fand ich vier $\mathrm{Z}$ oll lang. Eben so lang sollen auch jene seyn, welche am Ende des Schwanzes einen Schopf machen. Es gibt übrigens Elephanten, welche nur sehr dünne und wenig sichtbare Borsten auf dem ganzen Leibe haben. - Die Haut des Flusspferdes ist keineswegs ohne Haar, sondern mit wenig schiwarzen Borsten besetzt. Im Ganzen sind unter den Pachydermen die Schweine am meisten behaart. Man nennt ihre Haare vorzugsweise Borsten, Sie sind alle an ihrem freyen Ende gespalten. Beym Wildschwein ist das Haar struppig und schwarz, übrigens steifer, dicker und härter als beym zahmen, wo es verschiedene Farben hat, und meist gerade ist. - Das guineische Schwein hat nur am Rückgrath Borsten, denn das übrige Haar ist weich. - Das Nashorn (Rhinoceros) ist, nach der Angabe der Autoren, am ganzen Körper haarlos. Ich fand aber in dem Exemplare zu Wien am Hinterhaupt doch einige kleine Borsten von zwey Linien Länge, die sich in eine zwiebelartige Anschwellung endigten. Die zwischen den beyden Hörnern und der Schnauze waren nochmal so lang. Sein Horn sieht gerade so aus, als ob es aus zusammengehackenen Haaren bestünde. Nebstdem bemerkt man an der Grundfläche dieser Hörner äusserlich eine Menge steifer Haare, die von der ganzen Nasse abzuhängen scheinen, und diese Oberfläche raul, wie eine Bürste machen. - Dem Tapir sprechen Cuvier und viele andere Naturforscher alle Haare ab; dennoch hat der im hiesigen Museum nicht nur sehr kuzze Körperhaare, sondern überdiess zolllange Mähnenhaare. - Unter den Ein- 
hufern zeichnet sich das Pferd durch seine runden Haare aus, die man am Schwanze und der Mähne insbesondere Rossha a re zu nennen pflegt. Die Haare der wilden Pferde sind fast wollig. Der Halbesel (Equus hemionius) hat am Schwant ein Haarbüschel, so wie der eigentliche Esel.

\section{§. 84 .}

Sechsic Ordnung. Wiederkäuer (Ruminantia, Pecora).

Das Haar der Wiederkäuer ist im Allgemeinen meist wellenförmig gekrïuselt und kurz, übrigens ebenfalls von grosser Verschiedenheit. - Das Haar des Kamehles ist wie bekannt sehr fein und weich; doch hat dieses Thier auf der Brust und am Knie ganz haarlose Stellen. Zur Zeit des Haarwechsels verlieren die Kamehle fast alles Haar binnen kurzer Zeir. Das Dromedar (Cam. Dromedarius) hat ebenfalls krause, am Schwanze aber lange und harte Haare. Nach meinen Untersuchungen ist das Haar des Lama nicht, wie Cuvier sagt, grob, sondern sehr fein. - Die Vicunne (Auchenia Jicunnu) trägt bekanntlich eine gelbröthliche, seidenartig feine Wolle am Leibe. - Merkwürdig sind die Haare der Bisamthiere durch ihr grobes und brüchiges Wesen; wesshalb man sie fast stachlicht nennen könnte. An Beutel des mảnnlichen Moschusthieres (Moschus moschifor) zeigen sich flache Haare nit wellenförmigen Rändern, die ebenfalls sehr brüchig sind. - Das Hirschhaar ist ganz besonders wellenförmig gestaltet, wie wir weiter unten noch ausführlicher hören werden. Der Elemnhirsch (Cerous alces) hat am Kinn eine Art von Beutel, an welchem ein Bart sitzt, übrigens ist sein Haar lang und grob. - Bey dem indischen Hirschen sollen die Haare hie und da durchbohrt seyn, bey den englischen scheinen sie mit einer schuppichten Rinde bedeckt zu seyn. Uebrigens wird der Edelhirsch (Cersus claphus), der im Sommer gelbbraun ist, in Winter einfarbig graubraun. Doch bleiben das Kreuz und der Schwanz zu allen Jahreszciten blassfalb. Der sehr alte Jirsch wird schwärzer, die Haare am Halse länger und strıl'pichter, wesshalb solche Hirsche von Aristoteles IIippelap/li genannt wurden. - Die Hörner der Giraffe (Camclopardalis) sind nur mit einer haarigen Haut umbïllt, welche nach Cuvier von der Kopfhaut herstammt, und immer bleibt. 
Wir kommen nun zu den Wiederkäuern mit hohlen Hörnern. Unter diesen zeichnet sich die Gazelle (Antilope Dorcas) durch ein Haarbüschel an jedem Knie, der Gemsbock (Antilope Ory.x) durch sein aufwärts gegen den Nacken stehendes Haar, der Klippspringer (Antil. Oreotragus) durch sehr dickes, elastisches, spiralförmig gewundenes, an den Spitzen plattgedrücktes, an der Wurzel weisses, an der Spitze gelb und braun geringeltes Haar aus. - Die Haare der Gemse (Antil. rubicapra) sind grob, lang, im Frühjahr weissgrau, im Sommer rothbräunlich, im Winter oft ganz schwarz. - Das Geschlecht der Ziegen (Capra) ist bekannt durch den Bart. Unter diesen zeichnet sich die angorische Ziege durch ihre feinen seidenartigen Haare vortheilhaft aus. Ihr kommt dic Ziege von Juda am nächsten. Bey der Ziege von Ober-Aegy 1ten bilden die langen Haare am Rückgrath eine Mähne. Den Schafen mangelt der Bart; dafür haben sie langes, krauses, lockiges, unter einander gewirrtes $=$ Woll-Haar. Doch ist das guineische Schaf statt der Wolle bloss mit kurzen Ifaaren bedeckt. Nerkwürdig ist anch der Fettschwanz der persischen, tartarischen und chinesischen Race, bey welchen die Wolle zugleich mit IIaaren gemengt ist. - Unter den Ochsen macht sich der Anerochse (Bos urus) durch sein langes, wolliges, struppiges lfaar bemerkbar, welches Kopf und Hals des Männchens bedeckt, und unter dem Kinn eiuen Bart bildet. Der Ochs mit der Stimbinde (Bos frontalis) hat keine Naihne, weiche Körperhaare, die an der Stirn eine graue Binde machen, und seine Unterlippe ist mit stachlichten Haaren besetzt. - Das Bisamthier (Bjos moschatus) trägt an scinen Fieinen dichte, lange, fast auf die Erde bängende Haare, und sein Schwanz dient den Eskimos zu Mützen, indem seine Haarefuaste das Gesicht bedeckt. - An dem grunzenden Ochsen (Bos grunniens) ist die Nähne und der Schwanz aulfallend, die denen des Pferdes ähneln.

\section{\$. 85.}

Siebente Ordnung. Fischartige Säugethicre (Celacea).

Diese Ordnung der Säugethiere ist dic an Haaren ärmste; dorh hat man auch ihr mit Unrecht alle Haare abge- 
156 Von der Verschiedenheit der Thierhaare etc.

sprochen, indem die grasfressenden Wallfische an der Schnauze Haare und Bartborsten besitzen. Eben so findet man auch auf der grauen Haut des amerikanischen Manati (Manatus americanus) hin und wieder einzelne Haare. Die eigentlichen Wallfische zeigen jedoch keine Spur von Körperhaaren; dagegen schreibt Cuvier dem Wallfisch mit halbmondförmigen Flecken (Balaena lunulata) schwarze, steife Stachelhaare $\mathrm{zu}$, die er an den Kinnladen haben soll, und die vielleicht nichts anders als die schon von Aristoteles beschriebenen borstenähnlichen Zähne des Wallfisches sind. Auch besitzen die Wallfische überhaupt nach Blumenbach wenigstens Augenwimpern.

\section{$D$ rittes Hauptstïck.}

Von der Verschiedenheit der Thierhaare nach ihrer innern Beschaffenheit, d. ¿. nach ihrer Textur.

\section{§. 86 .}

Nachdem wir nun das ganze Thierreich in Bezug auf die verschiedenartige Vertheilung, äussere Gestalt und Umrisse der Haare durchgegangen, und uns somit hauptsächlich mit denjenigen Erscheinungen befasst haben, welche schon bey einer bloss oberflächlichen, wenn gleich in mancher Hinsicht genauen Betrachtung in die Sinne fallen; so erübrigt uns noch, auch in die feinere Organisation des Haares, in seine verschiedenartige Textur einzudringen, und die Merkmahle darzustellen, durch deren Manichfaltigkeit die grosse Menge der Thierhaare in Unterabtheilungen gebracht, $d . h$. in angemessene Gruppen vertheilt, und zum Behuf einer wissenschaftlichen Uebersicht zusammengestellt werden können.

Meinen Untersuchungen gemäss zerfallen die gesammten Thierhaare rücksichtlich ihres innern Gewebes und des damit in Verbindung gesetzten äussern Habitus zugleich in folgende Abtheilungen : 
Von der Verschiedenheit der Thierhaare etc. 157

A. Nach ihrem Baue, und zwar a) in Bezug aus die Zwiebel.

I. Haare als blosse Fortsätze der Oberhaut, ohne Spur einer $\mathrm{Z}$ wiebel.

Hieher gehören :

1) Die Haare der Z o ophyt en.

2) " " Entozoën.

5) " " Strahlthiere.

4) " " A r achniden.

5) " " " Anneliden.

6) Das äussere Haargebilde der Crustaceen.

7) Die Haare der Mollusken und Cirripeden.

II. Haare, die nicht aus der blossen Oberhaut, sondern aus einem zwiebelartigen Körper, oder einem wirklichen Balge, der die $\mathrm{Z}_{\text {wiebel }}$ eils chliesst, entspringen.

Ich zähle hieher nach der stufenweisen Ausbildung der Zwiebel und des Balges:

1) Die Haare der Insecten.

2) Das innere Haargebilde der Custaceen.

3) Die Haare der Fische.

4) " " Vögel.

5) " " $"$ S äu g e thiere.

b) In Rücksicht a uf die Beschaffenheit der Substanz.

III. Haare, die mehroderminder deutlich aus zwey Substanzen, der Rinden- und Marksubstanz bestehen.

Hieher gehören :

1) Die Haare der Strahlthiere.

2) " " Anneliden.

3) " " $"$ Arachniden.

4) " " Crustaceen.

5) " $"$ Insecten.

6) " $"$ F ische.

7) " " $"$ Vögel.

8) " " $"$ Såugethiere. 
158 Von der Verschiedenheit der Thierhaare etc.

IV. Haare mit einer einfachen Substanz, diezugleich meist hohl sind:

1) Die Haare der $Z$ o o phyten.

2) " " Nntozoën.

5) " " $"$ Cirripeden.

B. Nach Massgabe der. Beweglichkeit der einzelnen Haare, insofern dieselbe unabhängig oon derHaut, und durcheigene Muskeln bodingt wird.

a) Ganz unbeweglich sind:

1) Die Haare der Arachniden.

2) " " $"$ Crustaceen.

5) " " $"$ Sängethiere.

b) Beweglich, jedochohne nachweissbare Muskeln:

1) Die Haare der Z oophyten.

2) " " Entozoёn.

5) " " " Girrhipeden.

c) Beweglich durch deutliche Muskeln:

1) Die Hare der Strahlthiere.

2) " " Anneliden.

3) " ,, Fische.

4) „Federn der Vögel.

\section{§. 87.}

Die Haare der Säugethiere, als die vollkommensten unter allen, unterscheiden sich wieder manichfaltig in Bezug auf ihre Textur, und desshalb ist es nöthig, sie abernals nach dem Grad ihrer vollendeten Organisation in folgende Unterabtheilungen zu bringen:
1) Wollh a are.
2) Seidenhare.
3) Borsten.
4) Hornhare.
5) Stachelhare.
6) Platte Haare*).

*) Diese machen den Uebergang zu den Schuppen, so wie die Woll-Hlare dern Haargebilde der niedern Thierklassen am nächsten kommen. 
7) Gewöhnliche Haare, gefleckte, Zellenhaare.

8) Tasthate.

\section{§. 88 .}

\section{Von den Wollhaaren.}

Ich habe die Wolle von unserm, dem Merinos-, und von dem chinesischen Schafe mit dem Microscop untersucht, und allerdings eine auffallende V'crschiedenheit gefunden. Im Allgemeinen sind alle Wollhare abwechselnd rechts und links gebogen, und ihr Schaft hält nicht immer den gleichen Durchmesser, sondern scheint da und dort verdickt, manchmal sogar knotenartig angeschwollen zu seyn. Man kann sich jedoch hierin sehr leicht durch den fast jeder, auch der reinsten Wolle noch anklebenden Schmutz betrügen, und so verführt werden, die Schmutzknötchen für Anschwellungen des Haars zu halten. Ich bemerkte überall deutlich die sogenannte Marksubstanz - den durchsichtigen Canal - und konnte sie aufs genaueste von der Rindensubstanz unterscheiden. Doch lag gerade in dem verschiedenen Verhältniss beyder zu einander das Hauptmerkmal, wodurch sich das fcinere Wollhaar von dem gröbern unterschied. Die Rindensubstanz erscheint zwar in beyden fast gleich dick, und wenigstens am Rande undurchsichtig, dagegen war der sogenannte Canal in so fern verschieden, als er bey der gemeinen Wolle in viel mehr unregelmässige zellenartige Räume getheilt zu seyn schien, wahrend beym Merinoshaar die Zellen regelmaissi.er an Grösse aneinandergereiht waren. Diess rührt olme Ziweifel davon her, dass das blättrige liesen, welches die Medullarsubstanz des Haars ausmach, bey unsern Schafen ungleich zahlreicher, daher näher aneinandergedrängt, auch verschicdenartiger unter sich verbunden ist, ais beym Meriacs, wo der ganze Canal gleichsam nur durch querlaufende feine Blättchen treppenartig abgetheilt erscheint. - Auch die Zwiebel sah ich deatlich, obgleich ll eusinger*) das (Gegentheil angibt. - Die Merinoswolle von der Nasterherde, welche be- 
sonders fein ist, zeigt die Querblättchen nicht immer in gleichen Entfernungen; auch schien mir der Durchmesser des Haars nicht überall gleich. Das Haar der tibetanischen Ziege, wovon die Kashemir-Shawls gemacht werden, kömmt in der innern Textur der Merinoswolle sehr nahe, nur ist es noch feiner, kleiner im Durchmesser, und die Querblättchen scheinen mir nicht so regelmässig gestellt. - Das chinesische Schaf hat Wolle und gröbere - eigentliche Stammhaare. Erstere kommt fast ganz mit der Wolle der Merinos überein, letztere biethen in Bezug auf die gewöhnlichen Haare nichts Auffallendes dar. - An diese - eigentlichen Wollhaare reiht sich die Wolle der Kamehlarten, und zwar zunächst das Wollhaar des Lama. In den feinen Wollhaaren des Dromedars fiel mir der sehr breite, da und dort gleichsam verdunkelte, eigentlich mit dickerer Rindensubstanz bedeckte Canal durch die artigen Figuren auf, welche er auf diese Art unter dem Microscop zur Ansicht brachte. Ich habe selten das blätterige Gefüge der Marksubstanz besser gesehen, als gerade hier. Uebrigens haben die Kamehle durchaus nebst der Wolle noch gröbere, undurchsichtige Körperhaare - sogenannte Stammhaare.

Selten wurde eine Haargattung genauer untersucht, als gerade die Wolle, wovon der Grund in der verschiedenartigen 'Tauglichkeit, und dem dadurch gesteigerten Preise derselben im Handel ist. - Man hat sich sogar die Mühe genommen, den Durchmesser der einzelnen Wollhaare zu bestimmen, und angenommen, dass das feinste Wollhaar des Schafs einen Durchmesser von $\$ 3 / 20000$ engl. Zoll, und einen Umkreis von $\frac{40 \%}{20000}$, das stärkste aber einen Durchmesser von $\frac{7_{3}}{20000}$ engl. Zoll habe*).

Man fordert übrigens von einer guten, edlen Wolle

1) Dass sie gleichmässig fein sey. Die gewöhnlichste Form des Wollhaars ist die runde, ich habe wenigstens keine eckige gesehen; eben so wenig kann ich der Leu we nh o ek's chen und Wagner's chen**) Ansicht, dass die Wolle Aeste oder Widerhaken besitze, das Wort reden: ich muss diese scheinbaren Verlängerungen vielmehr mit

*) Block in Webers Schrift über Gewinnung der feinen und edlen Wolle. Breslau 1822. 8.

**) Beyträge zur Kenntniss und Behandlung der Wolle. Berlin 1821. 8. 
Heusinger für anhängenden Schmutz erklären. Nichts desto weniger zeigt schon meine Abbildung des gemeinen Wollhaars, dass ich sie da und dort knotig fand.

2) Dass sie gehörig sanft und milde anzufühlen sey; ohne dass jedoch diese Eigenschaft von dem anklebenden Schmutze oder Fette herrühre. Heusinger hat gewiss ganz recht, wenn er die Weichheit der Wolle mit der geringen Menge von Hornsubstanz in ursächlichen Zusammenhang bringt; ich möchte nur noch das beysetzen, dass mir eine Wolle um so milder und überhaupt feiner $z u$ seyn scheine, je feinblätteriger die Marksubstanz, und je geringer die Anzahl der sie bildenden Zellblättchen ist. 3) Sehr viel Gewicht legen die Oekonomen auf die gleichmässige, und zugleich feine Kräuselung der Wolle. Ersteres findet dann statt, wenn sich die oben genannten Biegungen der Wolle nach der einen und andern Seite in Bezug auf Grösse vollkommen gleich sind; und fein ist die Kräuselung, wenn die Bogen nur kurz sind. - Im Allgemeinen weist es sich wirklich nach, dass feine Wolle auch kleine Biegungen oder Bogen macht.

4) Es gehört ferner zu den Eigenschaften einer guten Wolle, dass sie angemessen fest - nervig (nach der Sprache der Wollhändler) - sey. Diese Eigenschaft trifft mit der unter $\mathrm{Nr}$. 1. angeführten zusammen; denn die Wolle trägt ein um so grösseres Gewicht ohne zu zerreissen, je gleich. mässiger fein sie ist. -

5) Was den Glanz betrift, so ist er ausserordentlich verschieden, weil er von so vielen Zufälligkeiten abhängr. Main kann im Allgemeinen diejenige Wolle nicht für die beste halten, die am meisten glänzt, weil sie dann oft zugleich spröde und brüchig ist. Es hat also der Glanz nur einen bedingten Werth. Endlich ist noch

6) Die Krimpekraft der Wolle zu berücksichtigen, welche nach unsern Begriffen mit ihrer Elasticität zusammenfallt. In dieser Hinsicht ist zu bemerken, dass die Elasticität der Wolle gleichen Schritt mit den von 1-5. angeführten guten Eigenschaften hält, und dass sie namentlich auch noch mit dem Gesundheitszustand der Schaafe in geradem Verhältniss steht.

A ninerkung. In Bezug auf den Grad der Vollkommenheit des Baues der Wollhaare habe ich schon erwähnt, dass sie zu den einfach. 
sten Thierhaaren gehören, und denen der wirbellosen Thiere, $\mathrm{ja}$ in mancher Hinsicht sogar den Pllanzenharen sehr nahe kom. men. Es ist daher der Vergleich recht passend, welchen II eus in. ge $r$ in dieser Beziehung anstellt, wenn er sagt: die Wolle verhält sich zum vollkommnen Har, wiedie lym. phatischen Gefässezu den Arterien.

Vergleiche Tab. VII. Fig. 69-71.

\section{§. 89 .}

\section{Von den Seidenhaaren.}

Diese stehen den vorhergehenden Haaren in jeder Hinsicht ganz nahe, und unterscheiden sich von ihnen nur durch ein stärkeres Verhältniss der Rindensubstanz zur Marksubstanz, und dadurch, dass sie in der Regel nie kraus sind. Uebrigens variirt die Beschaffenheit des sogenannten Canals so, dass er bey den Haaren eines jeden hieher gehörigen Geschlechtes verschieden ist, und man daher bey Bestimmung der allgemein gültigen Merkmale der Seidenhaare von ihm ganz abstrahiren muss. - Man versteht also unter einem Seidenhaar dasjenige, welches 1) in Bezug auf Feinheit nurderWolle nachsteht; 2) nie so fett, wie diese, ist, und sich 3) nicht kräuselt. - Ich zähle hieher die Haare der meisten $\mathrm{Nag}$ er, also des Bibers, der verschiedenen Mäusearten, des Hamsters, Hasens, Eichhörnchens, ferner des Marders, Wiesels, der Meerotter, des Maulwurfs, und der meisten $\mathrm{H}$ and flügler (Chiroptera).

Die meisten der hieher gehörigen Haare sind wegen ihrer Feinheit, oder besser gesagt, wegen des geringen Antheils von Rindensubstanz, und des überwiegenden innern (Mark-) Gewebes, unter dem Microscope, wenn gleich etwas weniger als die Wolle, durchsichtig. - Die eigenthümliche Gestaltung, und das gegenseitige Verhältniss des durchsichtigen zu dem nichtdurchsichtigen dieser Haare macht sie höchst verschieden unter einander, und bringt mitunter die artigsten $\mathrm{Fi}$ guren zum Vorschein. Namentlich zeichnen sich in dieser Hinsicht die Haare der Mäuse aus, deren einzelne Species immer wieder in etwas von einander abweichen, so ähnlich sie sich auch im Ganzen beym ersten Anblicke schon sind. Zur Versinnlichung der Eigenschaften dieser Haarart habe ich Stückchen von den Haaren des Maulwurfes, des Hasens, Eich- 
hörnchens, und einiger Fledermäuse abbilden lassen, wobey ich jedoch bemerken muss, dass, so sehr auch diese Abbildungen von denen Anderer (z. B. von Heusinger), und vorzüglich von jenen abweichen, die in einem kleinern Massstabe genommen sind, ich einerseits doch für ihre Aechtheit und Richtigkeit gut stehe, andererseits aber auf den Umstand aufmerksam mache, dass der grössere oder kleinere Massstab der Figur cine so auffallende Verschiedenheit mittheile, dass man im ersten Augenblicke gar nicht mehr das zu finden glaubt, was man doch so eben, aber bedeutend grösser oder kleiner, gesehen hat. Zur Bekräftigung dessen dient ein Vergleich zwischen Figur 77 und 79. Mlit Uebergehung der charakteristischen Eigenheiten der abgezeichneten Seidenhaare, rücksichtlich welcher ich auf die hinten folgende Beschreibung verweise, will ich jetzt noch einiger nachträglich erwähnen, die ich gleichzeitig mit jenen untersucht habe.

Nach Meckel sind die Haare der Hausmaus in regelmässigen kleinen Entfernungen mit erhabenen Reifen besetzt. Diese sind schwarz, die $\mathrm{Z}$ wischenräume weiss, und daher soll dann die graue Farbe dieses Thieres rühren. Professor Nitsch fand diese Structur bey allen Thieren, deren Seidenhaar aschgrau erscheint. Ich lasse letzteres dahin gestellt seyn, muss jedoch in Bezug auf die erhabenen Ringe bemerken, dass sie auf einer blossen Täuschung beruhen, indem sie, bey dem, dass das Haar ganz glatt ist, bloss von einer so eigenthümlich mehr angehäuften, und dadurch undurchsichtig gewordenen Hornsubstanz herrühren. Es gibt in der That in der ganzen Haarlehre nichts Interessanteres, als die Vergleichung der Maulwurfs-, Blindmaus-, Mäuse-, Ratten- und Hamsterhaare, und wenn mich nicht die Weitläufigkeit und Kostspieligkeit der Sache abhielte, würde ich diese Reihenfolge sinnlich dargestellt haben, wovon sich übrigeus ein Jeder leicht selbst iiberzeugen kann. Leuwenhök und Ruysch hielten das Haar der MI us für das durchsichtigste von allen (die Wolle ist gewiss noch durchsichtiger, nur muss sie frey von Schmutz seyn); es schien ihnen eine einzige durchsichtige Röhre zu seyn, die ein Mark enthält, welches aus Fasern zusammengesetzt ist, die eben so viel dunkle, in einigen Haaren querliegende, in andern spiralförmige, manchmal gegliederte Linien bildeten. - Die Körperhaare der Blindmaus unter- 


\section{Von der Verschiedenheit der Thierhaare etc.}

scheiden sich von denen des Maulwurfs nur dadurch, dass die etwas stärkern manchmal einen punctirten Canal haben. Bey der Feldmaus sind die dunkeln Querringe breiter, also auch näher aneinander gerückt, als beym Maulwurf; die Rattenhaare haben viel mehr Schmutansiize, und sind nicht sowohl gebändert, wie z. B. die IIaare von Talpa, sondern im eigentlichen Sinne des Wortes geringelt, dorh so, dass die einzelnen Ringe nicht nıehr so gleichartig vertheilt, also unordenticher gelagert sind, als bey den iibrigen Müusearten. Bey den Haaren der eigentlichen Feldmaus (Hy-pudaeus), welche im Ganzen wohl mit denen der Mus arralis übereinkommen, fand ich, namentlich in den grössern derselben, die Ringe so doppelt, dass ich in Versuchung kam, zu glauben: die Haare lägen doppelt neben einander. - Die Körperhaare des Hamsters sind fast denen des Maulwurfs gleich, doch sah ich unter ihnen einige, die den Rattenhaaren nahe kamen, wo nämlich die Ringe ebenfalls so unordentlich aneinandergereilit, oft mehr oval waren. - Auch in den feinen Haaren des Lepus variabilis fand ich einen ähulichen Bau, wie bey den Mäusen, nur mit dem Unterschiede, dass die Ringe näher an einander lagen, so zwar, dass man sie wegen ilirer Kleinheit und des ausserordentlichen Zusanmengedrängtseyns kaum von einander unterscheiden konnte.

Unter mehrern Haaren des gemeinen Wiesels (Muslela rulgaris), die ich zu gleicher Zeit unter das Vergrösserungsglas brachte, fand ich eine grosse Verschiedenheit. Die dicksten waren fast undurchsichtig, doch hie und da wie mit Kleinen durchsichtigen Puncten besetzt. Bey den feinen, und daher durchsichtigen sah ich einen geringelten Cánal, fast wie bey den Maulwurfshaaren. Noch andere schienen aus laute: Marksubstanz zu bestehen, deren Zellen ich sonst nie so schön vor mir ausgebildet sah. - Die Haare von Mustela foina, dem Marder, sind ganz undurchsichtig, die des Hermelins scheinen einen undeutlich geringelten Cinal zu haben, und bey der Mustela putorius hat der Canal das Eigene, dass die Marksubstanz undurchsichtig, aber durch einen lichten, gleichsam gezähnten Streifen auf jeder Seite von der ebenfalls undurchsichtigen Hornsubstanz unterschieden ist. Das Haar der Mustela lutris ist wollartig, übrigens wie aus langen Gliedern z11sammengesetzt, die sich seitwärts etwas verlängern, fast wie bey der Tespertilio pipistrellus. - Man kann es wirklich als 
eine aufallende Eigenheit der Fledermaushaare anseben, dass sie aus einer geraden und schwach durchsichtigen Linie zu bestehen scheinen, um welche sich eine andere undurchsichtige spiralförmig herum schlingt. So fand ich es bey den Haaren der Tespertilio noctula, pipistrellus, auritus und mystacinus nuit sehr geringen $\mathrm{Abweichungen;} \mathrm{doch} \mathrm{am} \mathrm{Vampyr} \mathrm{(Pteromys} \mathrm{edu-}$ lis) zeigt sich die gewöhnliche Structur der Haare. - Da ich durch die Güte des Herrn Barons Jac quin die Haare von sechzehn Arten Fledermänse und einige ihnen verwandter Thiere erhielt, so wird es nicht am unrechten Orte seyn, wenn ich die Verschiedenheit ihrer innern Textur, so wie sie mich eine sehr genaue Untersuchung lehrte, hier deutlich auseinandersetze. - Die Haare von Vespertilio pipistrellus und murinus sind fein, und letztere höchst regelmässig spiralförmig gedreht; the von Tesp. serotinus ähneln dem vorigen ganz, unterscheiden sich aber dennoch dadurch bedeutend, dass das Mittelstiick, umu welches sich die Spirallinie dreht, durchsichtig ist, was ihnen denn ein ganz besonders schönes Ansehen gibt. - Vespertilio Schreibersi hat noch feinere Haare, deren Spiralwindungen zwar weiter auseinanderlaufen, aber wegen ihrer Kleinheit kaum sichtbar sind. - Die Haare von Vesp. noctula und auritus kommen denen von Pipistrellus ziemlich nahe. - Auch die Haare der Nycteris thisbaica gleichen denen der Tespertilio murinus. Nerkwürdig ist der Unterschied zwischen den Haaren der Pteropus - Arten; denn während sie bey Pteropus aegyptius noch so gedreht sind, dass die Windungen schnell auf einander folgen, und so gleichsam das Ansehen von geringelten Haaren darbieten, gleichen die Haare von Pleropus rubicollis beynahe ganz der Nierinosivolle, und sind daher nicht gedreht; die von Plcropus Edwarsii sind sogar ganz gleichartiz rund, und zeigen im Innern ein sehr schönes netzartiges Gefüge; und die von Pteropus edulis sind ganz undurchsichtig. Phy-llostoma Spectrum hat dem ersten Anscheine nach ebenfalls runde Haare, aber bey genauerer Betrachtung findet man sie doch auch spiralformig; doch ist die Spirallamelle so fein und schmal, dass man sie kaum wahrnehmen kann. - Bey den Haaren des Phyllostoma haslatum stehen die Drehungen der Spirallamelle weit von einander ab, und das ganze Haar ist durchsichtig. - Die Haare des Rihinopoma microphy-llum gleichen wieder jenen von Verp. pipistrcllus, doch haben sie eine breitere Spiralplatte. - Taphozous perforalus komme dem vorigen zicmlich nahe, zeichnet 
sich aber vor allen dadurch aus, dass die einzelnen Spiralwindungen beynahe horizontal stehen, wodurch diese Haare ebenfalls ein sehr schönes Ansehen erhalten. - Bey den Haaren des Rhinolophus unihastatus ist der Schaft ganz durchsichtig, die Spiralplatte sehr fein, kaum hervorspringend. - Der Galeopithecus variegatus hat runde, geringelte Haare, wie die Näuse; Molossus obscurus wieder ausserordentlich feine Haare, die denen des Vesp. pipistrellus ähneln. - Die Haare von Cephaloles Pallasii sind wie bey den Mäusen.

Der afrikanische Goldmaulwurf (Chrysochloris aurata) hat feine Haare, an denen man gleichwohl keinen Canal erkennt, die aber die schönsten Querzellen zeigen, dagegen hat Chrysochloris radiata geringelte Haare, wie der europäische Maulwurf, nur mit dem Unterschiede, dass sie an den Seiten in regelmässigen Entfernungen Aestchen oder Häkchen tragen, die ihnen ein eigenthümliches Ansehen geben.

Noch muss ich bemerken, dass man bey den Seidenhaaren lıäufig die Beobachtung macht, dass die feinern und gröbern Haare dieser Art an ihrer Wurzel - Zwiebel - durch Zellgewebe mit einander verwachsen sind, ein Umstand, der leicht auf die unrichtige Vermuthung bringt, als wären die Haare selbst verwachsen, oder als käme eines aus dem andern hervor. Vergleiche 'Taf. VIII. Fig. 72-83.

\section{§. 90.}

\section{Von den Borstenhaaren.}

Obgleich sich im gewöhnlichen Sprachgebrauch die Borste, so wie in der Pflanzenterminologie von dem eigentlichen Haare nur durch den grössern Grad von Steifigkeit unterscheidet; so werden wir doch bey genauerer Betrachtung dieses Gegenstandes noch andere in der Textur gelegene Abweichungen zwischen beyden Haararten erkennen. Da sich nun aber die Eigenschaften der Borsten am deutlichsten bey jenen darstellen, welche wir bey den Schweinen finden, deren Haare denn auch vorzugsweise vor allen übrigen mit diesem Namen belegt werden, so will ich diese einer genauern Untersuchung unterziehen. - Vor allem ist nöthig, zu bemerken, dass die Borsten des Wildschweines länger, steifer, dicker und härter sind, als die des zahmen. - Beyde waren übrigens schon in friihern Zeiten Gegenstand anatomischer Forschungen, und 


\section{Von der Verschiedenheit der Thierhaare etc. 167}

namentlich hat sie der unermüdete $M$ alpigh $i^{*}$ ) ziemlich genau beschrieben: „Est autem dictus apri pilus cylindricum corpus, quasi diaphanum, exterius laeve, fistularum aggerie conflatum et speciem columnae striatae prae se fert. Componentes fistulae in gyrum siluatae in apice potentiores redduntur; nam hians quasi pilus in geminas dividitur partes, et componentes minimae fistulae a ferruminante succo liberiores redditae manifestantur, ita ut cnumerari possint. Has autem viginti et ultra numeravimus. Exortum trahunt - bulbo pili, et parallelae per longum ductae rotundum pilum efformant. V'ersus apicem omissa rotunditate in geminos, quandoque plures laciniantur fines; expositae fistulae pili substantiam integrantes tubulosae sunt, et frequentibus tunicis transversaliter siluatis, veluti valoulis pollent."

Nach Cuvier **) sieht man bey der microscopischen Intersuchung einer Schweinsborste in ihrer ganzen Länge ungefähr 20 Furchen, welche durch eben so viele Fäden gebildet werden, deren Vereinigung die Oberfläche des Haares bildet. In der Mitte der Borste befinden sich zwey Canäle, welche das Mark - eine Flüssigkeit - enthalten. Durch das Trocknen trennen sich die Fäden der Borste von der Spitze an von einander, wie man in den Haaren unserer Bürsten sieht; dann entleeren sich die Markhöhlen, und man sieht darin nur noch einige Blätter, die sich in verschiedenen Pichtungen kreuzen.

Was nun meine eigenen Erfahrungen betrift, so fand ich die Wurzel immer so schwach ausgedrückt, dass man sie mit unbewaflnetem Auge kaum als eine längliche, runde Anschwellung ausnehmen konnte, die in einem ebenfalls sehr dünnen Balge steckte, der beym Ausreissen der Borste grösstentheils mitging. Der Haarschaft stieg nun meist gerade aufwärts, bis ungefähr gegen den Anfang seines letzten LängenDrittheils, wo er sich immer spaltete. Diese Spaltung war meist so, dass sich zwey Aeste bildeten, die dann eine kleine Strecke noch fortliefen, und sich jetzt selbst wieder in mehrere einfach scheinende Borstenfasern theilten. Als ich jedoch auch die letzte Spitze einer solchen Faser unter das Microscop brachte, zeigte sich's, dass sie auch nicht mehr einfach war, sondern mit mehrern Zweigen endigte. - Ich kaun dic

*) Opera posthuma. p. 94.

**) Vorlesungen 2. Bd. S. r. d. Haaren, 


\section{$168 V_{\text {on }}$ der Verschiedenheit der Thierhaare etc.}

Oberfläche der Schweinsborsten, so sehr auch der Augensrhein dafür sprechen mag, dennoch nicht für glatt annehmen, denn mein Microscop zeigte selbe bey zweckmässiger Beleuchtung von oben stets auf das netteste und gleichartigste gerieft, wie ich es denn auch in Tab. IX. Fig. $9 j$ dargestellt habe. Niese tiefgehenden Linien liefen stets der Länge nach, und zwar, wie gesagt, höchst regelmässig neben einander. Man kann sie jedoch nur bey starker Vergrösserung und guter Beleuchtung von oben erkennen. - Malpighi sah also richtig, denn diess sind seine Fistulae, die dem Haar das Ansehen einer Columna striata geben. - Um mich von der höchst merkwürdigen Textur dieser feinern Theile noch genauer zu überzeugen, machte ich nun verschiedene Durchschnitte, und verglich die Flächen unter sich, und mit der Beschaffenheit der angeführten Oberfläche des ganzen Haares. Der schiefe Durchschnitt (Fig. 91) zeigte eine Menge jener durchgeschnittenen Röhren, die den angegebenen länglichen Furchen an der äussern Oberfläche an Zahl und Durchmesser vollkommen entsprachen. In der Nitte des J)urchschnittes aber erschien eine unregelmässig gestaltete, bey der Beleuchtung von oben weisse, bey der von unten schwarze, oder wenigstens dunkle Fläche, deren Basis jedoch gleichfalls aus solchen durchschnittenen Pïhren zu bestehen schien. Der vollkommene Querdurchschnitt ergab dieselben Resultate, nur weniger deutlich, weil man hier den Gegenstand nicht so zweckmässig beleuchten kann. - Beym I,ängedurchschnitt aber sah man die röhrige Beschaffenheit der Rindensubstanz ebenfalls sehr deutlich. Sie erstreckte sich aber nicht weit einwärts, sondern stiess bald auf das blätterige Wesen, welches die sogenannte Marksubstanz darstellt, und aus ciner unzählbaren Nenge der feinsten Blättchen besteht, die in der Regel, d. h. grösstentheils von einer Seite zur andern zu Jaufen, also Querwände zu bilden schienen. - Was nun noch den Canal betrifft, in so fern man ihn ungetheilt durch das Microscop, und zwar bey einer Beleuchtung von unten betrachtet, so zeigt sich derselbe schon ganz unten am Arfang, der Wurzel der Borste, und wird im weitern Verlaufe aufwärts in dem Masse deutlicher, als dic Rindensubstanz feiner, und daher durchsichtiger ist. Auch hier erscheint er schon bey ciner mässigen Vergrösserung durch querlaufende Blättchen vielfach getheilt, die gleichwohl nicht immer von ciner $W$ and zur andern, soudern gar of nur bis zur Mitte reichen, und 
sich dort mit andern verbinden. An jenen Stellen aber, wo sich, wie eben erinnert wurde, die Borste* theilt, sieht man recht deutlich, dass auch der Canal, und zwar ungefähr gerade so in seine Theile zerfällt, wie das Mark eines Baumes an dem Ursprung seiner Aeste. - Wenn man nun das bisher Gesagte mit vergleichendem Sinn überblickt, so ergibt sich die interessante Thatsache, dass

1) Auch die Schweinsborsten aus einer Rinden- oder Horn-, und aus einer Marksubstanz bestehen.

2) Dass erstere aus einer unbestimmbaren Anzahl (die abet gewiss grösser als 20 ist), von feinen Röhren bestehe, die in ihrem Innern ein feines blätteriges Gewebe enthalten, welches man die Marksubstanz zu nennen pflegt.

5) Dass höchst wahrscheinlich diese Rühren rücksichtlictı ihrer äussern hornartigen Umkleidung in dem Verhältniss feiner werden, je weiter sie nach innen liegen; und dass gerade dadurch der innerste Theil der Borste, der Canal, durchsichtig, und durch querlaufende Blättclien abgetheilt erscheine; endlich

4) Dass die Angabe Cuvier's gewiss unrichtig sey, wenn er sagt: dass sich 1. in der Mitte der Borste zwey Ca. näle befänden, und 2. dass die Anzahl der Spaltuheile riner Borste jener der Röhren oder Fäden, wie er sie nennt, entspreche. Niemals spaltet sich die Borste in so viele Theile, als sie Röhren besitzt.

Allcs dieses kann man nur bey einer zahmen Schweins. borste, und am besten bey einer weissen beobachten.

In Allgemeinen finden wir die Borsten unter den Pal chydermon, wo sie denn so ziemlich denselben Bau, wie bey den Schweinen haben; ob diess jedoch auch nur bey den meisten jener Haare der Fall sey, die wir da und dort mit dem Namen der Borsten zu benennen pflegten, und deren es wohl fast in jeder Thierfamilie gibt, muss ich selır bezweifeln, indem bey dieser Benennung eigentlich nur der grössere oder geringere Grad von Steif heit in Anschlag gebracht wird.

Da ich durch die Güte des Herrn Custos Na t t e r e r einige Stacheln oder vielmehr stachelartige Borsten von dem brasilianischen Schweine erhielt, und bey der genatuern Untersuchung durch das Microscop einc elwas abweichende Bau- 
170 Von der Verschiedenheit der Thierhaare etc.

art entdeckte, die sich höchst charakteristisch darstellen liess, so ist das Ganze gezeichnet worden.

Hieher scheinen endlich auch noch die steifern, borstenartigen Haare der Aguti Dassprocla (Illiger), namentlich des Dasyprocta Aguti zu gehören; wobey ich denn in mehreren derselben im einfachen Haar schon einen getheilten Canal bemerkte (etwas, das ich sonst nie beobachtete).

Vergleiche Tab. VIII. Fig. 84-99, und Taf. IX.

Fig. $90-95$.

\section{§. 91 .}

\section{Von den Hornharen.}

Unter diesem Namen begreife ich gewissermassen eine Abart der eigentlichen Borsten, und trenne sie von diesen letzteren, weil ihnen die Theilung an der Spitze abgeht, und die Menge der Hornsubstanz bedeutend überwiegt. Ferner haben sie das Eigene, dass sie auf ihren Durchschnittsflächen gleich dem Horne, glatt erscheinen, und nur in der Mitte meist einen einfachen, manchmal aber doch auch vielfach abgetheilten Canal besitzen.

Hieher zähle ich die Mähnen und Schwanzhaare der Einhufer, namentlich des Pferdes, ferner die stärksten Haare vom Rüssel und dem Schwanze des Elephanten.

In Bezug auf die Textur hat Heusinger wohl ganz Recht, dass er auch die Tasthaare der Robben und des Wallrosses unter seine Haarborsten aufnimmt; da ich aber die Tasthaare überhaupt von allen andern Haaren trennen will, und es wirklich noch viele andere unter ihnen gibt, z. B. die Schnauzhaare der Ochsen, die vermög ihrer Steifigkeit, ihres Ueberschusses an Hornsubstanz mit gleichem Rechte den Hornhaaren beygezählt werden könnten; so werde ich auch die Hornhaare in dem Barte der Robben und Wallrosse unter der Rubrik der Tasthaare abhandeln.

An dem Elephanten in der Menagerie zu Schönbrunn fand ich eigentlich dreyerley Haare; nämlich feinere Körperhaare vorziiglich in der Gegená der Ohren, gröbere Körperhaare da und dort, jedoch sehr sparsam zerstreut, und wahre Hornhaare an dem untern Rande des Rüssels. Der Schwanz 
aber war ganz haarlos. - Nach andern*) soll sich an der Spitze des Elephantenschwanzes ein Büschel dicker Haare befinden, die wie starker Eisendrath, glänzend, biegsam, und elastisch wie Horn sind. - Ich habe eines jener Hornhaare aus der untern Fläche des Rüssels (die nebenher gesagt das Eigene haben, dass sie oben an der Spitze gleichsam wie abgeschnitten, und ïberhaupt durchaus in ihrer ganzen Länge von gleicher Dicke sind), untersucht, und gefunden, dass es einen verhältnissmässig kleinen Balg (wahrscheinlich ist aber der Rest in der Haut stecken geblieben), hatte, vollkommen platt war, aber demungeachtet in der schiefen Jurchschnittsfläche eine Mlenge durchschnittener Röhren darstellte, die mich sogleich auf seine nahe Verwandtschaft mit den Schweinsborsten brachte. Nan kann sich davon recht anschaulich in meinen Abbildungen überzeugen. $\mathrm{W}$ as die Pferdhaare betriflt, so findet man das Nöthige bey Malpighi**) genau aufgezeichnet. -

Vergleiche Taf. IX. Fig. 96-99.

\section{92}

\section{Von den Stachelhaaren.}

Der Bau der Stachelhaare hat bey der genauesten Untersuchung lange nicht so viel Eigenthümliches, als man wohl erwarten könnte; und ich finde, wenn ich die Sache unparteyisch betrachte, eigentlich die Stacheln der Säugethiere von den andern Haaren wesentlich gar nicht, und nur zufällig dadurch unterschieden, dass sie steifer, spitziger, spröder, und überhaupt stärker als alle übrigen Haararten sind. Daher sagt Aristoteles mit Recht: spinae tanto sunt setis duriores, erasstiores et auctiores, quanto pili a setis supcr rantur. O pianus nennt die hierhergehörigen Thiere: stacheliche Schweine (Sues setosi). Die Sache wird auch so wenig genau genommen, dass man in den Schriften der Naturforscher dieselben Haare bald mit dem Namen Borsten, bald mit dem der Stacheln belegt findet. Uebrigens gibt es in der That stachelartige Haare, und wirkliche Stacheln selbst. Let/-

\footnotetext{
*) Heusinger a, a, Q. p. 176

**) A. a. $O$
} 
tere sind es nun, von denen ich zunächst handeln will. Bey uns in Europa haben wir eigentlich nur ein Thier das solche Stacheln besitzt, nämlich den Igel (Erinaceus europaeus), doch gehört hierher auch der Borstenigel (Centeles), und das Stachelschwein, welches nun auch nach Europa verpflanzt ist; nicht z.n gedenken, dass es noch mancherley Thiere gibt, welche kleinere Stacheln auf ihrem Körper tragen z. B. das Moschusthier auf seinem Schwanze u. a. m.

Da wir nun gerade bey diesen Stacheln die wahre Bildung der Haare überhaupt am schönsten und deutlichsten darstellen können, so wurden die Stacheln des Igels sowohl, als auch des Stachelschweins schon von verschiedenen Naturforschern diessfalls genauer untersucht. - Aristoteles gibt zwar keine genaue Beschreibung von den Stacheln des Stachelschweines, doch gedenkt er ihrer kurz im 1. Buch 6. Cap. seiner Naturgeschichte der Thiere. Viel ausführlicher spricht davon der schon angeführte $\mathbf{F}$ abrizius ab Aquapendente *), Er sagt nämlich: „Das Stachelschwein hat ungefähr 100 Stacheln, die länger, dicker und spitziger sind, als jene des Igels; sie sind fast auf dem ganzen Körper verbreitet, bunt gefärbt, meist jedoch weiss oder schwarz, und laufen von vorne nach hinten niedergebeugt, wo sie sich mit einer Spitze endigen, die sie, wie der Hirsch seine Geweihe, und die Schlangen ibre Haut zu bestimmten Zeiten erneuern (?)" - Der (iraf Buffon ${ }^{\text {*a }}$ ) beschreibt sie nach dem äussern Ansehen folgendermassen: „Die grössten Stacheln dieses Thiers sind auf dem Hintertheil des Rückens, etwa 9 Zoll, die kleinsten 4 Zoll lang, ihr Durchschnitt wechselt von 3-4 Linien Dicke. Sie sind an beyden Enden spitzig, schwärzlich und weissgelblich in grossen Ringen, die von einem Ende der Stacheln bis zum andern gegen fünfmal mit einander abwechseln. Der Schwanz starrt von Kielen, die am Ende quer abgeschnitten zu seyn scheinen. Sie sind hohl, am Ende offen, haben nur zwey Linien Durchmesser, und 1\% Zoll Länge. Sie sitzen an einem sehr zarten, und $3 / 4$ Zoll langen Stiel, der in die Haut lineingeltt, liegen den ganzen Schwanz hinuuter, und zwar in getwisser Weite einer von den andern entfernt, sind braun und weissgelblich gefärbt; ihre Wände überaus dünn und hlin-

*) A. a, O

*) In seincr Naturgeschichic Y. Thl, Bd, 11. S. 16. 
gend. Daher das klirrende Geräusch bey der Bewegung. Das Ende der Schnauze und die Füsse sind mit kleinen, braunen steifen Borsten bedeckt; die Barthaare bestehen aus schwarzen glïnzenden Borsten, die über $1 / 2$ Schuh lang sind. Uebrigens erscheinen die Stacheln am Kopf, Hals und Bauch dünner, kürzer und biegsamer, als am Rücken." - Nach $\mathrm{Cu}$ vi er befindet sich am Schwanze ein Dutzend Uaare, welche den Federkielen ähnlick, an ihrem freyen Ende abgestutzt und hobl sind. Das andere Ende ist solide, dïmn und biegsam. -

Ich habe mir schon einige Male viel, aber jederzeit vergebliche Mühe gegeben, um mich von der merkwürdigen Befestigungsart dieser Stacheln in der Haut selbst zu überzeugen. Ich bin daher genöthiget, die von Gaultier*) gegebene Beschreibung so anzuführen, wie sie Heusing er**) citirt: "Die abgezogene Haut zeigt auf ihrer innern Fläche Unebenheiten, welche von übereinander liegenden zahlreichen, aber symmetrisch geordneten Organen herrühren. Untersucht man diese Organe genauer, so findet man sie mit einer faserigen Haut umgeben, auf ihrer äussern Fläche platt, ungleich auf ihrer innern. Ich habe sic (Disques), Scheiben, Schilder genannt. Sie enthalten die Wurzeln von 5, 7, 9 oder 11 Haaren. Man kann die Schilder in kieine und grosse theilen; ihre Grösse steht im Verhältniss zur Grösse der Haare. Die grossen Schilder finden sich auf dem Rücken und auf den Seiten. Die Haare, deren Wurzeln in diesen Schildern enthalten sind, sind hart, dick, und unter dem Namen: Stacheln bekannt. Die kleinen Schilder finden sich fast an allen Theilen der Haut. Die grossen haben eine mehr als halbkreisförmige Gestalt, und einen Durchmesser von 12-16 Linien. Sie endigen sich zuweilen nach unten in eine Spitze, und sind bey ihrem dachziegelförmigen Aufeinanderliegen durch Muskellagen von einander geschieden. Diese auf ihrer äussern Fläche platten Schilder zeigen auf der innern zwey Reihen von Erhabenheiten, eine obere und untere, die durch eine bogenförmige Linie von einander getrennt werden. Die obern Erhabenheiten entsprechen den Hüllen der Stachelwurzelu, die untern gleichen denen, welche man unter den Zähnen findet, und sie entsprechen Fettzellen, die beständig in derselben Richtung, wie die Wur-

*) Journal de Physique. Vol. 90, Avril, 1820, p. 241.

${ }^{* *}$ ) A, a, O. p. 180 . 
zeln der Stacheln liegen. Der Raum, den die Fettzellen und die Hüllen der Haarwurzeln einnehmen, ist fast gleich gross. Eine jede Hülle (Gaine), gleicht der Substanz, die innerhalb des Balgs das Haar umgibt, enthält das untere Ende und die Wurzel eines Haars, und ist in eine Spitze blind geendigt. Die Hüllen der grössten Haare sind gewöhnlich 5 Linien lang, und haben $1 \frac{1}{2}$ Linie im Durchmesser. Die Wurzel der grössten Stachel liegt in der Mitte und am tiefsten, auf beyden Seiten nehmen sie an Grösse ab, und liegen weniger tief. Fine jede Hülle besteht aus einer perlmutterartig glänzenden, sehr glatten, mit Kreisfasern umgebenen Haut; sie ist dann auf zwey Seiten von der eigenthümlichen faserigen Substanz der Schilder ungeben. Diese beyden Häute vereinigen sich an der Mündung der Hülle

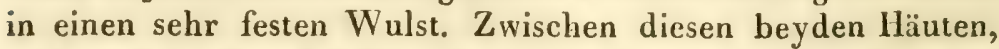
und zwar an der, der Haut gegenüberliegenden Seite befinden sich zwey kleine Höhlen neben einander; diejenige, welche der Mïndung der Hülle des Haars am nächsten liegt, ist voll Bälge (Drüsen, Follicules), und die andere enthält eine kleine Menge Fett; ich nenne die erste die Drüsenhöhle, die andere die Felthöhle. Die Drüsen nebst der Substanz, welche sie enthalten, wiegen in den Höhlen der grössten Stacheln ungefähr einen Gran, und das Fett ungefähr zwey Gran. Die Drüsen hängen an einer Stelle der Wand ihrer Höhle fest; das Fett lässt sich aus seiner Höhle leicht herausnehmen. Die Substanz der Drüsen ist gelb, das Fett weisslich. Eine jede Drüsenhöhle hat drey Oeffnungen, die eine steht durch einen, 1 bis 2 Linien langen Ausführungsgang mit der Hülle der Wurzel des Stachels in Verbindung; in diesen Ausführungsgang kann man leicht eine Nadel einbringen; die zweyte Oeffnung führt in die Fetthöhle; die dritte führt zu dem Faserngewebe, welches einen Theil der kegelförmigen Wurzel des Stachels umgibt. Die Hüllen der Wurzeln in einem Schilde liegen in einer Reihe; unten an den Wurzeln der Stacheln sind sie durch ein dichtes Fasergewebe mit einander verbunden, und durch Muskelfasern oben an ihren Mlündungen sind sie durch schlaffes Zellgewebe mit einander vereinigt. Der Theil des Schildes, welcher aus der Vereinigung dieser Hüllen entsteht, liegt gewöhnlich zwischen zwey Lagen Muskelfasern. Die Fettzellen liegen dicht an den Hüllen, und haben dieselbe Richtung. An ihrem untern Ende bilden sie einen blinden Sack, an dem obern aber zeigen sie einen Eindruck, in welchem die Wurzel 
des Stachels liegt, und sie sind durch einige Muskelfasern von der Hülle getrenut. Wenn man sie ganz ausleert, so erblickt man in ihrer Mitte einen Strang, welcher sich zur Wurzel des Stachels begibt. Die Fettzellen sind verschieden von den oben erwähnten Fetthöhlen." Dieses in Bezug auf die Befestigungsart der genannten Stacheln. -

Was nun die Textur des eigentlichen Schaftes betrifft, so kommt sie grösstentheils mit jener des Igelstachels überein, und da ich diese nicht allein ausführlich beschreiben, sondern auch durch naturgetreue Zeichnungen versinnlichen werde; so beschränke ich mich jetzt darauf, die etwaigen kleinen Abweichungen des Baues bey dem Stachel des Stachelschweins nachträglich anzuführen.

Sowohl das Männchen als auch das Weibchen des I gels ist vom Kopfe bis zum Schwanze gleich stark mit Stacheln besetzt, und nur die Unterfläche des Leibes ist behaart. Diese Haare sind aber nach Buffon zweyfach: Einige haben die Festigkeit der Schweinsborsten, obgleich sie viel kürzer sind. Thre Farbe ist weisslich, gelb und roth durchscheinend. Die längsten sind 16 Linien lang. $\mathrm{Z}$ wischen diesen Borsten ist ein dichteres, krauses und theils graues, theils braunes oder kastanienfarbiges Haar. Auf den Füssen und dem Schwanze findet sich ein dïnnes, kurzes und glattes Haar, das mit jenen Borsten von einer Art zu seyn scheint. - Malpighi*) beschreibt die Stacheln dieses Thieres schon sehr genau, indem er sagt: „Spinae in erinaceis praecipue, et consimilibus nil aliud sunt, quam duri et rigidi pili, igitur eadem structura et compages in utrisque reperitur; quae cum evidentissima sit, in confirmationem exaratorum exponenda venit. Spina stylus est rotundus, acuminalus, fistulis in gyrum statutis compactus. Haec autem insecta transversaliter erinacei spina patent; circum enim dura, compactaque subslantia fistulas nectens occurrit; in centro vero peluti medulla concluditur. Fistularum et medullaris ductus compages secta per longum spina manifestatur; exterius namque quasi cortex ambit, proximae luci succedunt fistulae, quae transversalibus valsulis muniuntur. Et sicut in plantis subrotundis orbiculis insicem hianlibus fistulae componuntur, ita in spinarum fibris intercepta spatia insicem hiantia utriculorum ordines aemulantur. Solent autem in crassioribus spinis mulliplicari fistularum ordines, sese insicem

H) A. a. O. 
176 Von der Verschiedenheit der Thierhaare etc.

continentes involucri instar, et interdum tres numeravi. In centro sinus per longum excurril valoulis interceptus; tunicas namque per transversum ductae non sunt omnino horizontales, nec invicem parallelae; sed invicem sibi occurrentes sinus et cellulas eformant, quales in liene, sel in laxata plantarum medulla observantur." Es wird sich sogleich aus dem Resultat meiner verlässlichen Untersuchungen ergeben, wie richtig $\mathbf{M a l}$ pighi diesen Gegenstand grösstentheils beobachtet habe. - Diesen zufolge fand ich in Bezug auf die Einpflanzung der Igelstacheln, dass sie sämmtlich gleich den übrigen Haaren zum Theil im, zum Theil unter dem Corion, also theilweise schon in der Fetthaut entspringen. Jederzeit reichen ihre Wurzeln tiefer, als die der feinern, neben ihnen entspringenden Borsten und Haare. Der die Wurzel umgebende Balg ist ein feines, fast durchsichtiges Häutchen, das eng an derselben anliegt, und nur am untersten Ende, gleich wie bey den übrigen Haaren der Säugthiere, wirklich mit iłr verwachsen ist. _- Die Wurzel bildet ein beynahe vollkommen rundes Knötchen, das mittelst eines Halses (dem engern Theile) aufivärts mit dem Haarschaft in Verbindung tritt. Dieses Knütchen steckt mit seinem Anfang (also dem untersten Theile) im Fettgewebe, mit welchem es durch ein kleines Loch, das sich gerade in der Mitte befindet, so zu sagen in unmittelbare Verbindung tritt. Wenigstens scheint von diesem Punkte aus die Ernährung des Haares mittelst eintretender Gefässe statt zu finden. - Betrachtet man nun dieses Wurzelknötchen unter dem Microscope genauer, so zeigt es sich, dass die äussere Oberfläche keineswegs glatt, und daher völlig abgerundet, sondern durch sechs Einschnitte fein abgetheilt ist, welche mittelst schwacher Linien in dem Centralloch convergiren. Schneidet man das Knötchen aber der Quere nach in der Mitte durch, so erscheint abermals das Centralloch in der Mitte, umgeben von sechs, gleich diesem durchschnittenen ovalen Canälen, die sämmtlich von Rinden - oder Hornsubstanz eingeschlossen sind. Mit diesen Ansichten, welche in Fig. 105 - 106 deutlich dargestellt sind, stimmt auch jene vollkommen überein, die dann erscheint, wenn das Wurzelknötchen der Länge nach durchschnitten wird (vergleiche Fig. 107-108), wo man dann sowohl das Centralloch in seiner Verlängerung, also den ganzen Centralcanal mit den sechs Seitenästchen, die am Ende alle sich in jenen öffnen, wiederfindet. — So verhält sich die Sache mit 
dem Wurzelknötchen. Dem Igelstachel, so wie wahrscheinlich den meisten Stachelhaaren scheint der conische Körper der Tasthaare, also die eigentliche gelatinöse Substanz, welche die Wurzel des Haares umgibt, gänzlich zu mangeln. Der aus ihm entspringende, und oben von mir mit dem Namen des Halses belegte, schmale Anfangstheil des Schaftes steckt grösstentheils in dem Corion, und an ihn legt sich auch äusserlich bey seinem Durchbruch die Oberhaut als feines Blättchen ringsherum an. Nunmehr, bald viel dicker werdend, steigt der cylindrische Stachelschaft, nur wenig nach einer Seite gebogen, aufwärts, verändert seine Farbe zweymal, und endigt zuletzt mit ciner lesten, geschlossenen Spitze. - Es handelt sich nun darun, seine innere Textur zu beschreiben, und in dieser Hinsicht fangen wir mit der äussern Oberfläche an. Diese ist, so wenig wir diess auch mit unsern Fingern wahrzunchmen im Stande. sind, keineswegs ganz glatt, sondern sehr fein gerieft, d. h. man sieht mehrere erhabene Linien (Leisten), die durch fast gleichweit von einander entfernte, vertiefte Linien getrennt sind. Sowohl die einen, als die andern laufen parallel mit einander und stets der Länge nach, und vereinigen sich gleichsam an der Spitze der Stacheln. Sie sind übrigens nicht durchaus gleich dick, d. h. der Durchmesser der feinen Leisten ist nicht gleich, sondern da am grössten, wo der Schaft des Stachels am breitesten ist.

Nebst diesen, der Lünge nach verlaufenden Furchen und Leisten, sieht man aber auch bey genauerer Betrachtung noch andere, viel kleinere, quere oder horizontal laufende Linien, welche die früher genannten erhabenen Linien zu durchschneiden scheinen. Diese sind aber nur so fein, dass sie löcherartig erscheinen.

Wir kommen nun auf die Betrachtung des queren Durchschnittes des ganzen Stachels. Hier zeigt sich zuerst am äussersten Umkreis eine feine Hornschichte, deren Gewebe ganz gleichartig ist; auf diese folgt eine aus blätterigem Gewebe gebildete Scheibe, die aus ungefähr 26 Strahlen zusammengesetzt ist. Diese letztern gleichen ganz den oben angeführten durchschnittenen sechs Canälen des Wurzeliknötchens an Gestalt und Grösse. Sie sind nämlich oval, und liegen dicht neben einander. Das Ganze besteht aus einer lockern, brüchigen Zellensubstanz, nur mit dem Unterschiede, dass, wie in dem Wurzelknötchen die einzelnen Strahlen an ihrem äussern Umfange bis 


\section{Von der Verschiedenheit der Thierhaare etc.}

auf eine kleine Strecke durch die einwärts laufende Rindenoder Ilornsubstanz von einander getrennt sind, und dadurch eigentlich deutlich begränzt sichtbar werden. Das Centrum dieser Scheibe ist ebenfalls mit einem feinblätterigen Zellgewebe angefüllt, uad zeigt keine regelmässige, beständige Figur. Uebrigens scheinen sich die Radii der Scheibe gegen diesen Mittelpunct zu öffnen.

Der Längedurchschnitt des Stachels gibt zwar ganz andere, aber doch mit den angegebenen vollkommen übereinstimmende Resultate: es zeigt sich nämlich hier eine dreyfache Substanz. Den äussersten Ueberzug macht natürlich die Hornschichte, die ich auch hier aus einfachem, gleichartigem Gewebe, und nicht aus Zellen gebildet glaube; darauf folgt einwärts ein aus feinen Zellen gebildetes Gewebe, deren einzelne Blätterchen fast treppenartig über einander in beynahe gleichen Entfernungen liegen. Die Breite derselben nimmt fast $1 / 3$ des ganzen Stachels ein. Der innerste Raum, der gleichfalls 1/3 des Ganzen beträgı, ist mit einer ähnlichen lamellösen Substanz angefüllt, deren Zellen aber aus viel gröbern Wandungen gebildet, und überhaupt nicht so regelmässig gebaut sind. Sämmtliche drey Substanzen nehmen so zu sagen aus dem Wurzelknötchen ihren Ursprung, gleichsam in verjüngtem Massstab, indem sie den sogenannten Hals so durchziehen, dass man sie hier nur mit der grössten Mühe von einander unterscheiden kann. - Die äusserste Spitze besteht jedoch nur aus Hornsubstanz, indem das blätterige innere Gefüge nicht so weit hinauf reicht.

Die oben kurz berührten kleinen Abweichungen der Textur des Igelstachels von jenem des Stachelschweines beruht erstens darauf, dass man hier im schmalen unteren Ende, das dem sogenannten Halse des Igelstachels entspricht, einen beynahe ganz leeren Raum antrifft, dessen Wandungen bloss von der ebenfalls deutlich gerieften Horn-Rindensubstanz gebildet werden, und an dessen oberem Ende sodann erst das blätterige Gewebe - die sogenannte Markmasse - des Schaftes beginnt; und zweytens, dass die mittelste der drey Substanzen, welche beym Längendurchschnitt zum Vorschein kommen, verhältnissmässig viel häufiger ist, also auch einen weit grössern Raum, etwa $2 / 3$ des ganzen Schaftes einnimmt. Auch ist der Stachel des Stachelschweines nicht so rund, wie der des Igels. - Ob übrigens, wie Heusinger sagt, die 
Zellen, welche aus einer harten, ganz gefässlosen, weissen, einer trockenen, serösen Ilaut gleichenden Haut bestehen sollen, im Innern mit Luft gefüllt sind, lasse ich dahin gestellt seyn. -

Anmerkung 1. Es gibt viele Thiere, deren Haare so zu sagen, eine Mittelgattung zwischen den Borsten und Stacheln bilden. Hieher gehören die Haare des Elenns, des Moschusthiers (aber nur an gewissen Gegenden des Körpers), des Tanrecks, die steifern Borsten des Igels und des Stachelschweines selbst; ferner die Bursten des Pecari und der Echidna, die feinern Stacheln der ibrigen Stachelthierarten, namentlich der Hystrix subspinosa, in. sidiosa, nychtemera, macroura (welche zugleich knotig sind), fasciculata, brasiliensis, dorsata, (die feine Wi derhäkchen haben), prehensilis und paragua ensis.

Anmerkung 2. Nach Sarrasin ${ }^{*}$ ) zeichnen sich die Stacheln des canadischen Stachelschweines durch eine ganz eigene Bildung ihrer Spize aus. Diese ist nämlich ganz allein schwarz, der uibrige Theil der Stacheln durchaus weiss. Unter dem Microscop soll man dann einige um die Spitze schraubenförmig laufende Streifen, (filets) und einen aus kleinen Zähnen bestehenden Rand bemerken, deren Spitzen gegen die Basis gerichtet sind, und die also gleich Widerhaken Widerstand leisten können.

Anmerkung 3. Bey einigen Stachelschweinen findet man nicht nur, wie wir bald sehen werden, platte Hare, sondern auch breite Stacheln, und so bilden eigentlich diese letztern den natiirlichen Uebergang zu denjenigen Haaren, die wir jelat genauer betrachien werden.

Vergleiche Tab. IX. Fig. 100-101 und Tab. X. Fig. 102-108.

\section{93.}

\section{Von den platten Haren.}

lch habe schon oben in der allgemeinen Uebersicht der Säugethicrhaare angeführt, dass die Stachelratten (Loncheres) rauhe, platte, breite Haare haben, welche sich mit einer harten Spitze endigen, und so eigentlich platte Stacheln bilden. Lichtenstein **) beschreibt die schuppenförmigen Stacheln dieser Thiere genau, indem er sagt: „Sie tragen nebst dem feinen, weissen Haar auf dem Rücken und an der äussern Seite

*) Mém. de l'Academie des sciences, de Paris 1727.

**) Ueber die Ratten mit platten Stacheln. In den Schriften der phys. Classe der Akademie d. Wissenschaften zu Berlin. 1819. Tab. 1. p. 187. 


\section{Von der Verschiedenheit der Thierhaare etc.}

der Schenkel breite, elastische, zugespitzte, aber an der Spitze weiche, daher nicht stechende Haare, die auf ihrer Oberfläche eine convexe Leiste, auf der untern eine Rinne haben." Ferner sagte ich, dass der grosse Ameisenbär (Myrmecophaga jubata) lange, breite, geradestehende, und das Schnabelthier auf seinen Zehen ebenfalls breite und zweyschneidige Haare tragen soll; endlich wurde von dem Haar des Klippspringers (Antilope Oreotragus) gesagt, dass es an den Spitzen plattgedrückt sey. Ausser diesen findet man nach F. Cuvier bey dem Wombat, ferner noch bey der Echidna, dem Pecari, den Stachelschweinen und Igeln nebst ihren Stacheln und andern feinern Körperhaaren solche platte, breite Haare, die mitunter eine ganz ausgezeichnete Bildung an sich haben. Hieraus ersieht man, dass dieselben platten Haare nur selten allein, sondern meist in Gesellschaft anderer angetroffen werden. So haben die Stachelratten ausser den platten Haaren auch runde. Am Stachelschweine habe ich oben viererley Ilaare angegeben, und der Igel trägt Stacheln, platte und rundeHaare. Nach Sarrasin*) soll das canadische Stachelschwein sogar ein 7 faches Haargebilde haben. - Uebrigens ist die Breite dieser platten Haare keineswegs überall dieselbe, sondern auch sehr verschieden. Am breitesten fand ich die Haare der $H_{\gamma}$ strix dorsata, sie waren so zu sagen schwertförmig; die des Faulthieres fangen gleichsam an breit zu werden, denn ihr Querdurchschnitt ist stark oval. - Die Haare der Pangolins sind so breit und abgeplattet, dass diese Thiere wie mit Schuppen (nach Art der Artischockenblumen) Łedeckt sind.

Auch ist ein und dasselbe Haar an verschiedenen Stellen verschiedentlich breit; so z. B. findet man auf den Füssen des Igels unten und oben schmälere, in der Mitte breitere Haare; zudem sind gewöhnlich fast alle Haare in der Mitte am breitesten. -

Ich habe die Haare des Faulthieres und der Hystriv dorsata microscopisch untersucht, und ihrer abweichenden Bildung wegen auch zeichnen lassen. Da wahrscheinlich alle hieher gehörigen Haare undurchsichtig (ich fand einige nur an der äussersten Spitze durchsichtig) sind, so müssen sie unter dem Vergrösserungsglas stets von oben beleuchtet werden. Auf diese Art beobachtete ich nun bey dem Haar des

8) A, a. O. 
Faulthieres, dass seine äussere Oberfläche wie mit vielen, meist quer laufenden Einschnitten, Rissen und Spalten versehen war, welche bald länger und durch die ganze Breite des Haares laufend, bald kürzer, und das Haar nur zur Hälfte einschneidend, bald ganz klein und kaum bemerkbar waren. Der Querdurchschnitt zeigte die ovale Figur des Haars, den in der Nitte gelegenen Markcanal, und da und dort dunklere Stellen, die wahrscheinlich den so eben angegebenen queren Einschnitten an der Oberfläche entsprechen. - Beym schiefen L ängedurchschnitt war die Ansicht dieser Theile noch deutlicher, vorzüglich stellte sich der gleichsam hohlscheinende Canal anf eine beträchtliche Länge dar. - Etwas abweichend von diesem war das Resultat einer Untersuchung der schwertförmigen Haare von Hystrix dorsala. - Denn, abgesehen von der viel beträchtlichern Breite hatte schon die äussere Oberfläche des Haars ein ganz anderes Ansehen. Ich erkannte nämlich sogleich eine unzählbare Menge unregelmässiger, meist fünfeckiger, dunkler Flecken (Zellen), die mich an die ähnlichen beym Rehhaar erinnerten. Der schiefe Längedurchschnitt zeigte einen sehr breiten Canal, der $2 / 3$ des Haars einnahm, und aus feinen Zellen zu bestehen schien. Die Farbe des durchschnittenen Stüclss wurde in dem Masse lichter, je dünner die zurückgebliebene Scheibe unter dem Microscope geworden war.

Vergleiche Tab. X. Fig. 109-11j.

\section{ङ. 94.}

Von den gefleckten Haren.

Hierunter verstehe ich alle jene Haare, deren Oberfläche unter dem Nicroscop bey guter Beleuchtung von oben geflecki erscheint. Damit will ich jedoch nicht gesagt haben, dass die Oberfläche wirklich gefleckt sey, sondern ich glaube vielmehr, dass das Haar äusserlich ganz gleichartig beschaffen und glatt sey, und dass die unter dem Microscope erscheinenden Flecken nichts anders, als die innern, durch die Beleuchtung von oben dunkel erscheinenden, kleinen eckigen Zellen des Haares seyen. Alles diess wird sich sogleich durch die genaue Beschreibung, noch mehr aber durch die bildliche Darstellung crweisen. 


\section{Von der Verschiedenheit der Thierhaare etc.}

Man findet diese Gattung von Haaren hauptsächlich bey den Wiederkäuern, und zwar namentlich in dem Geschlecht des Hirsches, der Ziege und des Bisamthiers. - Pallas*) verglich diese Haare rücksichtlich ihres innern Baues mit den Binsen, und nennt ihr Mark medullae scirpi simillima.

Ich wählte zur genauern microscopischen Untersuchung ein Haar vom Halse des Rehes. Da die Wurzel des Rehhaars selır klein ist, so muss es auch der sie umgebende Balg seyn, der sich denn auch durch eine ausserordentliche Feinheit auszeichnet, die so gross ist, dass man Mühe hat, den Balg selbst zu unterscheiden. - Die Wurzel ist nebstdem oval, ausserordentlich zart, weich und weiss. Ich zweifle wohl keinen Augenblick, dass sie durchbohrt sey, aber ich konnte mich davon nicht überzeugen. Auch sie besteht, gleich wie der Haarschaft, aus einer zweyfachen Substanz - der Rinden - und Marksubstanz. Letztere, die den sogenannten Canal bildet, beginnt zu unterst, und läuft etwas wenig geschlängelt, und manchmal etwas breiter werdend, in den Canal des Schaftes über, der hier sehr schmal beginnt, und so zu sagen den Hals bildet. Bey der Beleuchtung von oben zeigt sich sowohl in der Wurzel als auch im Schafthalse der Canal als ein dunkler, wenig gewundener Streifen von fast gleicher Breite, der da zu verschwinden scheint, wo der Hals in den Körper übergeht. Hier nimmt nämlich die Rindensubstanz so überhand, dass der Canal unsichtbar wird. Der Schaft selbst, der anfangs nur ein paar Linien lang gerade fortläuft, biegt sich nun bis zu seiner Spitze regelmässig von der einen zur andern Seite. Heusinger ${ }^{* *}$ ) hält diese Biegung nur für scheinbar, und nach ihm rühren diese Bogen nur daher, dass sich das Haar während seines Wachsens regelmässig spiralförmig um seine Achse gedreht hat, wie viele Pilanzen. Die Farbe des Schaftes ist verschieden, im Ganzen aschgrau, das Ende schwarz, die erste Hälfte der Spitze gelb, die letzte schwarz. Es ist mir sehr interessant, von He usinger die Bemerkung gemacht zu sehen, dass diese $\mathbf{F}$ ärbung nur von der äussern Substanz des Haares herrühre, und sich nicht in das Innere erstrecke. Ich werde mich hierüber bey den Menschenharen deutlicher erklären. Einige Ansätze abgerechnet, erscheint das Haar

*) Spicilegia zoologica. fasc, XIII. p. 28.

*) A. a. 0. p. 186. 
durchaus glatt, unter dem Vergrösserungsglas aber fallen die fast durchaus regelmässig aneinander gereiheten $\mathrm{Z}$ ellen (die sich als eckige dunkle Flecken darstellen) sogleich ins Auge. Die meisten dieser Zellen bilden Fünf-, manche auch beynahe ganz regelmüssige Vierecke. Man kann sie besser in der Quere als der Länge nach aneinander gereiht betrachten. Ihr Umfang ist verschieden, und scheint sich genau nach dem Durchmesser des betreffenden Haartheiles zu richten; so dass sie also in der Mitte des Schaftes, wo er am dicksten ist, ebenfalls den grössten, und in dem sogenannten Halse den kleinsten Umfang haben. - Der Querdurchschnitt zeigt den äussersten Rand ganz glatt, fein, und daher auch ohne Zellen, gleich darauf folgen grosse, ziemlich gut ausgedrückte eckige Zellen, dann kommen kleinere, nicht so genau begränzte, und die Mitte füllt ein mehr blätteriges Gewebe aus, das in undeutlichen Lagen, manchmal wie verworren aufgeschichtet ist. Im Längendurchschnitte erscheinen die Zellen viel deutlicher, besonders wenn der Schnitt nur sehr oberflächlich geführt wurde. Man unterscheidet ohne viele Nühe die oberflächlichen von den tiefer liegenden durch ihre dunklere Färbung. - Die Wände dieser Zellen bestehen aus ganz weissen, trocknen, spröden Blättchen; diess macht dann auch, dass die Rehhaare überhaupt spröde sind, und leicht abbrechen, wie wir denn solche an der Spitze abgestossene Haare unter dem Schwanze der Hirsche, am Moschusbeutel u. s. w. häufig finden.

Beleuchtet man aber diese Haare von unten, und wählt man hiezu den feinsten Theil, den Hals derselben, dann sehen wir die Rindensulstanz dunkel gefärbt, den Canal abeo durchsichtig, und durch feine Querwände unregelmässig abgetheilt.

Die Haare der Antilopen unterscheiden sich von den Rehhaaren, mit denen sie sonst sehr viel Aehnlichkeit haben, durch kleinere Zellen, und ein feineres inneres Gewebe. Diess gilt namentlich von der Antil. Dorcas, deren Knieharre ich untersuchte, und von der Rubicapra. Eben so verhält es sich auch mit den Haaren der Ziegen.

Anmerkung 1. Das Moschusthier zeichnet sich in dieser Gattung sehr durch die Manichfaligkeit seiner Haare aus, Seine Körperhaare kommen im Ganzen mit den Kehhaaren iberein, und zeigen unzählige kleine, runde Zellen, iibrigens kcinen $\mathrm{Ca}$. 


\section{Von der Verschiedenheit der Thierhaare etc.}

nal; dagegen sah ich an den flach anliegenden Schwanzharen, welche durchsichtig sind, den schönsten Doppelcanal. Endlich trägt das Thier in der Gegend, wo der Schwanz mit dem Rumpfe zusammenlıängt, eine feine Wolle, die sehr der Merinoswolle ähnelt. Anmerkung 2. So fand ich die Textur der Rehha are, und bin also mit der Ansicht von Heus inger iber diesen Gegenstand ibereinstimmend. Wenn er aber behanptet*), dass alle eigentlichen Haare, und selbst die Menschenhare, in den mehrsten Stücken mit den eben beschriebenen ibereinkommen, so scheint die. ser Ausspruch wohl eine Berichtigung zu verdienen. Zuvörderst miissen wir wissen, was man unter eigentlichen Haaren zu verste hen habe, und diese Definition ist gewiss nicht so leicht zu geben, als es Marchem scheinen möchte. Wenn Heusinger (wie man wohl zunächst glauben tnuss), darunter alle jene Hare zählt, die nicht zu den 'Tast-, schuppenförmigen, Borsten-, Woll- und Seidehaaren gehören, so möchte er wohl noch bey den Haaren mancher der übrigen Thiere auf Texturverschiedenheiten kommen, die sich nicht so ganz an die beschriebene derRehhare an reihen lassen. - Es ist überhaupt eine sehr schwierige Sache, die Haare nach ihrer Textur streng zu classificiren, weil die Manichfaltigkeit derselben zu gross ist. Welch' grosser Unterschied ist vollends nicht zwischen einem Reh - und einem Menschenhaar! Freylich finden wir in den meisten, oder wohl gar in allen Haaren Zellen, aber gerade ihre Gestalt und sonstige Beschaffenheit ist so verschieden, dass nicht das Haar einer Species dem einer andern, ihm sonst noch so sehr verwandten, ganz gleich kommt. - Auch gibt es noch eine Menge Haare, die in Bezug auf ihre Textur zwischen den platten und fleckigen Haaren gleichsem in der Mitte stehen, wie man diess schon in den Haaren der Hystrix dorsata ausgesprochen findet. Ferner trifft man öfters Haare, deren Oberfläche gleichsam wie aus feinen Schüppchen besetzt zu seyn scheint; und noch andere Thierhaare ähneln wicder sehr den Menschenhaaren, wie z. B. die einiger Affen, namentich des Cercopithecus rufus, Inuus aethiops, $\mathrm{Pap}$ io amatus etc, ferner der Unze, des Waschbärn, des Stinkthiers, des Bibers u. m. a. So bleibt also dem Forscher norh ein reiches Feld zu fernern Beobachtungen, denn wer ist im Stande, alle Haare genau zu untersuchen? -

Vergleiche Tab. XI. Fig. 114-118.

\section{§. 95 .}

Von den Tasthaaren.

Mit diesen Namen belegt man alle jene Haare, welche auf beyden Seiten um den Mund der Säugethicre, und zwar

*) A. а. O. P. 186. 
auf ihrer Oberlippe stehen, und sich einerseits durch ihre vorzügliche Länge, andrerseits durch ihre physiologische Bestimmung - als Gefühlsorgan - auszeichnen. Sie entsprechen also in Bezug auf ihre Lage dem Schnauzbarte des Menschen, und heissen daher auch Schnauz- oder Knebelbärte, (Moustaches) der Thiere. Im gewöhnlichen Sinne spricht man nur den Säugethieren diese Haare zu; es liessen sich aber nach meiner Neinung die um den Nund gelagerten Fühlfäden der wirbellosen Thiere, namentlich der Zoophyten und Würmer, ferner die Bartfäden der Fische wohl zu den Tasthaaren zählen. Ueber den Bau dieser letztern wurde schon frïher ( $\S .68)$ das Nöthige angeführt, und was ihre Function betrifft, so soll sie in den physiologischen Bemerkungen über die Thierhaare weiter besprochen werden. Ich beschränke mich daher jetzt bloss auf die Tasthaare der Säugethiere. Ihre Verbreitung in dieser Thierklasse ist, wo nicht allgemein, doch ausserordentlich gross, und ihr entspricht auch eine grosse Manichfaltigkeit in der einzelnen Anordnung, Lage, Menge, ja sogar in dem anatomischen Baue dieser Haare. So sind sie in manchen Thieren - namentlich den kleinern, zartern - ebenfalls feiner organisirt, als in andern, die sich überhaupt durch einen starken, torosen Körperbau auszeichnen. Man darf ja nur das Tasthaar einer Maus mit dem eines Ochsen vergleichen. - Was nun ihre innere Textur betrifft, so weichen sie nicht allein von den sogenannten eigentlichen Haaren nicht sonderlich $a b$, son. dern man kann sie mit allem Recht als die Normhaare des ganzen Thierreichs betrachten, und Jedermann wird zugeben müssen, dass das Tasthaar in jeder Hinsicht das vollkommenste unter allen Haaren ist. - Demnach bestehen sie 1) aus dem Balg und der in ihm enthaltenen $\mathrm{Z}$ wiebel, und 2) aus dem llaarschafte. - Was die erstern anbelangt, so habe ich selbe im §. 39 ausführlich und genau so beschrieben, wie ich sie wach wiederholten Versuchen in der Natur, und zwar in der Schnauze eines Ochsen fand. - Mit dem dort angegebenen Baue stimmen auch die Barthaare der übrigen Säugethiere in der Hauptsache durchaus überein, wesshalb es überflüssig ist, ihrer weiter zu erwähnen. - Der Haarschaft selbst fängt aul dem Boden des $\mathbf{Z}$ wiebelbalgs mit einer Anschwellung an, die man Wurzel - nach andern auch Z wiebel - nennt. Sie ist in den verschiedenen Thieren ebenfalls von sehr verschiedener, walurscheinlich bey jedem Individuum von eigener Gestalı, 


\section{Von der Verschiedenheit der Thierhaare etc.}

oft oval, cylindrisch, kugelförınig oder kreisrund, plattgedrückt etc. Sie ist ferner, wie schon gesagt, immer von weicherer Consistenz als das Haar selbst, und zeichnet sich durch die stets gleich bleibende weisse Farbe vor den übrigen Theilen des Haars aus. Sie ist hohl, und enthält in sich den sogenannten $\mathrm{Haar}$ kern oder Haarkeim (Pulpus pili). Dieser ist es nun hauptsächlich, wodurch sich die Tasthaare ganz besonders von den übrigen Haaren auszeichnen. Es ist nämlich ein weicher, meist roth gefärbter conischer, oder vielmehr nach der einschliessenden Höhle geformter, ich möchte sagen gelatinöser, und wahrscheinlich mit dem eigentlichen conischen Körper des Balges in Bezug auf seine Bestandtheile identischer Körper, der sich bey den Tasthaaren verhältnissmässig höher in den Haarschaft hinauf erstreckt, als in den andern Haaren. Er zeigt sich sogleich beym Durchschneiden eines Tasthaars (oft sogar desjenigen Theils, der bereits über der Haut hervorragt) durch einen blutigen Tropfen. - Da man nun diesen Körper als die eigentliche Materie ansehen muss, aus welcher das Haar zunächst entsteht, so begreift man leicht, warum sich die abgeschnittenen Tasthaare regeneriren und Knoten bilden, wenn der Schnitt so tief fällt, dass er noch den Haarkern trift.

Rücksichtlich des Schaftes der Tasthaare ist zu bemerken, dass er in manchen Thieren hornartig, oder den Borsten gleich, und daher mit sehr vieler Rindensubstanz begabt ist. Diess sehen wir bey den Barthaaren der meisten Cetaceen, namentlich der Robben. Ja ich bisher keine Gelegenheit hatte, diese Haare selbst zu untersuchen, so gebe ich hier ihre Beschreibung nach der Angabe anderer Autoren. Albin*) war wohl einer der Ersten, der seine Aufmerksamkeit auf den innern Bau dieser Haare lenkte. Der Graf B u ff o ${ }^{* *}$ ) sagt von ihnen Folgendes: Sie sind kurz, fein (?) und steif. Zu beyden Seiten der Schnauze ist ein Knebelbart, der vorn an der Schnauze theils mit schwarzen, theils halbweissen und halbschwarzen Borstenhaaren besteht. Ueber diesen finden sich andere, weit dickere und längere, die glatt und knotig sind, wie die Fühlhörner der Insecten. Eben solche Borstenhaare finden sich auch über den Vorderwinkeln des Auges. Die längsten haben $51 / 2$ Zoll. - Auch Rudolphi beschreibt ihre Structur in der angegebenen Dis-

*) Annot academ, lib, III, Cap. 15. p, 66.

*) A. a. O. 
sertation*), und in den Abhandlungen der königl. Akademie der Wisenschaften zu Berlin**). Die Angaben dieser Autoren benutzend hat wohl Heusing e ${ }^{* * *}$ ) das Beste hierüber geliefert, und durch Abbildungen erläutert. Nach ihm finden sich in dem Barte der Robben längere und kürzere Haarborsten, die sich von den Körperhaaren ganz verschieden zeigen. Die längsten stehen am weitesten nach vorne, die kürzern mehr nach hinten. Er fand die längsten über vier Zoll, die kürzesten kaum einen Zoll lang; sie sind weiss, hart, biegsam, elastisch, glänzend, in einen Bogen nach aussen und hinten gekrümmt, und an der feinen Spitze eingebogen. Am dicksten sind sie an der Basis, bilden aber hier keine Anschwellung, sondern nehmen von hier an bis zu der äussersten Spitze an Dicke ab. Die grössern sind von zwey Seiten zusammengedrückt und platt, und haben daher zwey Flächen und eben so viele Ränder. Diese letztern sind in regelmässigen $\mathrm{Z}_{\text {wischenräumen einge- }}$ drückt, und an diesen Stellen ist das Haar halb um seine Achse gedreht. Es scheint also, dass sich das Haar während seines Wachsthumes in regelmässigen Spiralwindungen gedreht habe; was sich vorzüglich an den kleinern Borsten zeigt, da diese nicht abgeplattet, aber ganz regelmässig spiralförmig gedreht sind. - Der Canal des Haars zeigt sich deutlich als ein braunrother Streifen von der Wurzel angefangen durch das ganze Haar; nur wird der Strich einen Zoll oberhalb der Wurzel feiner, ungefärbt, und verliert sich gegen die Spitze ganz. Heusing er hält diese Färbung begründet durch geronnenes Blut, das den Canal ausfüllt. Er fand übrigens ausser der Erweiterung des Canals auf dem Anfang der Wurzel keine andere Spur eines Kerns. - Der Balg bestelit aus einer harten, hornartigen, elastischen, gefässlosen Substanz, und hat eine ovale Gestalt. Nur auf dem Boden steht das Haar mit dem Balg in Verbin. dung, denn oben schliesst es sich zwar eng an denselben an, ohne jedoch mit ihm verwachsen zu seyn. Der conische Körper gleicht hier einem sehr zähen Fleische, in das sich viele Blutgefässe, nach Andern sogar Nerven fortsetzen. -

Anmerkung. 1. Der sogenannte Balg der Tasthare biethet manche Verschiedentieiten dar. Ich hahe ihn oben bey dem Ochsentast.

") De pilorum structura."Grygph. 1806. 4. p. 180.

**) Ueber Hornbildung.

***) A, \&. O, p. 176 
haare als sehr fest und dick - fibrös - beschrieben. Dagegen findet man ihn bey den kleinern Thieren, namentlich hunter den Hautfliglern (Chiroptera), oft von einer ganz basondern Feinheit, ja selbst durchsichtig. Hensinger will sogar die Cir. culation in dern Balg der Tasthaare von der kleinen Hufeisen. nase (Vesp. hipposideros) bey unverletzler Oberhaut un. ter dem Microscop gesehen haben. In den Tasthaaren des Hun. des fand ich ihn ebenfalls nu in der Mitte faserigt, oben und unten aber dïnn und fein. Bey der Kaze sind die Bälge verhälınissmässig dick und fest. - Auch ihre Farbe wechselt, doch sind sie meist entweder weiss oder gelblich. -

Anmerkung. 2. Auch der conische Körper ist Abänderungen unterworfen nach Verschiedenheit der 'l'hiere. Beym Ochsen fand ich ihn bald gelb, bald röthlich. In manchen Thieren soll er sugar schwarz seyn, gewöhnlich ist er jedoch roth. Seine Consisienz wechselt gleichfalls bey verschiedenen Thieren. --

Vergleiche Tab. XI. Fig. 119-122.

$$
\text { §. } 96 \text {. }
$$

Ich würde sehr irren, wenn ich mit den angegebenen IIauptverschiedenbeiten der Thierhaare in Bezug auf ibre Textur die Sache erschöpft zu haben glaubte; ich bin vielmehr überzeugt, dass man bey weiterer Verfolgung dieses Gegenstandes, und namentlich bey aufmerksamer Vergleichung der Haare von den einzelnen Arten der verschiedenen Thiergeschlechter noch auf sehr interessante Verschiedenheiten kommen würde. Eine solche Arbeit fordert aber eben so viel Zeit, als günstige Gelegenheit und tiefe Sachkenntniss. Erstere mangelt mir gegenwärtig, und letztere bin ich weit entfernt mir anzumassen. Nichtsdestoweniger habe ich von jedem Geschlecht wenigstens eine Species in Bezug auf die Haare untersucht; von schr vielen Geschlechtern bekam ich durch die Güte meiner Freunde die Haare mehrerer, namentlich aber aller ausgezeichneten Arten zu Gesichte. Wenn ührigens von dem verschiedenartigen Bau der Haare gesprochen wird, so ist diess fast immer auf die Structur des Haarschaftes zu beziehen. Rücksichtlich dessen sehen wir denn ein Hauptmoment in dem Verhältniss der Rinden- zur Marksubstanz, und in dern lockerern oder festerern Gewebe beyder. So ist die Rinden- oder Hornsubstanz in den meisten Haaren von einem durchaus gleicharligen - dem eigentlichen Horngewebe gebildet, doch auch in vielen Haaren mit wahren Zellen versehen, wie wir diess 
Von der Verschiedenheit der Thierhaare etc. 189

so schön bey den gefleckten Haaren gesehen haben, und $\mathrm{H}$ e u. sing e $r$ von den Haaren der Fischotter abbildete.

Nicht unbeträchtlich ist ferner die Anzahl derjenigen Haare, deren äusserste Rinde wie aus dicht aufeinandergelegenen, oder gleichsam zusammengebackenen Schüppchen zu bestehen scheint. - Manche Haare führen durch die Feinheit ihrer Textur auf den Gedanken, als wenn sie aus blossem Zellgewebe bestünden, und gar keine Rindensubstanz besässen. Wenigstens konnte ich z. B. in den Haaren des Goldmaul wurfs durchaus keinen Canal, also keine doppelte Substanz wahrnehmen, sondern das ganze Haar schien aus den niedlichsten Qterzellen zu bestehen. - Derley Haare treflen wir überhaupt unter den Seiden - und Wollhaaren an. Unter diesen erstern finden sich denn auch solche, wo die Rindensubstanz gleichsam querlaufende Verlängerungen nach einwärts zu machen scheint; wenigstens bin ich z. B. der Meinung, dass die dunkeln Stellen in den Maulwurfs-, Fledermäuse - und Eichhörnchen-Haaren bloss von einer dickern Hornsubstanz, nicht aber von besonders abgesetztem Pigmente herzuleiten seyen.

In der Regel ist das Haar in der Mitte durchsichtig, und zeigt einen Canal, doch gibt es hiervon unendliche Verschiedenheiten. Denn theils lässt diese Durchsichtigkeit eine Mrnge Abstufungen zu - wie beym Chilopales variegatus, und allen gegliederten Haaren z. B. den Mäusehaaren; - theils ist die Marksubstanz erst dadurch zu unterscheiden, dass an ihren beyden Rändern ein lichter Streifen läuft, der sie von der dunkelı Hornsubstanz scheidet, wie z. B. bey Mustela putorius; theils erscheint sie wie durchlöchert, wie z. B. bey Mustela rulgaris und Jachus penicillalus; bald ist sie selbst wieder durch regel. mässige Ringe abgetheilt, wie im Maulwurf, bald gegliedert; wenn diese Ringe breiter werden, und durch einen lichten Streif von der Hornsubstanz getrennt sind, wie beym Landbären; bald blóss gezackt wie beym Eisbären; bald stellenweise ganz dunkel und undurchsichtig, (ein Fall der sich häufig findet), bald endlich ganz gleichartig mit dicht aufgehäufter und daher kaum zu unterscheidender Marksubstanz, wie beym Löwen. Selten ist es, dass sich die Sache umgekehrt verhält, d. h. dass die Rindensubstanz durchsichtig, und die Medullarsubstanz undurchsichtig ist. Dennoch fand ich es so bey den Haaren des Lüwen. Ueberhaupt ist das Mengeverhältniss der beyden Substanzen sehr veränderlich; in der Mehrzahl mag 


\section{Von der Verschiedenheit der Thierhaare etc.}

wohl das Mark 1/3 des Ganzen einnehmen; doch gibt es auch Fälle, wo die Hornsubstanz bedeutend abnimmt, wie in den meisten Seiden- und Wollhaaren, und namentlich auch in denen des Lemur tardigradus, und des Goldmaulwurfs, die aus lauter gleichartigen Querzellen zu bestehen scheinen. Es ist gewiss interessant, dass gerade in dem Geschlechte: Felis, und namentlich beym Tieger und Löwen das Innere des Haars so voll Mark zu seyn scheint, dass es beynahe dem Hollundermark gleicht. Nichtsdestoweniger ähneln wieder die Haare des Panthers (Felis Pardalis), und Luchses (Felis Lynx:), in so fern den Mäusehaaren, dass sie geringelt sind. Oft findet man unter einer Anzahl Haaren von einem und demselben Thier ganz verschiedene Haare. Diess erfuhr ich, als ich die Haare der Mustela sulgaris untersuchte. Die dicksten unter ihnen waren undurchsichtig, höchstens da und dort wie fein punktirt; die feinern zeigten einen geringelten Canal; noch andere schienen alle Hornsubstanz verloren zu haben, waren völlig durchsichtig, und zeigten die feinsten und regelmässigsten Markzellen. - Endlich gibt es eine grosse Anzahl von Haaren, die denen des Nenschen sehr ähnlich sind, so von Cercopithecus rufus, Inuus aethiops, Papio amatus und Mormon, Stertor, Cebus und Colopus (Affen), ferner vom Biber, der Unze, dem Waschbären, Stinkthier u. a. m. -

Gewöhnlich sind die Spitzen der Haare - vorzüglich der grössern, starken - Haare, dicht, ohne Mlarksubstanz. Doch hat das auch seine häufigen Ausnahmen, und gar oft war es gerade die Spitze, die mir über den Bau des Canals, die Beschaffenheit des ihn ausfüllenden Zellgewebes den gewünschten Aufschluss zu geben vermochte, während alle übrigen Theile des Haars, aus zu grosser Nenge ihrer Hornsubstanz, vollkommen uudurchsichtig waren. -

Man wird übrigens bey einer aufmerksamen Vergleichung der von mir dem Werke beygegebenen Zeichnungen mit denen anderer Autoren ersehen, dass läufig bedeutende Abweichungen Statt finden. Natürlich wird wohl ein Jeder das Recht der richtigen Copirung für sich zu behaupten suchen. Ich verweise statt alles Rechtens den Leser an die Betrachtung der Natur, also zur Anstellung eigener Beobachtungen, um das Lob nach Verdienst auszutheilen. Es bleibt immer eine schwierige Sache, mit verschiedenen Instrumenten, und bey ungleicher Fertigkeit sie zu handhaben, gleiche 
Von der Verschiedenheit der Thierhaare etc. 191

Resultste zu erhalten; hiezu kommen denn noch die fatalen optischen Täuschungen. Dass man aber dennoch in der Hauptsache übereinkommen könne, davon zeugen die Kupfertafeln von $\mathrm{Heusinger}$ und meine eigenen Abbildungen, wenn beyde mit einander verglichen werden. Desto auffallender wird aber der Contrast zwischen diesen und den Abbildungen von Baster*) seyn, von welchen ich kühn behaupten möchte, dass sie in Bezug auf Trene sehr vieles zu wünschen übrig lassen. -

*) Twe ede Verhandeling over de Bekleedselen van de Huid der Dieren, voornamelyk van het Hair door Baster Job. In den Verhandelingen der Hollandsche Matschappye der Wetenschoppen te Haar. lem Deel XIV. p. $\mathbf{3 7 9 .}$ 


\section{Zweyter Abschnit.}

Ueber den physiologischen $Z_{\text {weck }}$ der Thierhaare.

$$
\begin{aligned}
& \text { §. } 97 . \\
& E i n \ell \text { e } i t \| n \text {. }
\end{aligned}
$$

Auch bey den Thierhaaren finde ich es zweckmässig, dic Functionen derselben in einer doppelten allgemeinen Rücksicht zu betrachten. Demnach theile ich selbe auch hier in

a) Haupt - oder allg emeine, und in

b) Neben - oder besondere Verrichtungen.

Ich verstehe ferner unter den ersten abermals solehe, welche 1) allen Haaren dieser Klasse zukommen, und die 2) einen wesentlichen Einfluss und Nutzen a uf die ganze Oekonomie, oder, wenn man anders sagen will, auf den ganzen Lebensprocess der Thiere haben; und zähle unter die zweyten alle jene, durch welche irgend ein besonderer $\mathrm{Z}$ weck eines Theils des Organismus vorzugsweise erfüllt wird.

$$
\text { Erstes } H \text { a uptst } \ddot{\text { ï } c k} \text {. }
$$

Von dem Nutzen der Thierhaare im Allgemeinen.

S. 98.

In diesem Bezuge kommen nach meinem Dafürhalten die Thierha a re so zu sagen fast ganz mit denen des Menschen überein, und es ist daher bey gehöriger Berücksichti- 
gung der auch hier einfliessenden Nebenumstände alles das anzuwenden, worüber ich später bey den Menschenhaaren sprechen werde. Ich verweise demnach, um unnütze Wiederhohlungen zu vermeiden, den Leser auf die Paragraphe der drey Abtheilungen der Menschenhaare, worin von der Ausdüntung, Einsaugung und der electrischen Spann u $\mathrm{n}$, insofern sie durch die Ilaare vermittelt werden, ausfïhrlich gehandelt wird, und bemerke noch, dass ich dort auch jene Phänomene in Anregung bringen werde, welrhe sich bey Thieren beobachten, und auf die fraglichen Puncte anwenden lassen.

$$
Z \text { w eytes } H \text { a uptst } t \text { ӥ } c \text { k. }
$$

Von dem speciellen Nutzen der Thierhatre.

\section{99 .}

In dieser Beziehung zerfällt die Function der Thierha are in folgende Theile:

a) Sie dienen zur Bedeckung.
b) " " zum Schutz und zur Verthei- digung,
c) " " zur Schönheit und Zierde.
d) Sie sind Organe des Gefühls und
e) " " " der Bewegung *).

\section{§. 100}

a) Vonden Haren der Thiereals Bedeckungsmittel.

In keiner andern Beziehung wird der Nutzen und $Z_{\text {weck }}$ der Thierhaare so allgemein giltig angenommen, als gerade

*) In ökonomischer Rücksicht dienen sie auch zur Befriedigung einiger Bedürfnisse des Menschen, wovon jedoch hier weiter keine Rede seyn kann. 
in dieser. Unser tägliches Leben mit seinen gewöhnlichen Bedürfnissen erinnert uns zu oft daran, Klima und Jahreszeit halten uns denselben so grell vor Augen, dass man sich nicht wundern darf, wenn unter dem Kapitel, welches vom Nutzen der Haare handelt, die Bedeckung des thierischen Körpers, und der dadurch bewirkte Schutz desselben vor äussern Unbilden jeglicher Art obenan steht. - Im Allgemeinen sehen wir wirklich gerade jene Thiere am haarigsten, welche dem feindseligen Einfluss des Klima und der Jahrszeit am meisten ausgesetzt sind. Desshalb hat die Natur alle Thiere im wilden Zustande mit einem stärkern Haarwuchs begabt, als die zahmen; desshalb verlieren mancbe Thiere, wenn sie ihr kaltes Klima, oder ihre rauhe Lebensweise mit einem wärmern Himmelsstriche und dem gemächlichen Zustande der Hausthiere vertauschen, ihre Haare in einem wirklich auffallenden Grade, wie uns das guineische Schaf, das nur Haare, statt Wolle, und der guineische Hund, der gar keine Haare hat, zur Genüge beweist. Ich müsste mich selbst wiederholen, wenn ich alle die Thatsachen hier anführen wollte, welche das Gesagte bekräftigen, und ich verweise demnach auf die $\$ \$ .45,46$, wo von dem Einflusse des Klima, der Jahrszeit und der Lebensart auf die Haare gehandelt wurde. - Dass die Thiere gerade an ihrer sogenannten Lichtseite, also jener, die den äussern Einflüssen zunächst ausgesetzt ist, behaarter sind, als an der Erdseite - also im Allgemeinen am Rücken mehr und stärker, als am Bauche - spricht ebenfalls zu Gunsten des zu beweisenden Satzes. Wollten wir übrigens die Naturgeschichte der behaarten Thiere, ihre Lebensart $u$. s. w. genauer durchgehen, so würden wir jeden Augenblick auf Thatsachen stossen, die diesen Gegenstand ausser allem $Z_{\text {weifel setzen, und nach allen }}$ Seiten bekräftigen. - Am allermeisten spricht wohl der aus unserm täglichen Leben genommene Umstand dafür, dass wir uns selbst in der rauhen Jahrszeit, oder im kalten Klima durch dic behaarten Felle der Thiere - das sogenannte Pelzwerk vor den Unbilden derselben zu schützen wissen.

Auch das wechselseitige Verhältniss, in welchem die Menge, oder auch nur das Vorhandenseyn, und die geringe Anzahl oder der gänzliche Abgang der Haare mit der derbern schaligen d. i. kalkartigen, und schuppigen Haut, und auf der andern Seite mit dem feinen Fell stehen, führt uns auf die Richtigkeit der angeführten Behanptung; und dass diejenigen 
Thiere, welche in Wasser leben müssen, gewöhnlich haarlos sind, lässt sich am besten dadurch erklären, dass sie ihrer nicht bedurften, weil sie, deren Körper ohnehin mit dem Wasser fast gleiche Temperatur hält, in diesem Medium gleichmässig fortleben, und von allen anderartigen Einflüssen, denen die Landthiere unauflörlich ausgesetzt sind, wenig oder gar nichts za leiden haben. - Uebrigens ist es immer eine bemerkenswerthe Sache, dass (mit Ausnabme der Fische und Amphibien) im Allgemeinen gerade die Klassen der höhern Thiere einen stärkern Haarwuchs von der Natur erhielten, als die der niedern, und dass wir unsern Satz: „Die Haare dienten zur Bedeckung" gerade bei den niedersten Thierklassen fast gar nicht anwenden können; obwohl auch hier die Natur, wie überall, ihre oft unerklärlichen Ausnahmen macht, so dass wir Thiere, die in den meisten Beziehungen einander ähnlich sind, oft in Bezug auf ihre Ilautbedeckung ganz abweichend finden.

Interessant war mir die von $\mathrm{R}$ ösel gemachte Bemerkung, dass der Nutzen der grauen Wollhaare, welche die Phalaenn bomb. lanestris $L$. als Schmetterling und Weibchen an den letzten Gliedern ihres Hinterleibs in einem starken Büschel beysammen hat, darin bestehe: dass das Thier die von ihm nach der Paarung gelegten Eyer damit überziehe, nach dem es sich dieselben mit dem zangenförmigen Ende seines Eyerganges ausgerissen hat. So bedeckt auch Phalaena dispar. ihre in ovalen Massen an Baumstämme gelegten Eyer mit ihren Haaren; und Phalaena processionea überzieht eine Stelle mit Schleim, streut die Hälfte ihres Haarbüschels darauf, legt dann reihenweise ihre Eyer darein, und bedeckt sie endlich mit dem Reste ihres Büschels, und zwar so, dass alle Haare eine gleiche Richtung haben, nämlich mit ihrem Wurzelende auf den Eyern stehen, mit dem andern Ende aber nach Aussen gerichtet sind. Auf gleiche Art reissen sich Pelikane, Seetaucher, Enten, Rebhühner und andere $\mathrm{V}$ ögel selbst die feinsten Federn aus der Brust, und bereiten damit eine wärmere und weichere Unterlage für ihre Eyer. So dient überhaupt die oft auffallende Menge feiner Haare, welche man in der Larve vieler Schnetterlinge findet, nebst dem daselbst liegenden Gespinnste zum Schutze des in der Metamorphose begriflenen Thit rchens; auch schützt der starke Haarwuchs mancher Insecten ihre zarte Haut vor einer ihnen nachtheiligen Reibung, und wohl zu berück- 


\section{Von dem speciellen Nutzen der Thierhaare.}

sichtigen ist die von C. Sprengel*) gemachte Beobachtung, dass die Luftlöcher (Stigmata) der Insecten oft durch Borsten und Haare gegen das Eindringen fremder Körper geschiitzt werden.

\section{§. 101 .}

b) Von den Thierhaaren als Vertheidigungsmittel.

Das Wesen der ganzen Natur offenbart sich durch einen beständigen Kampf; wir sehen diess nicht allein in dem unorganischen Reich, sondern jeder Schritt, den wir in der organisirten Welt vorwärts machen, sagt uns dasselbe. Auffallender tritt aber dieses Entgegenstreben dem gewöhnlichen Menschen da in die Sinne, wo der Kampf unter lehenden Geschöpfen besteht, die mit dem Menschen in näherer oder entfernterer Beziehung sind, und wo er sich wirklich den groben Augen als ein wahrer Vertilgungskrieg darstellt, indem diese die daraus jedesmal entstehende neue Schöpfung meist gänzlich übersehen. - Da wir also, wie gesagt, unmöglich läugnen können, dass alles zum Untergang bestimmt sey, und dass dieses immerkehrende Verderben zur Wesenheit der Schöpfung gehöre, so kann es uns allerdings einigermassen wundern, wie sich die Natur in mancher Beziehung diesfalls selbst im Wege steht, und jene Vernichtung auf manichfache Art zu hindern strebt. Die Sache auf unsern Gegenstand angewandt, ist es gewiss eine wunderbare Einrichtung in der Natur, dass gewisse Thiere mit allerhand Werkzeugen versehen sind, womit sie sich gegen die feindseligen Angriffe der Andern vertheidigen, und so ihr Leben schützen können. Unter diesen Waffenarten finden wir nun auch bey mehreren Thieren die Haare - namentlich die stärkern - Borsten - Stachelhaare. - Es ist schwer zu bestimmen, in wiefern die hierhergehörigen Haargebilde - ich meine die Haken - Borsten und Stacheln - den Zoophyten und Eingeweidewürmern zur Waffe dienen, und zwar aus dem Crunde, weil man diese kleinen wunderbaren Thierchen in ihren verschiedenen Lebensactionen nicht so leicht zu beobachten $\mathrm{Ge}$ legenheit hat, und ihre eigentliche Naturgeschichte sich gerade

*) Commentarius de partibus, quibus insecta spiritus ducunt. Lipsiae, 1815. 4, 
noch in einem sehr dürftigen Zustande befindet; wenigstens gilt diess gewiss von den Zoophyten. - Der mitunter gerade in dieser Beziehung sehr ausgezeichnete Bau der Ordnung: Stachelhäute nach Cuvier (Echinodermata), und namentlich des so bekannten Seeigels (Echinus), über dessen Stacheln ich oben das Nähere angegeben labe, kann wohl zunächst keinen andern $Z_{\text {weck }}$ haben, als das in der Schale enthaltene Thier zu schützen. Wir können diess um so eher glauben, als wir wissen, dass die Stacheln dieser 'Thiere mit Muskeln versehen sind, und daher nach Willkühr bewegt werden können. Mehr Ungewissheit herrscht schon in Bezug auf die Bestimmung des Nutzens der Stacheln und Borsten, die wir bey den Anneliden, namentlich bey den Arten von Aphrodile antreflen, doch werden wir nicht sehr unrecht thun, wenn wir sie nebst dem schon bekannten auch als zu diesem Zwecke bestimmt ansehen. - Weit deutlicher spricht sich dieser freylich bey den Insectén aus, und man kann kühn behaupten, dass die langen Haare, die steifen Borsten, scharfen Dornen, womit manche Raupen und andere Insecten bekleidet sind, wahre Vertheidigungsmittel darstelJen. Dass diess sich wirklich so verhalte, beweist schon der Umstand, dass diese Thiere bey ihrer letzten Mauser, ehe sie sich verpuppen (wo sie dann dieser Schutzmittel nicht mehr bedürfen) mit einer glaiten Haut, ohne jene Haare und Dornen erscheinen, wodurch sie früher so bemerkbar waren. -

Noch deutlicher zeigt sich dieser Nutzen z. B. bey der Raupe der grossen Tiegermotte, oder des braunen Bären (Phal. B. Cajn), welche, wie bekannt, mit sehr langen Haaren dicht besetzt ist. Diese Rauj)e rollt sich gleich dem Igel zusammen, sobald sie im Mindesten beunruhigt wird, und kann dann nicht leicht aufgerollt werden, weil sie immer zwischen den Fingern durcholeitet. So ist *) der kleine zerstörende Käfer (Anthrenus musaeorum) im Larvenzustande mit Bündeln von auseinanderlaufenden Haaren besetzt, und schlüpft daher zwischen den Fingern durch, als ob er mit Oel wäre schlüpfrig gemacht worden. Die zwey Haarschöpfe am Schwanze, welche ihrer ganzen Länge nach mit einander vereinigt sind, und sich in eine lange, scharle, hellebardenähnliche Spitze endigen, scheiuen tbenfalls zur Vertheidigung abzuzwecken. - So gibt es

*) Entomologie von Kirby und S pencet. Stultgardt 1824. Einleitung. 
198 Von dem speciellen Nutzen der Thierhaare.

Raupen, bey deren blossen Berührung mit den Händen diese entzündet werden. Da man diess insbesondere von der Fichten- und Processionsraupe sagt, so habe ich ihre Haare genau untersucht und gefunden, dass der Grund jener Entzündung offenbar darin liege, dass sich die feinen Haare dieser Raupe, die alle mit einer unzählbaren Menge ausserordentlich kleiner Seitenstacheln versehen sind, mittelst dieser letztern in der llaut festsetzen, und so wahrscheinlich auf rein mechanische Art jene Entzündung bewirken. - R ća a m u r *) hat die Jucken und Brennen erregende Eigenschaft einiger Haarraupen umıständlich beschrieben. Dr. Banks und Solander beobachteten auf einer Insel des Südmeeres auf den Mangroevebäumen in morastigen Gegenden eine Menge kleiner grüner Raupen, die sehr haarig waren, und bey der Berührting wie Brennnesseln stachen, ja einen noch durchdringendern, aber nicht so anhaltenden Schmerz verursachten. - Mit Recht nennt man also diese Haare passive Vertheidigungsmittel der Insecten.

\section{Vergleiche Tab. VI. Fig. $60-61$}

Es gehört uiberhaupt noch gar viel dazu, die eigenthümliche Stellung der manchmal so sonderbar gestalteten Haare und Borsten hinlänglich zu erklären, ungeachtet wir an einem dieser Stellung genau entsprechenden Zweck keinen Auggenblick zweifeln können. Die so saftreichen Haare der Arachniden sind wohl vielleicht durch den enthaltenen Saft schädlich; wenigstens lese ich in $\mathrm{R} \ddot{s}$ sel's Insectenbelustigungen, dass $\mathrm{Pi}$ is den Haaren einer grossen westindischen Winkelspinne eine brennende Kraft zuschreibt, wenn sie auf die Haut eines Menschen gebracht werden. Bey den Fis chen ist gewiss der ausgezeichnete Bau der Stachelbäuche und Igelfische ebenfalls auf dic Vertheidigung berechnet. Denn diese Thiere blasen sich, indem sie Luft verschlucken, und damit ilıren Kropf (Magen?) anfüllen, wie ein Ball auf, spannen dadurch ihre Haut, in welcher die Stacheln sitzen, und bilden so auf dieselbe Art eine Stachelkugel, wie der Igel auf festem Lande. - Dieser letztere ist es nun vorzüglich, an dem wir den Nutzen besagter Stacheln am besten zu beobachten Gelegenhicit haben. Schon Fabrizius ab Aquapendente**) hat

") Mémuires des Insects, tom. II. p. 1. mem, 4

**) Opera omnia anatom, et physiolog anno 1565. p. 445 de pilis. 
uns iiber den Zweck der Igelstacheln Folgendes berichtet: „Der Igel bedarf solcher Stacheln, weil er stets zwischen Dornen, Steinen, in Baumhöhlen und rauhen Gegenden herumzieht. Zudem ist das Thier klein, hat kurze Beine, bewegt sich dessbalb langsam und schwer. Diesen mangelhaften Bau musste also die Natur durch eine stachliche Bedeckung ersetzen, damit der Igel allen äussern Einflüssen mit seinen Stacheln begegne, so wie er seine edlen Eingeweide im Fall der Noth unter diese Schutzwehr zurückziehen kann." - Wirklich ist der Igel im Stande, seinen ganzen Körper mit grosser Kraft kugelförmig zusammenzuziehen, Kopf und Füsse ganz zu verstecken, so dass der ganze Körper einer Stachelkugel gleicht, die schwer anzugreifen ist. - Ueber das Stachelschwein sagt uns derselbe Fabrizius: „Dieses Thicr hat gleiche Mängel in seinem Bau wie der Igel, ist zum schnellen Laufen ungeschickt, und hat eine Menge Fett unter der Haut. Es soll sich gegen die Angriffe der Hunde durch Abschicken der Stacheln vertheidigen, indem es nämlich auf ihre Nläuler zielt (?!), und zwar soll diess mit solcher Gewalt geschehen, dass die weggeschleuderten Stacheln sich im Holze fangen, und getroffene Hunde an der Wunde sterben. - Diess wird zwar nicht von allen geglaubt, aber wahr ist es, dass dieses Thier, sobald es von Hunden verfolgt wird, keineswegs flieht, weil es sich untüchtig dazu fühlt, sondern stille hält, und im Vertrauen auf seine Waffen zuerst sich, wie zum Kampfe rüstend, am ganzen Körper aufblähet, dann die Stacheln nach einer gewissen Richtung erhebt, und zuletzt mit seltener Kunst bald sich zur Wehre setzt, bald die Hunde angreift, so zwar, dass die meisten derselben gar nicht, manche jedoch auf wiederholten Befehl ihrer Herren zum Angrille schreiten. Sobald sie nun das Stachelschwein nahe genug glaubt, wendet es seinen Hinterleib bey günstiger Gelegenleit gegen seine Verfolger; stets rückwärts gekehrt vorschreitend, schleudert es zwar keine Stacheln weg, sondern vertheidigt sich mit denselben gegen die Zähne der Hunde. Noch wunderbarer aber ist es, dass, sobald dieses Thier einige Stacheln in dem Körper der Hunde haften sieht, selbe alsbald abfallen, (daher nannte sie Plinius Spinae missiles), weil es sie eingesenkt zurücklässt, indem es in seiner Wuth die Gabe hat, selbe loszulassen. Zugleich schwillı es am ganzen Körper auf. Die Jäger aber halten eine solche Wunde für giftig, ziehen alsbald die Stacheln heraus, und stecken sic unter dic Erde, als wern ih- 
nen dadurch geholfen würde." - Wenn wir nun gleich dem Thiere die eigenthümliche Kraft, seine Stacheln abzuschiessen oder auch nur loszulassen in dem angeführten Sinne nicht zuschreiben wollen, so liegt doch in dem übrigen Theil der Angabe dieses alten Gewehrsmanns viel Wahres, und verdient daher nicht übergangen zu werden. - Cuvier*) sagt, dass es ihm scheine, als könnte das Thier seinen Harn in die hintern Stacheln lassen, um ihn nachher, wie nit einem Weihwedel weit weg zu spritzen. Diess wäre doch gewiss etwas ganz Besonderes! Fast möchte ich die Stacheln mancher Insecten, namentlich der Bienen ebenfalls hierher rechnen, welche doch am Ende auch nichts anders als steife Haare sind, die sich nur durch ibren Sitz, und einen eigenen giftartigen Saft, der in ihrer Höhle enthalten ist, von anderu ähnlichen Stacheln auszeichnen.

Endlich beobachten wir noch bey vielen andern Säugethieren, dass sie, wenn sie gereitzt, oder in Wuth versetzt werden, ihre Haare gleichsam aufrichten (was offenbar nur durch krampfhafte Zusammenziehung ihres Hautmuskels vermittelt wird); bey andern wieder, die eine Gefahr befürchten, oder Schläge zu gewärtigen haben, sehen wir, dass sie durch Runzelung ihrer Haut die Menge der, selbe bedeckenden Haare gleichsam künstlich vermehren, und so die Gewalı der äussern Einwirkung schwächen.

\section{\$. 102.}

c) Dic Thierhare dieuen zur Schönheit und Zierde des Körpers.

Ich bin überzeugt, dass die Natur, als sie den Thieren die Haare gab, nebst den bereits angeführten allgemeinen Zwecken, gewiss auch den zu erreichen strebte, die Form der 'Thiere in Gefälligkeit und Anmuth zu erhöhen; ja es ist nicht zu verkennen, dass die Vertheilung der Haare in Bezug auf Art und Menge derselben selbst mit den besondern Form-Verhältnissen der einzelnen Thiere in näherer Verbindung stelit. Dass übrigens die Haare ganz besonders geeignet sind, die äussere Form der Thiere zu modificiren, daran wird wohl Niemand zweifeln;

*) Vorlesungen 2. Bd, p. 568 . 
auch gibt uns die tägliche Erfahrung häufig genug Beyspiele und Belege für diesen Satz. Nan denke sich was immer für ein Thier, das im Naturzustande stark behaart ist, dieser Zierde auf einmal beraubt, wie hässlich stellı es sich unsern Blicken dar?

Auch können wir kühn behaupten, die Natur häle die ausserordentliche Manichfaltigkeit in der äussern Form ihrer Geschöpfe nicht wohl erreichen können, wenn sie sich nicht gerade des Haarschmucks dazu hätte bedienen können. Ein nur oberflächlicher Ueberblick in der Klasse der Sä u g e th i er e gibt uns davon den überzeugendsten Beweis; und hierin liegt auch der Grund, warum die Naturforscher aller Zeiten bey Zusammenstellung ihrer Systeme, namentlich aber bey Angabe der unterscheidenden Merkmale der Ueschlechter und Arten stets auch ihre Zuflucht zu den Haaren genommen haben. - Es würde mich übrigens zu weit führen, wenn ich alle die vielen Beyspiele anführen wollte, wodurch erhellen würde, dass sich die Natur gerade der Haare bediente, um einzelne Thierarten nicht allein aufs deutlichste, sondern auch durch anmuthige Form vor andern auszuzeichnen. Ein Rückblick auf die frühern Paragraphe, wo ich bemüht war, die auffallendsten Zeichnungen der Thiere einer jeden Klasse zusammenzustellen, und das Allgemeine über die Richtung, Länge, Menge und das Vorkommen der Haare überhaupt anzugeben, kann einen jeden Leser davon überzeugen. - Wollen wir die Sache noch weiter verfolgen, und von den Backenbärten, Schnauzbärten, Haar-

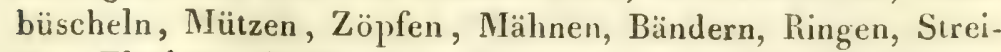
fen, Flecken, Schwänzen, Zotten u. s. w. der Säugethiere al :trahirend, in die Klasse der $\mathrm{V} \ddot{\text { öge }} \mathrm{l}$ übergehen, so werden wir vollends von Bewunderung hingerissen. Der gütige Schö. pfer, der uns diese muntern Thiere gleichsam zum Vergnïgen, zur allgemeinen Freude seiner belebten Schöpfung gab, verlieh der Annehmlichkeit und Schönheit ihres Körpers einen neuen unvergleichlichen Reitz durch die herrlichsten Farbenzeichnungen, die sich kaum ein Mensch denken kann, der sie nicht in ihrer ganzen Pracht bewundert hat. - Wie abschreckend sind dagegen die meisten Thiere, und namentlich die Amphibien, deren Haut aller Haare beraubt, und um diesen Mangel zu ersetzen, miit einer dicken knöchernen Schale bedeckt ist. Selbst unter den Säugethieren stehen gewiss die wenig oder gar nicht behaarten an Schönheit der Form allen 
ïbrigen weit nach. Nan vergleiche einmal die Pachydermata mit den Suhlen - und Zehengängern, man stelle den Elephanten, das Flusspferd, Nashorn den Arten des Hunde- und Katzengeschlechts: dem Löwen, Tieger, Leoparden u. dgl. gegenüher! wie abschreckend ist z. B. das Geschlecht der Schildkröten, unsrer Kröten und Frösche gegen unsre Mäuse- und Maulwurfsarten? Man wird vielleicht sagen: das liegt nicht in den Haaren allein, sondern im ganzen Bau des Thieres. Wohl! aber rasiere den genannten Thieren das Fell $a b$, und du wirst dich überzeugen, dass sie nun eben so hässlich, als die Thiere der andern Art sind. - Obgleich die Fis c h e in gewöhnlichen Sinne ohne Haare sind, so wird man doch eingestehen müissen, dass ihre Bartfäden manchen von ihnen gar wohl anstehen. \%udem hat die Natur den Abgang des Haarschmucks durch cine oft recht schön gezeichnete Schuppenhaut zu ersetzen gesucht. - Es ist unmöglich, all' das Schöne zu beschreiben, wodurch sich der Haarschmuck bey den Insecten auszeichnet. Die Manichfaltigkeit geht hier wieder ins Unendliche, und muss an den einzelnen Thicrchen selbst bewundert werden. Wahr ist es aber, dass die Haare überall da, wo sie vorzüglich zur Bewegung dienen, der Schönheit und Regelmässigkeit der äussern lorm der Thiere nicht so sehr zu entsprechen scheincn, obgleich sich auch hier Manches zu Gunsten des letztern anfiihren liesse. - Auch den Crustaceen geben die Randhaare ein gefälliges Ansehen. Je weiter wir nun in dem Thierreich hinabsteigen, und je kleiner die Thiere werden, desto weniger scheint es in Bezug auf ihre Haare darauf abgesehen zu seyn, die Schönheit des Körpers zu erhöhen. Nichts desto weniger geben die ausgestreckten haarartigen Verlängerungen den Strahlihieren, Entozoën, und besonders den Zoophyten manchmal eine ganz eigenthümliche, oft bewunderungswürdige Figur, die unsern erstaunten Blicken um so mehr auffillı, je schneller sie sich verändert, rerschwindet, und bald eben so, bald etwas modificirt wiederkehrt. - Alles dieses wird um so deutlicher werden, je tleissiger die bey den einzelnen Thierklassen angegebenen Haarverschiedenheiten auf' diesen Gegenstand bezogen, und Vergleichungen zwischen beyden angestellt werden.

Anmerkung. 1. Es ist allerdings richtig, dass wir bey manchen 'Thieren Haare finden, die zum $\Lambda$ uffasen der Nahru $\mathrm{N}$ bestimmt sind. Man kann hierher z, B, die Stachelu des Igels zälı. 
Von dem speciellen Nutzen der Thierhaare. 203

len, welcher sich dieses Thier offenhar bedient, nm Trauben, Kastanien, Eicheln, Maulbeeren, Birnen und Aepfeln anfzuspiessen, und seinen Jungen zu bringen. Eben so leben auch nach $\mathbf{C}$ u. vier's Angabe die sogenannten Stachelhäute unter den Fischen von kleinen Schalthieren, derer sic sich durch ihre Fisse und Stacheln bemächtigen, Selbst bey den Vorticellen und In fns orien ist es noch nicht ganz ausgemacht, ob die Kreisbewegungen und das Zittern und Schwingen ihrer Faare nicht doch mit der Auffassung ihrer Nahrung in ursächlichem Verhältnisse stche. -

A nmerkung. 2. Bey den Insecten ist wohl kein Zweifel, dass sie sich ihrer Haare håufig auch dazu bedienen, urn fremde Körper von ihrem eigenen abzuhalten, oder wenn selbe schon festsitzen, sie wieder wegzubringen. Um hier nur ein Beyspiel anzuführen, bemerke ich, dass die aus den Dornenraupen hervorkommenden Schmetterlinge statt des dritten Paares Fisse ein Paar kurze und slumpfe, aber ganz mit Haaren uiberzogene Pfoten haben, derer sie sich als Hände bedienen, indem sie immer ihren Kopf, die Augen, den Bart u. dgl. damit putzen.

A nmerkung. 3. Dem Hasen gab die Natur nach Columbus eine behaarte Fusssohle, um ihn als ein furchtsames Thier leichter zur Flucht geschickt zu machen.

Anmerkung. 4. Die Frage, warum die Thiere eigentlich keine Kopfhaare (wie der Mensch) habe, wurde schon in frühen Zeiten gestellt, und Glisson*) gab folgende Ursache als Antwort an: "Die Thiere sind ohne Vernunft und Hände, und geken mit ge. beugtem Kopfe; hätten sie nun auch, wie der Mensch lange Kopfhaare, so wïrden selbe nicht allein den Gebrauch der Augen, sondern auch des Mundes grösstentheils hindern. Auch sind ihre Schläfemuskeln stark genug, um sie vor Kälte zu schïizen。"

A nnerkung. 5. Ich kann nicht entscheiden, ob die Angabe richtig sey**), dass zwischen den Haaren einiger Insecten, die unter dem Wasser leben, eine mit Luft gefiillte Blase eingeschlossen sey, die ihnen (wie eine Schwimmblase) znm leichtern Aufstejgen im Wasser dienen kann.

\section{§. 103.}

(1) Vonden Thierharen, als Organen des Ge fühls.

Die Natur der Sache führt uns sogleich auf die sogenannten Tasthaare der Thiere. Wir haben oben gesehen, wie

*) A. a. O.

** Encyclopedie on Dictionnaire raisonné des sciences, arts cl melicró. Arlicle Poils. 
ausgedehnt ihre Verbreitung im Thierreich, und wie ausgezeichnet ibre Organisation vor allen übrigen llaaren ist. Diess allein nähert uns schon dem Thema in so fern, als der hohen Stufe der Organisation dieser Gebilde eine ihrer Wichtigkeit entsprechende Function parallel geht. - Fis handelt sich nun zuvörderst, zu beweisen, dass diese Organe wirklich das leisten, was man ihnen zuschreibt. - Obgleich es eine allgemein angenommene Sache ist, dass z. B. die Knebelbärte der Katzen und anderer Thiere zum schärfern Gefühl der Schnauzen so wesentlich beytragen, dass mit ihrem Verluste jene ebenfalls in hohem Grade leiden; so hat man doch über die Art und Weise, wie dieses geschieht, häufig gestritten. Heut zu Tag denkt wohl Niemand daran, dem Haar - und sey es auch ein sogenanntes Tasthaar - Nerven zuzuschreiben. Das äusserste, was die menschliche Kunst bisher darzustellen vermochte, und was ich desswegen auch bildlich von der Schnauze einer Katze nachbilden liess, ist, dass der Haarbalg Nerven besitzt. - Wenn wir also, wie es doch allgemein gebräuchlich, obgleich vielleicht nicht ganz richtig ist, nur jenen Theilen Gefühl zuschreiben, welche mit Nerven versehen sind, so müssen wir den Haaren insgesammt - somit auch den Tasthaaren - als solchen, d. h. als denjenigen Theilen des Haares, die wir oben mit dem Namen Haarschaft bezeichnet haben, das Gefühlsvermögen absprechen, oder besser gesagt, wir können nicht zugeben, dass sie für solche Organe gehalten werden, welche geeignet sind, den von aussen gekommenen Eindruck vermittelst der Nerven aufzunehmen, und weiter zu leiten. Nichts desto weniger stehe ich in einer andern Beziehung keinen Augenblick an, sie für wirkliche, und namentlich für im Thierreich höchst wichtige Organe des Gefühls zu balten. Um hier nur von den Tastha ar en zu reden, müssen wir doch zugeben, dass bey dem starren, höchst innigen Zusammenhange des Haarschaftes mit dem nerven- und gefässreichen Balge, jede, und sey es auch die feiuste mechanische Einwirkung — Erschütterung - von jenem auf diesen unmittelbar übertragen, und somit den Nerven

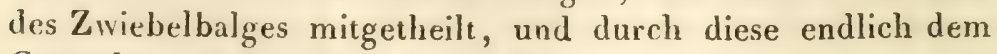
Centralorgane zugeleitet werde. Llierans ergibt sich, was es für eine Bewandtniss mit dem Ausspruch habe: dass nicht die Hare, sonderndie Hat fühle, oder dass erstere une dasticfühl der letatern crhühen u. s. w. - Inso- 


\section{Von dem speciellen Nutzen der Thierhaare. 205}

fern man also zugeben muss, dass der $\mathbf{Z}$ wiebelbalg der Tasthaare Nerven besitze, muss man auch den Tasthaaren Gefühl zuschreiben, und, insofern wir jene Nerven bey den übrigen Körperhaaren, aus Unvermögen sie nachzuweisen, nicht annehmen wollen, müssen wir wenigstens gestatten, dass diese Haare, als Theile der Haut, so zu sagen Werkzeuge des Gefühls sind.

Um übrigens jede $\mathrm{Z}$ weydeutigkeit zu vermeiden, muss zwischen $T$ asten und $\mathbf{F} \ddot{u} h l e n$ ein Unterschied gemacht werden. Denn obgleich ersteres nur ein erhöhtes, durch feinere Organe vermitteltes, und an bestimmten Stellen vorzingsweise ausgebildetes Fühlen ist, so muss mit allem diesem doch noch die Vorstellung verbunden werden, dass das Tast en zugleich ein Act der Willkühr, das Gefühl im Allgemeinen aber nur ein passives Aufnehmen äusserer Ein$\mathrm{d} \mathbf{r} \ddot{\mathrm{u}} \mathrm{cke}$ ist. Von diesem Gesichtspuncte aus erscheint uns das Tasten viel höher gestellt als das Gefühl, und so ist es auch. Organisation und Function der hieher gehörigen Theile harmoniren mit dieser Annahme eben so gut, als sie auch in der Erscheinung, also factisch nachzuweisen ist. Der vortreffliche Rudolphi*) hat uns schon von den Barthaa en der Seehunde gezeigt, wie ihre regelmässig neben einander gestellten cylindrischen Hornkapseln oder Zwicbeln von Muskelfasern umfasst werden; und bey unsern Hausthieren finden sich theils ähnliche Verlängerungen des allgemeinen Hautmuskels zu den Haarzwiebeln, theils werden diese, da sie tief in die Fetthaut eingepflanzt sind, bey den manichfaltigen Bewegungen der letztern gleichfalls verschiedentlich bewegt, und, je nachdem es die Willkiihr des Thieres erfordert, nach dieser oder jener Gegend hin gerichtet, bald gerade ausgestreckt, bald sanft zurück-, bald blitzschnell der Schnauze angebogen. - Bey dem Maulwurfe fand Treviranus ${ }^{*}$ ) auf dem vordern, behaarten Ende des Rüssels grössere und kleinere, kegelförmige, von einer dicken, zähen Haut gebildete Kapseln, die auf der Oberhaut hervorragen, und eine weiche Substanz enthalten, , in deren Mitte die Wurzel eines Barthaars enthal-

*) In den Abhandlungen der physikalischen Klasse der königl. preussischen Akademie der Wissenschaften. Jahrg. $1814-1815$, p. 175. Berlin 1818.4. p. 180.

*) Biologie 6ter Bd, p. 20 't 
ten ist. - Nicht umsonst haben auch diese Haare eine so beträchtliche Lïnge und Steif heit. Denn diese Eigenschaften dienen offenbar dazu, um den Gegenstand schon in einer gewissen Entfernung zu füblen, und durch die grössere Starrheit wird die mechanische Erschütterung nicht allein an und für sich erhöht, sondern auch viel leichter und schneller weiter geleitet. - G. Vrolick ${ }^{*}$ ) fand bey einem Versuche, dass ein Kaninchen, dem die Augen verbunden waren, sich nach abgeschnittenen Barthaaren nicht mehr, ohne anzustossen, aus einem engen verwickelten (aus Büchern gemachten) Gang herausfinden konnte. Jedermann kennt die Wichtigkeit dieser Gebilde bey vielen unserer Hausthiere, z. B. der Katze, von welcher allgemein behauptet wird, dass sie mit dem Verlust ihres Knebelbartes auch das Vermögen, oder wenigstens die Lust, Mäuse zu fangen, einbüsse. In dieser Beziehung kann ich aus eigener Erfahrung behaupten, dass auch Katzen, selbst mit verbundenen Augen, gleich dem oben angeführten Kaninchen, durch das Gefühl ihrer Schnurrbärte allen Gegenständen geschickt ausweichen, dagegen ihren Leitfaden verlieren, ungeschickt herumrennen, und endlich sogar zuBoden fallen, wenn man ihnen die Tasthaare genau an der Wurzel abschneidet.

Endlich scheint uns auch die Natur selbst einen Fingerzeig zur Bestimmung des eigentlichen Nutzens der Tasthaare durch die Vertheilung dieser Organe, und durch ihr Vorkommen an die Hand zu geben. Wir finden sie nämlich gerade bey jenen Thieren die zur Herbeyschaffung ihrer Lebensbedürfnisse, und zur Befriedigung mancher ihrer Triebe eines besseren Tastorgans bedürfen, als andere. Diess ist der Fall bey Raubthieren, Nagern u. s. w., die auch und grösstentheils bey Nacht auf Beute ausgehen, und ihrem Gesichtssinne durch ihr Tastorgan den wesentlichsten Vorschub leisten. Hier sind die Haare wie $\mathrm{Rudolphi}$ sich ausdrückt, unsern Sonden und Stöcken gleich zu achten, nur mit dem Unterschiede, dass diese mit unserer Hand in keiner so unmittelbaren Verbindung stehen, als jene mit ihren nervenreichen $Z$ wiebelbilgen. Auch hat sie die Natur nicht umsonst an die Gränze des Geschmacks - und Geruchssinns verlegt, indem sie auch auf diese einen Einfluss zu haben scheinen, wie man diess schon aus der eigenthümlichen Richtung bemerkt, welche manche Thiere ihren Tast-

*) Over het nut der Knevels by viervoetige Dieren. Amsterd. 1800. 8 . 
Von dem speciellen Nutzen der Thierhare. 207

haaren geben, wenn sie den Raub ergreifen und verzehren wollen. Denn an die Füsse konnten sie nicht versetzt werden, weil die Thiere keine Hände zum Tasten, sondern nur Füsse zum Gehen haben, und weil eben desswegen auch die Tastorgane dort zu vielen Beschädigungen ausgesetzt gewesen wären, was alles bey der Schnauze wegfällt. Auf diese Tasthaare lässt sich also der Satz nicht anwenden, dass das Gefühl da am schwächsten sey, wo Haare sich befinden.

Die sogenannten Greif's $\mathrm{ch}$ wänze (Cauda prehensilis) mancher Thiere, z. B. der Sapaju, der Beutelthiere, mehrerer Ameisenfresser, einer Art Stachelschweine u. a. m. sind so gebaut, dass diese Thiere damit die Körper, wie mit einer Hand umfassen und ergreifen können. Aber gerade in diesen Schwänzen finden sich nicht allein keine Tast-, sondern auch keine andern Haare an dem Theile ihrer untern Fläche, womit sie die Körper ergreifen. Es scheint also, die Natur babe hier mit einem Organe mehrere Zwecke zugleich erfüllen wollen.

So viel von den Tasthaaren, als Organen des Gefühlsinnes. Es erübrigt jetzt noch etwas weniges von den Kör perhaar en der'Thiere überhaupt in diesem Bezuge zu sagen. - Bevor ich jedoch zu diesen übergehe, kann ich nicht umhin, der Fühlfäden, die wir bey den $\mathrm{Z}$ o ophyten und andern wirbellosen Thieren, und der Bartfäden, die wir bey den Fischen antreflen, zu erwähnen. - Die Fühlfäden der Zoophyten, welche entweder gefiedert im einfachen Kranze, oder einfach sind, und daher die Thiere im ersten Fall den Polypen vieler Ceratophyten nahe bringen, im zweyten aber den Mund in mehrfachen Reihen umgeben, sind die Barth a a re dieser Thiere, und dienen ihnen wahrscheinlich zu ganz ähnlichen Zwecken; obgleich wir hier nicht im Stande sind, sie mit einem Nervensystem in Verbindung zu bringen, es wäre denn, dass wir uns das ganze Thier aus Nervenmasse zusammengesetzt denken. In wiefern dic hakenartigen Fortsätze an den Saugmündungen der B lasen-und Bandeing ew eid ew ürmer, vorzüglich aber der davon benannten Hakenwürmer (Entozoil crstica cestoidea und acanthocephala) ebenfalls hieher gerechnet, und als Organe des Gefühls angesehen werden können, wage ich nicht zu bestimmen, doch scheint mir die Sache nicht unwahrscheinlich zu seyn. In jedem Fall bleibt es merkiürdig, dass diese Fühlfäden und sogenannte Haken häufig gerade die 
Stelle der Barthaare einnehmen, wie diess ja fast ausschliesslich von den Blasen- und Hakenwürmern gilt ; ferner dass sie beweglich sind, und zwar in einem noch höhern Grade, als die Barthaare der Säugethiere. Denn nicht genug, dass sie eine Bewegung nach den Seiten gestatten, lassen sie sich auch noch vollkommen einziehen, und verschwinden. Dieses letztere geschieht, indem die hohlen Fäden stellenweise in ihre eigene Höhle umgestülpt hineintreten.

Noch könnte man hierher die Tentakeln der Crustaceen, die Antennen der Insecten, welche überdiess mit äusserst zarten und hëchst beweglichen Haaren (z. B. unter den $\mathrm{Z}$ weyflüglern) versehen sind, und endlich die Bartfäden der Fische zälllen, die alle, so sehr auch ihr Bau verschieden ist, in physiologischer Beziehung grosse Analogie besitzen. - Die Cirrhen der Fische sind ziemlich weich, und erhalten gleich den Barthaaren der Säugethiere Nervenfäden vom fünften Paare. - Nach Treviranus"), welcher die Cirrhen des Stöhrs näher untersuchte, hängen sie als vier lange, dünne, von der Basis zur Spitze allmählig verschmälerte Fortsätze zu beyden Seiten der untern Kinnlade von dem Munde herab. Inwendig enthalten sie eine von Muskeln umgebene Sehne, und Zerästlungen vom fünften Paar; auswendig sind sie an der Basis mit Nervenwärzchen, nach oben mit höchst zarten, ausgezackten Häuten gedrängt besetzt. - Sie sind diesen Thieren in Bezug auf den Gefühlssinn gewiss von der grössten Wichtigkeit, da ihnen sonst die Glieder mit beweglichen, zum Betasten der Körper dienenden Zehen und Fingern gänzlich fehlen, und ihr ganzer Körper überhaupt wenig Fortsätze hat. -

Was nun noch den Antheil betrifft, den die sogenannten Körperhaare der Thiere an dem Gefühlssinn haben, so ist er bey manchen Thieren sehr auffallend, in andern wieder kaum zu bemerken. - Indem ich die haarartigen Verlängerungen der niedern wirbellosen Thiere in dieser Beziehung übergehe, da sie, wie wir bald sehen werden, mehr zur Bewegung, oder, was mir wahrscheinlicher ist, zur Bewegung und zum Fühlen zugleich dienen, will ich nur von den Insecten bemerken, dass

1) Die Schmetterlingsbärte nach De Geer's Meinung

*) Biolog. 6. Thl, p. 308. 
nur dazu dienen sollen, dem Saugrüssel, welchen sie, wenn er spiralförmig zusammengerollt ist, auf beyden Seiten umgeben, ein Futteral abzugeben; eine Meinung, die De Geer selbst als sehr mangelhaft ansieht. Sollten sie nicht als Barthaare zu betrachten seyn?

2) L y onnet*) hält die Haare der Weidenraupe für Organe des Gefühlssinns. (Il me paroit, que ce sont des organes du Tact).

Auch $\mathbf{R}$ ösel ${ }^{* *}$ ) sagt von den Haaren der Dornraupen, dass ihr Nutzen darin bestehe, die Empfindlichkeit zu erhöhen. Die Borstenraupen ziehen sich bekanntlich so zusammen, dass, wie beym Igel, nur die durch Borsten vertheidigte Seite ihres Körpers frey steht; und diess geschieht schon bey der leisesten Berührung. Man kann also diesen Haaren den Einfluss auf die Erhöhung des Gefühls, wenn auch nur durch mechanische Leitung der Erschïtterung, keineswegs absprechen. - Selbst gegen die Bewegung der Luft sind die angeführten zarten und beweglichen Haare an den Fülıl. hörnern mancher Insecten sehr empfindlich, wodurch es denn auch möglich wird, dass diese Thiere, wie Treviranus sagt, auf eine bloss physische Art Vorgefühle oder Empfindungen aus der Ferne von Eindrücken haben können, die von unsern Sinnorganen nicht wahrgenommen werden. - Die beschriebenen Fïhlfäden der Fische haben gleichfalls ihre Benennung von ihrem physiologiscinen Zwecke, indem auch sie als Fühlorgane nüzzen. Bey den Vögeln und Säugethieren, wo der Tastsinn durch andere, weit höher als die Haare ausgebildete Organe vermittelt wird, tritt, wie wir später hören werden, so zu sagen, fast gerade das entgegengesetzte Verhältniss ein, indem die hier meist den ganzen Körper bedeckenden Haare mehr dazu dienen, die zu grosse Empfindlichkeit der ncrvenreichen Haut vor den beleidigenden Einflüssen der Witterung etc. zu schützen, als dass sie vorzugsweise das Organ des Tastsinnes unmittelbar verstärkten. Ich sage unmittelbar, denn ganz kann man ihnen den Antheil an der Erhöhung des Gefühls nicht absprechen, und zivar aus zwey Gründen:

1) Weil sie, so wie in andern Thieren, nur in geringerm Grade den erhaltenen Eindruck durch ihren stetigen Zu-

*) A. a. O.

*) A. a, O. 
210 Von dem speciellen Nutzen der Thierhaare.

sammenhang mit der Haut dieser selbst mittheilen, und daher Empfindungen erregen, die nur durch sie vermittelt werden.

2) Weil sie der Haut den hohen Grad von Empfindlichkeit gerade dadurch bewahren, dass sie den zu starken Einfluss äusserer Potenzen mässigen, und den gewöhnlichen ganz abhalten, so zu sagen, vernichten; mit einem Worte die Erregbarkeit der Haut auf dem gehörigen Grade zu erhalten beytragen.

§. 104.

Von den Thierhaaren als Organeder Bew e g u n g.

So neu und ungewöhnlich die Idee auch scheinen mag, dass die Haare vieler Thiere zur Bewegung die$\mathrm{n}$ en, so führt uns doch ein aufmerksames Studium dieses Gegenstandes auf die unwiderlegbare Wahrheit des ausgesprochenen Satzes. Ich habe schon oben gesagt, dass es in der Natur der sulzartigen Masse liege, aus welcher die Thiere der untersten Klassen, nämlich die sogenannten Gallertthiere, bestehen, Bewegung und Empfindung zugleich zu vermitteln. Wenigstens sind wir ohne diese Annahme nicht im Stande, die Erscheinungen beyder in den angefïhrten Thieren genügend zu erklüren. Wir sehen, dass diese Thierchen sich, und zwar oft mit einer ausserordentlichen Geschwindigkeit bewegen, und auf der andern Seite stehen unleugbare Thatsachen da, aus denen hervorgeht, dass sie auch Empfindung äussern. Wo sind nun die Organe dafür? Mit unsern schärfsten Gläsern können wir bey sehr vielen dieser Thiere trotz der sorgfältigsten Mülıe die mancherley Fortsätze ihres Körpers, wovon ich denn einige auch unter die Haare zählte, für durchaus nichts anderes, als für wahre Verlängerungen ihres kugelförmigen Darmleibes halten, der ebenfalls wieder bloss aus einer einzigen homogenen Masse zu bestehen scheint. Von einzelnen Organen, die sich auf was immer für eine Art in Bezug auf ihr Gewebe von dem Mutterstamm unterscheiden, kann durchaus keine Rede seyn. Demnach bleibt uns nichts anderes übrig, als der Substanz, aus welcher dicser letztere besteht, Empfindungs - und Bcwegungsvermögen 
zugleich zuzuschreiben. Für das erste habe ich bereits in dem vorhergehenden Paragraphe einige Beweise aus der Erfahrung abgezogen; es bleibt mir also noch übrig, auch für das letztere die genügenden Thatsachen anzuführen:

Bey den $\mathrm{Z}_{\text {o oph }} \mathrm{yten}$ haben wir oben gehört, dass die Species Pubes von dem Genus Trichoda an der stumpfen Spitze ganz kleine Haare besitze. Diese Haare kann man nur in agone mortis des Thierchens erkennen, denn in diesem Momente streckt es selbe aus der Spitzenspalte mit aller Kraft hervor, und bewegt sie beym Einziehen des letzten Wassertropfens heftig. Bey dem Genus Leucophra sind die Haare ein Hauptmittel zur Bewegung. Leucoph. conflictor drebt durch Hülfe ihrer kleinen Cilien die ganze Masse kreisförmig herum. Leucoph. mamilla hat, wie schon gesagt, grössere gekrümmte Cilien, die ihr nicht allein zum Drehen, sondern auch zum Schwimmen dienen. Eben so streckt die Leucoph. resiculifora ihre Radii erst zum Vorschein, wenn sie in agione mortis liegt. Die Cilien an der Seite der Leucoph. cornuta sind sehr klein, die vordern aber dreymal länger, und bewegen sich in einem, nie aber, wie in der Polymorpha, in zwey Zirkeln. Uebrigens schwingen die einen wie die andern, nach Belieben des Thieres. - Am allerauffallendsten zeigen sich diese Schwingungen bey den Vorticellen. So z. B. macht die Vort. sputarium, die nur wenig lange, excentrische Cilien hat, welche aus der Scheibe strahlenförmig hervorkommen, mit diesen $\mathrm{Ci}_{\text {i- }}$ lien verschiedene Schwingungen im Kreise herum, und fährt sehr schnell durchs Wasser, wo man dann die Cilien kaum wahrnehmen kann. Die Polymorpha, das wunderbarste dieser Thiere, hat seine Cilien bald zerstreut, bald bervegen sich selbe in Bündeln; bald zeigt sich an einer Seite ein hakenformiges Glied u. dgl. mehr. Welch einen bewunderungswürdigen Anblick macht nicht die Bewegung der mancherley Cilien von Brashiomus Bakeri? - Die hornartigen Stacheln bey Kerona rastellum liegen in einer dreyfachen Reibe am Bauche, und werden entweder alle zugleich oder einzeln bewegt, und dienen wohl auch zu Füssen. Eben so leisten bey Trichoda cimex die Cilien am Bauche den Dienst der Füsse; und beym Schwimmen wird sie mittelst ihrer Borsten durch's Wasser getragen. Als Otto Yïller die Kerona mytilus aufs Trockene: brachte, und das ron dem Thierchen begierig aufgenommens Wasser mangelte, sah $\mathrm{er}$, wic sich der Körper in der Mitte 


\section{Von dem speciellen Nutzen der Thierhaare.}

theilte, und die Moleculn klumpenweise herausfielen, während die Vibration der Cilien und die Bewegung der Hörnchen und Borsten bis zum letzten Moment des Lebens noch fortdauerten. - Die langborstige Vorticelle schwimmt mit gerade gestrecktem Körper, und parallel laufenden Borsten. In der Ruhe wird sie dreymal kleiner, die Cilien verschwinden, die Borsten aber stehen auseinander. - L e uwe n lı o ek*) scheint den Thierchen, die mit vielen Füssen, wie er diese Fortsätze nennt, schwimmen, die Fähigkeit, einen Beyschlat zu pflegen, beygelegt zu baben. Die meisten Autoren vor Müller geben an, dass die kleinern Thiere den grössern zur Nahrung dienten, und wollten selbe sogar im Verschlingen der letztern überrascht haben. Müller aber sah, seiner emsigen Beobachtungen ungeachtet, diess nie bey den Zoophyten, die er Infus orie n nennt, bestätigt; im Gegentheil überzeugte er sich, dass alles das, was durch die Kreisbewegung der Vorticellen, oder durch das Zittern und Schwingen der Haare in den Arten von Trichoda und Kerona in ihren Rachen (?) gebracht wurde, durch Gewalt in die Cilienhaare verstrickt, und nachdem es einige Augenblicke herumgetrieben, ohne Verlust des Lebens von den Thieren wieder ausgeworfen wurde. Diese Haare scheinen also grösstentheils zur Bewegung dieser Thiere zu dienen.

Auch den Eingeweidew ürmern dienen die angeführten Stacheln oflenbar zur Bewegung, indem sie ihnen wahre Stützpuncte abgehen, mit welchen sie sich während der Bewegung festhalten. Obgleich der Körper dieser Thiere in der Regel nur aus einem contractilen Schleime besteht (denn nur wenige haben wirkliche Muskelfasern) und daher sehr weich ist, so sind dagegen diese stacheligen fortsätze doch oft von besonderer Härte. Schweigger glaubı übrigens, dass sie nicht bloss als Erleichterungsmittel der Bewegung dienen, sondern auch und vorzüglich, um durch ihren Reitz den Zufluss der Säfte zu vermehren, und dadurch der Einsaugung günstig zu seyn.

Die beweglichen Stacheln zu beyden Seiten der Strahlenrinne in den Asterien befördern ebenfalls die Ortsveränderung, wăhrend ihre Füsschen bloss zur Anhefung dienen. - Da wir bey den Echiniden schon eine Art von Ein-

*) Arcana naturae. Vol. I. p. 22, 255. 
lenkung der Stacheln auf die knopfförmigen Erhöhungen der Schale, und Muskelfasern bemerken, mittelst welcher, da sie von der Grundfläche der Stacheln in die zusammziehbare Schalenhaut gehen, jene bewegbar sind, so ist gar nicht zu ziveifeln, dass auch diese Stacheln Einfluss auf die Bewegung der Thiere äussern; wie denn auch schon Aristoteles*) und Réaumur**) behaupten, dass sie beym Gehen gebraucht werden, Tiede m an n***) aber angibt, dass sie bloss als Stützpunkte dienen, während die Füsse in Bewegung sind, was auch wirklich der Fall ist. Cuvier****) sagt deutlich, dass der Igel durch diese Stacheln und die dazwischen liegenden Füsschen sich von einem Orte zum andern begebe. - Viel ausgezeichneter zeigt sich alles diess bey den A n n eliden, welche mit Borsten rersehen sind, die ihnen bey ihrem schlangenartigen Weiterkriechen Stützpunkte darbiethen. Auch sollen sie sich mit16.lst dieser Borsten in ihren Löchern so fest anklemmen, dass sie häufig leichter zerreissen, als hervorgezogen werden können. Bey den Näiden scheinen sie ihnen auch gleich Rudern zum Schwimmen zu dienen. - Cuvier †) beschreibt die Muskeln genau, welche auf die Bewegung der Borsten Einfluss haben, indem sie durch ihre Zusammenziehungen die Borsten und Haare in der Richtung, welche sie selbst erhalten, nach aussen treiben, während eine andere Art von Muskeln die er zum Unterschied von diesen Herausziehern Zurückzieher nenut, bey der Contraction der Herauszieher herausgetrieben wird, und wenn sie selbst sich zusammenziehen, die Stacheln nach innen ziehen. - Der Zweck der Fangarme der Cirrhipeden scheint mehr auf das Ergreifen der Gegenstände, als auf das Gehen selbst Bezug zu haben.

Nan kann von vielen Raupen, namentlich von den Bürstenraupen in Bezug auf ihre Borsten mit gleichem Rechte, wie von den Igelstacheln behaupten, dass sie einigermassen in gewissen Verhältnissen die Bewegung zu unterstützen im Stande

*) Histor, animal, lib, IV, C, 5.

**) A. a. 0. 1712 .

***) In seiner Preisschrift: Anatomie der Röhrenholothurie, des pome. ranzenfärbigen Seesterns und Steinsecigels. Landshut 1816, Tab. 10. Ein Auszug davon in Oken's Isis 1818.

"***) Das Thierreich 4. Bd. p. 18.

i) A, a. 0, 1. Bd. p, 439 . 


\section{Von dem speciellen Nutzen der Thierhaare.}

sind, weil diese Dornen und Borsten auf den Ringen der weichen Haut befestigt sind, welche Ringe von eigenen Muskeln verschicdentlich bewegt werden. Dass dann diese Dornen etc. wahre Stützpunkte abgeben, und so die Bewegung erleichtern, sehen wir ausser bey den Borstenraupen auch an einigen Fliegen, Bremsen, Schnecken (Pipula), Syrphen und Stratyomysarten. - Ein Gleiches gilt auch von den Arachuiden. Dagegen ist es gewiss sehr merkwürdig, dass die Hülle der mittlern Fusswurzel bey den Haarflüglern oder Wasserfaltern (Phryanea) gleich den hintern Fusswurzeln der Schwimmkäfer (Dylisci) auf einer Seite mit Haaren gefranzt sind, wodurch sie als Schwimmfüsse dienen, während sich dieser Bau weder bey den Larven, noch bey den vollkommenen Kerfen findet.

Wir haben oben gesehen, dass es auch in der Klasse der Fische Familien gibt, die gleich den Echiniden, Borstenraupen, und Landigeln mehr oder weniger mit, freylich verlhältnissmässig viel stärkern, Stacheln versehen sind; ich rechne hierher die sogenannten Stachelbäuche, Tetra od o nten, und die Igelfische, Diodonten. Diese Fische scheinen sich zwar ihrer Stacheln als einer Wafle zur Vertheidigung, ganz nach Art unseres Igels, zu bedienen, dennoch mögen selbe gerade in dem aufgeblasenen Zustande dieser Fische die nothdürfige Bewegung einigermassen unterstützen, obwohl diess gewiss ihr geringster Nutzen seyn kann. - Dagegen finden wir diese Eigenschaft der Haare bey den Federn der Vögel zum Hauptzweck erhoben, indem letztere hauptsächlich durch den Bau ihres Gefieders in den Stand gesetzt sind, so unermessliche Räume in der grössten Geschwindigkeit zu durchfliegen, und überhaupt die manichfaltigsten Bewegungen des ganzen Körpers sowohl, als auch der einzelnen Federn selbst zu machen. - Nur bey den Säugethieren vermissen wir den angegebenen physiologischen Charakter der Haare so zu sagen gänzlich, obgleich die Stacheln des Igels und wohl auch des Stachelschweins hier wieder eine merkwürdige Ausnahme machen; und obgleich die Bewegungen einiger Säugethiere, die im Wasser zu leben gewohnt sind, auch durch ihre Haare unterstützl werden. So sagt man wenigstens von der Wasserspitzmaus, dass die steifen Haare, welche in einer Reihe an ihren Füssen stehen, ihr das Schwimmen erleichtern. Etwas Aehnliches könnte sich wohl auch vom Biber, dem Eisbären. 
Von dem speciellen Nutzen der Thierhaare. 215

und ïberhaupt den starkbehaarten Säugethieren sagen lassen, die das Element der Luft mit dem des Wassers zu vertauschen pllegen.

\section{§. 105 .}

\section{S c h l us s b e merkunge $n$.}

Werfen wir einen prüfenden Rückblick auf das bisher von den Haaren der 'Thiere Gesagte, so dringen sich uns folgende Sätze als giltig auf:

1) Durch das Haargebilde steht die Thier - mit der Pflarizenwelt in nächster Beziehung, daher der alte Spruch: „Pili ut plantae," und so sagt auch Oken*): „Der Pelz ist die peripherische Verbindung des Pflanzlichen und Thierigen. Die Haare sind das höchste Pflanzliche." Die Haare wurzeln gleichsam parasitisch auf dem Körper der Thiere, und bilden so zu sagen das Mittelglied zwischen der äussern Oberfläche des Körpers und der ihn umgebenden Natur; sie entsprechen hauptsächlich der Lichtseite des Thierkörpers. - Diese Neigung zu einer auf der Rückenoder Lichtseite des Organismus stärkern Entwicklung des Haargebildes zeigt sich auf eine sehr analoge Art auch bey jenen Thieren, die wenig oder gar keine Haare an ihrer Hautoberfläche haben, und zwar durch stärkere Erhärtung, Erstarrung des Hautgebildes, durch Bildung von Schuppen und Schildern (in Fischen und Amphibien, in einigen Säugethieren), und bey Vögeln vielleicht wenigstens durch dunklere Färbung des Gefieders. Bey allen behaarten Thieren ist aber die Bauch- oder Erdseite mit wenigern Haaren besetzt, als die entgegengesetzte Lichtseite.

2) Die Haare erscheinen bey allen Thieren als Aeusserungen einer niedern organischen Bildung, stellen so zu sagen die cine Seite des pflanzlichen Lebens, in so fern es an der Körperoberfläche blüht, dar. Doch ist der Satz nicht richtig, dass sie nach Massgabe der höhern Entwicklung des Thiercharakters zurücktreten, und umgekehrt bey den niedersten Klassen der Thiere am ausgebildetsten erscheinen. Ein einziger Blick auf dic frühern Paragraphe wird uns davon lebhaft ïberzeugen. Gleichwohl scheint es richtig

*) A, a. O. p. $33 j$ 
zu seyn, dass dieser Satz dann mehr gelte, wenn er auf die einzelnen Ordnungen angewandt wird, d. h. diejenigen Thiere einer und derselben Ordnung sind manchmal am behaartesten, deren Organisation am niedrigsten steht. So sind es z. B. nicht die vollkommenen Insecten, die Käfer, bey welchen das Haar seine höchste Ausbildung zeigt, sondern es sind die Schmetterlinge, deren Organisation viel tiefer steht. - Dagegen kann diese Annahme durchaus nicht auf Allgemeingültigkeit Anspruch machen, indemı 1. gerade die Säugethiere vorzugsweise, und wenn man die Sache im weitesten Sinne nimmt, eigentlich ausnahmsweise behaart sind, (denn es ist gewiss, dass die Feder, wenn sie gleich in extensiver und namentlich in Hinsicht auf das Colorit dem Tasthaare der Säugethiere voranstehet, doch gewiss in Bezug auf Feinheit der Organisation von denselben weit übertroffen wird); 2. weil sich unter den Sïugethieren gerade diejenigen durch einen auffallenden Haarwuchs vor allen auszeichnen, die dem Menschen am nächsten, also unter den Thieren am höchsten stehen, die Affen; 3. wir bey den mittlern Thierklassen - den Amphibien und Fischen - gleichsam nur Andeutungen von einem Haargebilde finden, während dasselbe wie gesagt, unter den wirbellosen Thieren gerade wieder bey den Insecten einen besonders hohen Grad von Ausbildung in jeder Hinsicht erreicht; so dass wir also nicht im Stande sind, solche allgemein hingeworfene Sätze in der Natur praktisch nachzuweisen, wenn nämlich von einer Vergleichung des Haargebildes mit der übrigen Organisation, und der darauf gestützten Klassification der Thierc die Rede ist. -

5) Viel richtiger und schön ist der Gedanke, den ich in Picrer's Realwörterbuch *) las, „dass, so wie die Pflanze überhaupt dem Reiche der Luft und des Lichtes mehr angehörı, als dem des Wassers; so auch das Haar im Thierreich vorzugsweise dort crscheine, und eigentlich als solches erst da beginne, wo die Thiergeschlechter aus dem Reiche des Wassers in das der Luft übertreıen." - Denn obgleich ich die Stacheln der Fische, dic Borsten der Anneliden u. dgl, auch den Haaren beyge.

*) $3 \operatorname{ter}$ Bd, r. 788 . 
zählt habe, so ist und bleibt es doch immer ein Hauptcharakter der eigentlichen Haare, dass sie als einfache Kiemen frey in die Luft ragen; und die Stacheln, Borsten, ja selbst die Schuppen und Schilder der Amphibien kann man nur desshalb den Haaren anreihen, weil ihnen als erstarrte $\mathrm{Ha}$ atkiemen das Urbild für alle Haare, nämlich der Begriff der Hautkeime zu Grunde liegt.

4) In wie fern aber wirklich das Thierhaar an der Respiration Antheil nehme, und also mit dem Pflanzenblatt zu vergleichen sey, soll beym Menschenhaar erörtert werden.

5) So wie wir bey den Pflanzen die Haare als verlängerte Hautzellen betrachtet und bezeichnet haben, so könnten wir auch die Haare der niedern, wirbellosen Thiere, selbst jene der Insecten, und in mancher Beziehung auch die Stacheln der Fische als zellenartige Verlängerungen der allgemeinen Hautdecke ansehen. Am deutlichsten spricht sich dieses bey den gegliederten, oder mit Gelenkchen versehenen Borstenfäden der Cirrhipeden aus. Bey den höhern Thierklassen, wo ein besonderes Organ die Verbindung des Haars mit der Hautoberfläche, nämlich der Haarbalg sammt der Haarzwiebel, vermittelt, findet diesc Ansicht nicht mehr Platz, und das Haar tritt hier schon als ein mehr selbstständiges Gebilde hervor. - Hieraus ergibt sich, was von der Idee zu halten sey, nach welcher die Haare als verlängerte Gefässe, und das Horn für ein gefilztes Haar gehalten wurde*).

6) Nach Carus **) ist die Kegelform als allgemeiner Typus für Haarbildung im Thierreich anzusehen. Bey den Insecten entstehen nach ihm die Haare als kugelige Hervorliebungen auf der Oberfläche des Thieres, dehnen sich dann einfach oder getheilt kegelig aus, und werden zellig und röhrenförmig. Bey niederer Entwicklung sondern sie sich nicht von der Oberhaut ab, sondern bilden theilweise röhrenartige Ausdehnungen derselben, so bey den Zoophyten, Entozoën, Nuschel- und Schneckenschalen, Anneliden und Raupen, an manchen Mollusken und Krabbenschalen. - Bey hüherer Entwickelung bilden sich

*) Oke n a. a, O. p. 229.

**) Von den Ur.'Theilen des Knochen- und Schalengeriistes, Lgipzig 1823 
218 Von dem speciellen Nutzen der Thierhaare.

dann erst die Bälge, als hohlkugelige Bildungen der Oberhaut, und aus diesen entstehen endlich dic mit $Z_{\text {wie- }}$ beln versehenen Haare der höchsten Thierklasse und des Nenschen. Mit der grössten Vollendung paart sich am Ende auch die zarteste Bildung der Haare bey den Säugcthieren, bey welchen die Stacheln und Borsten schon seltner werden. 


\section{Dritter Abschnitt.}

Etwas über die Pathologie der Thierhare.

\section{§. 106.}

Ich bin nicht im Stande, die Krankheiten der Thierhaare auch nur von der Ferne so abzuhandeln, wie sich's z. B. von den Menschenhaaren erwarten lässt, weil ich 1) kein Thierarzt bin, und 2) weil selbst solche Aerzte, die sich fast ausschliesslich mit den Krankheiten der Thiere beschäftigten, die Pathologie der Thierhaare bisher nur wenig cultivirten. Denn es ist meines Wissens nicht allein nie die Rede davon gewesen, die Krankheiten der Thierhaare systematisch zu bearbeiten, sondern diese Gebilde wurden bis jetzt nicht einmal werth gehalten, als Substrat einer eigenen Kranklieit angesehen zu werden; indem man sich damit bcgnügte, ihrer in der allgemeinen Symptomengruppe der verschiedenen Hauptkrankheiten ebenfalls nebenbey zu erwäbnen; an eine, ihnen eigenthümliche Krankheit, dachte man in den meisten Fällen wohl eben so wenig, als an eine dieser angemessenen ärztlichen Behandlung.

Wenn man jedoch von der andern Seite bedenkt, wie sehr die Schönheit eines behaarten Thieres von der gesunden Beschaffenheit seiner Haare abhangt, und welch' einen wichtigen Einfluss der Zustand der Haare auf die Verwendung des Felles der liaut zu verschiedenen Zwecken im häuslichen Leben hat; so wäre es, abgesehen von der rein wissenschaftlichen Seite, wohl der Mühe werth, dass sich einmal ein tiichtiger Thierarzt die Mühe nähme, und diesem Gegenstand seine Aufmerksamkeit schenkte. - Diess wïre um so leichter, als er wahrscheinlich nebst einigen eigenthümlichen, auch bey den Thieren die- 
jenigen Haarkrankheiten antreffen wird, die wir beym Menschen genauer betrachten wollen, und er dürfte also nur das dort aufgestellte Schema auf den fraglichen Gegenstand zweckgemíss anwenden. Was mich in dem gegenwärtigen Falle betrillt, so kann ich leider nur etwas Weniges von den pathologiselıen Verhältnissen der Thierhaare in so fern sagen, als, wie gesagt, sich auch au ihnen manche allgemeine Krankheiten deutlich oflenbaren.

In dieser linsicht ist nun vor allem zu bemerken, dass das Haar bey allen, vorzüglich aber in den fieberhafien Krankheiten der Thiere immer in das Krankenexamen aufzunebmen sey, wie diess denn auch wirklich von den besten Schriftstellern anempfohlen und ausgeführt wird. Der das kranke Thier zu untersuchende Arzt hat daher in dieser Hinsicht jederzeit sein Augenmerk darauf zt richten, ob das Haar glatt anliegend, oderstruppig, glänzend oderglanzlos, elastisch (wie die Wolle), oder weich ist.

So finden wir bey den entzündlichen Fiebern, so wie auch bey Entzündungen, und zwar namentlich beym Ausbruch derselben - im Zeitraume des Frostes - die Haare auf der ganzen Oberfläche des Körpers struppig aufgerichtet, wo sie dagegen im Zeitraum der Crise wieder glatt anliegend und glänzend werden. - In den Faulfi ebern sind die Haare gewöhnlich glatt anliegend, und von der zähen Ilautschmiere etwas befeuchtet. Bey Schafen ist die Wolle schmierig und von geringer Krimpekraft. Bey Thieren, die von der fauligen Brustcnt zündung, Brust- oder Lung en seuch e befallenwerden, gehört der verminderte Gilanz der Haare zu den Vorbothen, und im weitern Verlaufe werden die Haare auch noch verworren. Dasselbe glanzlose, oder weniger glänzende Haar findet man auch in den catarrhös-lymphatischen Fiebern des Pferdes, namentlich bey dem Strengel, bey den gastrischen Fiebern mit Likrankung des Drüsensystemes, wo es sich zugleich sträubt; vorzüglich und am ausgezeichnetsten aber in den Anthrax-Fiebern, besonders dem sogenannten $\mathrm{Mil}$ z brandfieber, wo die llaare nebst dem, dass sie allen Glanz verlieren, auch noch struppig und verworren sind. Im schleichenden Milzbrand richten sich die Haare ganz borstig auf. Sellost bey der Rose der Schweine sind die Borsten vicl melır aufgesträubt als im gesunden Zustande. - Iis einem noch höhern Grade erkranken die Haare beym Honvich, das von der typhösen Tumgenscuche oder 
Lungenfäule befallen wird. Denn da zeigt sich bey trockner gespannter Haut das Haar glanzlos, struppig und rauh, und gibt dem Thiere ein hässliches Ansehen. - Bey den von der $\mathbf{R} \mathbf{u} \mathbf{r}$ ergriffenen Thieren ist das Besondere, dass das Haar vorzüglich in der Gegend des letzten Rückenwirbelbeines struppig wird, und in der beginnenden Rinderpest erstreckt sich dieses Sträuben längs des ganzen Rückens, obgleich es sich wieder am letzten Brustwirbel am auffallendsten darstellt; später wird das Haar am ganzen Körper davon ergriffen; und in der dritten Periode der Krankheit erreicht die Aufsträubung des ganz rauhen und glanzlosen Haares den höchsten Grad, un! trägt sehr viel zu dem abschreckenden Ansehen dieser Thiere bey. Tritt im Verlauf der Krankheit ein dem Friesel ihnlicher Hautausschlag linzu, so fallen, wenn der Eiter zu Schorlen und Schuppen vertrocknet ist, die Haare an solchen Stellen ganz ab. - Unter den chronischen Krankheiten sind es nun vorzüglich die Cachexien, wo ebenfalls das Haar struppig und verworren wird, so wie bey den lymphatischen, z. B. dem Rotz und dem Hautwurm der Pferde, der Drüsen - oder FranzosenKrankheit des Hornviehes u. so w. Wenn die Schafe an der Fäule (Bleichsucht) leiden, so lässt sich bey grosser Aufgedunsenheit ihrer Haut, die ohnehin viel weniger gekränselte Wolle in ganzen Flocken mit leichter Mlüle ausrupfen. - Unter die wesentlichen Kennzeichen der Finnenkrankheit gehört die sogenannte Borstenfäule, oder das leichte Ausgehen der Borsten sammt ihren Wurzeln, die wie blutig oder gelbroth erscheinen. - Die S chäbe oder $\mathbf{R} a ̈ \mathbf{u}$ de vertilgt die Haare desshalb, weil sich die ganze Epidermis nach und nach abschuppt, und die Haare also nit ausfallen. Die nasse oder fette Räude (R g g enfäule) der Schafe, zerrüttet das Gewebe der Haut noch mehr, und man findet längs des Rückens, besonders oberhalb der Bug- und tiüfigegend, dann an der Vorderbrust, am Halse, Schweife, manchmal auch zwischen den Hinterschenkeln kahle, oder mit verworrener, knotig verfilzier, bleicher und rauher Wolle besetzte Stellen, wo die Haut zugleich beträchtlich verdickt und hart, oder geschwürig entartet ist.

Ich habe dieses Wenige nur angeführt, um einerseits zu zeigen, dass auch bey den Thieren die Haare an vielen Krankheiten, welche tiefer in die Organisation, und namentlich in die reproductive Sphäre des Körpers eingreifen, auffallendea 
Antheil nehmen, und um andererseits zur weitern Vervollkommnung dieses eigentlich noch gar nicht bearbeiteten Gegenstandes aufzumuntern.

๒. 107 .

Und nun zum Schlusse dieses Theiles noch etwas weniges über das abnorme Vork o mmen der Haare bey Thieren. Indem ich das übergehe, was in der Pathologie der Menschenhaare diessfalls ausführlicher behandelt wird, erwähne ich hier bloss derjenigen Haare, dit man namentlich in dem Magen des Kukuks so auffallend findet, und welche unter den Gelehrten so grosse Streitigkeiten hervorgebracht haben, bis endlich Herr Hofrath und Professor Nits ch in Halle besvies, „dass diess keine Producte eincr selbstständigen Behaarung des Magens, sondern Haare von Insecten sind, die der Kukuk verzehrt. - Eine andere abnorme Bildung sind die sogenanten Haarbälle, wovon später bey den Menschenhaaren die Rede seyn wird. 


\section{Literatur der Thierhare.}

Achard, Sammlung physical, medicinischer Abhandlungen. B. I. (In Bezug auf die chemische Zerlegung der Thierhaare.)

Acta Academiae c. L. C. nat. Cur. 19, tom.

Albinus, Annotationes academ. lib. III. (Haare der Phoca.)

A ristoteles Historia animal. de partibus et de zeneratione. loc. divers. Baster Job over de Bekleedselen van de Huid der Dieren, vornamelyk van het Hair. In den Verhandlingen van de Holland'sche Maat. schappye der Wetenschoppen te Harlem. Deel XIV. p. 379.

- Sweede Verhandeling over de Bekleedselen etc. (Abbildungen von Haaren.)

- De squammis piscium opuscul. subseciva. Vol. I.

B lock in Weber's Schrift ïber Gewinnung der feinen und edlen Wolle. Breslau 1822. 8.

Bla inville, Principes d'anatomie comparée. Tom. I.

Blumenbach Handbuch der Naturgeschichte.

- Handbuch der vergleichenden Anatomie.

Bra connot, Annal. de Chemie. Vol. 93. p. 268. (Ueber chemische Bestandtheile.)

- Annal. de Chemie et Physique. Vol. XII. p. 186. (Ueber chemische Bestandtheile.)

Bnffon, Histoire naturelle generale et particuliere. 56. Vol. Paris 1749 - 1789. 4.

Cuvicr (G.), Le regne animal etc.

- Leçons d'Anat. comparée. 5. Vol. 8. Paris 1800-1805.

- (F r.), de la structure et formation des plumes. Memoir. du Mus, d'histoire naturelle. Ann. 7. cah. 5.

Encyclopedie ou dictionnaire raisonné des sciences, arts et metiers. Art. Poils.

Fabricius ab Aquapendente, Opera omnia anat. et physiol. De pilis. p. 445.

Fourcroy und Vauquelin, Memoir, de l'institut, nat. tom. 1I. pig.

431. (Chemische Bestandtheile.)

Ga u $t$ i e r Ueber die Tasthaare im Journal d. Physique. Vol. 90. Avril 1820.

$D_{e} \mathrm{G}$ e e r, Abhandlungen zur Geschichte der Insecten. Uebers. von G ötze.

Leipz. 1776.

Glisson Tractat. de partibus continentibus in genere. In operib.omn.?

H a t s che tt in Philosoph. transactions 1799. p. 332. (Chemisch. Bestandeh.)

Herold's Entwicklungsgeschichte der Schmetterlinge. Cassel u. Marburg

1815. mit $33 \mathrm{Kupfern.} \mathrm{(Schmetterlingshaare.)}$

H e us ing er, System der Histologie, Eisenach 1823. 8. a. v. Orten.

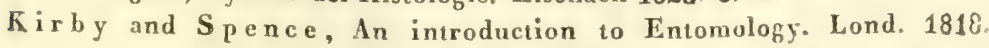

Ucbersetzt von Oken. Stuttg. 1821-1828. (Insectcnhare.)

K I e mann, Beyträge zur Natur- und Insectenkunde etc.

L a mark, Histoire des animaux sovertebres. Paris 1815-1822.7 Tom,

3. A. $r, 0$. 
Lamouroux Memoir. du Mus. d'hist, naturelle. Vol, II. Auch in Oken's Isis 1817. p. 921. (Haaro der Sirahlthiere.)

Latreille, Histoire naturelle generale et particulière des Crustacées et des Insectes, 14. Vol, in 8. avec Fig. Paris 1802-1805. tom. 2.

Lyonet, Traité anatomique de la chenille, qui ronge le hois de Saule ęc.

- Remarques sur la telologie des insectes de M. L es ser. tom. I.

L ichtenstein, über die Ratten mit platten Stacheln. In den Schriften der physiol. Klasse der Wissenschaften zn Berlin. 1819.

L e u w e hoek Arcana naturae detecta. Vol. I. p. 22 und 255.

M alpighi Opera posthuma, de pilis et pennis, plumis et spinis.

Mïller Otto, Animalcula infusoria fluviatil. et marina. Opus posthumum cura Fabricii. Havniae 1786.

- Zoologica danica. Fasc. 4. in Fol. Havniae 1788-1789.

M eckel's Archiv für Physiologie. VII, Bd, 4. Hft. Ueber das Ilären.

$\mathrm{Nit}$, s ch über die merkwïrdige Gestalt und Buntheit des Flaums. Voigts

Magazin für den neuesten Zustand der Naturkunde. Bd. II. Stück 5. J. 1806.

Oke n's Naturphilosophie. 1. u. III. Bd. p. 33j3, 334.

Pallas Spicilegia zoologica. Fasc. 14. Berol. 1;67-1780. loc. div.

Youpart, Fro, Sur les plumes des oiseaux. Mem, de l'acad. des sciences de Paris. A. 1699. H. p. 434.

Ré a mur, Memoires sur l'histoire naturelle des Insects. VI. Vol. Paris 1734-1742. Vol. I. p. 197.

R ös el Insectenbelustigungen. A. v. O.

Rostan, E. M., Parallele de la nourriture des plumes et do celle des dents. Acta Helvetica. Vol، V. p. 407.

R udolphi, Dissertat. de pilorum structura. Gryphiswald. 1806.

$\rightarrow \quad$ in den Abhandlungen der phys. Klasse der k. preuss. Akademic der Wissenschafien. Jahrg. 1814 - 1815. p. 175. Berlin 1818. 4.

p. 180. (Ueber Hornbildung und die Robbenhaare.)

Sarrasin Memoires de l'Academie des sciences de Paris 1727. (Stacheln?. S a vigny, Recherches pour servir á la classification des Annelides. (Auch

in Annales generales des sciences physiques. Vol. V. 1.)

S c hweigger's Journal der Chemie. B. 29. p. 353. (Chemie.)

- Aug. Frid., Handbuch d. Naturgeschichte d. skeletlosen Thiere. Leipz. 1820. A. vo. O.

$S_{p}$ igelius $\Lambda$ drianus de hum. corp. fabrica. De pilis.

$\mathrm{S}$ wammerdam Biblia naturae. p. 75. Insecten - und Molluskenhaare.

Tie demann, Preisschrift üher den Bau der Röhrenholothurie, des pomeranzenfarbenen Seesterns und Steinsecigels, Landshut 1816. Auch im Auszuge in der Isis von Oke n, 1818.

Tiedemann und Treviran us, Zeitschrift fiir Physiologie. 3. Band.

(Haare der Anneliden.)

Treviranus Biologie 6. Bd. p. 202. (Ueber die Tasthaare.)

Va quelin, Annales de Chimie. tom. 58. p. $5 \tilde{3}$.

Wagner, Beyträge zur Kenntniss und Behandlung d. Wolle. Berl. 1821. 8.

Wonzel, J. u. C., Bemerkungen iiber die Structur der ausgewachsenen Schwung- und Schweiffedern. Tuibingen 1797. 4. 


\section{Druckfehler}

\section{des e r s t e n B a d e s.}

\begin{tabular}{|c|c|c|c|c|}
\hline Seite & & Zeile & stàtt & lese man \\
\hline 5 & 10 & von oben & vollkommnern & rollkommnen \\
\hline 10 & 16 & von unten & Samen & Saum \\
\hline Is & 13 & v. 0 . & Zoten & Zotten \\
\hline 13 & 12 & v. u. & dreiplättrig & dreiblättrig \\
\hline 15 & 17 & v. 0. & Doroniceum & Doronicum \\
\hline 16 & 13 & v. $o_{0}$ & Malphighiae & MIalpighiac \\
\hline 28 & 18 & v. 0. & pállustre & palustre \\
\hline 33 & 9 & v. u. & hantia & hiantia \\
\hline 64 & 5 & จ. 0. & ihr & ihm \\
\hline 68 & 6 & v. $\quad 0$. & welcher & welch' \\
\hline 88 & 2 & จ. u. & geliebtes & geliebten \\
\hline 89 & y & v. $\quad 0$. & verweichlichtes & verweichlichten \\
\hline IOI & 4 & v. 0 . & Raknen & Ranken \\
\hline 106 & 4 & v. 0. & Brochionus & Brachionus \\
\hline 108 & 24 & v. $o$. & welcher & welchen \\
\hline 128 & 6 & จ. u. & allen & alten \\
\hline 141 & 26 & v. 0. & grössern & grösserer \\
\hline$\times 46$ & 8 & vo $o$. & geben & gibt \\
\hline 165 & 19 & จ. $\quad 0$. & Schreibersi & Schrebersi \\
\hline I 70 & $2 t$ & v. 0 . & Haarborsten & Hornborsten \\
\hline 171 & 2 & v. $\boldsymbol{u}$. & erastiones & crassiores \\
\hline 178 & 13 & v. u. & beruht & beruhen \\
\hline 200 & 5 & v. $\quad$. & Gewehrsmann & Gewrihrsmann \\
\hline 216 & 16 & v. 0 . & denselben & demselben \\
\hline
\end{tabular}




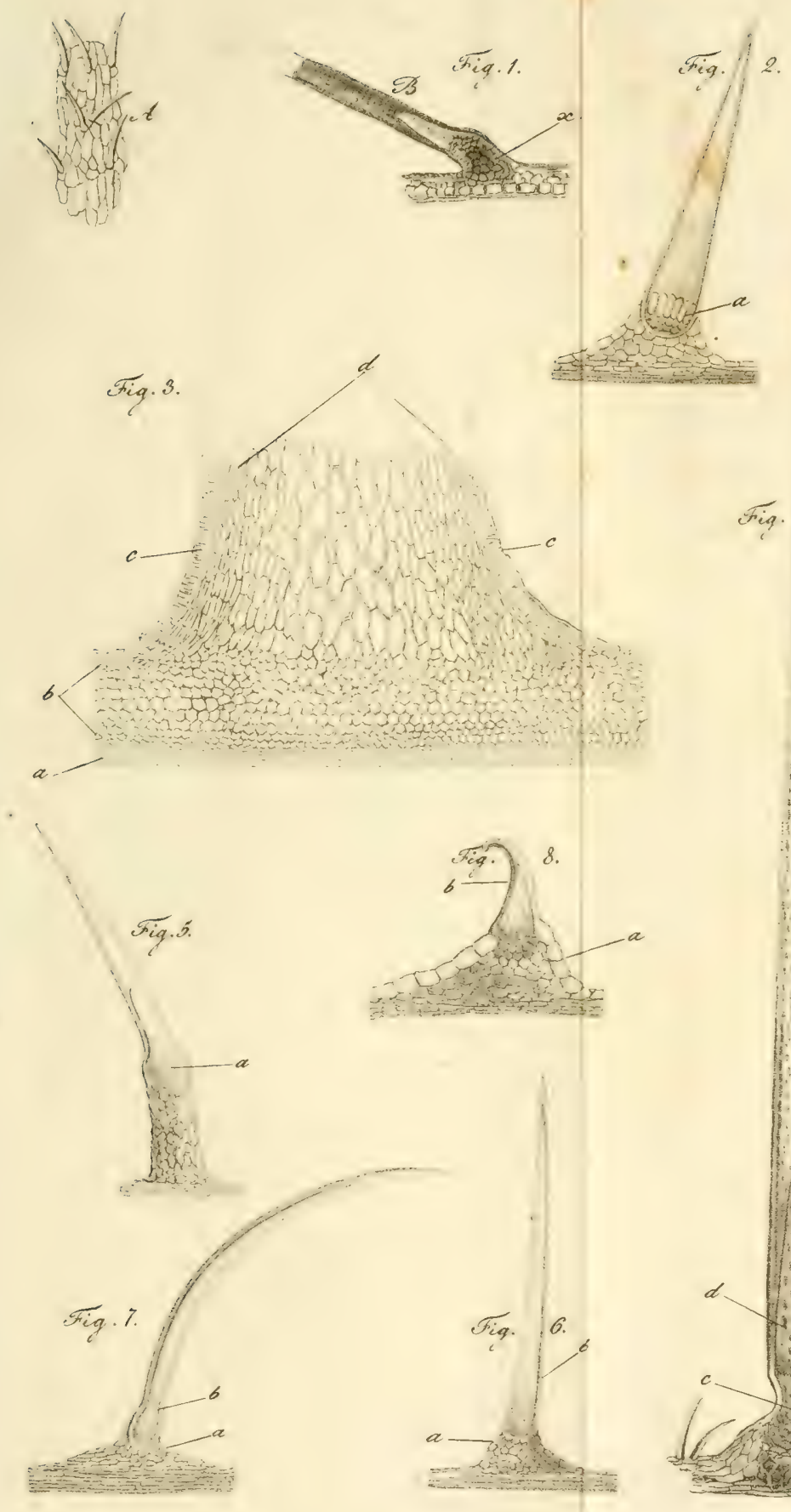



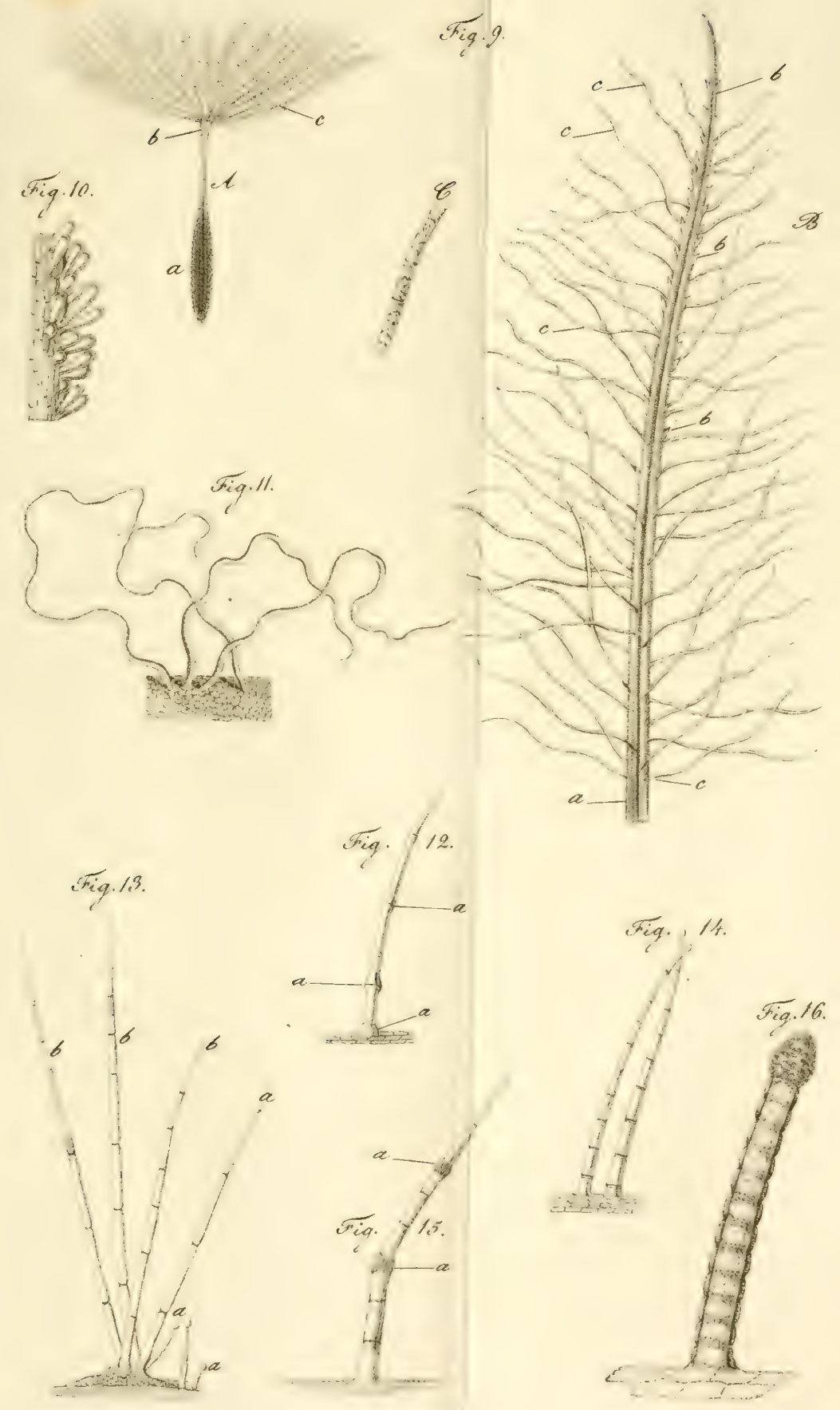




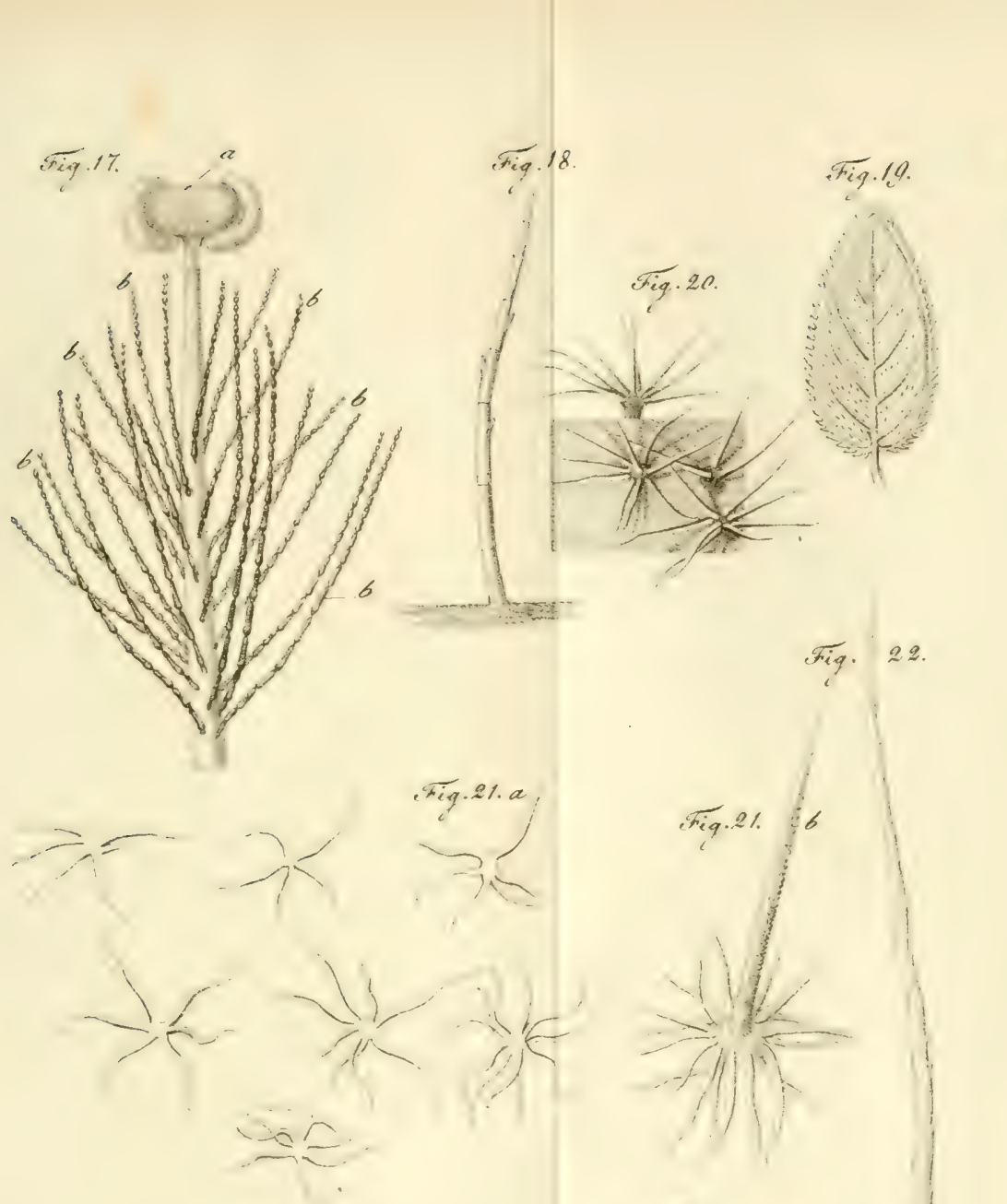

Fig. 22.

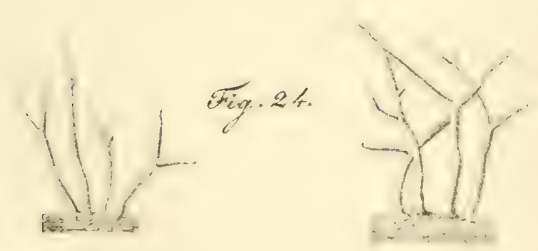

Fig. 25.
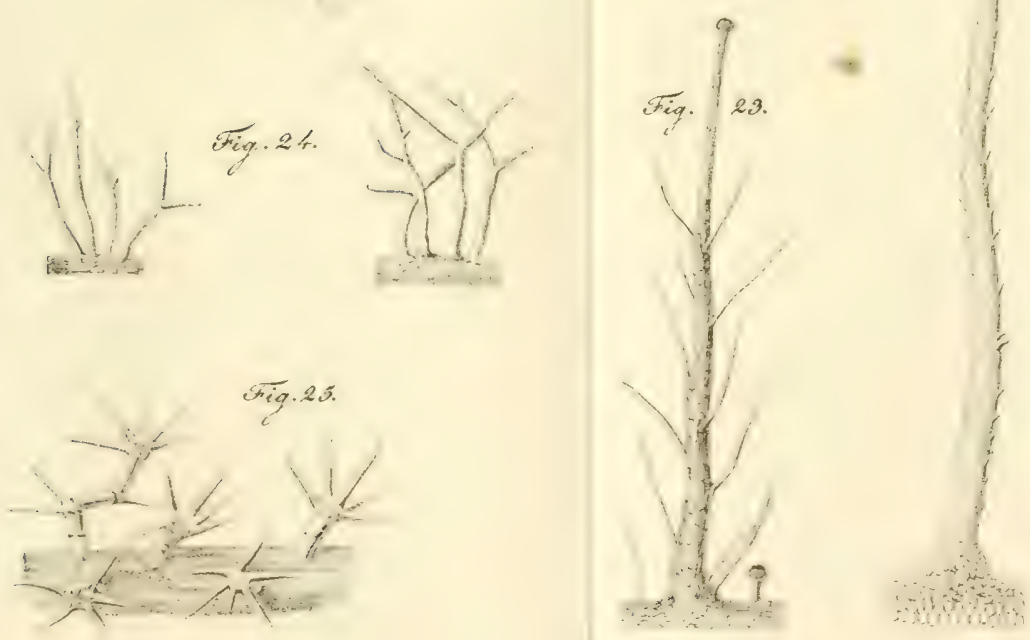



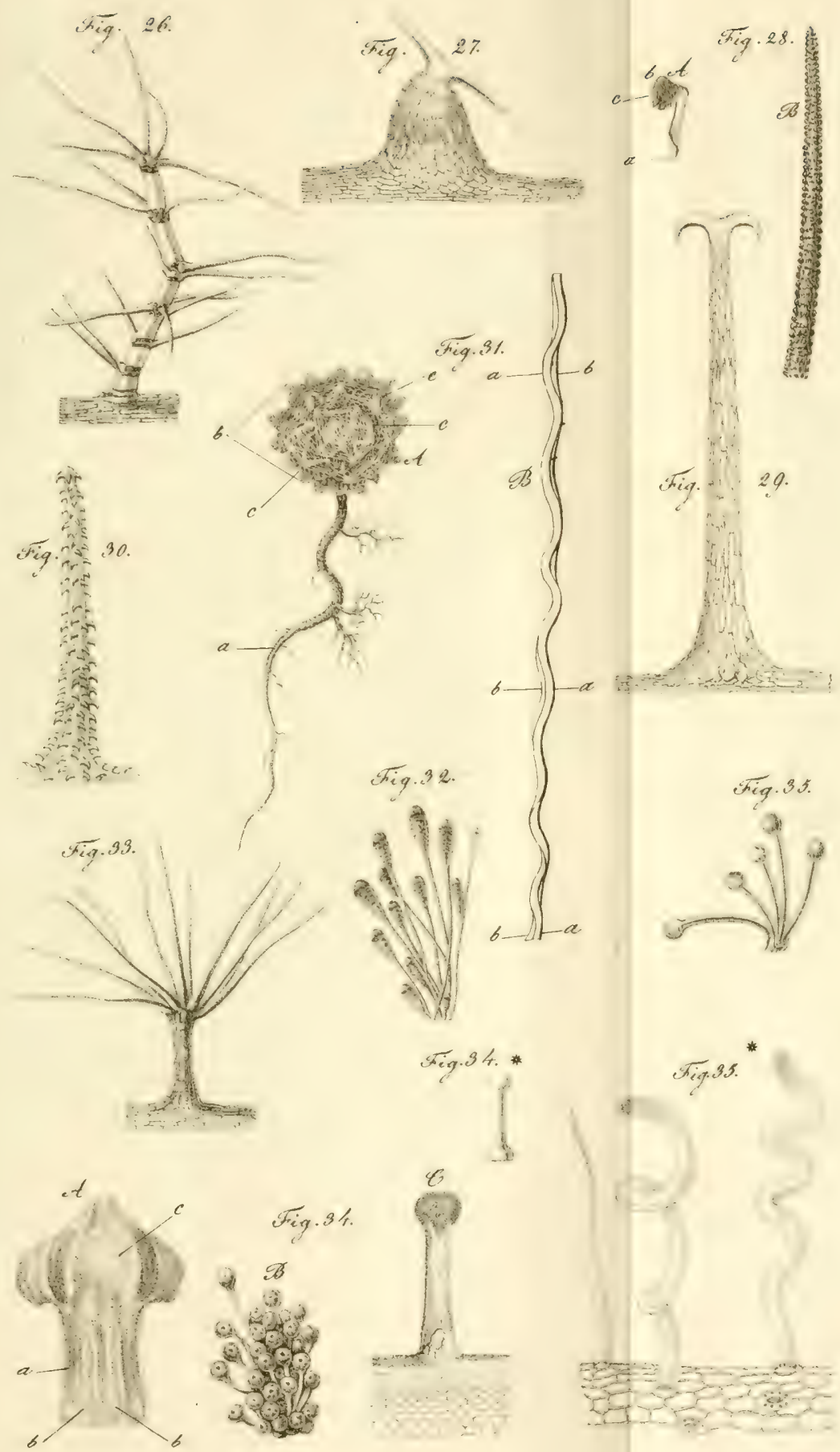





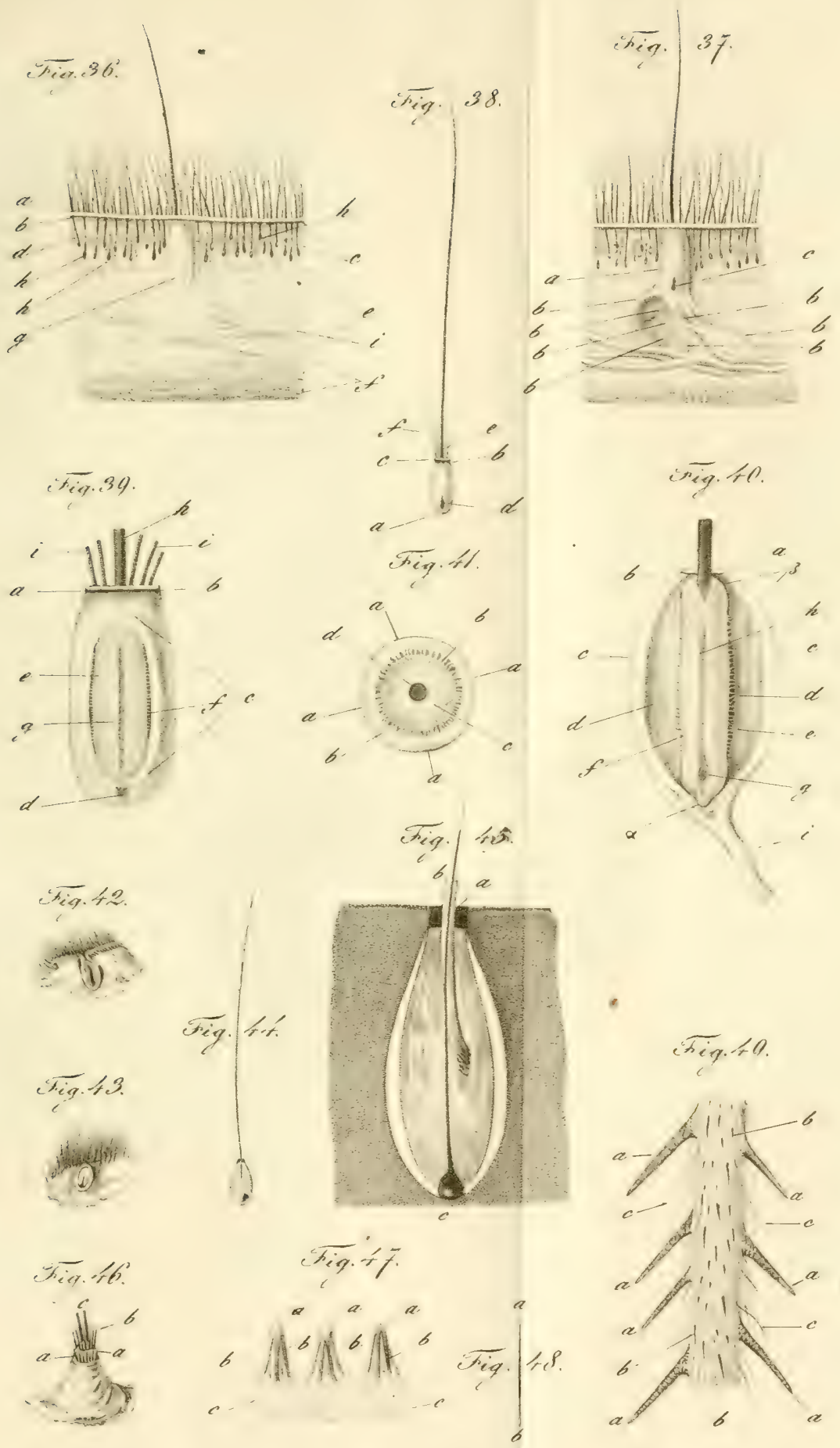





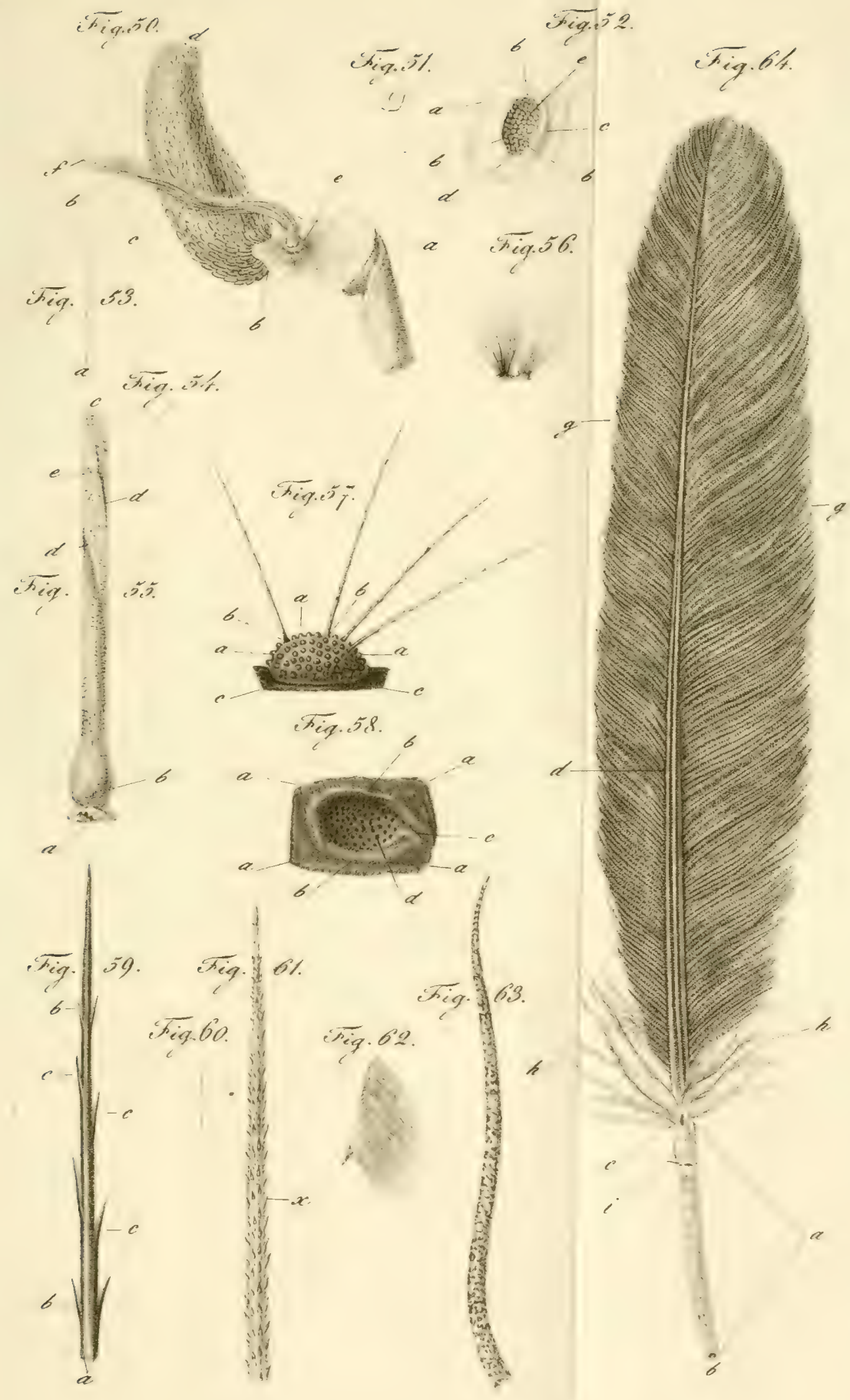




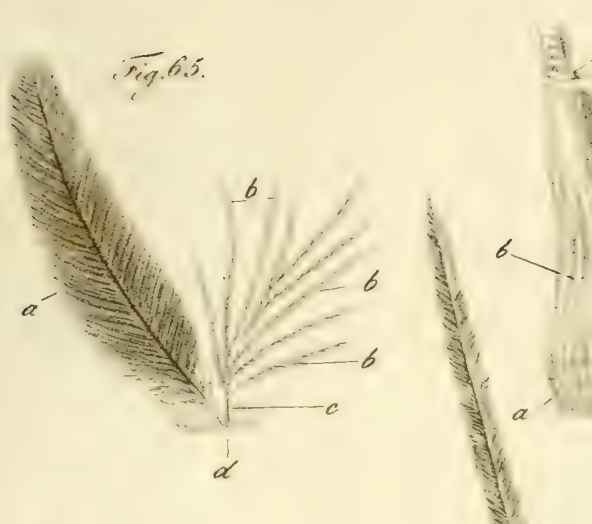

$\mathscr{B}$

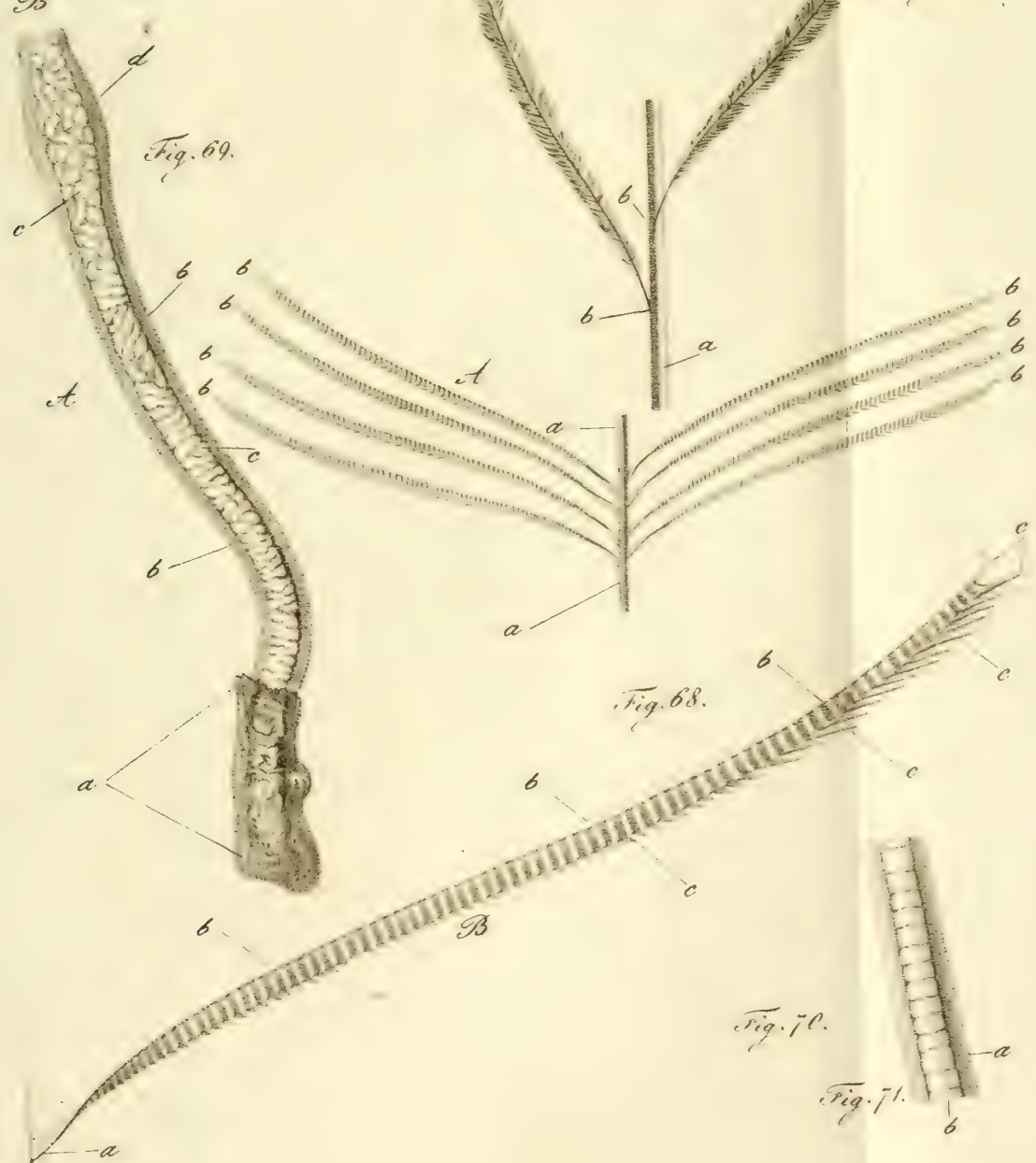





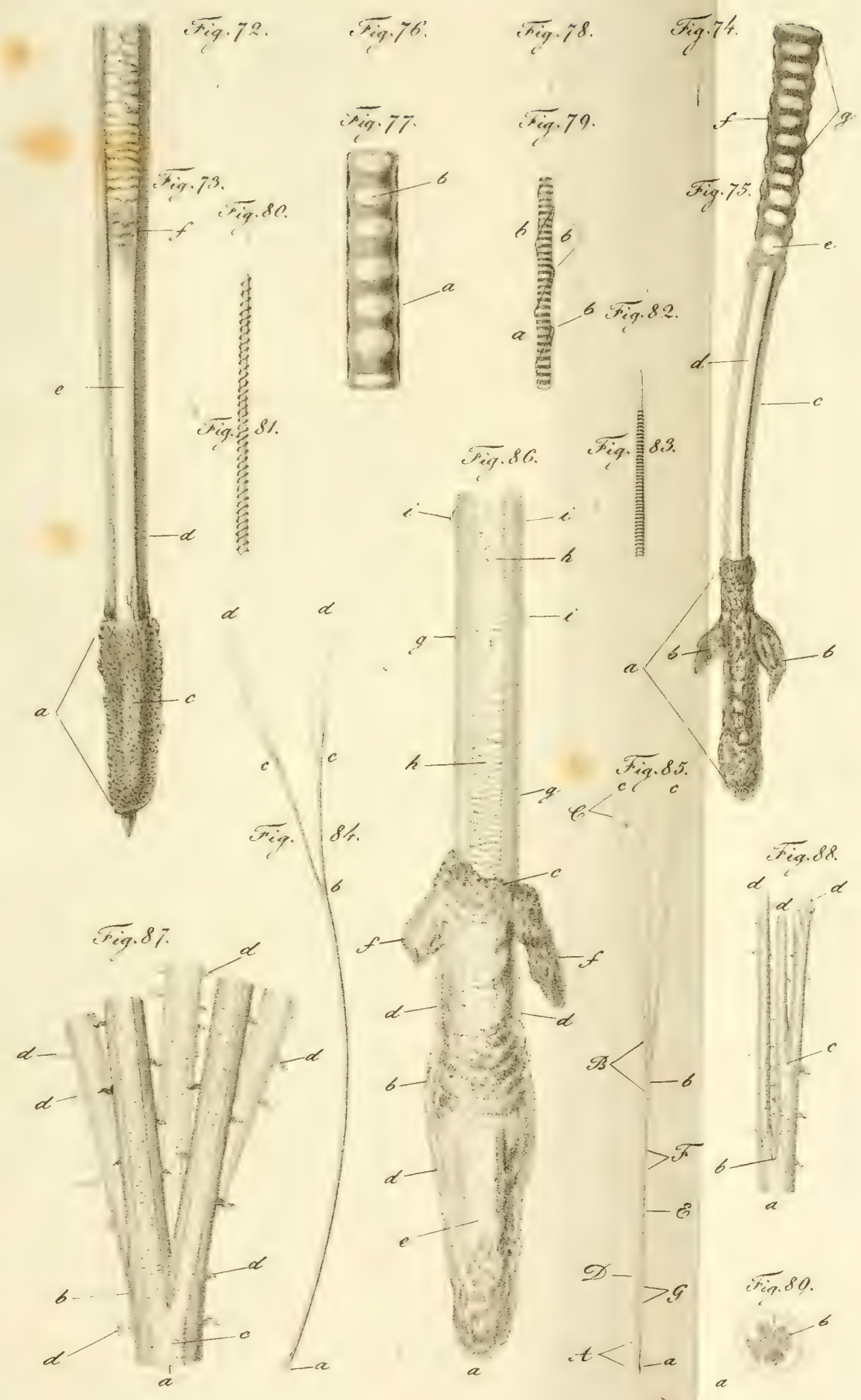



inig.an.

$c$

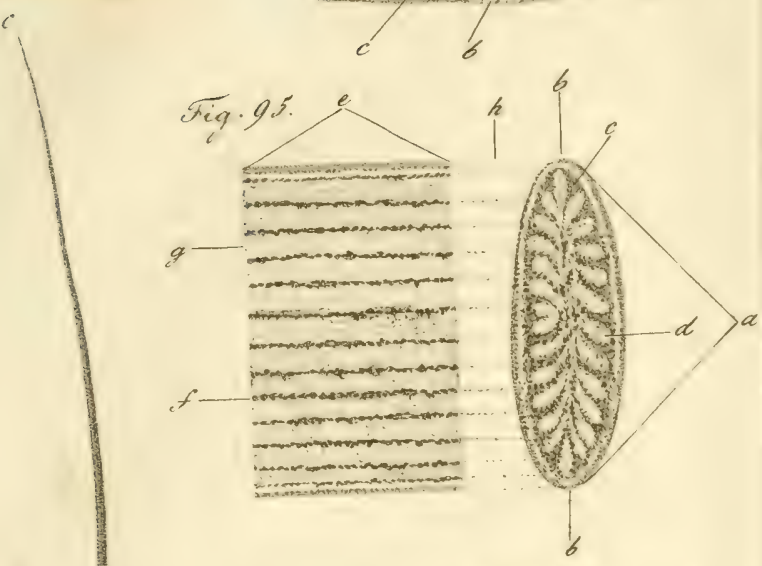

3

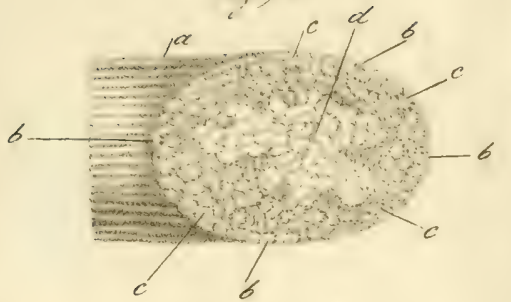

ifig. 92

Glate Celive

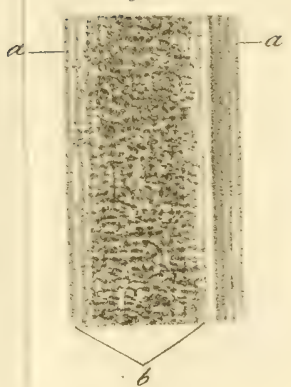

Fig. 93.
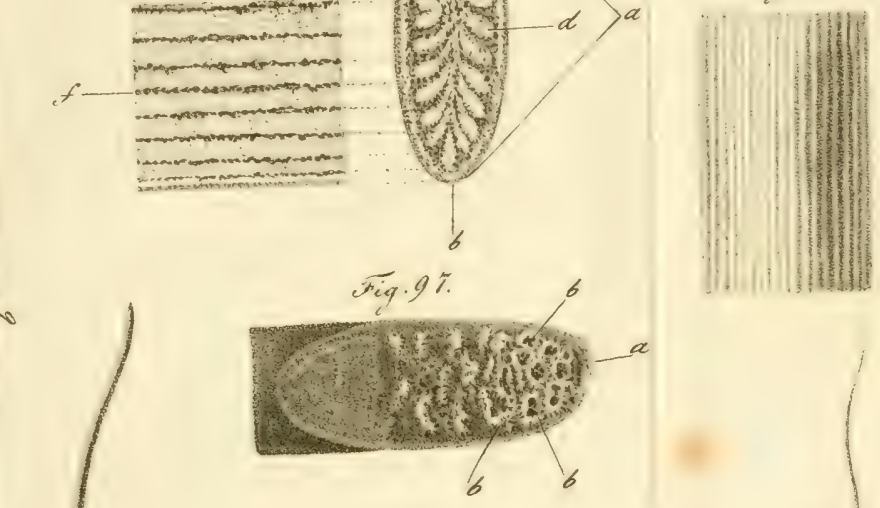

Fing. 100

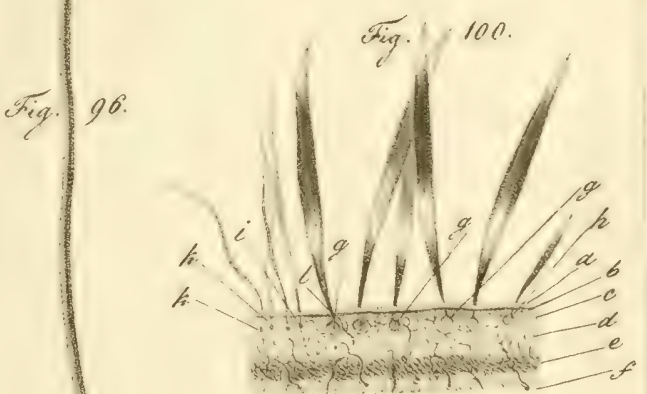

Fig. 98 . 



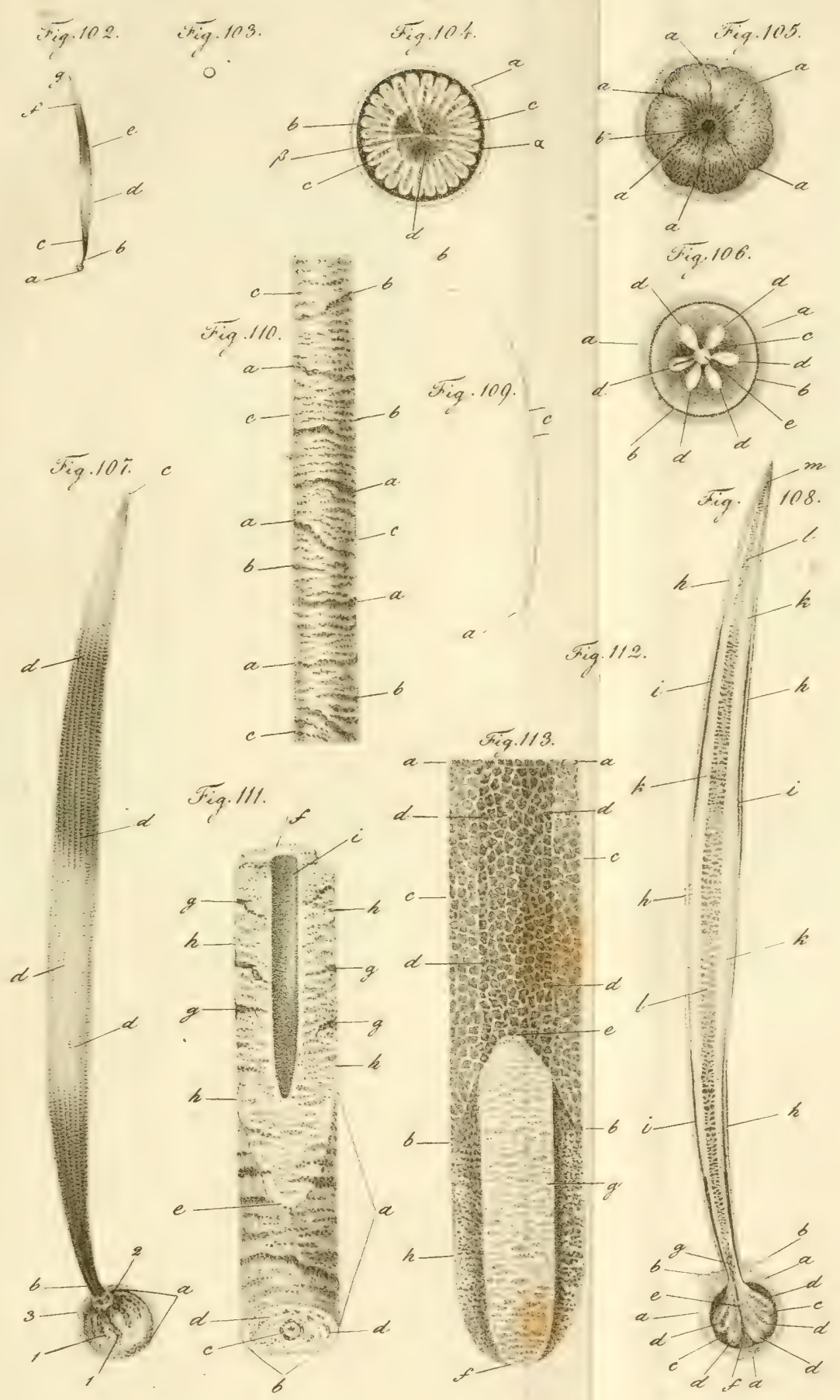





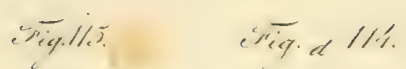

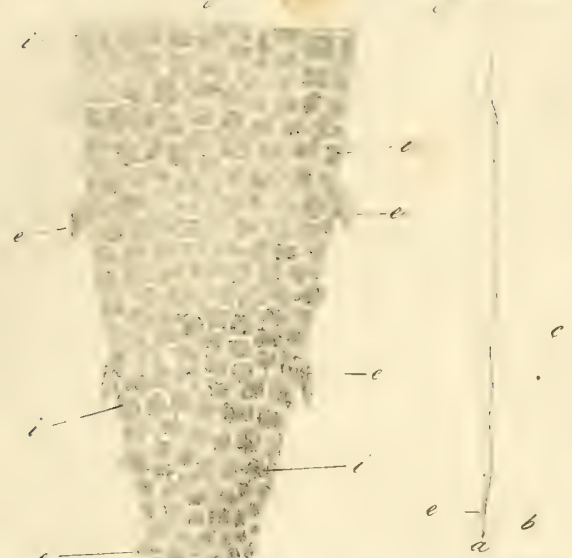

6 ETig. 116

Ebber Lelixe ram

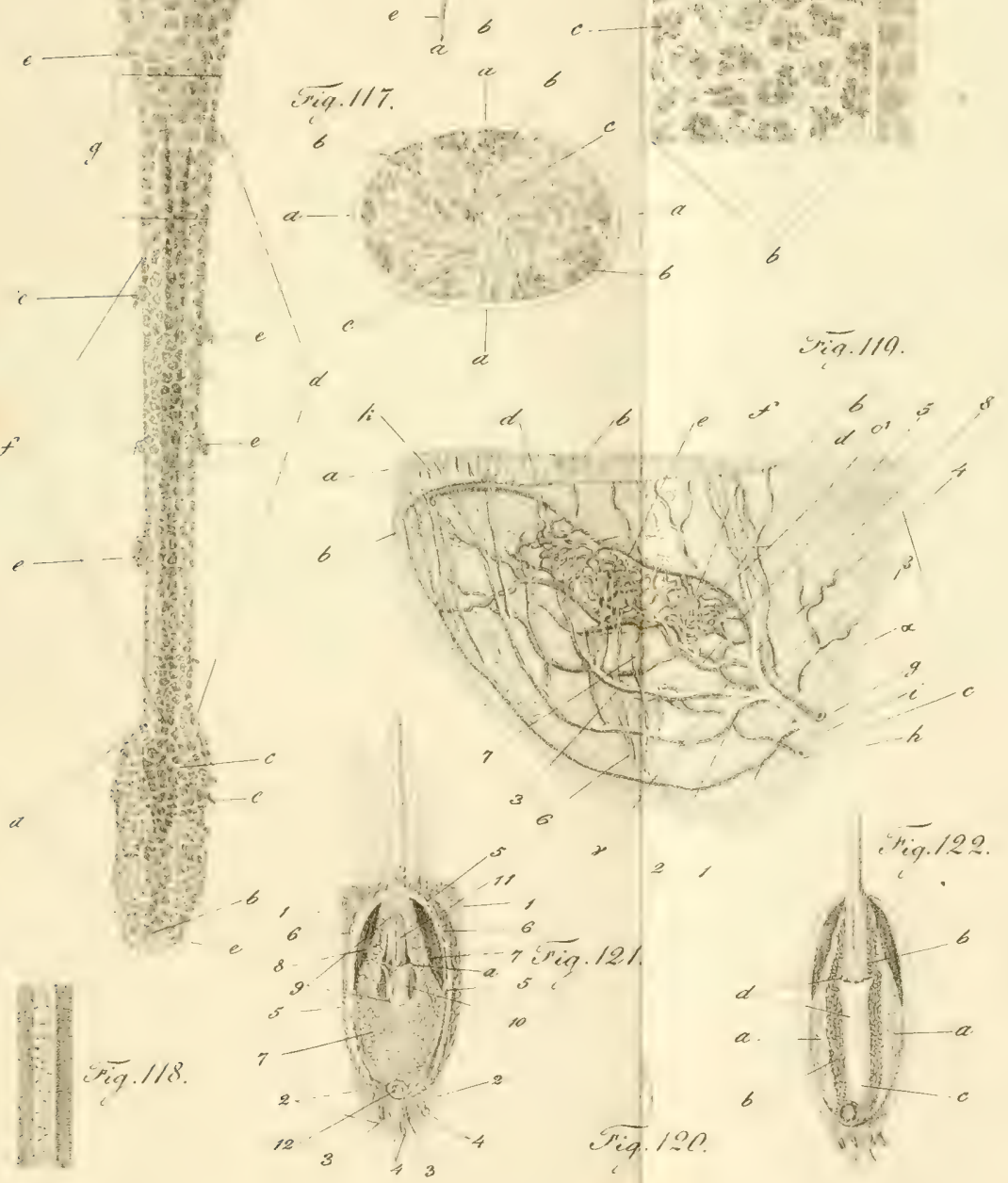








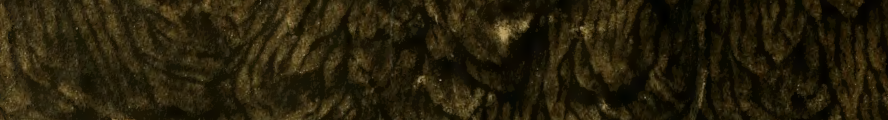

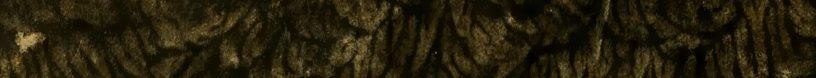
W. P.

14. 4.5 10
4

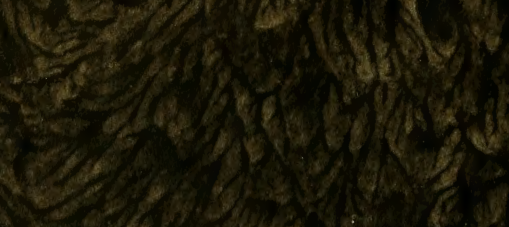

y

\section{0}

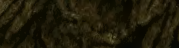

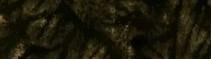

(15)

(15)

(15)

(15)

1) $\log _{4} \log ^{2}$

(190.)

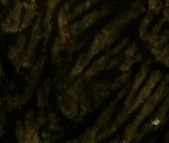

39

a.

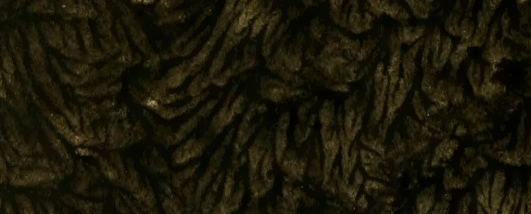

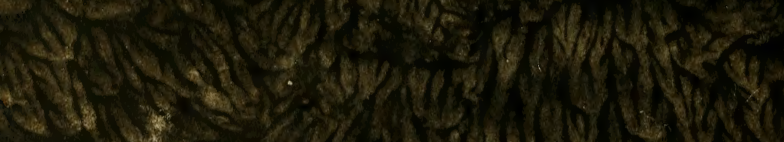
Aly

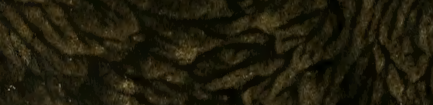

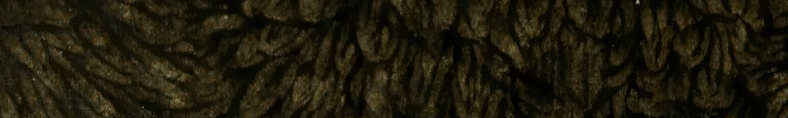

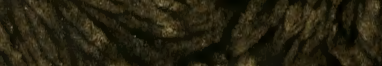<smiles>C#CC(CC)(CC)CCC1CCCC1</smiles>
? 